\title{
Weather, Climate, and Hydrologic Forecasting for the Southwest U.S.
}

Holly C. Hartmann, Roger Bales, and Soroosh Sorooshian

\section{CLIMAS Report Series CL2-99}

Institute for the Study of Planet Earth 715 North Park, 2nd Floor The University of Arizona, Tucson, AZ 85721 


\section{Weather, Climate, and Hydrologic Forecasting for the Southwest U.S.}

Holly C. Hartmann

Hydrology and Water Resources, University of Arizona

Roger Bales

Hydrology and Water Resources, University of Arizona

Soroosh Sorooshian

Hydrology and Water Resources, University of Arizona

The Climate Assessment Project for the Southwest (CLIMAS)

Working Paper Series: WP2-99

February 1999

Institute for the Study of Planet Earth

715 North Park, $2^{\text {nd }}$ Floor

The University of Arizona, Tucson, AZ 85721

Phone: (520) 622-9062

FAX: (520) 792-8795

Email: ispe@ispe.arizona.edu

http://www.ispe.arizona.edu 


\section{TABLE OF CONTENTS}

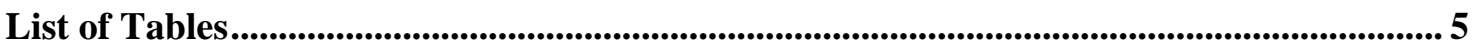

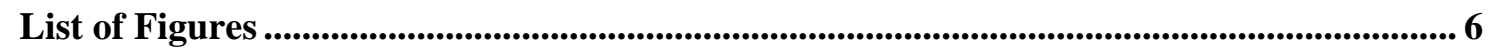

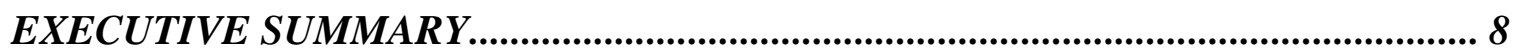

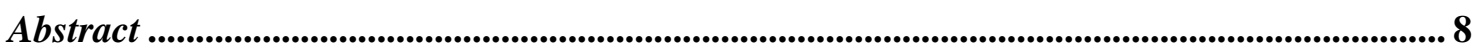

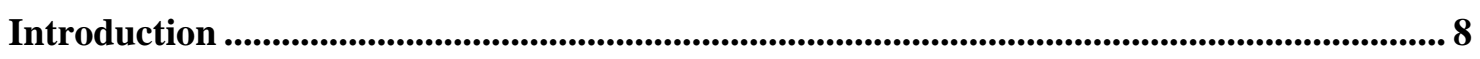

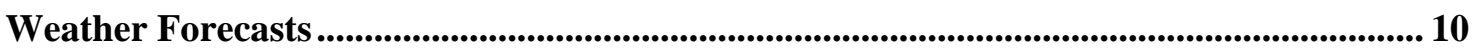

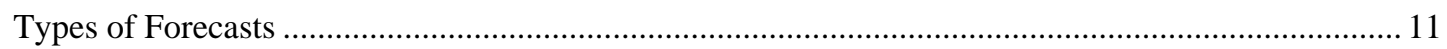

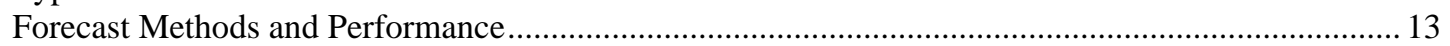

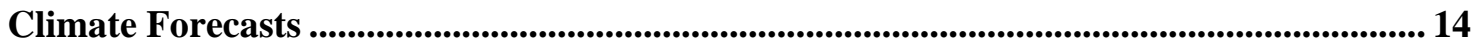

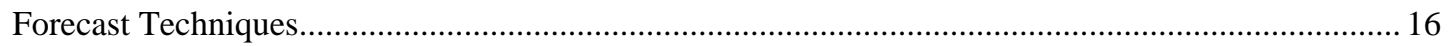

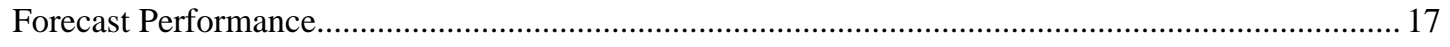

Hydrologic Forecasts....................................................................................................................... 18

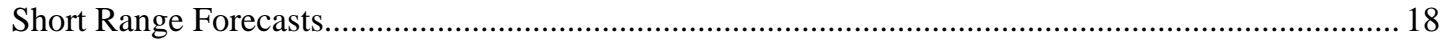

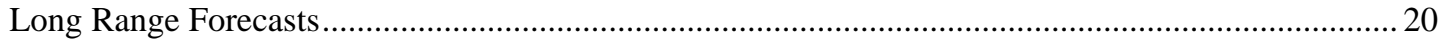

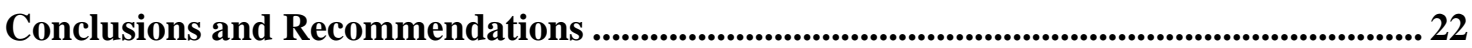

Hydrologic versus Weather and Climate Forecasting ………........................................................ 22

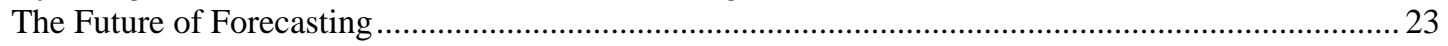

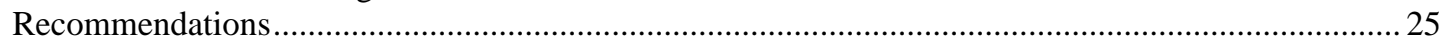

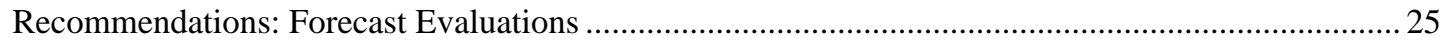

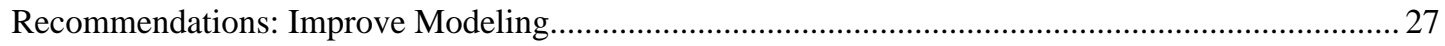

Recommendations: Improve Forecast Products and Communication ................................................... 27

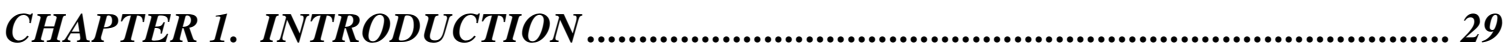

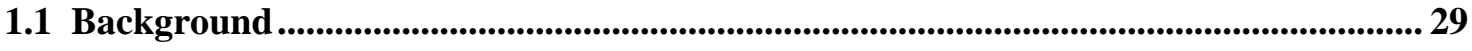

1.2 Forecasts and Resource Management …................................................................................. 30

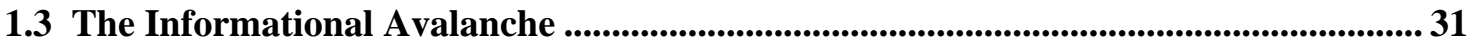

1.4 Statistics versus Forecasts............................................................................................................ 32

1.5 Scenarios versus Forecasts.............................................................................................................. 33

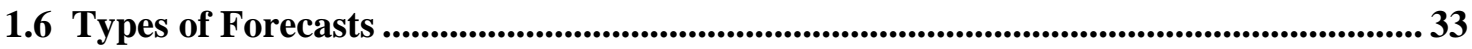

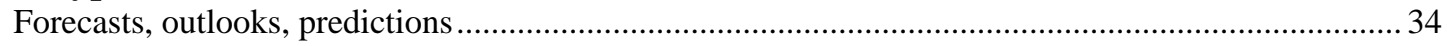

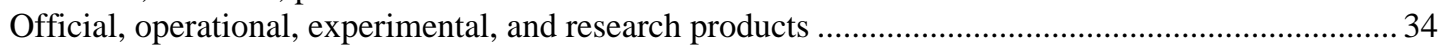

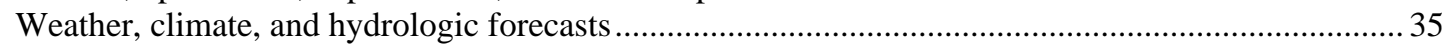

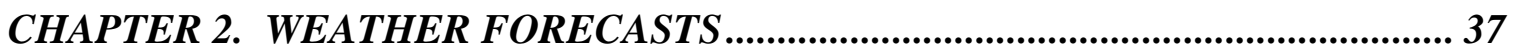

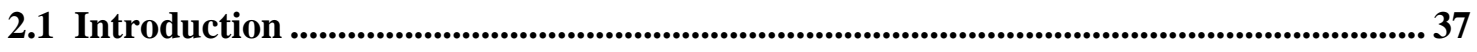

2.2 National Weather Service Weather Forecast Offices................................................... 37

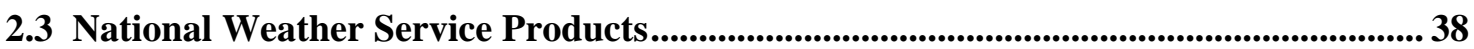

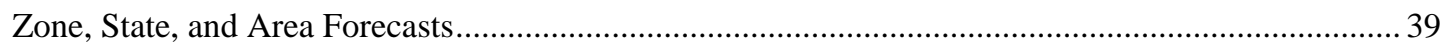

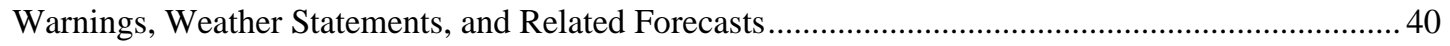

Short Range Forecasts........................................................................................................................ 41 


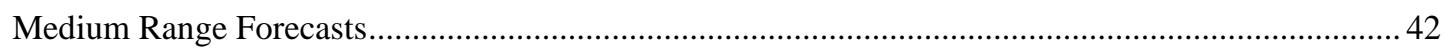

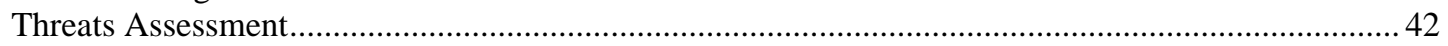

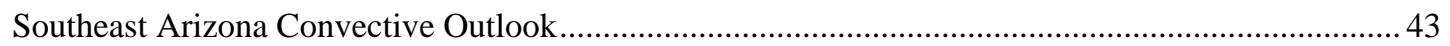

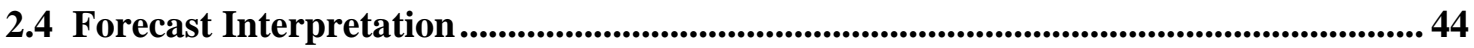

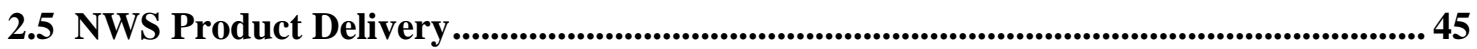

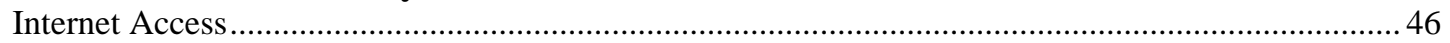

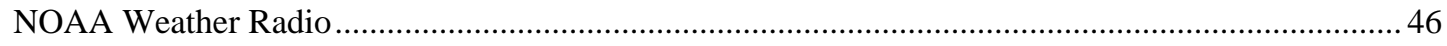

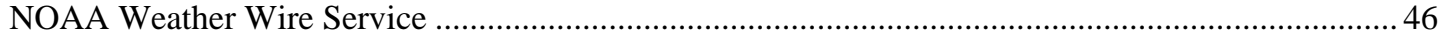

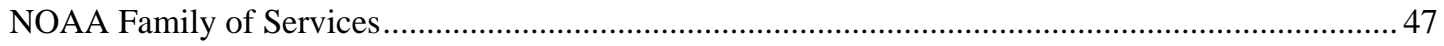

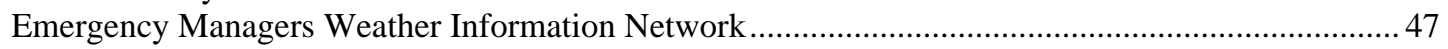

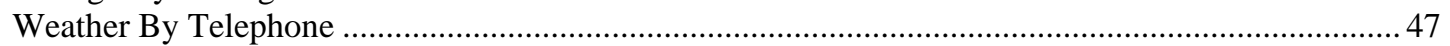

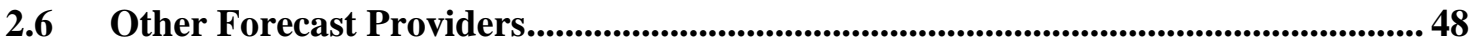

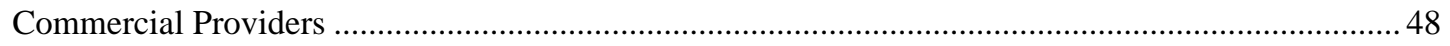

Other Governmental Agencies..................................................................................................... 51

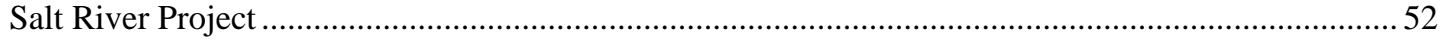

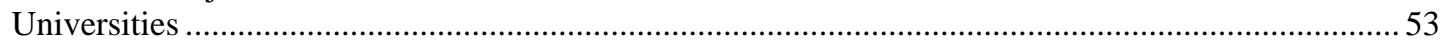

2.7 Forecast Methods and Performance .........................................................................5 53

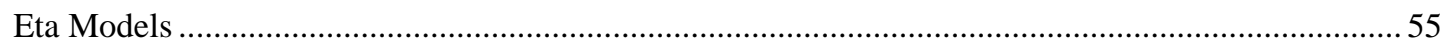

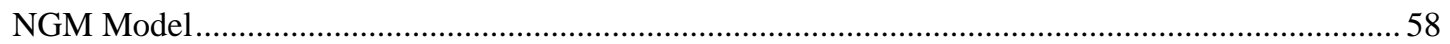

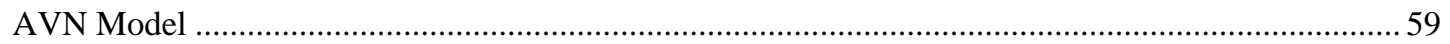

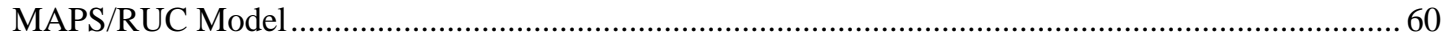

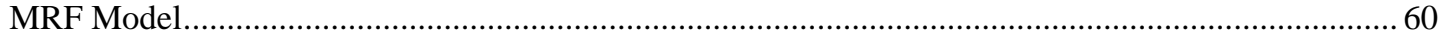

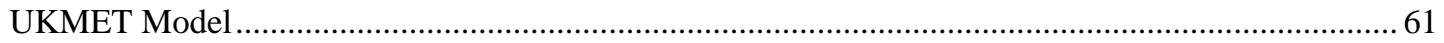

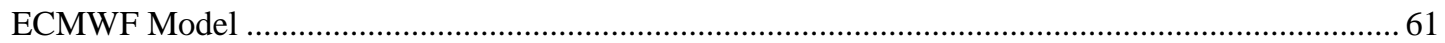

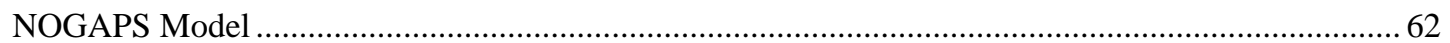

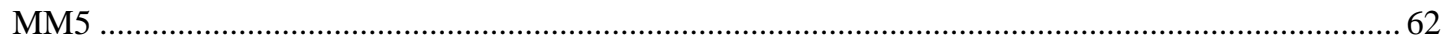

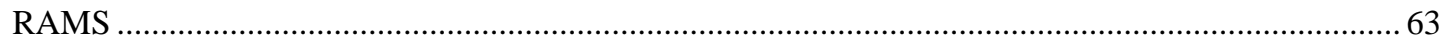

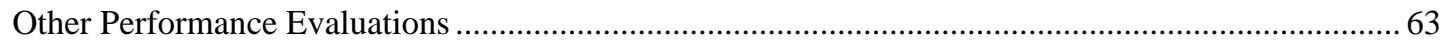

CHAPTER 3. CLIMATE FORECASTS................................................................ 64

3.1 Official U.S. Climate Forecasts ..................................................................................................... 64

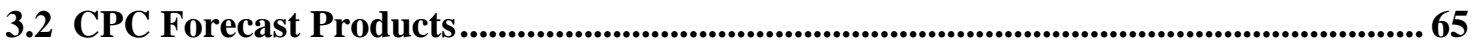

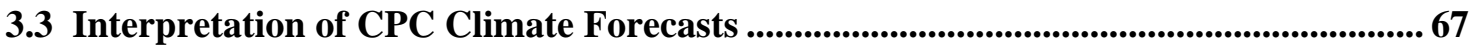

3.4 CPC Forecast Techniques................................................................................................... 68

3.5 CPC Forecast Quality .............................................................................................................. 72

3.6 Other Climate Forecasts and Sources ......................................................................................... 73

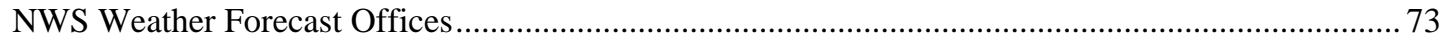

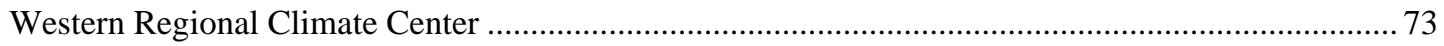

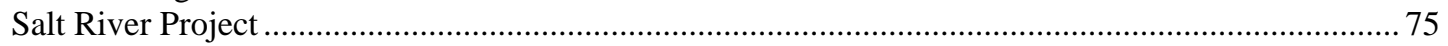

International Research Institute for Climate Prediction....................................................................... 75

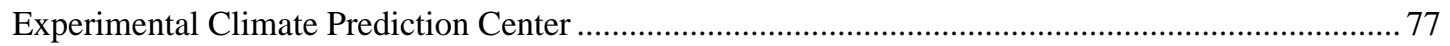

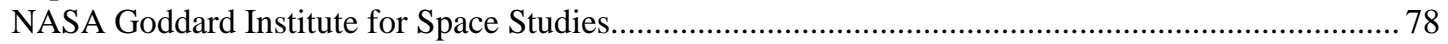

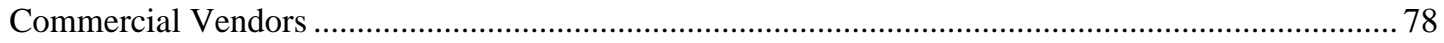

CHAPTER 4. HYDROLOGIC FORECASTS …….................................................... 79

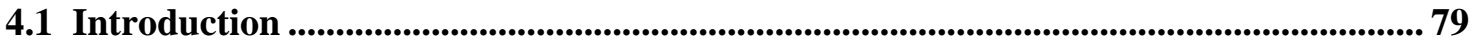

4.2 Major Hydrologic Forecasting Institutions...................................................................... 80

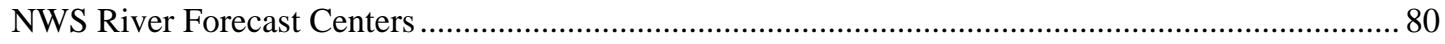

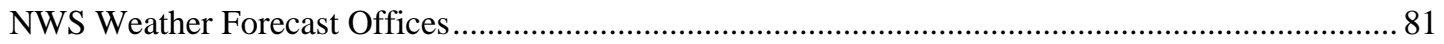




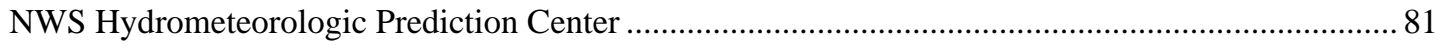

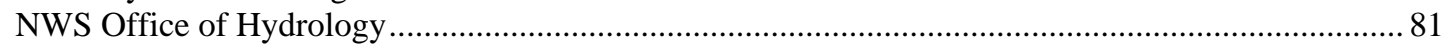

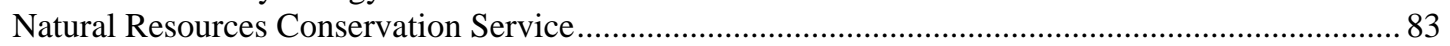

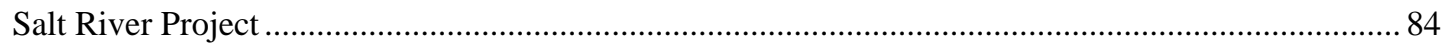

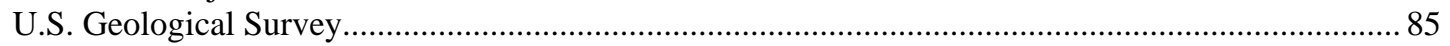

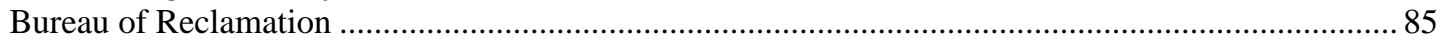

4.3 Short Range Forecasts .......................................................................................86

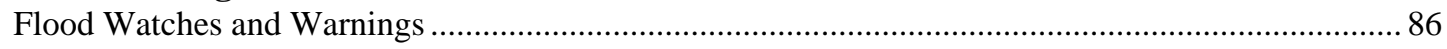

Quantitative Precipitation Forecasts ........................................................................................ 89

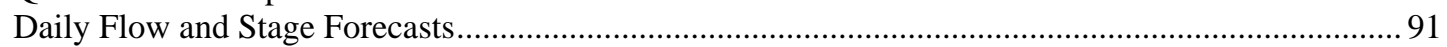

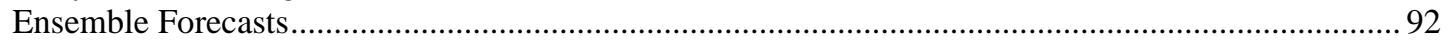

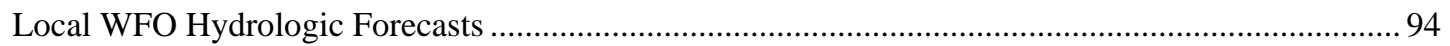

4.4 Long-Range Forecasts...................................................................................95

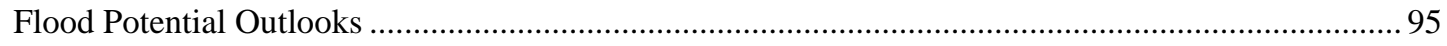

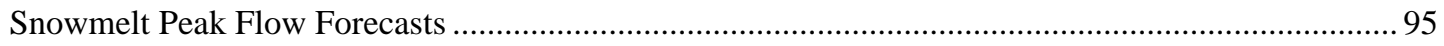

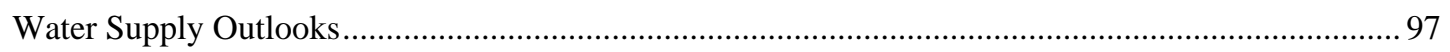

4.5 Other Forecasts............................................................................................................ 107

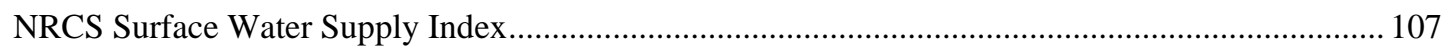

NWS CPC Integrated Soil Moisture Anomaly Forecasts .......................................................... 108

Bureau of Reclamation Forecasts ......................................................................................... 108

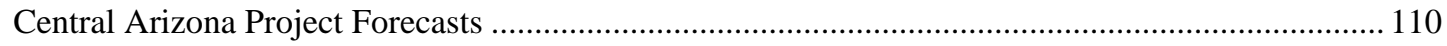

International Boundary and Water Commission Forecasts .................................................... 110

California Department of Water Resources Forecasts ......................................................... 111

Forecasts from Universities, Institutes/Centers/Consortiums ................................................... 111

4.6 The Future of Hydrologic Forecasting .................................................................. 112

CHAPTER V. CONCLUSIONS AND RECOMMENDATIONS ............................. 115

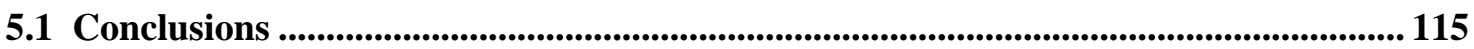

Hydrologic versus Weather and Climate Forecasting ....................................................... 115

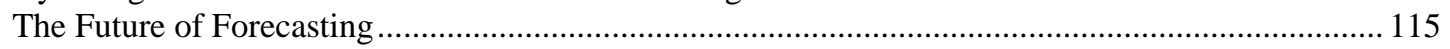

5.2 Recommendations............................................................................................. 117

Recommendations: Forecast Evaluations ....................................................................... 118

Recommendations: Improve Modeling ............................................................................ 119

Recommendations: Improve Forecast Products and Communication ....................................... 120

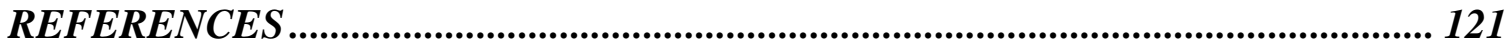




\section{List of Tables}

Page Table

38 Table 1. NWS Weather Forecast Office coverage in the Colorado River Basin and Southwest U.S.

40 Table 2. NWS zone forecast designations within states of the Colorado River Basin and the Southwest U.S.

41 Table 3. NWS county warning area designations within states of the Colorado River Basin and the Southwest U.S.

45 Table 4. Definition of NWS phrases used in weather forecasts.

48 Table 5. Select commercial weather forecast vendors with coverage of the U.S. Southwest

$57 \quad$ Table 6. Eta model bias for selected station locations

57 Table 7. Eta model bias and threat scores for the Intermountain West.

59 Table 8. NGM model 12-36 hour forecast threat scores for selected locations.

59 Table 9. NGM forecast precipitation bias characteristics.

98 Table 10. Watersheds in the U.S. Southwest for which water supply outlooks are made.

105 Table 11. Selected water supply outlook performance statistics from Shafer and Huddleston (1984).

107 Table 12. NRCS snow survey and water supply forecasting government performance review act survey. 


\section{List of Figures}

Page Figure

135 Figure 1. 12-hour short-range weather forecast graphical product issued by the NWS Hydrometeorological Prediction Center (HPC).

136 Figure 2. 48-hour short-range weather forecast graphical product issued by the NWS HPC.

137 Figure 3. 3-day lead-time forecast of daily maximum air temperature issued by the NWS HPC.

138 Figure 4. 5-day lead-time forecast of precipitation probability issued by the NWS HPC.

139 Figure 5. 5-day total precipitation forecast issued by the NWS HPC.

140 Figure 6. 7-day lead-time precipitation probability forecast issued by the NWS HPC.

141 Figure 7. Ensembles of forecasts of atmospheric pressure height contours, from the NCEP Medium Range Forecast (MRF) model. Top image is for day 3 of the forecast period, middle image is for day 7, and bottom image shows the day 3-7 mean contour location.

142 Figure 8. Experimental threats assessment issued by the NWS National Centers for Environmental Prediction (NCEP).

143 Figure 9. Southeast Arizona convective outlook graphical forecast of expected areal coverage of thunderstorms. Issued by the NWS Tucson Weather Forecast Office (WFO).

144 Figure 10. Southeast Arizona convective outlook graphical forecast showing the conditional probability of receiving at least 1 inch of precipitation from a thunderstorm. Issued by the NWS Tucson Weather Forecast Office (WFO).

145 Figure 11. Example 1- and 3-month climate outlooks for temperature and precipitation, issued by the NWS Climate Prediction Center (CPC).

146 Figure 12. Example series of 12 seasonal temperature outlooks, issued by the NWS CPC.

147 Figure 13. Example series of 12 seasonal precipitation outlooks, issued by the NWS CPC.

148 Figure 14. Legend to be used with NWS CPC climate outlooks.

149 Figure 15. Example text discussion for monthly and seasonal climate outlook series, issued by the NWS CPC.

152 Figure 16. Contour map of $33.3 \%$ non-exceedance quantile precipitation for August-October, issued by the NWS CPC.

153 Figure 17. Contour map of $66.7 \%$ non-exceedance quantile precipitation for August-October, issued by the NWS CPC.

154 Figure 18. Contour map of mean temperatures for August-October, issued by the NWS CPC. Dashed line shows one standard deviation class limits.

155 Figure 19. Contour map of mean temperatures for January-March, issued by the NWS CPC. Dashed line shows one standard deviation class limits.

156 Figure 20. Map of predictive skill for temperature and precipitation using canonical correlation analysis with 0.5 -month lead-time, from the NWS CPC. 
157 Figure 21. Map of predictive skill for temperature and precipitation using optimal climate normals with 0.5- to 8.5-month lead-times, from the NWS CPC.

158 Figure 22. Example alternate form of monthly climate outlook, issued by the NWS CPC.

159 Figure 23. Map of predictive skill for October-December temperatures based on screen multiple linear regression (SMLR) with 1-month lead-times, from Unger (1996b). Values are correlation between forecasts and observations over 1955-1995.

160 Figure 24. Map of predictive skill for October-December precipitation based on screen multiple linear regression (SMLR) with 1-month lead-times, from Unger (1996b). Values are correlation between forecasts and observations over 1955-1995.

161 Figure 25. Example experimental seasonal precipitation forecast issued by the International Research Institute for Climate Prediction (IRI).

162 Figure 26. Observations corresponding to the seasonal precipitation forecast of

Figure 25, issued by the IRI.

163 Figure 27. Example quantitative precipitation forecast (QPF) for 6-hour precipitation totals with a 6-hour lead-time. Issued by the NWS HPC.

164 Figure 28. Example day 1 quantitative precipitation forecast (QPF) for 24-hour precipitation totals, issued by the NWS HPC.

165 Figure 29. Example forecast of potential for precipitation to exceed flash flood guidance of NWS River Forecast Centers (RFCs), issued by the NWS HPC. APCGH = may approach potential from synoptic systems. ISOLD = spatially isolated potential.

166 Figure 30. Example experimental Ensemble Streamflow Prediction (ESP) forecast of maximum daily discharge of Roaring Fork River, Colorado. Issued by the NWS Colorado Basin River Forecast Center (CBRFC).

167 Figure 31. Location schematic for snowmelt peak flow forecasts issued by the NWS CBRFC.

168 Figure 32. Location schematic for specific river reach snowmelt peak flow forecasts issued by the NWS CBRFC.

169 Figure 33. Location schematic for Lower Colorado Basin water supply outlooks issued by the NWS CBRFC.

170 Figure 34. Schematic of adjustments affecting use of naturalized water supply outlooks, from the NWS CBRFC.

171 Figure 35. Correlation between seasonal water supplies and Southern Oscillation Index. From the Natural Resources Conservation Service (NRCS).

172 Figure 36. Map of correlation coefficients between seasonal water supply volumes and Southern Oscillation Index, from the NRCS. 


\title{
EXECUTIVE SUMMARY
}

\begin{abstract}
In support of the Climate Assessment (CLIMAS) Project for the Southwest, a review was conducted of the current state of weather, climate, and hydrologic forecasting for the Southwest. A key element of the review was a workshop that examined the availability, use, accuracy, and value of forecasts, with participants consisting primarily of agency personnel involved in operational forecasting via directly issuing forecasts, providing key data for making forecasts, or serving as a key link for communicating forecasts. The broad range of forecast products encompasses myriad variables, time-scales from minutes to seasons, and lead-times from minutes to over a year. Current forecast products and techniques are reviewed, and implications for use in decision making are discussed. The forecast review identified needs for additional research to be addressed by the CLIMAS Project, including local evaluation of monthly and seasonal climate outlooks, retrospective evaluation of operational water supply outlooks, hindcast reanalysis of probabilistic water supply outlook techniques, and incorporation of climate outlooks into statistical water supply outlook techniques.
\end{abstract}

\section{Introduction}

Whether explicitly recognized or not, most decisions related to natural resource management make use of some sort of hydrometeorologic forecast. Forecast techniques exist along a continuum of sophistication, ranging from complex objective techniques using many types of data, mathematical representations of physical processes, and teams of scientific experts, to simple implicit, subjective, and ad hoc processes (e.g., simply feeling that future conditions will be much like the past). Regardless, all forecasters face common dilemmas (Changnon, 1990), including insufficient physical understanding to appropriately integrate data and related predictions, lack of direct and timely measurements of recent conditions, inadequacy of appropriate means to incorporate forecasts into complex decisions, and perceptions of poor forecast quality.

Individuals using hydrometeorologic forecasts face myriad products, issued by a seemingly bewildering milieu of organizations using a complex mix of media. It is not possible to review every type of forecast relevant to the U.S. Southwest; there are simply too many, when all possible forecast sources, forecast elements, time-scales, spacescales, and lead-times are considered. This report focuses on operational products issued by governmental agencies, although some other forecasts are considered as well. This review provides a basis for discussion of many issues related to forecasts that apply to other products not specifically mentioned herein. 
The wide variety of forecast products can be categorized according to several different perspectives. Although texts may distinguish among forecasts, outlooks, and predictions, in practice there are no naming conventions. However, the distinction among official, operational, experimental, and research forecasts has taken on practical importance because users now have direct access to all forecast types.

Operational products are those that are routinely produced by an agency and generally created using established procedures or guidelines that have undergone extensive review. Agencies may produce a variety of operational products, with some being required as part of the organization's mandate and others being issued at the organization's discretion. The former can be considered official products; while a legal mandate may not exist for issuance of a specific product, offices would face internal discipline and external rebuke if the products were not issued according to established schedules. Clear examples include flood watches and warnings issued by NWS. Alternatively, offices may issue non-official operational forecasts at their discretion; an example is the Southeast Arizona Convective Outlook issued by the NWS Tucson Weather Forecast Office. Although NWS has responsibility for most official forecasts related to weather, climate, and hydrology within the U.S., the agency does not typically identify which products are discretionary and which are required. Experimental products have not yet received official approval, although they may be generated in an operational setting for an extended period of time to test whether they warrant transition to operational status. Research products are at even earlier stages of development; however, they may be posted on the Internet in a form looking like an operational forecast, as a means of sharing results and demonstrating conversion of research into useable products.

This report is divided into 3 categories of forecasts: weather, climate, and hydrologic forecasts. Weather forecasts generally track movement and evolution of specific air masses, while climate forecasts make statements about composite conditions. The NWS Climate Prediction Center (CPC) defines short-term climate as average behavior over a month or more (CPC, 1995), with shorter periods $(6,8,10,14$ days) considered as extended weather outlooks. In this report, weather forecasts cover periods approaching 1 month, while climate forecasts cover periods 1 month or longer. Hydrologic forecasts cover time scales equivalent to both weather and climate forecasts due to the integrative character of hydrologic processes. For example, while snowmelt peak streamflows are short-term hydrologic conditions, they reflect a watershed's hydrologic response to melt of seasonal snowpack accumulation. Hydrologic and meteorologic forecasts are clearly distinguished, except that quantitative precipitation forecasts (QPFs) are often considered hydrologic forecasts, since they are produced specifically as critical inputs for flood forecasts.

Further distinction is made here among forecasts, statistics, and scenarios. Statistical summaries of historic conditions do not, alone, constitute a forecast; they require some statement, preferably explicit, about the relationship between historic and future conditions. Common assumptions include persistence of recent conditions or trends, and inter-decadal stationarity, although evidence exists in many regions for hydroclimatic non-stationarity. Scenarios are used to explore implications of 
anthropogenic or natural hydroclimatic changes (e.g., changes in land use, prolonged drought) beyond those expressed in available historic records. While scenarios have a rational basis for their selection, they are not generally considered forecasts. Several studies using scenarios have been conducted specifically for the Southwest; streamflow scenarios based on re-ordering historic records and paleologic tree-ring data were used to study implications of severe sustained drought for Colorado River management (American Water Resources Association [AWRA], 1995).

Finally, it must be stressed that the state of forecasting is constantly evolving. New products are generated, and standard products are communicated in new ways, on an ever-changing trajectory. Easily available Internet access has radically changed means for obtaining forecast products. Most products, along with ancillary information (e.g., technique descriptions, input data), are now delivered primarily, if not exclusively, via the Internet. In many cases, ancillary information on the Internet more accurately reflects current interpretations and techniques than published literature, because electronic texts can be periodically updated. However, much of the information describing exactly how specific forecasts have been made is simply unavailable from any source.

\section{Weather Forecasts}

The National Weather Service (NWS) is the official U.S. government provider of weather forecasts. Both the NWS institutional structure and resulting mix of forecast products are complex. Additionally, the agency has been in the throes of a massive modernization effort for several years; until its completion in mid-1999, the modernization produced seemingly constant change in product sources and formats. NWS Weather Forecast Offices (WFOs) are responsible for providing all forecasts and warnings for their area of responsibility; most weather products are created within WFOs, while climate products are created by other NWS units and simply transmitted by WFOs. Systems for WFO forecast delivery include the Internet, NOAA Weather Radio, NOAA Weather Wire Service, NOAA Family of Services, EMWIN, and Weather by Telephone. Presently, WFOs maintain their own websites; the look and feel of each site is different, with varying ease of product access. Internet push technology allows newly issued watches or warnings to be automatically provided to users, without periodic inquiry. However, NOAA Weather Radio and Weather Wire are the only official lines of forecast communication.

Several features distinguish NWS and commercial vendor forecasts. Private forecast services often offer unique types of forecasts for user-specified locations, for a fee. Some fee-for-service vendors also offer free forecasts. Still other providers offer only free forecasts, deriving revenue from targeted advertising. Vendors targeting specific markets offer "one stop shopping" for easy access to forecasts and other marketsector information. Free forecasts are typically reproductions of official NWS products or products available from other providers. It is increasingly common for governmental agencies to link to, or collect and reformat, NWS forecasts as well. With so many different avenues and formats for these weather forecasts, there is real potential for 
confusion among users about which entity is actually providing forecasts; Pagano (1999) interviewed an emergency management official in Arizona that did not distinguish between the Weather Channel and National Weather Service as forecast sources. Further, web links may access only portions of an official NWS forecast, while ignoring essential ancillary products (e.g., text discussions, forecast category definitions).

\section{Types of Forecasts}

Operational NWS forecast products, include local area, state, and zone forecasts; watches and warnings for severe local storms, winter storms, floods, and flash floods; local aviation watches and warnings, terminal forecasts, and domestic aviation en route forecasts; marine warnings and forecasts; fire weather forecasts; crop forecasts; and hydrologic forecasts; as well as more general short- and medium-range weather forecasts. There are even more experimental and research forecast products with varying accessibility. For a specific region, the most efficient means for learning of available NWS operational forecast products is through the appropriate WFO. In addition, decision makers can benefit from establishing personal contact with WFO staff concerning which products are most appropriate for their particular needs and for ensuring proper forecast interpretation. Pagano at al. (1999) found Arizona water management agencies that had ongoing relationships with WFOs had the best understanding of the 1997-1998 El Nino and related forecasts.

Zone, state, and area forecasts are generated and issued by NWS WFOs. Zone and state forecasts, issued twice daily, cover different regions, but are otherwise similar products consisting of brief text and tables that include predictions about general weather conditions, likelihood of precipitation, expected high and low temperatures, and expected wind directions and speed. Area forecasts, issued 4 times daily, cover larger regions than zone forecasts. While full of cryptic abbreviations and technical jargon, area forecasts allow WFO forecasters to discuss their rationale in making a specific forecast. Forecasts are generated by subjective combination of a variety of data inputs (e.g., local radiosonde measurements of atmospheric stability conditions), guidance from numerical weather models results produced by other NWS units and other agencies (even agencies in other countries), and the expertise of the WFO meteorologists. Forecasters realize that some numerical weather models perform better than others during certain types of conditions and for specific locations. Based on their understanding of model strengths and limitations, they subjectively choose which model results to consider most heavily in shaping their forecast. In areas subject to complicated or localized weather conditions, e.g., the Southwest during the summer monsoon season, forecaster expertise is especially important.

With few exceptions, watches, warnings, and other special weather forecast products are generated and issued by NWS WFOs. WFO has responsibility for specific counties. Each forecast is issued as conditions warrant and consists of text only. While WFOs may receive guidance from other NWS units that special weather conditions may occur, the official forecasts are issued by the responsible WFO (G. Sampson, NWS Tucson WFO, personal communication, 1999). An exception is the issuance of official 
tornado and severe thunderstorm watches, which originate from the NWS Storm Prediction Center (SPC), a unit of the NWS National Centers for Environmental Prediction (NCEP). Communication and coordination is intense between these NWS units during periods of severe weather threat.

Short range forecasts with national coverage are produced by multiple units within the NWS; the forecasts may be operational, experimental, or research products. Local WFOs access the suite of national forecasts they consider relevant, perform subjective analysis of their content, and then typically combine results with additional local information to create various short range forecast products (e.g, wind advisories, heat advisories, zone and area forecasts) with locally relevant coverage. Often, especially in the Southwest where local-scale orographic effects and convective storms are important, national products are given little or no weight. Rather, the WFOs rely more directly on results from specific numerical weather models, measurements of local atmospheric conditions, and subjective forecaster expertise. Examples of national coverage short range forecasts are those produced by the NWS SPC and Hydrometeorologic Prediction Center (HPC), both units within NCEP. SPC nationallevel forecasts deal with local-scale phenomena that last only for several hours. HPC short range forecast products (Figures 1-6) predict the timing and location of fronts, and the occurrence, coverage, and type of precipitation. SPC and HPC forecasts are generated by subjective combination of a variety of data inputs and guidance from numerical weather models, including the Eta, NGM, and AVN models, among others.

While the NWS SPC issues convective outlooks several times each day over the conterminous U.S., local versions may be prepared by local NWS WFOs as well. Beginning in 1998, the Tucson WFO began issuing a Southeast Arizona Convective Outlook each afternoon, after about 12:45 pm, during the summer thunderstorm season (Figures 9-10). The convective outlook is different from other kinds of precipitation forecasts, in that it forecasts the areal coverage associated with expected thunderstorm occurrence. The outlook also contains a conditional probability forecast for the thunderstorm to be severe, i.e., given that a thunderstorm does indeed occur, the forecast specifies the probability it will be a severe storm. Another outlook product is a conditional quantitative precipitation forecast, i.e., given that a thunderstorm does occur, the forecast specifies probabilities for different precipitation amounts (>1", >2") being produced by a storm somewhere within the coverage area. Finally, a forecast is made for the expected direction of thunderstorm motion.

Medium range forecasts with national coverage are also produced by multiple units within the NWS. For example, HPC medium range forecast products cover daily intervals with lead-times of 3-5 days, issued once each day and consisting of maps of (1) daily surface pressure patterns, circulation centers, and fronts, (2) daily maximum and minimum air temperature anomalies, (3) daily precipitation anomaly probabilities, and (4) total precipitation expected over the next 5 days, in increments of $0.25,0.50,1.00$ inches and increasing thereafter at 1.00 inch intervals. Forecasts are based on subjective integration of MRF, ECMWF, and UKMET operational medium range weather models and the Navy NOGAPS MRFX experimental model and ensembles, among others. Local 
WFOs perform additional subjective analysis of national forecasts, typically combined with additional local information, to create various medium range forecast products, which are often denoted as "extended" forecasts.

A relatively recent type of forecast is the threats assessment produced by NCEP for the conterminous U.S. It combines NWS medium- (3-5 day), extended- (6-10 day), and long- (monthly and seasonal) range forecasts, and hydrologic analyses and forecasts into a series of graphical and textual products forecasting the potential for extreme hydrometeorologic conditions (Figure 8). The threats assessment provides local WFOs with initial notice to pay special attention to the possibility of the indicated severe conditions; the local WFOs are then responsible for issuing official NWS products related to those threats, as they deem appropriate. While the threats assessment implies that the identified events have exceeded some threshold of probability of occurrence, no explicit probability statements or expressions of uncertainty are provided with the product.

\section{Forecast Methods and Performance}

Briefly, weather forecasts are generated using complex, non-linear numerical models describing the physical interactions between solar radiation, and atmosphere, ocean, and land systems. Results from individual models comprise separate weather forecasts, although "sensible weather guidance" is more accurate since results are subjectively combined by forecasters to create final products. In addition to local observations, WFO meteorologists may consider output from over a dozen weather models, including Eta, NGM, AVN, MRF, UKMET, ECMWF, Navy NOGAPS, and MAPS/RUC models, among others. A shift in NWS institutional philosophy this decade dramatically accelerated evolution of operational weather forecast models (Mittelstadt, 1997). Previously, NWS operational models were limited to those passing development and evaluation thresholds; they were used unchanged until major scientific and technological advancements were incorporated and evaluated. Now, however, model changes are incorporated as soon as they pass initial testing and operational adjustments (e.g., data handling) can be made.

According to HPC (Junker, 1998), all numerical meteorological models do a "decent job" of forecasting synoptic scale features over 0-36 hours; model performance degrades as the forecast interval increases. All models have problems describing small features and convection processes. Lack of fine detail, combined with atmospheric system non-linearities, means small errors in estimating current land and atmospheric conditions can lead to substantial differences in model results. Thus, models are sometimes run several times, each run beginning with slightly different starting conditions, to create an ensemble of forecasts; ensembles can also include forecasts from several models. Statistics are then computed from the entire ensemble or a more likely subset.

Detailed evaluations of forecast techniques are not typically focused on the Southwest. Rather, the Southwest is often lumped into larger regional analyses for the Interior West and Central/Southern Rocky Mountains. Additionally, specific performance 
characteristics of operational models are typically undocumented. HPC admits that better verification of forecast performance is needed, especially at local scales (HPC, 1997; Junker, 1998). Comparison of model performance is complicated by slight variations in variable definitions used in different model formulations. For example, since each model uses unique terrain descriptions that can be vastly different, temperatures don't actually represent the same location, especially in the West. Finally, model formulations are not static; adjustments are routinely made to improve model performance, although improvements in one region do not necessarily result in improvements for other regions or for all conditions.

\section{Climate Forecasts}

Experimental and research climate outlooks are produced by an expanding array of institutions, including the International Research Institute for Climate Prediction, Experimental Climate Prediction Center, and Goddard Institute for Space Studies, among others. Official U.S. government climate forecasts are produced by the Climate Prediction Center (CPC), a unit of NCEP. Because CPC efforts are directed at agencies, an implicit assumption is that sufficient expertise is available to correctly interpret CPC products. Some products make very specific probabilistic statements, while other products incorporate discussions of highly technical and scientific concepts. Those products may be poorly understood by users lacking appropriate training or access to skilled interpretation by others. Limited to climate variations up to about 1 year, CPC climate forecasts are not sufficient for all decision making. Changes over decades can have important consequences, especially for infrastructure (structural or institutional) that may be difficult or expensive to modify as climate changes evolve. Thus, decisions that may be sensitive to longer-term climate fluctuations should also consider climate statistics based on historic or even paleologic data, as well as scenarios of potential future climate conditions.

The current suite of operational climate forecasts consists of one 1-month outlook and a series of thirteen 3-month outlooks, with the entire set issued anew near the middle of each month (Figures 11-15). The outlooks begin with the upcoming calendar month, and the 3-month outlooks shift forward by one month until the same period next year. For any single outlook (1-month, or a specific 3-month outlook), the complete forecast package consists of: 1) maps of surface air temperature and precipitation probability anomalies for the outlook period, 2) a legend describing the appropriate interpretation of the probability anomaly maps, 3) text discussion of the outlook, 4) maps and tables of historic climatology and probability class limits, and 5) skill maps for some of forecast techniques. Proper use of the outlooks requires consulting the entire package, not just the outlook maps. It is increasingly common for governmental agencies to link to, or collect and reformat, CPC climate outlooks; some web-sites provide only outlook maps, often without text discussions, historical probability anomaly class limits, or even a legend.

Each outlook has only a limited time of applicability. The 1-month outlook is to be used only until the forecast month begins (i.e., for about 2 weeks), after which 
observations and shorter-term forecasts (e.g., 6-14 day extended weather outlooks) should be used. The first 3-month outlook also is to be used only until the forecast period begins (i.e., only about 2 weeks). The 12 subsequent 3 -month outlooks, each having a progressively longer lead time, are superseded by the set of forecasts issued the following month, and so are to be used only for about 1 month.

CPC climate outlook maps show the likelihood of occurrence, expressed as a probability anomaly, for average air temperature or total precipitation over the specified forecast period to fall within the upper, middle, or lower third of conditions reflected in the historic record from 1961-1990. Proper interpretation of the outlook thus requires examining actual average temperatures or total precipitation corresponding to the upper, middle, and lower thirds of the 1961-1990 historic record. A climatologic probability (i.e., a zero probability anomaly outlook) says that there is an equal probability (33.3\%) that the average temperature or total precipitation over the forecast period will fall within the upper, middle, or lower third of the conditions that occurred over 1961-1990. For probability anomalies up to $30 \%$, the outlook shifts the probability of average temperatures and total precipitation only within the upper and lower third of the 19611990 historic distribution; the probability of average temperatures or total precipitation falling within the middle third of the 1961-1990 historic record remains at 33.3\%. For probability anomalies larger than 30\%, the likelihood of occurrence of conditions represented by the central third of historic distribution is decreased as well, leaving a $3.3 \%$ probability in the least-likely category. Climatologic probabilities are specified for regions where forecast techniques have marginal accuracy. Thus, when an outlook specifies some anomalous probability for a region, there is an implicit statement that the tools used to create that outlook have some record of skill for that region for that forecast period. In contrast, a climatologic probability may mean that several forecast tools suggest typical conditions over the forecast period, that no forecast tools work well for that region for that season, that some tools have not been tested over a sufficient period to establish skill at that location, or some combination. The outlook maps don't specify which reasons apply, reinforcing the importance of consulting the outlook text discussion.

Several key aspects of the outlooks should be emphasized. First, the outlooks relate only to the 1961-1990 historic record and do not express likelihoods of experiencing average temperatures or total precipitation outside that period. Where extreme conditions have occurred at other times, the full historic record should be considered in decision making, but CPC outlooks provide no data to do so. Users should compare the frequency distribution of the full historic record with that of 1961-1990, and then with the shifted distribution of the CPC outlooks. Second, the outlooks concern only average temperatures and total precipitation over the entire forecast period. They do not forecast conditions for any particular day within the forecast period. The outlooks say nothing about the likelihood of experiencing daily or weekly temperature extremes, or even about monthly extremes within a 3-month forecast period. Average temperatures within the middle third of the 1961-1990 historic record may occur as a combination of extreme cold and extreme warm conditions, especially over longer forecast periods, e.g., 
the 3-month outlooks. Additionally, the outlooks say nothing about whether precipitation, even above average precipitation, will occur as many small events or a few severe events.

\section{Forecast Techniques}

Each outlook is created by combining results from several methodologies having varying levels of scientific sophistication. Expert judgement is used to determine how results are combined and sometimes to further adjust the forecasts. Forecasts produced by individual techniques may be accorded more or less importance, depending on diagnoses of recent climate behavior and recognized strengths and limitations of individual techniques. Thus, one outlook may be created in a different manner than another, both within a suite of forecasts and from one month to the next. Additionally, product interpretation may change; current CPC climate outlooks differ from those prior to July 1998 in that climatologic probability forecasts must now be made for regions where forecast techniques have only marginal accuracy. Individual forecast techniques change more frequently than their documentation, producing inconsistent and unpredictably outdated descriptions. Further, while techniques may be described in the scientific literature, they often differ in operational implementation.

Current techniques are a mix of statistical and conceptual modeling approaches. Canonical Correlation Analysis (CCA) is a form of multiple linear regression used to predict spatial patterns of anomalies of temperature and precipitation based on spatial pattern anomalies over 4 prior seasons, for global sea surface temperatures (SSTs), atmospheric pressure heights, and temperature and precipitation at 59 U.S. locations. CCA considers slowly evolving effects of ocean conditions on the atmosphere, such as the El Niño-Southern Oscillation (ENSO) and the North Atlantic Oscillation. Screen Multiple Linear Regression (SMLR) is similar to CCA (Unger, 1996), but provides forecasts only for specific stations, including Flagstaff, Phoenix, Tucson, and Winslow, AZ. SMLR considers only the single prior 3-month season and determines which variables are used for each location and forecast period. It recognizes that climate in locations with significant geographic features (e.g., mountains, coastlines) may have unique relationships with only a few controlling ocean or atmospheric conditions. Autumn evaluations with a 1-month lead time (Unger, 1996) show SMLR temperature forecasts have highest skill in Arizona, Nevada, and Utah; SMLR precipitation forecasts are not as good, but also have their highest skill in the lower Colorado River basin, excluding the Gila River basin.

The Optimal Climate Normal (OCN) method is a relatively simple statistical technique that recognizes interdecadal shifts in climate regimes. OCN forecasts are computed by subtracting 30-year climatologic averages (presently 1961-1990) from averages of the past 10 years for temperature and 15 years for precipitation. This approach reflects persistence of conditions from year-to-year within a regime, but also improves forecasts during long-term trends. OCN is not so useful during periods of regime transition. Averaging periods other than 10 or 15 years may be more optimal for some regimes and regions. The Soil Moisture Tool (SMT) considers soil moisture conditions and prior month temperature anomalies to reflect intraseasonal effects that soil moisture can have on regional surface climatology. SMT is generally extended only a 
few months during summer when linkages are strongest. Constructed Analogs (CAs) are used for special cases where conditions have a strong signal with several occurrences in the historic record (e.g., El Niño). Usefulness of CAs depends on the strength of similarities between present and analog conditions.

Coupled Model Prediction uses global climate models (GCM) to consider the myriad complex physical processes that affect climate, including the mutual influence between the oceans and atmosphere. Different GCMs are used, since some models contain more detail about slowly evolving interactions (e.g., heat transfer), while other models contain more detail about rapidly changing atmospheric conditions (e.g., deep cumulus convection). Additionally, single GCMs may be used slightly differently, typically by varying starting conditions. Operational procedures change often, with some implementations still experimental. Generally, several different coupled oceanatmosphere models are used to forecast SSTs then used as starting conditions for several runs of the NCEP MRF model. Typically, other MRF runs use starting conditions of recent observed SSTs (e.g., from the prior half-month or 3-months). The total number of model runs varies, but each extends out only 6 months, limiting their influence to only earlier 3-month outlooks.

\section{Forecast Performance}

Quality of CPC climate outlooks varies by region, by season, and by the dominant modes of climate variability. When several forecast techniques produce similar results, consistency suggests higher confidence in the combined forecast. Alternatively, if individual forecast techniques produce different results, sometimes none of the forecasts are used and forecast probabilities are based only on climatology (i.e., historical climate statistics). Depending on specific circumstances, a prediction for a 3-month period 8 months into the future may actually be more reliable than one for the next 3 months. Greater confidence is possible for regions where climates are stabilized by nearby oceans, resulting in climate variations that are more easily distinguished from small-scale weather influences. Outlooks have lower confidence in regions where short-term variations are more common; in the mountainous West, including the Southwest, short-term complex interactions of air masses with widely varying terrain can overwhelm any clear signal of persistent climate variations. Generally, outlooks are more accurate for average temperature than total precipitation. Average temperatures show less variation over larger regions than precipitation in historic records, allowing longer-term climate variations to be more readily recognized, understood, and predicted. Precipitation records show much larger variation over even small regions, masking large-scale and persistent climate influences that would enable better prediction.

Detailed climate outlook evaluations, whether for individual techniques or the composite forecasts, are not usually focused on the Southwest. Rather, evaluations typically include the Southwest within a national analysis, using a few observation stations in the region. For the conterminous U.S. in general, January-March and JulySeptember outlooks have the highest reliability or "skill". Likewise, April-June and 
November-January outlooks have lowest skill, because they are periods of transition between seasons, when weather is more highly variable (Western Regional Climate Center, 1998). However, this is likely not true for the April-June period in the Southwest, since this period has relatively constant weather with notable lack of precipitation. Leetma (1998) concluded that CPC climate outlooks generally have higher accuracy during extremely warm ENSO conditions because recent analogs in the historic record, including a decadal signal in precipitation records, are similar to El Niño precipitation patterns; numerical models work well under El Niño's strong and persistent SST signal as well. Livezey et al. (1996, 1997) concluded winter season forecasts during warm and cold ENSO phases have moderate skill over the U.S., but not otherwise. The Salt River Project (SRP, 1998) found CPC climate outlooks unusable for predicting summer peak power loads. Also, temperature probability anomalies were biased by the 1961-1990 period used in determining climatologic normals; with Phoenix, AZ, experiencing rising air temperatures due to urban heat island effects, use of only more recent years to determine "normal" may be more appropriate.

\section{Hydrologic Forecasts}

Official NWS hydrologic forecast products may be issued by the national Hydrologic Information Center, regional River Forecast Centers (RFCs), and local WFOs. In the West, some forecasts are issued simultaneously by both RFCs and the USDA Natural Resources Conservation Service (NRCS), but with slightly different content and format. In addition to NWS units, many other entities provide hydrologic forecasts (e.g., water demand forecasts of BOR, Central Arizona Project, International Boundary and Water Commission). Increasingly, other groups reproduce or reformat official NWS hydrologic forecasts to offer "one stop shopping" to targeted clientele. Research groups may offer reinterpretations or extensions of NWS products, or have entirely new experimental products; NCEP threats assessments provide CPC soil moisture anomaly forecasts when conditions warrant.

In addition, NWS has recently completed a major modernization initiative, changing institutional structure, distribution of responsibilities, programmatic activities, software installations, and documentation. To garner support for ancillary modernization related to hydrologic forecasting activities, recent NWS programmatic documentation related to hydrologic forecasting has focused on plans for the future, swamping out communication about present practices. Additionally, modernization has, in some cases, produced inconsistent and out-dated documentation; it is also difficult to sort out from hydrologic modernization plans what procedures are really operational at various locations.

\section{Short Range Forecasts}

NWS Weather Forecast Offices (WFOs) are responsible for issuing flood and flash flood watches and warnings for their service areas. Flash flood watches and warnings are used for events that are projected to occur within 6 hours, while flood 
watches and warnings refer to events projected to occur more than 6 hours after product issuance. Flash flood watches are generally issued for multi-county areas, while flash flood warnings are targeted to portions of counties; both may focus on specific river or stream reaches and be associated with a specific flood forecast point. Depending on time of issuance relative to onset and termination of flooding, flood forecast products may be known as Flood Warnings, Flood Statements, or River Statements. Key inputs required by WFOs include observed precipitation, forecast precipitation, and flash flood guidance. These inputs and issuance of flood watches and warnings rely on intense coordination among the NWS WFO, NWS RFC, and local emergency management agencies. While RFCs provide flash flood guidance to the WFOs, the WFOs don't necessarily use that input for determining whether to issue a watch or warning. In practice, the CBRFC issues guidance because they are procedurally required to do so, but WFOs typically rely instead on real-time monitoring of watershed conditions through coordination with local Flood Control Districts.

Quantitative precipitation forecasts (QPFs) have been issued by the NWS since 1960. The HPC has responsibility for generating national QPFs and currently issues 24hour QPFs, 6-hour QPFs, 24-hour forecasts of excessive rainfall potential, and heavy snow forecasts (Figures 27-29). All QPFs issued by the HPC result from a forecaster combining a variety of input data with the results of several NWS meteorologic models, including the Eta, NGM, AVN, meso-Eta, and RUC models. Winchell (1996) notes that there is a need for more effective use of QPFs in subsequent hydrologic forecasting. However, acceptance of QPFs for operational hydrologic forecasting has been slow, due to difficulties in hydrologic use of QPFs resulting from a mismatch between the areal coverage represented by QPFs and flood forecasts. NWS WFOs also generated QPFs for their local area of coverage, using many of the same numerical weather models. However, WFO forecasters are able to also run higher resolution numerical weather models (e.g., MM5) focused on their local areas, that more effectively consider orographic effects. Additionally, WFO forecasters have more expertise in subjectively combining model results with local observations and detailed understanding of local weather patterns. Thus, WFOs typically rely more on their own QPFs than those generated by the HPC. Further, the RFCs, especially during flood threats, may rely on WFO QPFs.

Daily stage or discharge forecasts are made routinely by the NWS RFCs for over 4000 locations in the conterminous U.S. and then issued through local NWS WFOs without modification. Stage forecasts are typically issued with 1-3 day lead times at most forecast points, while stage crests are forecast out to about 1 week for a few selected points. Evaluations of daily forecast products generally are retrospective analyses of specific extreme events rather than regional reviews of long-term forecast success. All daily forecasts make use of the NWS River Forecast System (NWSRFS). Initially developed in 1971, this complex software system links numerous legacy computer programs for data management and modeling with new GUIs and improved graphical output. Streamflow or stage forecasts are determined by use of continuous hydrologic models with near real-time inputs of precipitation, air temperature, snow water equivalent, soil moisture, and river and reservoir stage data, combined with pre- 
determined model parameters. Output is deterministic (i.e., a single forecast streamflow hydrograph). The NWSRFS Ensemble Streamflow Prediction (ESP) system generates probabilistic forecasts by successive consideration of various meteorologic scenarios of precipitation, air temperature, and potential evaporation extracted from the historic record; composite statistics describe the full or partial set of individual streamflow hydrographs. Only 2 continuous hydrologic models are generally used within NWSRFS. First developed in the 1940s, the relatively simple statistically based Antecedent Precipitation Index (API) model is still used for some forecasts, including some basins within Arizona (HRL, 1998). Current implementation at the Colorado Basin RFC (CBRFC) uses daily API values, 6-hourly basin rainfall and melt, and daily percent areal snow cover to generate runoff at 6-hour intervals. With exceptions, RFCs rely primarily on the Sacramento Soil Moisture Accounting (SAC-SMA) model, initially developed in the early 1970s, to generate forecasts for watersheds with hydrologic response times greater than 12 hours. CBRFC predominately uses the SAC-SMA as the continuous hydrologic model within the NWSRFS, although it has not been implemented for all watersheds in the basin. Snow accumulation and ablation are modeled using concepts only slightly changed from early 1970s formulations, although Kalman filter updates with observed snow water equivalent areal estimates are now possible (HRL, 1998).

\section{Long Range Forecasts}

While hydrometeorologic dynamics are complex, non-linear, and highly variable in both space and time, longer-term water supply forecasts are practical in the Southwest because most usable water supplies originate as mountain snowfall. Winter snow accumulation provides intrinsic system memory affecting water supplies throughout spring and summer. In the Southwest, the relationship is particularly strong because late spring and early summer have little additional precipitation. Further, rains associated with the summer monsoon typically produce only transient local effects with little impact on useable water supplies in larger basins.

NWS WFOs issue flood potential outlooks as simple text discussions, using RFC quantitative guidance over periods longer than for previously mentioned forecasts. A common threshold for identifying flood flows is exceedance of stream channel capacity (i.e., overtopping streambanks). However, the NWS defines flood flows based on initiation of damages; overbank flows may occur without damages. NWS flood flow thresholds can change yearly due to changes in channel characteristics, but also over longer periods due to changes in damage vulnerability.

Snowmelt peak flows generally occur during April-July, except in Arizona where the normal snowmelt period is March-May. CBRFC issues snowmelt peak flow forecasts each month over March-June and March-April for the upper and lower Colorado River Basins, respectively. They predict maximum mean daily flows at specific river locations resulting from spring melt of accumulated snowpack. Snowmelt peak flows describe actual flows, reflecting regulations and diversions. Because human impacts are difficult to forecast, especially during extreme conditions, peak flow forecast locations in the Colorado River Basin are generally restricted to headwater locations or where regulation 
effects are highly correlated with natural flows with little interannual variability (Figures 31-32). Forecasts provide 5 exceedance probabilities $(90,75,50,25$, and $10 \%$ quantiles), compared to maximum period-of-record mean daily flows, average peak flows (through 1990), flood flows (defined as for flood potential outlooks), and normal peak flow dates (through 1990). Snowmelt peak flow forecasts are generated using either statistical regression or ESP application of SAC-SMA; the latter requires reservoir operations projections up to 5 months ahead, so forecasts are generally restricted to headwater basins. Calibration of regression or conceptual models uses historic maximum mean daily flows over March-May, even though peak flows may typically occur outside that period. Further, those maximum daily flows are not selected to exclude unusual events (e.g., rain-on-snow, chinooks). Snowmelt peak flow forecasts have large uncertainty because they attempt to predict short-period events with long and indeterminate lead times.

Comprehensive evaluations are lacking, but CBRFC considers narrow quantile ranges to imply a high degree of confidence, even while warning that the forecasts are much more uncertain than water supply outlooks.

Official U.S. government water supply outlooks for the U.S. West are issued jointly by NWS RFCs and NRCS. Each makes provisional outlooks using in-house techniques, subsequently coordinated into an official joint product, although the 2 agencies provide the coordinated outlooks in different formats. Outlooks made for the Salt and Verde River basins also incorporate, via coordination, forecasts made by SRP using proprietary techniques. Coordination occurs via subjective assessment of strengths and limitations of individual forecasts. Outlooks are usually issued beginning in January, with mid-month or monthly updates. Outlooks vary in temporal coverage (e.g., JanuaryMay for Gila Basin, April-July for Virgin Basin) depending on basin seasonal flow characteristics; they may be produced sooner with early snow accumulation. Water supply outlooks represent "naturalized" flows without any water management influence. Practical use requires users to adjust projected runoff volumes for anticipated diversions and reservoir regulations; adjustments can be complex yet incomplete. Additionally, values used are only projections based on typical management; extreme conditions make large deviations likely and adjustments even less certain.

Water supply outlooks are given as exceedance probabilities, but confusion can result without skilled interpretation. The "most probable" forecast is described as a "best estimate" of anticipated seasonal runoff volumes based on hydrometeorologic conditions up to the forecast date. The best estimate description derives from considering error to be normally distributed, with the mean centered about the forecast; $10 \%$ and $90 \%$ exceedance quantiles simply derive from using different fractions of the error distribution and do not represent estimates of $10 \%$ or $90 \%$ exceedance flow volumes. Highly skewed flows (e.g., Gila River) preclude use of best estimates and instead require median estimates; confidence bound interpretation remains unchanged, however. NWS RFC outlooks designate their exceedance quantiles as reasonable maximum and reasonable minimum forecasts. However, reasonableness of the forecast depends on occurrence of typical climate conditions; when CPC monthly and seasonal climate outlooks project significant climate anomalies, water supply outlooks become less reasonable. Further, the 
term "reasonable" suggests direct application for decision making, although actually the appropriate quantiles depend on individual risk tolerance and loss functions.

Operational water supply outlooks are generated using multiple linear regression techniques developed by NRCS and transferred to RFCs; agency applications differ only in specific equation formulations. Unique regressions for each forecast period and location use subsets of monthly or seasonal observations of precipitation, streamflow, and ground-based snow conditions, and routed forecast streamflows. Southern Oscillation Index (SOI) values and even seasonal CPC outlooks can be incorporated, although only SOI is presently used and only for a few Arizona locations (e.g., along the Gila River). Variables may be normalized using transformations or de-correlated using principal component analysis. SRP water supply outlooks start with a proprietary seasonal precipitation model that evaluates spatial patterns and temporal trends in air temperatures, precipitation, and Pacific SSTs using pattern recognition. Regression equations convert seasonal precipitation probability forecasts into water supply outlooks. CBRFC also concurrently generates experimental water supply forecasts using ESP with SAC-SMA and historic meteorology, but for internal evaluation only.

NRCS and RFC regression equations are evaluated using standard error computed directly and as regression parameters vary with successive data elimination. However, operational forecasts rarely receive comprehensive evaluation, the latest being done by Shafer and Huddleston (1984). Forecasts issued in mid-March or April for lower Colorado River watersheds are generally considered most accurate because these basins see little additional precipitation in late spring or early summer. Additionally, if all individual forecasts are consistent, the agencies have high confidence in the coordinated outlooks. CBRFC experimental ESP forecasts are too few for retrospective evaluation.

\section{Conclusions and Recommendations}

\section{Hydrologic versus Weather and Climate Forecasting}

The state of hydrologic forecasting shows clear contrasts with that of weather and climate forecasting and appears to stem in part from different institutional philosophies within the NWS units responsible for the different forecasts. The state of meteorologic forecasting can be characterized by the rapid incorporation of a wide variety of research findings and products; experimental forecasts are routinely issued and operational forecasts can be adjusted based on recent climate diagnoses and newly-improved conceptual understanding of ocean and atmospheric dynamics and linkages. Different forecast techniques can take precedence in different regions, during different seasons, and for unusual conditions. New forecast techniques move relatively quickly from research to experimental to operational status. Different units within NOAA have responsibility for different types of forecasts and even for the different models. Forecasts generated by groups outside NOAA are also routinely incorporated into official meteorologic forecast products. Additionally, meteorologic forecasting has a strong history of forecast quality assessment. 
In contrast, the state of hydrologic forecasting is characterized by much slower evolution, with constraints imposed by complex legacy data management systems, longstanding standard operating procedures, and an institutional preference for uniformity in operations. The NWS has made a strong commitment to only 2 conceptual hydrologic models (API and SAC-SMA); any new models must accommodate the infrastructure surrounding those 2 core models. Further, quality assessments of operational products are uncommon; even coordinated comparisons of hydrologic model performance have been infrequent and typically contentious. However, the philosophy reflected in the production of official water supply outlooks offers some opportunity for extending hydrologic modeling capabilities beyond the API and SAC-SMA models. Official water supply outlooks issued by the NWS are generated through coordination with other groups, including private organizations (e.g., the Salt River Project). This precedence provides potential for incorporating new forecast methodologies more rapidly, by having other organizations produce experimental or operational forecast products that can then be coordinated with NWS hydrologic forecasts.

\section{The Future of Forecasting}

Rapidly increasing computer power and the evolution of remote sensing of oceanic, atmospheric, and land (surface and below) conditions have produced significant shifts in the philosophy and practice of weather, climate, and hydrologic forecasting, although less so for the latter. The climate modeling community experienced an earlier shift than the hydrologic community to a spatially variable approach to dynamic conceptual modeling, usually via use of grids. Conceptual hydrologic models are still largely lumped models, where large regions are considered to behave as a single unit, without spatial variation in behavior. However, the availability of geographic information systems, digital elevation models of terrain characteristics, and satellite remote sensing have fostered substantial research effort to develop distributed hydrologic models, where spatial variations in watershed characteristics are explicitly considered. Development of distributed hydrologic models is an active area of research, with models far from being used operationally.

Additionally, there is much research focused on the interaction among oceanic, atmospheric, and land systems, although only limited coupling is presently incorporated into operational forecasts. In particular, sea surface temperatures (SSTs) over the Pacific Ocean are used in several large-scale climate models to affect climate forecasts over continental areas. The El Nino-Southern Oscillation (ENSO) phenomenon is incorporated into some statistical models for water supply in the Southwest. However, other large-scale phenomena (e.g., the Pacific North America [PNA] and Southwest Trough circulation patterns), while recognized as having important consequences for Southwest hydroclimatology (Cayan and Peterson, 1989; Redmond and Kock, 1991; Cayan, 1996; Woodhouse, 1997), have not yet been incorporated into operational models or forecasts. Further, many other teleconnections (e.g., the Pacific Decadal Oscillation [PDO]) are the focus of active research programs, with much work to be done before they can be incorporated into operational forecasts. 
Because different climate and hydrologic processes occur at different spatial and temporal scales, coupling between climate and hydrologic models may need to occur at multiple scales as well. The use of nested models is becoming more typical in atmospheric models, but many alternative implementations remain to be explored (e.g., use of one-way or two-way feedbacks between nested models, nesting with more than two tiers of models). Use of nesting in strictly hydrologic models would generally be limited to one-way nesting, because with the exception of relatively limited backwater effects, flows are affected only in the downstream direction. For short-term hydrologic forecasts, one-way nesting is accomplished by routing forecast flows downstream. Longterm hydrologic forecasts are not nested; anticipated flow conditions are computed only for separate watersheds, with no relationship between upstream and downstream forecasts, with the exceptions that flow at an upstream gage is sometimes an input variable in statistical regression techniques.

Nesting of models of different spatial coverage and resolution is wrought with complexity relating to the appropriate linkage of processes and other issues. In contrast, temporal nesting is conceptually straightforward, yet has been comparatively neglected. The climate occurring over several months is comprised of a succession of short-term conditions. While operational forecasts are made for time scales ranging from minutes to several months, there are no explicit connections between such forecasts. Further, while there is general recognition that the accumulation of short-term forecasts should be consistent with the longer-term forecasts, evaluations of models or forecasts generally do not consider multiple time intervals.

A reasonable vision of forecasting over the extended future is for increasing complexity and interconnectivity of all phases of modeling. A forecast system of the future might be expected to include incorporation of a greater variety of data; coupling between oceanic, atmospheric, and hydrologic processes; nesting across multiple spatial and temporal scales; and updating of forecasts by assimilation of recent observational data based on forecast error characteristics. Further, the future of forecasting is likely to include a larger number of forecast techniques, both statistical and dynamical, empirical and conceptual. The best means for integrating and communicating those diverse forecasts will likely become an increasingly important question for both forecasters and forecast users.

Large research programs, with joint participation of many research groups, are focused on developing the next generation of forecast tools. However, based on the present rate of transition of research into operational tools for hydrologic modeling, it is likely to be many years before these research programs result in new operational forecast tools; the present generation of hydrologic forecast tools is likely to be in place for years to come. Theoretically, there are significant opportunities for relatively rapid improvement of operational hydrologic forecasts based on recent improvements in the skill of climate forecasts. However, because current operational techniques are not included in hydrologic research programs, which are generally devoted to the next generation of forecast tools, those opportunities have not been realized. Additionally, 
there is a notable lack of research attention being paid to the on-going evaluation of present operational hydrologic forecasting techniques. This results in an absence of any quantitative basis for forecast credibility.

\section{Recommendations}

Review of the climate, weather, and hydrologic forecasts available for the Southwest, along with consideration of the efforts of agencies and institutions, suggests a range of needs that CLIMAS is uniquely suited to address. The following recommendations for future CLIMAS activities have been assigned varying levels of priority, based primarily on consensus views of participants at the Forecast Assessment Workshop. Priority 1 recommendations are those that can relatively quickly provide results directly applicable to stakeholders in the Southwest; typically, the tasks use data and forecast products that already exist in usable form. Priority 2 recommendations require more extensive work, generally to recreate forecast products using special procedures. Priority 3 recommendations are important for improved hydrologic forecasting, but either they do not directly affect current operational forecast procedures, are expected to require years of effort, or are the focus of other research programs outside of CLIMAS.

\section{Recommendations: Forecast Evaluations}

Priority 1. Evaluate CPC 1- and 3-month temperature and precipitation outlooks. Assessment of the complete series of CPC outlooks, focusing on just the Southwest, enables demonstration of incremental improvements in the outlooks over time, providing a quantitative basis for forecast credibility within the region, and identification of seasons during which the outlooks have been consistently strong or weak. Evaluations should consider both regional fields and point locations. This will identify locations where forecasts are especially reliable, although it is more likely to identify locations where forecasts are especially inappropriate, suggesting the presence of unique land-atmosphere interactions, e.g., orographic effects, and identifying needs for improved modeling. Because techniques for producing the climate outlooks are constantly evolving, there is an insufficient record of outlooks for evaluating the current mix of techniques. Such an evaluation requires a reanalysis approach, whereby current techniques are used in a simulated operational setting covering a suitably extensive historic period. Reanalysis is practical only for individual techniques, however, since the process for combining forecasts is subjective and requires substantial forecaster expertise. However, the objective requirement that climatologic probabilities be issued where techniques have only marginal skill could be incorporated in a more comprehensive reanalysis. Further, while climate forecast techniques have changed, it is still appropriate to assess the historical archive of forecasts, because resource management decisions have been made using those forecasts, providing a more realistic assessment of vulnerability to climate variability and forecast uncertainty.

Priority 1. Evaluate water supply outlooks: coordinated seasonal volumes. There is a notable lack of research attention being paid to the on-going evaluation of present 
operational hydrologic forecasting techniques. This results in an absence of any quantitative basis for forecast credibility. Although forecast techniques have changed over the decades, it is appropriate to assess the historical archive of forecasts. Many water management decisions have been made using those forecasts, providing a more realistic assessment of vulnerability to climate variability and forecast uncertainty. After creation of the historic forecast database, various measures of forecast quality will be evaluated, since different users require different forecast performance qualities.

Priority 2. Reanalysis of water supply outlooks: seasonal volumes and hydrographs from ESP forecast procedures. Past problems with specific weather, climate, and hydrologic outlooks can engender a tendency towards skepticism, even though physical understanding and forecast techniques have improved. One approach to improving credibility associated with current forecasts is to conduct reanalysis or hindcast evaluation studies. Both reanalysis and hindcasting refer to the use of current operational techniques with historic data to create forecasts in a simulated operational setting. That series of forecasts is then used to evaluate the predictive skill of current operational procedures.

Presently, the NWS CBRFC generates experimental probabilistic water supply outlooks using Ensemble Streamflow Prediction (ESP) procedures. However, the number of forecasts is insufficient for evaluation. Reanalysis evaluation of the ESP forecasts was identified as a critical need by participants in the Forecast Assessment Workshop and water managers elsewhere (Roos, 1998). The NWS Office of Hydrology has created procedures for reanalysis studies using the experimental ESP procedures (Perica, 1998), although no forecast assessments have yet been done (Schaake, 1998). Reanalysis evaluation of ESP forecasts will also enable comparison of different methodologies for selection of appropriate meteorology to drive the conceptual runoff models.

Priority 2. Reanalysis of water supply outlooks: seasonal volumes and hydrographs from statistical forecast procedures. Except for the standard error analysis conducted during determination of the regression coefficients used in the statisical approach for water supply forecasting, little evaluation of model performance has been conducted. Historic records of official water supply outlooks have been made using a mix of evolving techniques. More appropriate evaluation of the strengths and limitations of the current water supply outlook techniques requires use of those techniques in reanalysis or hindcast studies. Both reanalysis and hindcasting refer to the use of current operational techniques with historic data to create forecasts in a simulated operational setting. That series of forecasts is then used to evaluate the predictive skill of current operational procedures. Such an approach will allow consideration of a broader variety of forecast performance measures of quality than simple standard error analysis. In particular, evaluation of marginal and conditional probabilities should be informative for directing future areas of focus for improving statistical-based water supply forecasts. 


\section{Recommendations: Improve Modeling}

Priority 1. Incorporate climate outlooks into statistical water supply outlook techniques. Although this recommendation was rated at the highest priority in the Forecast Assessment Workshop, it was noted that such activities are often ranked low in advanced modeling research programs. However, based on the present rate of transition of research into operational tools for hydrologic modeling, it is likely to be many years before these research programs result in new operational forecast tools; the present generation of hydrologic forecast tools is likely to be in place for years to come. There are significant opportunities for relatively rapid improvement of operational hydrologic forecasts based on recent improvements in the skill of climate forecasts. However, because current operational techniques are not included in hydrologic research programs, which are generally devoted to the next generation of forecast tools, those opportunities have not been realized.

Priority 3. Evaluate gridded precipitation and snow estimates for use in forthcoming distributed forecast procedures. Proper initialization of hydrologic models requires good estimates of moisture storage available for runoff. Depending on the forecast time scale and lead time, good estimates are required of the spatial distribution of precipitation, snowpack conditions, or both. For water supply outlooks, high quality estimates of snow water equivalent are required throughout a watershed. Snow data over 1990-present, archived by the NOAA NOHRSC, will be converted to a consistent format. Hypertemporal spatial analyses will be used in conjunction with water balance analyses to evaluate the potential use of those gridded snow products in anticipated distributed hydrologic forecast procedures, as well as in extending existing operational statistical models.

\section{Priority 3. Improve conceptual distributed hydrologic modeling capabilities. This} activity is a high priority of other research programs (e.g., NASA's EOS program). However, in the context of the CLIMAS mission, other activities have higher precedence. Thus, while acknowledged here as an important area for future activity, CLIMAS involvement should be ancillary to other efforts.

\section{Recommendations: Improve Forecast Products and Communication}

Priority 1. Evaluate use of climate and hydrologic forecasts products during the 1998-99 La Nina episode. Recent work completed in conjunction with the CLIMAS project used in-depth interviews of key personnel in water management agencies in Arizona to develop a thorough understanding about the relationship between 1997-98 El Nino information and forecasts and decision making related to anticipated water surpluses. Subsequent transition to strong La Nina conditions provides a unique opportunity to extend that understanding to drought conditions, given that the La Nina signal in the Southwest is even stronger and more certain than for El Nino or when compared to other regions. However, drought is a slowly cumulative condition that does not receive the same media coverage as potential flooding; additionally, impending drought and water deficits have no easy action options. 
Priority 1. Develop location-specific climate outlook products. Presently, CPC climate outlooks are shown as regionally varying maps of probability anomalies. Proper interpretation requires coordination with historic data, although that's not provided in the CPC outlooks. A useful product would show the 1961-1990 distribution, a shifted distribution based on the CPC outlooks, and the full period-of-record distribution. The distributions could be developed for specific locations (e.g., Benson, AZ) or relatively localized regions (e.g., Tohono O'odham reservation lands). Additionally, the shifted distributions should reflect the uncertainty associated with the climate outlooks, based on past forecast performance. New products and formats should be developed through an ongoing iterative process with stakeholders, to ensure their needs are directly addressed.

\section{Priority 1. Develop improved hydrologic forecast products. Individual NWS RFCs} present water supply outlooks in different formats, some of which are more informative than those presently issued by the CBRFC. Improvements are possible in graphical presentation of water supply outlook volumes, past forecast performance, and comparison to flow distributions based on varying historic periods. New products and formats should be developed through an ongoing iterative process with stakeholders, to ensure their needs are directly addressed. 


\section{CHAPTER 1. INTRODUCTION}

\subsection{Background}

This report is a product of the NOAA-funded Southwest Climate Assessment (CLIMAS) Project. The CLIMAS mission is to enhance regional capabilities to respond appropriately to climate events and changes, through improved understanding of regional climate variability and potential vulnerabilities. Early project efforts have focused on synthesizing existing information and identifying additional research and development needs, for both natural- and social-science topics. This report attempts to synthesize information related to weather, climate, and hydrologic forecasts that are available for the Southwest. A simple approach would have been to simply focus on only a few forecast products. However, this report attempts to provide a more comprehensive review of the state of forecasting for the Southwest, and includes many kinds of forecast products. It also addresses a variety of issues related to forecasting that are not limited to a regional perspective. Thus, this report attempts to set the stage for additional work under CLIMAS that reflects both local and more general needs.

A significant source of material used in this report was obtained through a 2-day workshop held in Tucson, Arizona, in July 1998. The 23 participants primarily consisted of agency personnel involved in operational forecasts, via directly issuing forecasts, providing key data for making forecasts, or serving as a key link for communicating forecasts. Organizations represented at the workshop include the National Weather Service (NWS) Weather Forecast Offices of Phoenix and Tucson, NWS Colorado Basin River Forecast Center, NWS Office of Hydrology, Natural Resources Conservation Service, Bureau of Reclamation, Salt River Project, NOAA GCIP, Western Regional Climate Center, Portland State University, and University of Arizona Institute for the Study of Planet Earth and Departments of Hydrology and Water Resources, Civil Engineering, and Public Administration. A list of attendees is provided in Appendix A. Several participants served as key ongoing contacts for further information about forecast products, techniques, and evaluations of forecast quality.

Much of the information used in this report is accompanied by URL addresses; the on-line version of this report provides direct linkages to forecast products and other information sources. The World Wide Web and easily available Internet access have radically changed the means for obtaining forecast products over the past few years. Most products, along with ancillary information (e.g., technique descriptions and input data), are now delivered primarily, if not exclusively, via the Web. In many cases, ancillary information on the Web more accurately reflects current interpretations and techniques than published literature, because electronic texts can be periodically updated. For example, the meaning of precipitation probabilities from the Eta family of numerical weather models changed 14 September 1998, with documentation being available only on-line. 
An important consideration limiting this report is that much of the information describing how exactly how specific forecasts were made is simply unavailable. While forecast techniques may be described in the scientific literature, those descriptions generally address research or experimental techniques that often change during the transition to operational use. Agencies don't necessarily intend that their operations are cryptic; rather, the situation results from the limited mandates and resources associated with operational activities. Typically, there are few records describing when and how procedures change and practically no records about how expert judgement was incorporated into the coordination of individual forecast techniques. Further, the individual variables associated with operational forecasts are typically not archived. For example, basin moisture storage conditions used to initialize forecasts made by conceptual hydrologic models have generally not been archived. Additionally, only select statistics about the forecast (e.g., specific distribution quantile values of peak flows) are generally archived, rather than the complete suite of hydrographs from an ensemble of forecasts.

\subsection{Forecasts and Resource Management}

Whether explicitly recognized or not, most decisions related to management of natural resources make use of some sort of climate or hydrologic forecast. Those forecasts may be derived from complex objective techniques using many types of data, sophisticated mathematical representations of physical processes, and teams of scientific experts. Alternatively, those forecasts can be made using simple, subjective, and ad hoc processes that are not even explicitly described; an individual decisionmaker may simply have a feeling about future conditions, based on an implicit forecast that future conditions will be much like the past. In between these extremes, there is a continuum of types of forecasts that may be used by a decisionmaker, including simple statistical techniques based on limited data, and complex subjective heuristics.

Further, resource managers possess a range of abilities to access, interpret, and use weather, climate, and hydrologic forecasts. In the context of Arizona water management agency response to the 1998-1999 El Nino, Pagano et al. (1999) found 3 dominant approaches to hydroclimatic forecasts. Some agencies (e.g., Salt River Project) have sufficient resources to employ meteorologists, climatologists, or hydrologists that provide internal expertise. Other agencies rely on external expertise, generally provided by federal agencies (e.g., National Weather Service); consultants may also provide this expertise, although the case studies of Pagano et al (1999) did not include any such examples. Finally, some resource managers attempt to access and interpret forecasts made by others (e.g., NWS), even though they have no special training. This last situation presents a real challenge to forecasting agencies: to provide useful forecast products that can be properly interpreted even by non-specialists.

Changnon (1990) identifies 4 key dilemmas related to climate and hydrologic forecasts that are also relevant to weather forecasts. First, the lack of sufficient understanding of the hydrologic system makes it difficult to appropriately integrate a 
variety of existing data and climate predictions into hydrologic forecasts. Similarly, incomplete understanding of oceanic and atmospheric systems, their joint interaction, and coupling with hydrologic processes limits weather and, especially, climate forecasting capabilities. Second, there is typically a lack of direct and timely measurements, often at crucial times, of the important variables affecting hydrologic conditions. In the Southwest, estimates of precipitation coverage and intensity, soil moisture, and snow coverage and water equivalence are especially problematic. Weather and climate forecasts are also limited by poor estimation of current conditions in key locations. Third, the limited accuracy of climate outlooks, especially with extended lead times, subsequently affects the potential accuracy of hydrologic forecasts that make use of those climate outlooks. However, the lack of established means for incorporating weather and climate forecasts into hydrologic models is also an important limitation. Fourth, user perceptions of poor forecast quality reduce use of forecasts, as does the inadequacy of appropriate means to incorporate forecasts into complex decisions. Changnon notes that part of this dilemma results from the general belief that climate forecasts must be less accurate than weather forecasts, which can be far from perfect, and results in a general lack of credibility of any long-term forecast.

The important role of credibility in the communication of risk-related information is well established and is generally applicable to weather, climate, and hydrologic forecasts as well. A review by O'Grady and Shabman (1990) identifies key elements required for effective communication of probabilistic information, including forecasts. Users that have difficulty interpreting probability statements or incorporating them into decisions may be persistent in requesting forecasts as single values (i.e., deterministic forecasts). However, users inevitably assign a greater degree of confidence to deterministic forecasts than is warranted, resulting in long-term overall loss of confidence in forecast quality as surprises (i.e., conditions substantially different from the deterministic forecast) inevitably occur. O'Grady and Shabman also note that consistently communicating the uncertainty of forecasts can, counterintuitively, increase forecast credibility.

\subsection{The Informational Avalanche}

There is an incredible variety of hydrometeorologic forecasts, so many as to be potentially confusing or overwhelming. Forecasts are issued by a complex mix of agencies, universities, institutions, and other organizations, with many institutions being joint enterprises of agencies and universities. Additionally, there are many private enterprises making forecasts for individual clients. Forecasts are issued through a complex mix of media as well, including published reports, newspaper, radio, and increasingly via computer. This variety of forecast products and sources has real potential to reduce credibility attributed to any specific forecast. A user might well question why slightly different forecasts are distributed by different agencies or, when forecasts are quite different, wonder which one is more reliable. They may become overwhelmed by the many choices available and simply select the forecast that is easiest to access, rather 
than the most appropriate. While many agencies and institutions are mentioned herein, no attempt is made to evaluate this institutional milieu.

Further, the state of forecasting is constantly evolving. New products are being generated, or standard products are being communicated in new ways, on an everchanging trajectory. Forecast descriptions and reviews presented herein are accurate at the time of their creation (July 1998-July 1999), but will likely change over time, some almost immediately after sections of this report are written. Agencies and institutions have long-term research agendas focused on development of new technologies to support and produce forecasts. Some of these new technologies will be radically different than those currently used to create forecasts.

This report cannot hope to identify and review every type of forecast product relevant to the U.S. Southwest; there are simply too many, when all possible forecast sources, forecast elements, time-scales, space-scales, and lead-times are considered. The first priority of this report is to address the operational products issued by governmental agencies. There are a host of issues related to the generation, distribution, interpretation, and use of forecast products; while this report may briefly discuss some issues, others are not considered. Notably, this report does not address issues associated with the value of forecasts to various users or issues concerning equity of access or interpretive ability among different users.

\subsection{Statistics versus Forecasts}

While extensive, the wealth of forecast products is dwarfed by the availability of statistical products describing past conditions. A review of climate and hydrologic statistics is beyond the scope of this report, because statistical summaries of historic conditions do not, alone, constitute a forecast. Creation of forecasts from statistical summaries requires some statement, preferably explicit but often implicit, about the relationship between historic conditions and the future. An assumption of stationarity considers that both the past and future conditions are from the same population of possibilities and, thus, that statistics of past conditions can be used as predictive statements of future conditions. Many water resource development and management decisions have been made under assumptions of stationarity. For example, the Colorado River Compact of 1922 was based on an assumption that records then available, showing mean annual flows of 18 million acre-feet (MAF), could be used to guide water management decisions over many future decades. However, those flow records were collected during what is now understood to be an unusually wet period, and flows have since averaged on $14 \mathrm{MAF}$, creating intense conflict among water users (ADWR, 1994).

Evidence exists in many regions for the non-stationarity of meteorologic and hydrologic conditions. Conditions shift among regimes, i.e., periods of time within which conditions are more similar than over larger periods; examples for the Southwest U.S. are provided by Sheppard et al. (1999). Thus, statistics summarized over a shorter period (i.e., during a specific regime) may be better for use as predictive statements of 
future conditions. Changnon et al. (1988) found that agribusiness decisionmakers often make such an assumption, implicitly, by basing their decisions on conditions that have occurred over just the past 3-6 years.

Recent statistical summaries or direct measurements of recent conditions are also readily available but, used alone, do not constitute a forecast. However, assumptions of persistence of recent conditions or persistence in the trend of recent conditions can lead to forecasts of future conditions. The NWS periodically issues river statements for select river locations; these statements typically list measurements of recent stream flow and stage conditions, along with the short-term trend in conditions. Alone, these river statements are not forecasts. However, it's not unreasonable to think that river conditions in the near future might reflect current conditions adjusted by a continuation of the recent trend in conditions. However, the NWS leaves it up to the user of the river statement to, implictly or explicitly, make the assumptions and the forecast.

\subsection{Scenarios versus Forecasts}

Likewise, while many special purpose studies have been conducted using a variety of scenarios of potential climate and hydrologic conditions, their review is also beyond the scope of this report. While scenarios have some reasoned basis for their selection, they are not considered deterministic forecasts, nor are they typically associated with any probability of occurrence. Rather, scenarios are used to explore implications of anthropogenic or hydroclimatic changes (e.g., changes in land use or prolonged drought, respectively) beyond those expressed in available historic records.

Several studies using scenarios have been conducted specifically for the Southwest. The U.S. Bureau of Reclamation (BuRec) used atmospheric circulation pattern analogs to develop scenarios of precipitation in the U.S. West under conditions of global warming (Leverson, 1997). They have also used stochastically generated hydrologic scenarios with the Colorado River reservoir simulation model (CRRSez) to assess the ability of extant reservoir operating rules to satisfy requirements (BuRec, 1996). Tarboton (1995) developed a variety of scenarios based on both historic streamflow and paleologic tree-ring data, for use in a comprehensive study on implications of severe sustained drought for Colorado River management and use (Gregg and Getches, 1991; AWRA, 1995). The National Water and Climate Center of the Natural Resources Conservation Service has developed tools for stochastic generation of weather scenarios for use in a variety of studies (USDA, 1998).

\subsection{Types of Forecasts}

The wide variety of forecast products can be categorized according to several different perspectives; categories often have some overlap. 


\section{Forecasts, outlooks, predictions}

Users of forecast products may be confused by the alternative designations of products as forecasts, predictions, or outlooks. In the Handbook of Hydrology (Maidment, 1993), Lettenmaier and Wood (1993) distinguish between forecasts and predictions. Forecasts are estimates of conditions at a specific time or during a specific interval. Predictions are estimates of conditions without reference to any specific time. However, forecast products often do not follow these naming conventions. Forecasts of natural river flow volumes (i.e., adjusted to remove impacts of water management) over periods of several specified months, produced by the National Weather Service (NWS), are titled water supply outlooks, rather than water supply forecasts. On the other hand, NWS estimates of peak streamflows due to melt and runoff of the seasonal snowpack are made without any associated time of occurrence or specific interval (just sometime this season), but are termed peak flow forecasts rather than peak flow predictions. For the purposes of this report, no distinction is made between the several terms that are used to describe estimates of future conditions.

\section{Official, operational, experimental, and research products}

While this report may mention select experimental and research products, the emphasis is on official operational forecast products. Prior to easy Internet access to the World Wide Web (WWW), there was not much need for distinction between official, operational, experimental, and research products. Users simply received the official operational products and could easily be unaware of other products unless they had established relationships with groups making discretionary operational, experimental, or research forecasts. However, because users can now directly access experimental and research forecast products, it is critical to understand their differences from operational and official products.

Operational products are those that are routinely produced by an agency. They are generally created using established procedures or guidelines that have undergone extensive review, although there is often considerable opportunity for incorporation of subjective adjustments based on professional expertise or other ancillary information, including experimental and research products. Agencies may produce a variety of operational products, with some being required as part of the organization's mandate and others being issued at the organization's discretion. The former can be considered official products; while a legal mandate may not exist for issuance of a specific product, offices would face internal discipline and external rebuke if the products were not issued according to established schedules. Clear examples include flood watches and warnings issued by NWS. Over the long term, forecast offices will continue to make official forecasts using consistent formats and time schedules, until directed otherwise by higher level units within their agency. Alternatively, offices may issue non-official operational forecasts at their discretion; an example is the Southeast Arizona Convective Outlook issued by the NWS Tucson Weather Forecast Office. Although NWS has responsibility for most official forecasts related to weather, climate, and hydrology within the U.S., the agency does not typically identify which products are discretionary and which are required. 
Experimental products have not yet received official approval as being wellunderstood products generated with fully-developed procedures. Typically, experimental products are generated in a simulated operational setting for an extended period of time, to test whether they warrant transition to operational status. For example, the canonical correlation analysis and optimal climate normal techniques for making climate outlooks were considered experimental for several years, but have recently transitioned to operational status. They are now used routinely, along with several other operational techniques, to create the official NWS climate outlooks. Water supply outlooks for the Southwest based on the NWS Ensemble Streamflow Prediction (ESP) procedures are considered experimental, since the NWS is still in the process of evaluating the technique in a simulated operational setting at various forecast offices.

Research products are generally at even earlier stages of development than experimental products. The proliferation of joint agency and academic institutes, centers, and other consortia has contributed to the increasing array of easily available research forecast products, especially for weather forecasts. Often, results are posted on the Internet in a form looking like an operational forecast, as a means of sharing results and showing conversion of research into useable products.

\section{Weather, climate, and hydrologic forecasts}

The CLIMAS Project was developed to focus on seasonal, interannual, and even longer-period climate variability and change, with the mission of improving regional abilities to use climate information and to appropriately respond to climate events and changes. Although climate accrues from the temporal accumulation of weather events, the project focus is not on weather conditions. Thus, this report initially intended to focus on climate-scale forecasts, i.e., regional in spatial scale and monthly or longer in temporal scale. However, an earlier CLIMAS study (Benequista and James, 1998) found that stakeholders in Arizona often were more aware of and responsive to weather forecasts than climate forecasts. Further, within the hydrologic research community, there are long-term plans for integration of modeling across large and small spatial scales and short and long temporal scales. Thus, this report was extended to include local and shortterm forecasts as well. However, the diversity of local and short-term forecasts, especially weather forecasts, precludes comprehensive coverage within this report. Forecasts that are not discussed herein include degree-day forecasts for heating, cooling, or growing crops; forecasts of water demand; fire weather forecasts; and aviation forecasts.

This report is divided into 3 forecast sections: (1) weather forecasts, (2) climate forecasts, and (3) hydrologic forecasts. Weather forecasts generally track movement and evolution of specific air masses, while climate forecasts make statements about composite conditions. The NWS Climate Prediction Center (CPC) defines short-term climate as average behavior over a month or more (CPC, 1995), so shorter periods $(6,8$, 10, 14 days) may be more appropriately considered as extended weather outlooks; as such, they are addressed in the section on weather forecasts. Thus, in this report, weather 
forecasts cover periods approaching 1 month, while climate forecasts cover periods 1 month or longer. The hydrologic forecast section covers time scales equivalent to both climate and weather forecasts, because of the integrative character of hydrologic processes. For example, while peak stream flows are short-term hydrologic conditions, snowmelt peak flow forecasts represent a watershed's hydrologic response to seasonal snowpack accumulation and subsequent melt.

Generally, there should be little confusion between hydrologic and the meteorologic or climatic forecasts. Forecasts of river flows are clearly hydrologic forecasts, while forecasts of seasonal air temperatures are clearly climatic forecasts. However, both hydrologic and meteorologic groups are involved in forecasting fluxes of water between the earth and atmosphere (i.e., precipitation and evaporation). Quantative precipitation forecasts (QPFs) are often considered by the hydrologic community to be hydrologic forecasts, since they are critical inputs for short-term stream flow and stage forecasts, including flood forecasts. Thus, QPFs are included in the hydrologic forecasting section of this report. 


\section{CHAPTER 2. WEATHER FORECASTS}

\subsection{Introduction}

Weather forecasts encompass a broad range of time and space scales, include a tremendous variety of forecast types, and are available from a bewildering milieu of sources. It is impractical to document all the types of forecasts and their sources, let alone the scientific techniques upon which they are based or descriptions of all extant evaluations. For example, every media outlet (e.g., newspapers, radio and television stations) represents a source of weather forecasts. Even documentation of official U.S. government products, from the National Weather Service (NWS), is difficult because there are so many products and so many avenues to products that appear similar, but are not identical.

Neither is it possible to comprehensively review the literature on weather forecast techniques or their evaluation. The journal, Weather and Forecasting, has been issued by the American Meteorological Society (AMS) since 1986; the AMS also conducts a variety of conferences and symposia each year focusing on the latest weather forecast model implementations and evaluation of operational performance. Finally, the most recent model formulation descriptions and forecast evaluations are typically available only on the Web. For example, Northern Illinois University has established a real-time operational forecast model verification program that uses a web site for communication of near real-time results from ongoing evaluations (http://taiga.geog.niu.edu/verification/). However, comprehensive review of all web links and pages related to weather forecasting is impractical for this report.

This chapter begins by presenting the NWS as the provider of official U.S. government weather forecasts, and the special role of local NWS offices. Description of several NWS forecast products is then provided, followed by a section on proper interpretation of several NWS weather forecast elements. Next, a description of the variety of means used to deliver NWS forecasts is presented. The chapter continues by describing weather forecasts generated or issued by other providers, including commercial vendors, governmental agencies, and universities. Finally, the chapter concludes by describing a plethora of individual weather forecast techniques, with comments on their performance.

\subsection{National Weather Service Weather Forecast Offices}

The NWS is the official U.S. government provider of weather forecasts. The agency mission is "to provide weather warnings and forecasts for protection of life and property and to enhance the Nation's economy". The NWS institutional structure is 
complex, as is the resulting mix of forecast products. In fact, NOAA even offers professional development courses for staff to better understand that complex organizational structure; presentation and review of that organizational structure is beyond the scope of this report. Additionally, the NWS has recently completed a major modernization effort, which modified the long-standing institutional structure, primarily through shifts in the responsibilities of various NWS offices and centers for data management, forecast creation, product issuance, research, and transfer of research to operations.

NWS Weather Forecast Offices (WFOs) are now responsible for providing almost all forecasts for their areas of responsibility. While many of the products are created within a WFO, others are created by national or regional units within NWS (e.g., climate outlooks from the Climate Prediction Center, water supply outlooks from the River Forecast Centers) and then may be simply transmitted by the WFOs. Further, while national and regional NWS units may generate products for use by local WFOs, WFO forecasters may decide to give those products little or no weight in their generation of local products. An in-depth description of the WFO responsibilities, organization, and relationships with other NWS offices is available at http://www.nws.noaa.gov/modernize/wfo.htm; that site also shows the location of all 121 WFOs in the conterminous U.S. Table 1 lists WFOs with coverage in the Colorado River Basin and Southwest U.S. Each WFO maintains their own website, so the look and feel of each site is different, with varying ease of accessing specific products. WFOs also forward some of their products to other NWS units for distribution through a variety of means (see section on NWS Product Delivery).

Table 1. NWS Weather Forecast Office coverage in the Colorado River Basin and Southwest U.S.

\begin{tabular}{|c|c|}
\hline Weather Forecast Office & URL \\
\hline Flagstaff AZ & $\begin{array}{l}----- \\
\text { httn·/www wrh noaa oov/Flagstaff/ }\end{array}$ \\
\hline Phoenix, AZ & http://www.phx.noaa.gov/ \\
\hline Tucson, AZ & http://nimbo.wrh.noaa.gov/Tucson/twc.html \\
\hline Las Vegas, NV & http://www.wrh.noaa.gov/Lasvegas/ \\
\hline Albuquerque, NM & http://www.srh.noaa.gov/abq/ \\
\hline El Paso, TX & http://nwselp.epcc.edu/ \\
\hline Midland/Odessa, TX & http://www.srh.noaa.gov/maf/ \\
\hline Salt Lake City, UT & http://nimbo.wrh.noaa.gov/Saltlake/ \\
\hline Grand Junction, CO & http://www.crh.noaa.gov/gjt/ \\
\hline Pueblo, CO & http://www.crh.noaa.gov/pub \\
\hline Riverton, WY & http://www.crh.noaa.gov/riw/index.htm \\
\hline
\end{tabular}

\subsection{National Weather Service Products}

There is a tremendous variety of NWS operational forecast products, including local and zone public forecasts; watches and warnings for severe local storms, winter 
storms, floods, and flash floods; local aviation watches and warnings, terminal forecasts, and domestic aviation en route forecasts; marine warnings and forecasts; fire weather forecasts; crop forecasts; and hydrologic forecasts; as well as more general short- and medium-range weather forecasts. There are even more experimental and research forecast products with varying accessibility. For a specific region, the most efficient means for learning of available NWS operational forecast products is through the appropriate WFO. For example, the Tucson WFO website (http://nimbo.wrh.noaa.gov/Tucson/twc.html) provides a listing of available products, along with a brief description and issuance schedule. In addition, decision makers can benefit from establishing personal contact with WFO staff concerning which products are most appropriate for their particular needs and for ensuring proper forecast interpretation. Pagano at al. (1999) found Arizona water management agencies that had ongoing relationships with WFOs had the best understanding of the 1997-1998 El Nino and related forecasts.

\section{Zone, State, and Area Forecasts}

Zone, state, and area forecasts are generated and issued by NWS WFOs. Table 2 references NWS zone maps for each state in Colorado River Basin and the Southwest U.S. Zone coverage is determined by the NWS and typically determined by political boundaries (counties) or using some geographical division. Zone forecasts are issued twice daily but may be updated more often when rapidly changing conditions warrant. Zone forecasts are brief text and tabular products that include predictions about general weather conditions, likelihood of precipitation, expected high and low temperatures, and expected wind directions and speed.

State forecasts are quite similar to zone forecasts. They are issued twice daily with optional updating and consist of similar brief text and tabular products. These forecasts provide statewide coverage using several regions within the state. For example, Arizona state forecasts break the state into 6 regions: northwest, northcentral, northeast, southwest, southcentral, and southeast.

Area forecasts cover larger regions than zone forecasts. For example, Arizona is covered by 40 zones, but only 3 regions: southeast, southwest, and northern Arizona. Area forecasts are issued 4 times each day as text products covering whatever the forecaster considers important. While full of cryptic abbreviations and technical jargon, area forecasts allow WFO forecasters to discuss their rationale in making a specific forecast. They may describe recent performance of numerical weather models, unique conditions underlying their skepticism in some model forecasts, conditions that create forecast difficulty and uncertainty, prospects for improved or deteriorating predictability beyond a specific forecast period, and other issues. Area forecasts also identify which WFO forecaster made the forecast.

Zone, state, and area forecasts are generated by individual NWS WFOs. Forecasts are generated by subjective combination of a variety of data inputs (e.g., local radiosonde measurements of atmospheric stability conditions), guidance from numerical weather models results produced by other NWS units and other agencies (even agencies in other countries), and the expertise of the WFO meteorologists. Forecasters realize that some 
numerical weather models perform better than others during certain types of conditions and for specific locations. Based on their understanding of model strengths and limitations, they subjectively choose which model results to consider most heavily in shaping their forecast. In some cases, forecasters may consider no model results to be particularly reliable. Forecasters must then base their predictions on their detailed understanding of those unique conditions, or simply admit low confidence in any forecast they issue. In these cases, and in general, in areas subject to complicated or localized weather conditions, forecaster expertise is especially important. The specific rules to be followed by WFOs in issuing different types of forecasts are given by internal documents called Station Duty Manuals; portions of the manual used by the Tucson WFO are available at http://awips.wrh.noaa.gov/twc/index.htm.

Table 2. NWS zone forecast designations within states of the Colorado River Basin and the Southwest U.S.

\begin{tabular}{|c|c|}
\hline State & Zone Map URL Address \\
\hline----- & \\
\hline Arizona & http://www.nws.noaa.gov/modernize/shapemap/zones/states/az.htm \\
\hline New Mexico & http://www.nws.noaa.gov/modernize/shapemap/zones/states/nm.htm \\
\hline California & http://www.nws.noaa.gov/modernize/shapemap/zones/states/ca.htm \\
\hline Colorado & http://www.nws.noaa.gov/modernize/shapemap/zones/states/co.htm \\
\hline Utah & http://www.nws.noaa.gov/modernize/shapemap/zones/states/ut.htm \\
\hline Wyoming & http://www.nws.noaa.gov/modernize/shapemap/zones/states/wy.htm \\
\hline Texas & http://www.nws.noaa.gov/modernize/shapemap/zones/states/tx.htm \\
\hline
\end{tabular}

\section{Warnings, Weather Statements, and Related Forecasts}

With few exceptions, watches, warnings, and other special weather forecast products are generated and issued by NWS WFOs. When prospective weather conditions may be extreme, hazardous, or rapidly changing, WFOs may issue a variety of special purpose forecasts. Each WFO has responsibility for specific counties. Table 3 references NWS county warning area maps for each state in Colorado River Basin and the Southwest U.S.; the maps also show the responsible WFO for each warning area, as well as locations of Advanced Surface Observing System (ASOS) stations and NEXRAD Doppler radar stations. These special purpose weather forecasts are text products that may cover multiple counties or much smaller locations (e.g, canyon areas known for hazardous driving conditions during high winds).

Special weather forecasts have many names, some self-explanatory, e.g., watches and warnings for severe thunderstorms, tornadoes, and winter storms. Other forecasts, however, have more generic names that may encompass a wide variety of weather conditions: advisories, special weather statements, significant weather outlooks, urgent weather messages, short-term forecasts. Each forecast is issued as conditions warrant and consists of text only. While WFOs may receive guidance from other NWS units that special weather conditions may occur, the official forecasts are issued by the responsible WFO (G. Sampson, NWS Tucson WFO, personal communication, 1999). An exception 
is the issuance of official tornado and severe thunderstorm watches, which originate from the NWS Storm Prediction Center (SPC, http://www.spc.noaa.gov), a unit of the NWS National Centers for Environmental Prediction (NCEP). Affected WFOs then also issue the watch, but the watch areal coverage (the "watch box" seen on television reports) is determined by SPC. Tornado warnings are issued from both SPC and the affected WFO. Communication and coordination is intense between these NWS units during periods of severe weather threat. Another exception is that the Climate Prediction Center (CPC) and Hydrometeorological Prediction Center (HPC), also NCEP units with a national focus, can issue special weather statements for extreme temperature and humidity events. The specific rules to be followed by WFOs in issuing different types of watches, warnings, and other special weather forecasts are given by internal documents called Station Duty Manuals; portions of the manual used by the Tucson WFO are available at http://awips.wrh.noaa.gov/twc/index.html.

Table 3. NWS county warning area designations within states of the Colorado River Basin and the Southwest U.S.

\begin{tabular}{|c|c|}
\hline State & County Warning Area Map URL Address \\
\hline Arizona & http://www.nws.noaa.gov/modernize/st-maps/az-cwa.htm \\
\hline New Mexico & http://www.nws.noaa.gov/modernize/st-maps/nm-cwa.htm \\
\hline California & http://www.nws.noaa.gov/modernize/st-maps/ca-cwas.htm \\
\hline Colorado & http://www.nws.noaa.gov/modernize/st-maps/co-cwas.htm \\
\hline Utah & http://www.nws.noaa.gov/modernize/st-maps/ut-cwa.htm \\
\hline Wyoming & http://www.nws.noaa.gov/modernize/st-maps/wy-cwa.htm \\
\hline Texas & http://www.nws.noaa.gov/modernize/st-maps/tx-cwaw.htm \\
\hline
\end{tabular}

\section{Short Range Forecasts}

Short range forecasts with national coverage are produced by multiple units within the NWS; the forecasts may be operational, experimental, or research products. Local WFOs access the suite of national forecasts they consider relevant, perform subjective analysis of their content, and then typically combine results with additional local information to create various short range forecast products (e.g, wind advisories, heat advisories, zone and area forecasts) with locally relevant coverage. Often, especially in the Southwest where local-scale orographic effects and convective storms are important, national products are given little or no weight. Rather, the WFOs rely more directly on results from specific numerical weather models, measurements of local atmospheric conditions, and subjective forecaster expertise. The official forecasts issued by the local WFOs are text products, not graphical. They are described in previous sections (zone, state, and area forecasts; warnings, watches, and related forecasts); this section focuses on short range forecasts with national coverage.

Operational short range forecasts of numerous meteorologic variables with national coverage are produced by the NWS Hydrometeorologic Prediction Center (HPC, 
http://www.hpc.ncep.noaa.gov). HPC short range forecast products cover intervals of $12,18,24,30,36$, and 48 hours with varying lead times; they are issued twice each day. The forecasts are provided in graphical form for the conterminous U.S. and predict the timing and location of fronts, and the occurrence, coverage, and type of precipitation. Examples are shown in Figures 1 and 2. Forecasts are generated by subjective combination of a variety of data inputs and guidance from numerical weather models, including the Eta, NGM, and AVN models, among others. These models and others are described in detail in the last section of this chapter. Use of these models is not independent, as some model runs provide boundary conditions for other model runs.

The NWS Storm Prediction Center (SPC) also uses a variety of numerical weather models and subjective expertise to generate national-level forecasts that deal with more local-scale phenomena that last only for several hours. For example, SPC issues, several times daily, convective outlooks consisting of maps highlighting regions with anticipated convective activity over the forecast period.

\section{Medium Range Forecasts}

Medium range forecasts with national coverage are also produced by multiple units within the NWS. For example, HPC medium range forecast products cover daily intervals with lead-times of 3-5 days; they are issued once each day. Forecasts are based on subjective integration of MRF, ECMWF, and UKMET operational medium range weather models and the Navy NOGAPS MRFX experimental model and ensembles, among others. These models and others are described in detail in the last section of this chapter. Medium range HPC forecast products are provided in graphical form for the conterminous U.S. and include: (1) daily surface pressure patterns, circulation centers, and fronts, (2) daily maximum and minimum air temperature anomalies, (3) daily precipitation anomaly probabilities, and (4) total precipitation expected over the next 5 days, in increments of $0.25,0.50,1.00$ inches and increasing thereafter at 1.00 inch intervals. Examples are shown in Figures 3-5. Local WFOs perform additional subjective analysis of national forecasts, typically combined with additional local information, to create various medium range forecast products, which are often denoted as "extended" forecasts. Medium range forecast products issued by the local WFOs are text products, not graphical.

The HPC also issues experimental medium range forecasts, with lead-times of 6-7 days. However, products are limited to daily maximum and minimum air temperature anomalies and daily precipitation anomaly probabilities. Figure 6 shows an example precipitation probability forecast with a 7-day lead-time. Examples of the use of ensembles are presented in Figure 7. Each ensemble member represents output from a single model run.

\section{Threats Assessment}

A relatively recent type of forecast is the threats assessment produced by NCEP (http://www.cpc.ncep.noaa.gov/products/predictions/threats/index.html) for the conterminous U.S. It was produced experimentally for about a year before being christened operational in late 1999 (Ucellini, 1999). The threats assessment combines 
NWS medium- (3-5 day), extended- (6-10 day), and long- (monthly and seasonal) range forecasts, and hydrologic analyses and forecasts into a series of graphical and textual products forecasting the potential for extreme hydrometeorologic conditions. Although the text discussion is updated only weekly, on Tuesday afternoons, many graphical products are updated daily. An example is shown in Figure 8. The threats assessment provides local WFOs with initial notice to pay special attention to the possibility of the indicated severe conditions; the local WFOs are then responsible for issuing official NWS products related to those threats, as they deem appropriate. While the threats assessment implies that the identified events have exceeded some threshold of probability of occurrence, no explicit probability statements or expressions of uncertainty are provided with the product.

\section{Southeast Arizona Convective Outlook}

While the NWS SPC issues convective outlooks several times each day over the conterminous U.S., local versions may be prepared by local NWS WFOs as well. Beginning in 1998, the Tucson WFO began issuing a Southeast Arizona Convective Outlook each afternoon, after about 12:45 pm, during the summer thunderstorm season. Although the Tucson WFO has been asked to make the forecast sooner, the forecasters stress that reliable forecasts require waiting until late morning when reliable measurements of atmospheric stability conditions are available (J. Glueck, NWS Tucson WFO, personal communication, 1998). The forecast can be accessed at http://nimbo.wrh.noaa.gov/Tucson/swo/swo.shtml during the monsoon season.

The convective outlook is different from other kinds of precipitation forecasts, in that it forecasts the areal coverage associated with expected thunderstorm occurrence. The outlook also contains a conditional probability forecast for the thunderstorm to be severe, i.e., given that a thunderstorm does indeed occur, the forecast specifies the probability it will be a severe storm. Another outlook product is a conditional quantitative precipitation forecast, i.e., given that a thunderstorm does occur, the forecast specifies probabilities for different precipitation amounts (>1", >2") being produced by a storm somewhere within the coverage area. Finally, a forecast is made for the expected direction of thunderstorm motion. The complete outlook is given in text form, but selected components (areal coverage, severe storm conditional probability, precipitation conditional probabilities) are also available in graphical form. Figure 9 shows an areal coverage outlook, while Figure 10 shows the conditional probability of receiving over 1" of precipitation from a storm.

During the inaugural season for the Southeast Arizona Convective Outlook, CLIMAS conducted an on-line questionnaire survey of self-selected outlook users (CLIMAS, 1998). Although the convective outlook is issued only once daily, almost half of the survey respondents said they accessed the outlooks more than once each day. The predominant use of the outlooks was for personal interest, although 5 of 30 respondents did use the outlooks for planning related to their profession. Most users found the outlooks to provide clear and understandable information and graphics. The Tucson WFO has saved the graphical convective outlook products over the past 2 summers, offering opportunity for evaluation of forecast performance. Additionally, all text 
forecasts are saved on the NOAA National Climate Data Center (NCDC) Surface Records Retention System (SRRS), although access of past forecasts may be difficult and expensive.

\subsection{Forecast Interpretation}

Forecasts that are expressed numerically are relatively clear in their interpretation, even when expressed as probability anomalies. Alternatively, text-based forecasts may appear to be coarse generalizations. However, the phrases used in text-based forecasts have specific quantitative meanings that would be cumbersome to repeat in full with every forecast. These quantitative interpretations of text-based forecasts can be incorporated in risk-based decision support systems or used in subsequent forecast evaluations. Some of these forecast phrases are listed in Table 4, along with their quantitative meaning.

The proper interpretation of precipitation forecasts is not entirely clear. Some NWS documentation (NWS, 1999) describes precipitation probability forecasts as the likelihood that precipitation will occur at a single point within the forecast area, generally the first-order precipitation gage location located at an airport. However, WFO forecasters have their own, more flexible, interpretation whereby the probability may be the expected areal coverage of precipitation within the forecast area (G. Sampson, NWS Tucson WFO, personal communication, 1999). If storm location is random within a forecast region and storms actually occur with $100 \%$ probability, then $30 \%$ precipitation coverage would produce rain at a single specific location $30 \%$ of the time, on average, and the two forecast interpretations are identical. However, in a practical sense, the two interpretations are not identical, because storms don't occur with $100 \%$ probability when forecast and storm location is not random, especially in the Southwest where orographic effects are significant. During the peak of the summer monsoon season, storms are highly likely to occur somewhere within the forecast area, so a forecast interpretation of areal coverage may be appropriate. In that case, a $30 \%$ precipitation probability means forecasters are saying they have $100 \%$ confidence that precipitation will occur, covering $30 \%$ of the forecast region. However, because precipitation is strongly linked to topography, even though $30 \%$ of the forecast region may experience rain, the actual probability of precipitation is greater near the mountains than in the distant desert plains where the forecast point (i.e., the airport) is typically located. In contrast, because winter storms have broader spatial extent, an areal coverage interpretation of precipitation probability would require high forecast values (e.g., 70\%) which are rarely used. Winter precipitation forecasts are more appropriately thought of as confidence forecasts. That is, a $30 \%$ precipitation probability forecast means forecasters are saying they have $30 \%$ confidence that precipitation will occur, covering $100 \%$ of the region. However, precipitation forecasts do not identify which interpretation is intended by the issuing forecaster. 
Table 4. Definition of NWS phrases used in weather forecasts. ${ }^{1}$

\begin{tabular}{|c|c|}
\hline Phrase & Quantitative Definition \\
\hline ------- & -------------------------- \\
\hline Slight Chance & $20 \%$ \\
\hline Chance & $30-50 \%$ \\
\hline \multirow[t]{3}{*}{ Likely } & $60-70 \%$ \\
\hline & probability that 1 point in the forecast area will have precipitation. \\
\hline & Showers or thunderstorms with \\
\hline Isolated & $1-25 \%$ \\
\hline Scattered & $25-55 \%$ \\
\hline \multirow[t]{2}{*}{ Numerous } & $\begin{array}{l}55-75 \% \\
\text { areal coverage. }\end{array}$ \\
\hline & Severe thunderstorms with \\
\hline Slight Risk & $2-5 \%$ \\
\hline Moderate Risk & $5-10 \%$ \\
\hline \multirow[t]{2}{*}{ High Risk } & $\begin{array}{l}>10 \% \\
\text { areal coverage. }\end{array}$ \\
\hline & Rain, with drops of having diameters of \\
\hline Drizzle & $0.2-0.5 \mathrm{~mm}$ \\
\hline Rain & $>0.5 \mathrm{~mm}$ \\
\hline \multicolumn{2}{|l|}{ Sustained winds } \\
\hline Windy & 20-30mph \\
\hline High Wind & $>40 \mathrm{mph}$ or non-thunderstorm gusts $>57 \mathrm{mph}$ \\
\hline \multicolumn{2}{|c|}{ expected to last for an extended period of time. } \\
\hline \multicolumn{2}{|c|}{ Severe Thunderstorm Winds $>57 \mathrm{mph}$, or hail $>3 / 4$ " diameter. } \\
\hline Clear & $<10 \%$ \\
\hline Scattered Clouds & $10-50 \%$ \\
\hline Partly Cloudy & $30-70 \%$ \\
\hline Broken Clouds & $60-90 \%$ \\
\hline \multirow[t]{2}{*}{ Overcast } & $>90 \%$ \\
\hline & cloud coverage. \\
\hline
\end{tabular}

${ }^{1}$ From Branick (1996), Weathersite (1998), NWS (1999).

\subsection{NWS Product Delivery}

The NWS uses a variety of means to deliver weather and climate information, including forecasts of many types. An overview of NWS dissemination systems is given at http://www.nws.noaa.gov/wordout. Some systems exist primarily for delivery of information (e.g., GOES satellite images) rather than forecasts; systems of interest for 
delivering forecasts include the Internet, NOAA Weather Radio, NOAA Weather Wire Service, NOAA Family of Services, EMWIN, and Weather by Telephone. Only NOAA Weather Radio and Weather Wire are official routes for delivery of official products. While other delivery mechanisms, especially the Internet, may be convenient or offer graphical products, they are not official systems.

\section{Internet Access}

Within the NWS alone, there is a large and rapidly growing number of WWW locations providing Internet access to NWS products. Each WFO has its own site for distributing forecast products (see Table 1). In addition, NCEP and each individual center within NCEP provides access to their specific products, although typically in a form different than that given by the WFOs. The Interactive Weather Information Network (IWIN; http://iwin.nws.noaa.gov/) provides easy access to weather watches and warnings. Optional IWIN "push" software allows any newly issued watches or warnings to be automatically provided to a user, rather than requiring a user to periodically access the IWIN site. While NWS forecasts that are available via the Internet may be the same as those available via other means, web-based products are not official forecasts.

\section{NOAA Weather Radio}

NOAA Weather Radio is the nationally-implemented official NWS communication system that provides weather information, forecasts, and warning alerts. Weather Radio broadcasts are transmitted 24 hours/day over high-band VHF-FM radio frequencies ranging from 162.40 to $162.55 \mathrm{MHz}$. These frequencies are not received by standard home or car radios, but special purpose receivers or expanded coverage radio receivers are readily available. According to the NWS, NOAA Weather Radio transmissions presently can reach $70-80 \%$ of the U.S. population and are expected soon to be receivable by $95 \%$ of the population, but actual usage is much lower (http://www.nws.noaa.gov/wordout; http://www.wrh.noaa.gov/Flagstaff/nwr.html). The Weather Radio station network is not static; current station listings are available at http://tgsv5.nws.noaa.gov/nwr/listcov.htm, while recent changes are given at http://tgsv5.nws.noaa.gov/nwr/status.htm. The areal coverage provided by these stations is listed, for each county, at http://tgsv5.nws.noaa.gov/nwr/indexnw.htm. Some counties have no Weather Radio coverage due to excessive distance from available transmitters or blockage of the radio signal by mountains (e.g., Graham, Greenlee, and La Paz counties in Arizona; Catron, Grant, Hildalgo, and Luna counties in New Mexico). Broadcasts are programmed by individual NWS WFOs, with consideration for the interests and needs of local users.

\section{NOAA Weather Wire Service}

The NOAA Weather Wire Service (NWWS) is considered by the NWS to be the primary official telecommunications delivery system for disseminating NWS forecasts and warnings to the mass media and emergency management agencies (http://www.nws.noaa.gov/wordout). The NWWS transmits thousands of NWS products per day, by uplinking to commercial communications satellites, whose broadcasts can 
then be accessed by service subscribers with proper equipment. For example, all WFO forecasts are transmitted via NWWS to the Associated Press for media distribution.

\section{NOAA Family of Services}

The NOAA Family of Services (FOS) is a collection of data services accessed by dedicated telecommunications lines at NWS headquarters in the Washington, DC, area. Primary users of the FOS are private companies that access NWS and resell the data, either as received or after some value-added processing. Users subscribe to specific individual services within the FOS; services providing NWS forecasts include the:

- Public Provider Service (PPS), which carries all public warnings and watches, and various hydrologic, agricultural, and miscellaneous forecasts and products,

- Domestic Data Service (DDS), which carries basic observations and various aviation, marine, and miscellaneous products,

- High Resolution Data Service (HRS), which carries global model-derived forecasts and analyses, mostly in the gridded binary (GRIB) format,

- AFOS Graphics Service (AGS), which carries centrally-produced weather charts, and

- Digital Facsimile Service (DIFAX), which carries primarily aviation-related products.

\section{Emergency Managers Weather Information Network}

The Emergency Managers Weather Information Network (EMWIN) enables rapid dissemination of watches, warnings, and other forecasts, directly to users. A joint project of the NWS and the Federal Emergency Management Agency (FEMA), EMWIN provides a continual stream of NWS products, using a variety of delivery modes, that can be displayed on a user's personal computer (PC). Users must be within an EMWIN radio broadcast area, have a satellite downlink, or be connected to the Internet. Each method of access requires specific equipment and either free or commercial software. Updated technical instructions, including required equipment, for accessing EMWIN are given at http://iwin.nws.noaa.gov/emwin/index.htm.

\section{Weather By Telephone}

While using less sophisticated technology than other delivery systems in the NWS repertoire, the Weather By Telephone system communicates a variety of forecasts, including public forecasts, marine forecasts, and extended forecasts. It consists of recorded announcements that users can access by telephone; some phone lines allow subsequent direct contact with NWS personnel, enabling users to obtain additional information. While the NWS has been contracting operation of the recording system to the private sector, they contend that Weather By Telephone will continue to be an important means for communicating NWS forecasts to users (http://www.nws.noaa.gov/wordout). 


\subsection{Other Forecast Providers}

\section{Commercial Providers}

The National Weather Service maintains a list of commercial weather vendors (http://www.nws.noaa.gov/im/more.htm); as of September 1998, the list contained 113 companies. While some obviously do not target the southwest U.S. (e.g., New England Weather Science), there are still too many commercial sources of forecasts to practically review herein. Additionally, the Bulletin of the American Meteorological Society (AMS) routinely lists consulting meteorologists that are AMS members. Table 5 lists selected commercial forecast vendors and their websites; endorsement is not implied by inclusion. Commercial vendors offer a broad range of weather forecast types; Table 5 also lists several types of products available from the selected vendors.

Table 5. Select commercial weather forecast vendors with coverage of the U.S. Southwest. ${ }^{1}$

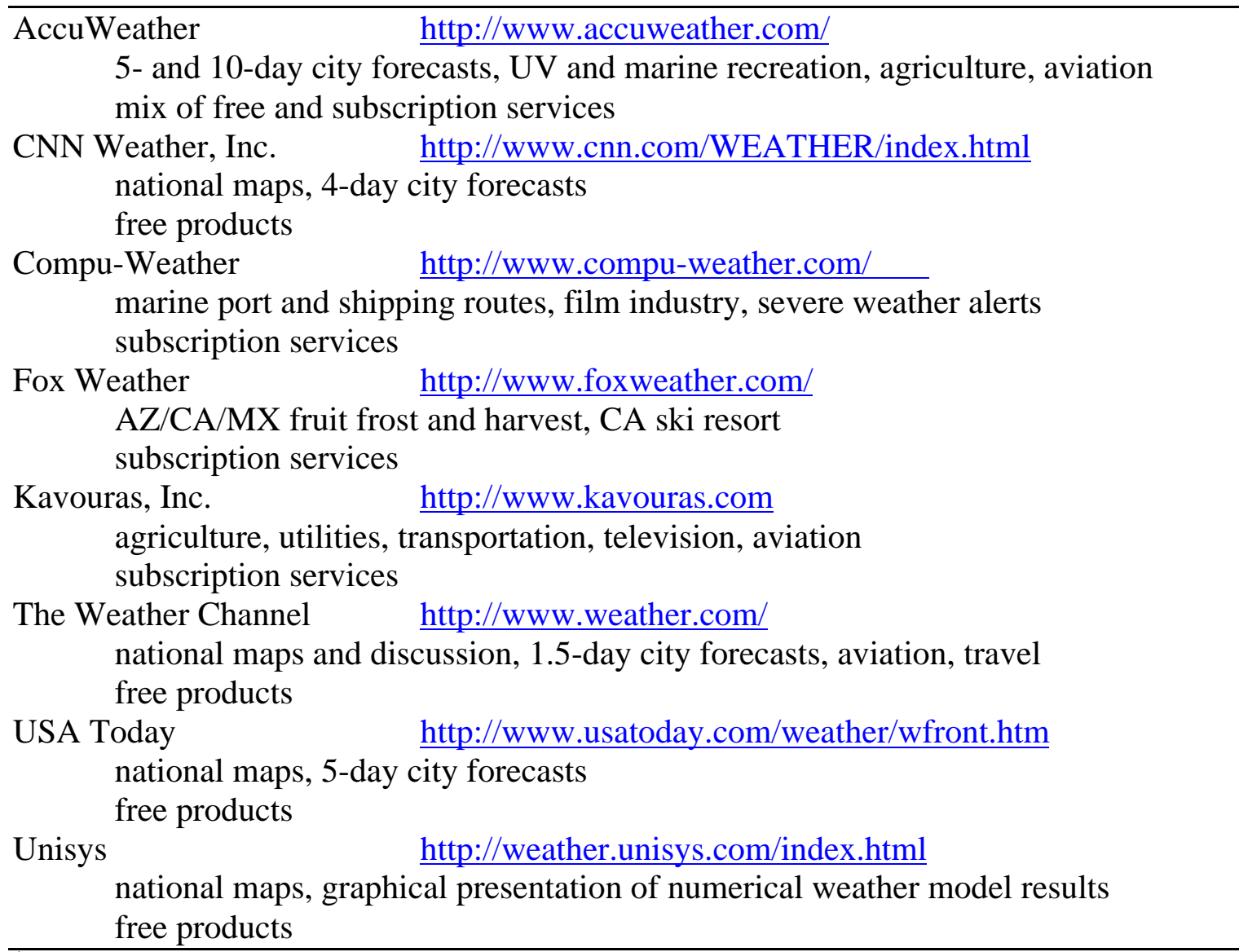

${ }^{1}$ Inclusion does not imply endorsement of vendor services.

The Weather Channel and CNN Weather are especially well-known commercial weather forecast vendors, because of their high visibility on television; each vendor also maintains weather forecast websites as well. Because Weather Channel television broadcasts are dedicated strictly to weather (with the exception of advertising), they have 
become a common source of weather forecasts for the general public and even resource management decision makers. Pagano (1999) interviewed an emergency management official in Arizona that did not distinguish between the Weather Channel and National Weather Service as forecast sources. While not an official source of NWS weather forecasts, the Weather Channel does routinely display WFO text forecasts as issued, without any intervening interpretation. Additionally, official NWS watches and warnings are displayed as issued. However, forecasts presented by Weather Channel broadcast meteorologists are not NWS forecasts, creating the potential for confusion by forecast users.

Formed in 1962 and employing over 90 meteorologists, AccuWeather is the oldest and largest commercial vendor of weather forecasts. AccuWeather evolved from academic work at the meteorology department at the Pennsylvania State University. AccuWeather is the source for many weather forecast graphics products in both television and print media (e.g., CBS, CNN, local television stations, Associate Press, local newspapers). It is AccuWeather's weather warning service, not the NWS, that generates the crawl line seen on television screens communicating NWS issuance of weather watches and warnings. AccuWeather provides a wide range of special forecasts for clients on a subscription basis.

Unisys is a large computer technology corporation that provides free graphical outputs from a variety of numerical weather models, as a way to advertise their weather product analysis software package. Unisys portrays these graphical products as forecasts and cites the National Weather Service as the source of the forecast data, potentially creating confusion on the part of casual users. The range of graphical products provided by Unisys is subtantial, encompassing virtually all outputs from 7 different numerical weather models.

Other vendors target a narrower clientele. For example, Baja Weather Service (http://www.baja-cabo.com/weather.html) targets adventure travelers, offering fee-forservice forecasts for specific locations and travel dates. However, they also offer free access to selected city outlooks, precipitation forecasts, low and high temperature forecasts, wind chill forecasts, heat index forecasts, cloud cover forecasts, current and forecast storm warnings, foggy or windy travel forecasts, and thunderstorm threats. Weather Sites, Inc. (http://www.agriculturalweather.com/) targets agricultural interests, offering free access to a broad array of NWS weather, climate, and hydrologic forecasts products, including 6-10 day temperature and precipitation forecasts; 10 day temperature and precipitation forecasts; 14 day soil moisture forecasts; area, zone, and state forecasts and discussions; coded cities forecasts; forecast guidance provided by individual numerical weather models (AVN, MRF, NGM); monthly and seasonal temperature and precipitation outlooks; flash flood guidance; fire weather forecasts; and recreational forecasts. Fox Weather (http://www.foxweather.com) specializes in agricultural weather forecasting for Arizona, California, and western Mexico; their clients also include water management and flood control agencies, and California ski resorts. Fox Weather forecasts are not simply interpretations or extensions of NWS products. While they may 
make use of NWS numerical weather model results, the forecasts can be considered independent products.

Several features distinguish NWS and commercial vendor forecasts. Private forecast services often offer unique types of forecasts for user-specified locations, for a fee. Generally, their graphics are more aesthetic than standard NWS products. Some fee-for-service providers also offer free forecasts. Other providers offer only free forecasts, deriving their revenue from advertising targeted at general markets (e.g., newspaper and television media) or very specific markets (e.g., Weather Sites, Inc. and the agricultural market). Vendors targeting specific markets offer "one stop shopping" for easy access to weather forecasts and other market-sector related information. Free forecasts are typically reproductions of official NWS products or products available from other providers. For example, Baja Weather Service accesses different types of forecasts from both the Weather Channel and EarthWatch [http://www.earthwatch.com/], a company specializing in weather forecast graphics. Weather Sites, Inc. simply links to other sites that contain NWS forecast products. Many weather forecasts issued via television, radio, newspaper, and the Internet actually originate from AccuWeather, not NWS. With so many different avenues and formats for weather forecasts, there is real potential for confusion among users about what entity is actually providing the forecasts. Further, web links may access only portions of an official NWS forecast, while ignoring essential ancillary products, e.g., text discussions, or definitions of forecast categories.

The relationship between commercial weather forecast vendors and the NWS is not always clear. As described in NOAA's "Policy Statement on the Weather Service/Private Sector Roles" (NOAA, 1991), the NWS is considered the sole official provider of weather watches and warnings. However, some decision makers require warning of conditions (e.g., low temperatures relevant to specific agricultural crops) not encompassed by NWS products. While commercial forecasts can most often be thought of as refinements of NWS forecasts, there is potential for confusion when the two forecasts are widely different, e.g., during rapidly evolving weather situations. Commercial weather forecast vendors may have access to NWS guidance from numerical weather models, but may also use their own proprietary models not be described in scientific literature.

Analysis of forecasts available from commercial vendors, especially media outlets, routinely appears in AMS conference proceedings and the journal, Weather and Forecasting. However, those evaluations generally don't focus on locations in the Southwest. As part of a study on the affect of climate on water demand, Woodard and Horn (1988) evaluated 17-22 years of precipitation forecasts provided in the Arizona Daily Star newspaper for Tucson and Phoenix, Arizona. They compared forecast probabilities of precipitation (PoP) with the conditional actual frequency of occurrence. Thus, forecasts of $20 \% \mathrm{PoP}$ were considered perfect if rain actually occurred in $20 \%$ of the cases for which the $20 \% \mathrm{PoP}$ was made. Using this evaluation measure, the forecasts were generally correct, except that when the forecasts specified a $5 \% \mathrm{PoP}$, precipitation actually occurred only about $2 \%$ of the time. Forecasts of $0 \%$ PoP were highly reliable, with rain actually occurring only 6-7 times during the evaluation period; all incorrect $0 \%$ PoP forecasts occurred during October. 
There is also a seemingly endless and ever-changing mix of private, noncommercial websites that provide weather forecasts (e.g., Ken's Weather and Railroad Page, http://www.trainweather.com). Their products have many of the same attributes of the commercial vendors, but are free. Private providers are typically enthusiastic hobbyists and there is tremendous variability in the content and quality of their websites.

\section{Other Governmental Agencies}

With the rapid growth of the WWW and easy linkage of websites, it is becoming increasingly common for governmental agencies to link to, or collect and reformat, NWS forecasts. Like the commercial providers, these governmental agencies are trying to provide "one stop shopping" for their constituents (e.g., the Bureau of Reclamation site, http://www.usbr.gov/rsmg/nexrad). However, with so many different avenues and formats for the same weather forecasts, there is real potential for confusion among users about which agency is actually providing the forecasts. Further, web links may access only portions of a forecast, while ignoring essential ancillary products, e.g., text discussions, or definitions of forecast categories. For example, the Bureau of Reclamation includes 1-day forecasts, with a 1-day lead time, of precipitation depth and Penman evaporation within their Agricultural Water Resources Decision Support (AWARDS) system, but no forecast source is given. Finally, agencies may initiate a communications effort to provide forecasts, but lack resources to provide reliable continuity; products and interpretations may be outdated or the project ultimately abandoned without removal of the website.

Many governmental research laboratories generate research weather forecasts. The University Corporation of Atmospheric Research (UCAR) maintains a list of entities making weather forecasts (http://www.mmm.ucar.edu/mm5/mm5forecast/sites.html). Of these other governmental agencies, the Navy generates operational forecasts in support of Department of Defense activities (http://www.weather.nps.navy.mil/ dkmiller/MM5/). The Navy has developed the NOGAPS model; results are used by NWS units and other forecasters as well. Generally, however, most other governmental weather forecasts are strictly research, or at best experimental, products; thus, they are not mentioned here in detail. Generation and evaluation of these forecasts are the subject of ongoing research, primarily directed at improving physical process descriptions and parameterizations of the numerical weather models. Many governmental groups making these research forecasts are non-NWS units within NOAA, e.g., the Forecast Systems Laboratory (FSL; http://www.fsl.noaa.gov/), Air Resources Laboratory (ARL;

http://www.arl.noaa.gov/ready-bin/plotrams.pl). Other agencies making research weather forecasts include the NASA Global Hydrology and Climate Center (GHCC; http://wwwghcc.msfc.nasa.gov/Model/model_mm5.html). Generally, these agencies use models developed elsewhere (e.g., MM5, RAMS).

The Natural Resources Conservation Service's National Water and Climate Center has built upon the stochastic climate modeling work of several Agricultural Research Service (ARS) researchers over the past few decades (Woolhiser et al., 1988), in the development of techniques for the Generation of Weather Elements for Multiple 
Applications (GEM) model (USDA, 1998). The GEM model produces statistically representative time series of weather for specific locations, providing daily time series of maximum and minimum air temperatures, precipitation, and solar radiation. Efforts are underway to extend GEM capabilities to include dewpoint temperature, relative humidity, and wind speed; to produce spatially interpolated time series for small regions; to incorporate spatial correlation and produce time series for large regions; to generate subdaily weather products, including within-storm precipitation intensities; and to incorporate large-scale atmospheric conditions, e.g., ENSO. The GEM model can be used as a predictive technique, although it is not presently used operationally. The intent is not to provide weather forecasts for the general public, but to support activities within NRCS. The ARS in Tucson, AZ (D. Goodrich) is taking the research lead for GEM forecasting efforts.

\section{Salt River Project}

In support of their water supply and power production operations, the Salt River Project (SRP) generates a variety of short- and long-range weather, climate, and hydrologic forecasts. Although they generally make use of forecasts generated by others (e.g., NWS) and adapt the products to their watersheds in the Southwest, 2 forecast techniques are proprietary to SRP. The various climate forecasts and hydrologic forecasts (including quantitative precipitation forecasts used in runoff forecasting) are described subsequently, in their respective sections. However, this section describes SRP weather forecasts that cover periods ranging from the next few hours to the next 2 weeks. SRP forecasts are generally available for internal use only, with forecast needs determined by the Water Resource Operations and Power Operations groups. However, SRP does offer value-added services that may include select forecast products and they have an established commitment to cooperate with other agencies, especially the NWS Colorado Basin River Forecast Center and the Natural Resources Conservation Service.

SRP forecasts over the next few hours are based on subjective evaluation of near real-time atmospheric conditions observed using gages, radar, and satellite remote sensing. After training, SRP meteorologists can make "limited interpretations" (SRP, 1998b) of the Phoenix Doppler radar and GOES-9 satellite images. They also monitor lightning strikes from the Lightning Strike Detection Network and surface weather observations from a local network of gages (the PRISM network). SRP issues weather advisories as needed, for lighting, winds exceeding $25 \mathrm{mph}$, and heavy rains in the Phoenix, AZ, metroplex. Every morning from late June-September, SRP makes a sameday maximum temperature forecast based primarily on soundings from SRP-funded weather balloons sent aloft at 4-5 am.

SRP power operations are particularly sensitive to air temperatures and humidity, with peak demands occurring Monday-Friday during summer. In addition, with the advent of utility deregulation in California, SRP has begun energy marketing there. Thus, each weekday SRP generates 3 types of forecasts. One set of forecasts provides temperature and relative humidity forecasts for several cities throughout the West with wholesale power market potential. Another focuses more specifically on temperatures at various locations in California. These forecasts are made via subjective combination of 
results from NWS Eta, NGM, AVN, Navy NOGAPS, and ECMWF numerical weather models. These models and others are described in detail in the last section of this chapter. The third set of forecasts provides daily maximum and minimum air temperatures and relative humidity forecasts over a 7-day period, issued anew each day, Monday-Friday, using a variety of numerical weather models. The NWS MRF model is used at high and low resolutions, out to 240 and 360 hours, respectively. Both the Navy NOGAPS and ECMWF models are used out to 144 hours. SRP is also beginning to incorporate the 610 day outlooks issued 3 times each week by the NWS NCEP. Improvements in SRP forecasts over this longer interval has "greatly improved" with the use of NWS NCEP ensemble forecasts obtained over the WWW (SRP, 1998b).

\section{Universities}

Many universities have meteorology or atmospheric sciences departments involved in research related to numerical weather modeling or weather forecasting. In order to coordinate research efforts with others, highlight their research accomplishments, or fulfill educational mandates, university groups are increasingly using the Internet to disseminate weather forecasts in various forms. However, these sites suffer from some of the same problems as non-NWS governmental sites, especially continuity in reliable updating of information. Forecast products available from university sites may simply consist of links to NWS forecasts or collections of products generated by others, e.g., numerical weather model outputs from other forecasting organizations. However, some provide their own uniquely generated forecasts. For example, the University of Arizona Department of Atmospheric Sciences makes available their research weather forecasts produced by the MM5 numerical weather model (http://www.atmo.arizona.edu/deptwxprod.html). In addition the University of Arizona and NWS Tucson WFO jointly operate a real-time MM5 forecast site (http://nimbo.wrh.noaa.gov/Tucson/mm5/mm5tus.html). Once daily, their MM5 implementation generates 42 1-hour forecasts for the eastern Pacific Ocean and U.S. West at $63 \mathrm{~km}$ resolution, for the Southwest at $21 \mathrm{~km}$ resolution, and for Arizona at $7 \mathrm{~km}$ resolution. Other universities that produce MM5-based weather forecasts with at least partial Southwest coverage include the Pennsylvania State University (http://mm5.met.psu.edu/mm5/), University of Washington (http://www.atmos.washington.edu/mm5rt/mm5.cgi), and University of Utah (http://www.met.utah.edu/jimsteen/mm5/rtmm5.html). Colorado State University provides weather forecasts based on the Regional Atmospheric Modeling System (RAMS; http://rams.atmos.colostate.edu). These models and others are described in detail in the last section of this chapter.

\subsection{Forecast Methods and Performance}

The tremendous variety of forecast products suggests, appropriately, that there is also much variety in the methods used to create forecasts. Briefly, weather forecasts are generated using complex, non-linear numerical models describing the physics of the interplay between solar radiation, and atmosphere, ocean, and land systems. The 
complexity of these models should not be under estimated; the EMC (1998) describes ongoing efforts by NWS personnel to find a long-lived suspected multiplication error in the NGM that corrupts snow depth forecasts (e.g., "somewhere in the bowels of that godawful code"). Results from individual numerical models can be thought of as separate weather forecasts, although "sensible weather guidance" is probably more appropriate (EMC, 1998), because results are subsequently subjectively combined by forecasters to create final weather forecast products.

According to the HPC (Junker, 1998), all operational numerical meteorological models do a "decent job" of forecasting synoptic scale features over 0-36 hours. Model performance degrades as the forecast interval increases. Thus, 1-2 day forecasts are better than those for 3 days or more. However, the Northern Illinois University real-time operational forecast model verification program (Silberberg, 1998) has found that no analysis can determine in advance which model will be correct for any given day.

All models have problems describing small features and convection processes. This lack of fine detail, combined with the non-linearity of the atmospheric system, means small errors in estimating current land and atmospheric conditions can lead to substantial differences in model results. Thus, models are sometimes run several times, each time beginning with slightly different starting conditions, to create an ensemble of forecasts. Statistics can then be computed from the ensemble or specific ensemble members can be selected as more reasonable. Ensembles can also include forecasts from several models, each run under slightly different formulations or initializations; operational examples are available at http://nic.fb4.noaa.gov/products/predictions/threats/ensembles/diagrams.html.

Each model has strengths as well as weaknesses, with some attributes being more relevant for the Southwest U.S. than others (e.g., convective processes, orographic effects). However, detailed model evaluations that look for specific attributes of model behavior for specific weather or climate events are not typically focused on the Southwest. Rather, the Southwest is often lumped into larger regional analyses for the Interior West and Central/Southern Rocky Mountains. Additionally, the specific performance characteristics of operational models are typically undocumented. HPC encourages studies of model forecast performance at local scales (HPC, 1997) and agrees that better verification of operational models is needed (Junker, 1998). Also needed is sharing of evaluation results with forecasters and users, including the media (Junker, 1998).

Comparison of model performance is complicated by the slight variation in variable definitions that may be used in different numerical model formulations. For example, lifted index products that describe atmospheric stability differ between Eta and NGM models. Temperatures from these 2 models also differed until recently (July 1997), with temperatures reflecting different heights above the model terrain; even now, since each model uses its own unique terrain descriptions that can be vastly different, especially in the West, model temperatures actually represent different locations. One alternative is to adjust select model outputs to actual surface locations, compensating for 
differences between areally averaged grid terrain and actual surface station elevations (EMC, 1998).

Finally, model formulations are not static; model adjustments are made to improve model performance, although improvements in one region do not necessarily result in improvements for other regions or for all conditions. For example, the AVN and MRF models were updated in June, July, and October 1998 (Junker, 1998; http://sgi62.wwb.noaa.gov:8080/tpb97/T126/html/T126.html), with the last incorporating emergency changes to correct poor model performance. Various Eta model implementations have experienced changes in February 1997 and 1998 (EMC, 1998).

These examples reflect an important shift in NWS institutional philosophy this decade that has dramatically increased the rate of change in operational weather forecast models (Mittelstadt, 1997), as a way to more rapidly incorporate research advances into operational activities. Prior to the 1990s, NWS operational models were limited to those that had exceeded a threshold of development and evaluation; then, they were used unchanged until major scientific and technological advancements were incorporated and evaluated. Now, however, model changes are incorporated as soon as they pass initial testing and operational adjustments (e.g., in data handling) can be made. Thus, forecast performance must be continually evaluated and communicated to users. How to do this effectively is not clear, since the rate of change in operational models poses training difficulties even for WFO forecasters (EMC, 1998). However, WFO meteorologists have been granted the autonomy to use results from new research in generating their operational and even official forecasts, as they deem appropriate.

The NWS Cooperative Program for Operational Meteorology, Education and Training (COMET) program attempts to address ongoing training needs through periodic workshops that focus on local needs. COMET workshops offer one means for rapid incorporation of recent research findings into operational activities and products. One such workshop http://www.wrh.noaa.gov/Tucson/twc.html was recently held in conjunction with the University of Arizona and focused on problems related to operational weather forecasting in Southwest arid and semi-arid areas. Sessions covered a range of forecasting areas, including mesoscale modeling in the Southwest, forecasting severe weather, and quantitative precipitation forecasts (QPFs) for flash flood and streamflow forecasting.

\section{Eta Models}

The family of Eta models was developed to allow calculation of atmospheric processes to include processes occurring over smaller scales than can be recognized in synoptic-scale numerical models, e.g., the NGM or AVN models (Staudenmaier, 1996). In particular, model formulation was designed to better compute atmospheric pressure gradients in areas of steep topography and uses the Betts-Miller-Janjic convenction scheme. The models are managed by the NWS National Centers for Environmental Prediction (NCEP). Details of each model are provided through a series of technical reports (Staudenmaier, 1996a,b,c,d; Staudenmaier, 1997a,b,c; Mittelstadt, 1997) and updates to an on-line FAQ (frequently asked questions) report 
([http://nic.fb4.noaa.gov:8000/research/FAQ-eta.html]), as well as the scientific literature (Janzic, 1994; Rogers et al., 1995). Model changes occur frequently; recent changes include increased resolution, larger areas of coverage, longer model runs, and shifts in which model is run at which time; additionally, different types of output are generated $(80-90 \mathrm{~km}, 40 \mathrm{~km}, 20 \mathrm{~km})$ for use by NWS WFOs. This complexity makes comprehensive description of current Eta model practices impractical.

The Eta model is the oldest in the suite of models, replacing the Limited Fine Mesh (LFM) model for operational forecasts in 1993. The original Eta model used a resolution of $80 \mathrm{~km}$ and 38 vertical layers, was changed to a $48 \mathrm{~km}$ resolution with the same 38 layers, and now runs at a $32 \mathrm{~km}$ resolution with 45 layers; approximately $9.7 \times 103$ grid points are used at the $32 \mathrm{~km}$ resolution to cover North America. The mesoEta model runs at a $29 \mathrm{~km}$ resolution, with 50 vertical levels ranging in depth from $2 \mathrm{~m}$ in the boundary layer to $2 \mathrm{~km}$ in the upper atmosphere. Eta and meso-Eta models are run several times each day, with variable areal coverage, forecast periods, and initialization procedures. Ultimately, the Eta model will be completely replaced by the meso-Eta model (Mittelstadt, 1997).

The Eta-10 model is only experimental, not operational. It has been run over portions of the Intermountain West, including parts of the Southwest. Eta-10 is conceptually the same as the meso-Eta model, with differences existing only in the model's vertical and horizontal resolution, area of coverage, and initialization scheme. The Eta-10 model runs at a $10 \mathrm{~km}$ resolution, with 60 vertical levels, and is initialized from meso-Eta model output. The whole family of Eta models is constantly evolving. The experimental Eta-10 is expected to significantly improve QPFs, because precipitation maximums can be produced at the spatial scale of individual river basins. Experimental runs in 1998 included a special focus on summertime convective behavior over Arizona. As computer resources allow, the Eta-10 model is expected to replace the Eta and mesoEta models. Longer term plans include development of non-hydrostatic Eta models as well, important when vertical air movements are changing rapidly (e.g., convective storms).

The Eta models produce forecasts, every 3 hours throughout the forecast period, for an extensive array of hydrometeorologic variables, including: wind speed and direction at 10 meters above the surface, air temperature and dew point at 2 meters above the surface, maximum and minimum air temperatures at 2 meters above the surface, 3hour total precipitation accumulation, 3-hour snow water equivalent accumulation, percent cloud cover, and thunderstorm probability. Probabilities of various forms of precipitation are given only as $0 \%$ or $100 \%$. Hourly output for select station locations is also provided by the Eta models, generally corresponding to rawinsonde station locations. Other model outputs include convective available potential energy (CAPE) and storm motion, including low-level shear which can correspond with tornadic thunderstorms.

The HPC contends that the Eta model is a significant advance over other models (Junker, 1998) and is better than other models at forecasting precipitation over complex terrain, especially for the West Coast including the Cascade and Sierra mountain ranges. However, the Eta model generally under-predicts precipitation on and downwind of 
mountain peaks, over-forecasts the strength of anticyclones, and over-predicts the strength of vorticity centers in the summer when flows are usually weak. It significantly underpredicts monsoonal convection, in both amounts and areal coverage, over the Southwest (HPC, 1997). Table 6 gives Eta model bias statistics for various periods, computed at specific locations in the Southwest. Table 7 provides Eta model bias and threat score statistics for the Intermountain West between the continental divide and the Cascade and Sierra mountains, covering much of the Southwest.

Table 6. Eta model bias for selected station locations. ${ }^{1}$

\begin{tabular}{|c|c|c|c|c|}
\hline \multirow{2}{*}{ Station location } & \multirow{2}{*}{$\begin{array}{l}\text { August } 1997 \\
-12-24 \text { hr fcst }\end{array}$} & \multirow{2}{*}{$\begin{array}{l}\text { September } 1997 \\
12-24 \text { hr fcst }\end{array}$} & \multicolumn{2}{|c|}{ December 1997-February 1998} \\
\hline & & & $12-24 \mathrm{hr}$ fcst & 24-30 hr fcst \\
\hline Tucson, AZ & 1.11 & 0.90 & 1.21 & 1.31 \\
\hline Prescott, AZ & 0.50 & 0.64 & 2.08 & 1.79 \\
\hline Albuquerque, NM & 1.38 & 2.33 & 2.40 & 2.63 \\
\hline El Paso, TX & 5.00 & 0.71 & 1.50 & 1.20 \\
\hline Las Vegas, NV & 1.00 & 2.20 & 2.39 & 2.56 \\
\hline Salt Lake City, UT & 1.33 & 3.00 & 1.85 & 1.94 \\
\hline Grand Junction, CO & $\mathrm{N} / \mathrm{A}^{2}$ & 0.67 & 3.81 & 4.10 \\
\hline
\end{tabular}

${ }^{1}$ From Junker (1998).

${ }^{2}$ Not available.

Table 7. Eta model bias and threat scores for the Intermountain West. ${ }^{1,2}$

\begin{tabular}{|c|c|c|c|}
\hline \multirow[b]{2}{*}{ Precipitation Depth } & \multicolumn{2}{|c|}{ Warm Season } & Cold Season \\
\hline & Bias & Threat & Bias Threat \\
\hline$>0.01$ inches & 0.82 & 0.23 & 0.95 \\
\hline$>0.50$ inches & 0.88 & 0.12 & $\mathrm{~N} / \mathrm{A}^{3}$ \\
\hline$>1.00$ inches & 0.35 & 0.09 & 0.58 \\
\hline
\end{tabular}

${ }^{1}$ From Junker (1998).

${ }^{2}$ No forecast interval or evaluation dates specified.

${ }^{3}$ Not available.

According to the EMC (1998), Eta model objective equitable threat score statistics for precipitation are consistently superior to statistics from other models, for all seasons. However, proper comparison of Eta model products with surface observations requires adjustment of forecast values from the areally averaged Eta grid terrain to the actual terrain; such adjustments are planned, but not yet implemented (EMC, 1988). The increased sensitivity of Eta models to atmospheric conditions, especially at the highest spatial resolutions, results in the potential for model output to be more erratic than from other numerical atmospheric models or earlier Eta model implementations, especially when initial conditions are poorly estimated (EMC, 1998). 


\section{NGM Model}

The Nested Grid Model (NGM) is the oldest model in the suite of operational weather models used by NWS forecasters. Standard operating procedures have traditionally considered NGM forecasts, and distribution of their model output statistics (MOSs) to the WFOs, as a top priority (EMC, 1998). Resources are still devoted to maintaining some consistency between more advanced models and the NGM, through the use of legacy computer systems and orphan program code to degrade advanced products to NGM resolution. However, expectations are that use of the NGM will be terminated in the near future, whenever significant efforts are required to transport NGM code to new computers (EMC, 1998).

The NGM has a relatively coarse spatial resolution, $80-90 \mathrm{~km}$, and uses the Kuo convective parameterization scheme. NGM forecast output includes minimum and maximum air temperatures, winds, and precipitation for specific locations. Snow depth output is not useable, due to long-unsolved code errors that can produce unrealistic values (ranging from -19256 to $10 x 5$ meters!) (EMC, 1988).

One advantage of NGM operational forecasts is the productions of model output statistics for many specific locations. While AVN and MRF forecasts are available for 4 locations in both Arizona and New Mexico, NGM MOSs are available for 10 and 13 locations in Arizona and New Mexico, respectively. NGM MOS locations in Arizona are: Flagstaff, Kingman, Page, Phoenix, Prescott, Safford, Tucson-Davis Monthan Air Force Base, Tucson-Airport, Winslow, and Yuma. NGM MOS locations in New Mexico are: Albuquerque, Cannon Air Force Base, Carlsbad, Clayton, Farmington, Gallup, Hobbs, Holloman Air Force Base, Las Vegas, Roswell, Santa Fe, Truth or Consequences, and Tucumcari.

Junker's (1998) review of model performance indicates that the NGM model has a lack of skill in the U.S. West. Specifically, model precipitation is biased low during the winter in the Southwest and the NGM almost always significantly underpredicts maximum precipitation throughout the year. HPC (1997) lists an assortment of difficulties with the NGM, including:

- overprediction of anticyclonic surface pressures across the West,

- overdevelopment of surface cyclones leeward of mountains, and

- poor handling of the movement of digging troughs in the West.

Errors generally decrease during the summer months, however. Overall, the NGM only poorly predicts precipitation over the Interior West, due to lack of terrain details. It produces too much precipitation leeward of the Cascades and Sierras, but too little along windward slopes. However, it overpredicts upslope precipitation in the southern Rocky Mountains. Model performance differs by season and by the amount of rain observed. Table 8 presents threat score statistics for select locations in the Southwest, while Table 9 summarizes the HPC perspective on model bias. In general, the NGM has low threat scores over the Interior West for all seasons. 
Table 8. NGM model 12-36 hour forecast threat scores for selected locations. ${ }^{1,2}$

\begin{tabular}{lcc}
\hline Station location & Warm Season & Cold Season \\
\hline Tucson, AZ & 0 & 0 \\
Prescott, AZ & 17 & 0 \\
Albuquerque, NM & 0 & 0 \\
El Paso, TX & 0 & 13 \\
Las Vegas, NV & 0 & 50 \\
Salt Lake City, UT & 33 & 0 \\
Grand Junction, CO & 0 & 0 \\
\hline
\end{tabular}

${ }^{1}$ From Junker (1998).

${ }^{2}$ No evaluation dates specified.

Table 9. NGM forecast precipitation bias characteristics. ${ }^{1,2}$

\begin{tabular}{|c|c|c|c|c|}
\hline & Cool Season & & Warm Season & \\
\hline & $>0.01$ inches & $>0.50$ inches & $>0.01$ inches & $>0.50$ inches \\
\hline $\begin{array}{l}\text { Interior West } \\
\text { Southern Rocky }\end{array}$ & High & Low & Low & Low \\
\hline Mountains & High & High, upslope & $N / A^{3}$ & High \\
\hline
\end{tabular}

${ }^{1}$ From HPC (1997).

${ }^{2}$ Based on HPC forecaster perceptions of undocumented model performance.

${ }^{3}$ Not available.

\section{A VN Model}

The Aviation (AVN) model is a short to medium range computer weather prediction model run twice daily by NCEP. Initially developed to provide forecasts for aviation operations, the AVN model is one of the older operational weather forecast models. Model resolution is about $100 \mathrm{~km}$. AVN forecast output (FAN) is comprised of maximum and minimum air temperatures and precipitation at specific locations. Those values are often considered a "first guess" by the NWS meteorologists. The AVN and MRF models are the same numerical models, but they are operated differently, with AVN not making use of Global Data Assimilation System (GDAS) data (HPC, 1997). Both use a modified Arakawa-Schubert convective parameterization.

HPC forecaster perceptions of the AVN model (HPC, 1997) are that the model is better than the NGM. However, it lacks the terrain detail of the Eta model. It overpredicts upslope precipitation and wind speeds over the southern Rocky Mountains. However, it also significantly underforecasts monsoonal precipitation. 


\section{MAPS/RUC Model}

The Mesoscale Analysis and Predictions System (MAPS) is a regional data assimilation and weather forecast system operated by NCEP. It is run several times daily using very recent observations for initialization, in a mode termed the Rapid Update Cycle (RUC). The most recent model implementation, RUC-2, extends across the U.S. and its coastal regions, with a horizontal resolution of $40 \mathrm{~km}$ and 40 vertical levels (Benjamin et al., 1998). It can resolve local atmospheric circulations and orographic precipitation, but with less internal smoothing than the Eta models. MAPS/RUC forecasts are made every hour for the next 12 hours. While designed for making short range weather forecasts, MAPS/RUC forecasts also affect longer range forecasts. Comparison of MAPS/RUC forecasts with predictions generated by models that also produce medium range forecasts allows forecasters to establish which longer range model is most accurate in the first 12-hour period.

\section{MRF Model}

The medium range forecast (MRF) model is just that, a medium range computer weather prediction model. It is run once daily by NCEP, in the evenings. Spatial resolution is about $150 \mathrm{~km}$, with coverage over the entire Northern Hemisphere. The AVN and MRF models are the same numerical models, but they are operated differently, with MRF making use of Global Data Assimilation System (GDAS) data (HPC, 1997). Both use a modified Arakawa-Schubert convective parameterization. Graphical ensembles of MRF forecast pressure height fields are available as part of the NCEP threats assessment forecast product for every 12-hour period from 3 to 10 days ahead (http://nic.fb4.noaa.gov/products/predictions/threats/ensembles/diagrams.html). The spread of ensemble members is considered a good indicator of the predictive skill of the MRF forecast (Whitaker et al., 1996, NCEP: http:// www.cpc.ncep.noaa.gov/products/predictions/threats/ensembles_brief.html).

MRF performance characteristics have changed significantly over the past several years. However, the MRF model still generally causes upper level lows coming out of the Southwest to weaken too quickly (Junker, 1998). HPC (1997) lists an assortment of difficulties with the MRF model, including:

- surface high pressures are too strong west of the Rocky Mountains,

- closed upper level lows move too fast, especially in the Southwest and during El Nino, and

- mid and upper level lows weaken too rapidly as they move across the Southwest.

The MRF tends to have a wet bias, typically overforecasting areal extent of precipitation. However, precipitation is underforecast when subtropical moisture is streaming into a weather system and overall, MRF underestimates precipitation amounts over mountains due to poor terrain characterization. Finally, the MRF model underpredicts monsoonal precipitation throughout the West. 


\section{UKMET Model}

United Kingdom Meteorological (UKMET) model output is used by NWS forecasters, even though it is operated outside their agency and even outside the U.S. federal government. Also known as the Unified Model, it was implemented operationally in 1992 and is managed by the Numerical Weather Prediction Division of the United Kingdom Meteorological Office (http://www.meto.gov.uk/sec5/sec5pg2.html). The global configuration of the model is run operationally, twice daily, for forecasts with lead times of up to 6 days. Model resolution is about $60 \mathrm{~km}$, with 30 vertical levels. Global model output then provides boundary conditions for higher resolution regional models.

The HPC (1997) lists an assortment of difficulties with the UKMET model, including:

- surface high pressures are often much too weak west of the Rocky Mountains,

- closed upper level lows move too fast, especially in the Southwest, and

- when upper ridging dominates during the warm season, there is a significant low pressure bias over the entire West.

Precipitation is generally forecast too low when subtropical moisture is streaming into a weather system and overall, the UKMET model underestimates precipitation amounts over mountains due to poor terrain characterization. Finally, the UKMET model under predicts monsoonal precipitation throughout the West.

\section{ECMWF Model}

The European Centre for Medium Range Weather Forecasts (ECMWF) model is also operated outside the purview of the NWS or other U.S. federal agencies. A brief summary provided by Woods (1997) describes some of the basic characteristics of the ECMWF. The ECMWF model is run 5 times each day, with runs extending forward 6 days and 1 run extending out to 10 days ahead. The model domain is the entire globe, with 31 levels of atmosphere considered between the earth surface and $30 \mathrm{~km}$ upward. Computations use a 30 minute time step. The model uses a semi-Lagrangian, semiimplicit formulation. There are over $4.2 \times 10^{6}$ grid points for atmospheric computations and over $5.5 \times 10^{5}$ grid points for land surface and sub-surface layers, with a grid spacing close to $62 \mathrm{~km}$. Variables that are recalculated at each time step include wind speed and direction, temperature, humidity, cloud fractions, water and ice content, and surface pressure. The model includes terrain height and sub-grid scale orographic characteristics; sub-grid scale orographic drag effects, including gravity waves and blocking effects; 4 surface and sub-surface layers with accommodation for vegetation cover, gravitational drainage, capillary exchange, and surface and sub-surface runoff; stratiform and convective precipitation, carbon dioxide, aerosols, and ozone conditions; solar angle; diffusion; ground and sea surface roughness; ground and sea surface temperature; ground humidity; snow fall, snow cover, and snow melt; evaporation and sensible and latent heat fluxes; incoming short-wave and outgoing long-wave radiation; and surface and free atmosphere friction. The model uses data on humidity, wind, sea surface temperatures, sea ice, snow depth, and soil water content from a variety of global sources, with 5-8x10 ${ }^{4}$ observations used in each analysis. 
The HPC (1997) lists an assortment of difficulties with the ECMWF model, including:

- surface high pressures are often much too weak west of the Rocky Mountains,

- closed upper level lows move too fast, especially in the Southwest, and

- mid and upper level lows over the Southwest are typically too strong and for some situations, they move out of the deserts too slowly.

Precipitation is generally forecast too low when subtropical moisture is streaming into a weather system and overall, the ECMWF underestimates precipitation amounts over mountains due to poor terrain characterization. Finally, the ECMWF model under predicts monsoonal precipitation throughout the West.

\section{NOGAPS Model}

The Navy Operational Global Atmospheric Prediction System (NOGAPS) is, as the name suggests, operated by the U.S. Navy. The original model and its extensions (NOGAPS2), used operationally since the early 1980s, were simply abandoned when the ECMWF and other spectral models proved to have consistently superior performance (Staudenmaier, 1997d). The Navy subsequently developed a completely new model, NOGAPS3, based on a spectral formulation. Model details are presented in Rosmond (1992) and Hogan and Brody (1993). The NOGAPS coordinate system is the same as the ECMWF model, with $80 \mathrm{~km}$ horizontal resolution and 18 vertical levels. The model incorporates gravity-wave drag, vertical diffusion, shallow and deep convection, and both longwave and shortwave radiation. Because the Navy is especially interested in forecasting for naval operations throughout the world's oceans, model formulations emphasize interactions of heat and momentum fluxes at the ocean surface with clouds and radiation.

Performance review comments by the Air Weather Service (1996) relate to largescale behavior, not on any regional scale and not for the Southwest. According to Staudenmaier (1997d), the model performs well over the oceans and tropical regions. Little verification has been done over inland areas, however.

\section{MM5}

MM5 is the fifth-generation version of the Mesoscale Model (Anthes and Warner, 1978; Dudhia, 1999) developed jointly by the Pennsylvania State University and the University Corporation for Atmospheric Research (UCAR); the standard version of the model is maintained by the NOAA National Center for Atmospheric Research (NCAR; http://www.mmm.ucar.edu/mm5/). MM5 model implementations range from the global scale down to cloud scale, with users specifying the region of application; grid scale typically ranges from 1-100 km, with finer grids covering smaller regions. Users can also implement multiple levels of grids, nesting smaller areas with higher resolution inside larger regions modeled with coarser resolution. Vertical layering in the model grid system follows the actual land terrain, and the model has both hydrostatic and nonhydrostatic options; non-hydrostatic processes are important when there are rapid 
changes in vertical atmospheric motion, e.g, convective thunderstorms. MM5 is perhaps the most widely used numerical weather model within the university research community; frequent model changes incorporate improvements contributed by research groups at universities and governmental laboratories. Complete documentation is provided by NCAR at http://www.mmmucar.edu/mm5/. MM5 is a research-oriented numerical weather prediction model; its application to different areas and performance evaluation are the subject of ongoing research, primarily directed at improving physical process descriptions and parameterizations.

\section{RAMS}

The Regional Atmospheric Modeling Systems (RAMS) was developed at Colorado State University (Pielke et al, 1992), by merging advances in modeling dynamic microscale cloud processes (Cotton et al., 1994, 1995) with mesoscale models of land-atmosphere interactions (Pielke, 1985). RAMS incorporates the fundamental physics of atmospheric motion, turbulent diffusion, cloud formation and interaction with precipitating liquid and ice, cumulus convection, latent and sensible heat exchange, kinematic terrain effects, multiple soil layers, vegetation, and surface water. It has capabilities for interactive two-way nesting of grids; high resolution grids covering limited areas can model small atmospheric phenomena, e.g., thunderstorms, while coarse grids covering larger areas can consider synoptic weather systems. While applications have been configured to cover global hemispheres, and there is no lower limit to grid coverage or mesh size. Rather than being a single model, RAMS is an entire modeling system, allowing multiple configuration options, including hydrostatic or non-hydrostatic equations; 1-3 spatial dimensions; different vertical and horizontal coordinate systems; unlimited numbers and levels of grid nesting; varying finite difference implementations; different choices for describing turbulence closure, condensation, cloud microphysics, radiation, transport and diffusion processes, and upper, lower, and lateral boundary conditions; and different types of model initialization. RAMS is a research-oriented numerical weather prediction model; its application to different areas and performance evaluation are the subject of ongoing research, primarily directed at improving physical process descriptions and parameterizations.

\section{Other Performance Evaluations}

The U.S. Geological Survey (USGS) is involved in several research projects to assess the value of weather forecasts for improving hydrologic forecasts, but the areas of focus are in California, Colorado, and the Northwest rather than the Southwest (Schaefer, 1997). For those studies, NOAA's NCEP and Climate Diagnostics Center (CDC), as well as select WFOs, will provide past and future weather forecasts, with time scales ranging from days to weeks, for use in experimental hydrologic models. Additionally, 7day temperature and precipitation forecasts from NCEP are being assessed for use in forecasting flood magnitudes and timing in select rivers draining the Sierra Nevada Mountains in California; preliminary results suggest that the 7-day weather forecasts enable successful flood predictions with lead times of 7-9 days. 


\section{CHAPTER 3. CLIMATE FORECASTS}

\subsection{Official U.S. Climate Forecasts}

The official U.S. government climate forecasts are produced by the National Oceanic and Atmospheric Administration's (NOAA) Climate Prediction Center (CPC), which is a unit of the National Centers for Environmental Prediction (NCEP) within the National Weather Service (NWS). The mission of the CPC is "to maintain a continuous watch on short-term climate fluctuations and to diagnose and predict them. These efforts are designed to assist agencies both inside and outside the federal government in coping with such climate related problems as food supply, energy allocation, and water resources" (CPC, http://www.nnic.noaa.gov/cpc/).

Note that the CPC mission does not explicitly include outreach to the general public; rather, their efforts are aimed at agencies. Note also that the CPC mission does not address long-range climate fluctuations that occur over decades or longer; rather, their focus is on changes over weeks, months, seasons, and from year to year. Finally, note that a major focus is monitoring fluctuations and diagnosing their causes; predictions comprise only part of the CPC mission.

Each of these distinctions has implications for use and interpretation of CPC products. Because CPC efforts are directed at agencies, an implicit assumption is that sufficient expertise is available to correctly interpret CPC products. Some products make very specific probabilistic statements, while other products incorporate discussions of highly technical and scientific concepts. Those products may be poorly understood by users without appropriate professional training or access to experts that can provide skilled interpretation. Further, both the technology behind the forecasts and access to the forecast products are constantly evolving. Users that cannot devote significant resources to acquiring and interpreting CPC products may be confused by the plethora of similar, but not identical, products; by the myriad avenues by which these similar products may be accessed; or by continual changes in documentation, access, and interpretation of products.

Because the CPC mission focuses on short-term climate fluctuations, CPC prediction products are not sufficient for all decision making. Climate fluctuations also occur over longer periods. Changes over decades can have important consequences, especially for infrastructure (structural or institutional) that may be difficult or expensive to modify as climate changes evolve. Thus, decisions that may be sensitive to longerterm climate fluctuations should also consider climate statistics based on historic or even paleologic data, as well as scenarios of potential future climate conditions.

While the CPC mission focuses on short-term climate fluctuations, the concurrent mandate to monitor and diagnose climate fluctuations can sometimes suggest the potential for longer-term changes. Comparison of current atmospheric conditions with a 
long history of observations may show consistency with recurring patterns of atmospheric behavior. While the CPC doesn't make official multi-year predictions, their monitoring and diagnosis activities sometimes suggest the potential for shifting into a different climate regime. For example, the Pacific Decadal Oscillation (PDO) transitions between warm and cool sea surface temperatures in the North Pacific, with distinct shifts between regimes that last for 2-3 decades and that affect other climate events, especially ENSO (Mote, 1998). Confirmation of a suspected shift to a cool PDO regime in the mid1990s would suggest different conditional probabilities for climate conditions over the next decade or more.

The climate monitoring and diagnosis functions of the $\mathrm{CPC}$ also reflect that climate fluctuations are not completely understood. As the CPC assesses the causes of climate fluctuations, new findings may be used to adjust the outputs of the modeling and statistical tools for making their climate predictions. Eventually, the new findings may be incorporated directly into the modeling and statistical tools, or entirely new tools may be developed. Thus, any description of the procedures used by CPC to create their outlooks, or of the appropriate interpretation of CPC products, can soon be outdated. This implies that education of users of CPC products must be ongoing.

\subsection{CPC Forecast Products}

The CPC issues a broad array of products (http://www.nnic.noaa.gov/information/products/), encompassing historical data, the reporting and diagnosis of recent climate conditions, special summaries diagnosing unusual climate events, predictions, and special projects. Their prediction products include both operational and experimental forecasts, and address time periods ranging from 6 days to more than a year. The CPC defines short-term climate as average behavior over a month or more (Section 7 at http://www.nnic.noaa.gov/products/predictions/README), so the shorter periods $(6,8$, 10, 14 days) may be more appropriately considered as extended weather outlooks; as such, they are addressed in the section on weather forecasts.

The current suite of operational climate forecasts consists of one 1-month outlook and a series of thirteen 3-month outlooks, with the entire set issued anew at approximately the middle of each month. The outlooks begin with the upcoming calendar month, and the 3-month outlooks shift forward by one month until the same period of the next year. For any single outlook (1-month, or a specific 3-month outlook), the complete forecast package consists of: 1) maps of surface air temperature and precipitation probability anomalies for the outlook period, 2) a legend describing the appropriate interpretation of the probability anomaly maps, 3) text discussion of the outlook, 4) maps and tables of historic climatology and probability class limits, and 5) skill maps for some of the techniques used to create the outlook maps (http://www.nnic.noaa.gov/products/predictions/monthly_climate/current_outlook/). 
Proper use of the outlooks requires consulting the entire package, not just the outlook maps. Additionally, the outlook maps, text discussion, and skill maps each require specialized understanding to properly interpret. Because outlook probabilities are specified in comparison to actual conditions over 1961-1990, proper interpretation and use of the outlooks requires historic data for the region of interest as well. However, those historic data, except for maps with only very coarse resolution, are not provided as part of the forecasts, and must be accessed separately by the user from other sources (e.g., from the NOAA National Climatic Data Center, http://www.ncdc.noaa.gov/ol/climate/climateresources.html).

Each outlook has only a limited time of applicability. The 1-month outlook is to be used only until the forecast month begins (i.e., for about 2 weeks), after which observations and shorter-term forecasts (e.g., the 6-14 day extended weather outlooks) should be used. The first 3-month outlook also is to be used only until the forecast period begins (i.e., only about 2 weeks). The twelve subsequent 3 -month outlooks, each having a progressively longer lead time, are superseded by the set of forecasts issued in the following month, and so are to be used only for about 1 month.

The monthly climate outlook package can be accessed at http://www.nnic.noaa.gov/products/predictions/monthly_climate/current_outlook/. The 3-month outlooks can be accessed at http://www.nnic.noaa.gov/products/predictions/multi season/13 seasonal outlooks/. A single text discussion product covers all thirteen 3-month outlooks and is accessed at http://www.nnic.noaa.gov/products/predictions/multi_season/13_seasonal_outlooks/fxus 05.doc. Figure 11 provides an example CPC climate outlook, covering a single 1- and 3month period for both precipitation and temperature. Figures 12 and 13 present the remainder of the associated 3-month outlooks for temperature and precipitation, respectively. Figure 14 is provides the legend necessary for interpreting these graphical forecast products. Figure 15 presents the associated text discussion. Figures 16 and 17 are maps showing contours of the $33.3 \%$ and $66.7 \%$ exceedance quantile class limits for precipitation; they are notably uninformative for the Southwest. Figure 18 is a map showing contours of seasonal mean temperatures, with class limits designated by standard deviation contour lines. Because the map for August-October shown in Figure 18 has such low variance, a higher variance map for January-March is shown in Figure 19. Finally, skill maps for 2 of the several techniques used in creating the CPC climate outlooks are presented in Figures 20 and 21. They show skill score contours associated with use of canonical correlation analysis and optimal climate normals, respectively.

Other Internet addresses access the same products (e.g., http://nic.fb4.noaa.gov), but with a different look and feel (e.g., frames and menus), possibly creating confusion about which online address provides the "official" product. For example, Figure 22 shows the monthly climate outlook illustrated with lower graphical quality, but with more information because the anomaly contours are identified directly rather than requiring a separate legend; similar maps are produced for the seasonal climate outlooks. Further, the use of frames for accessing the $\mathrm{CPC}$ outlooks requires stepping through a series of 
menus, rather than allowing direct access to a specific web page at a specific URL, creating additional potential confusion for communication with users.

\subsection{Interpretation of CPC Climate Forecasts}

The CPC climate outlook maps show the likelihood, expressed as a probability anomaly, that average air temperature or total precipitation, over the specified forecast period, will fall within the upper, middle, or lower third of conditions reflected in the historic record from 1961-1990. Proper interpretation of the outlook thus requires examining the actual average temperatures or total precipitation that correspond to the upper, middle, and lower thirds of the 1961-1990 historic record for the specific forecast period. A climatological outlook (i.e., a zero probability anomaly outlook) says that there is an equal probability $(33.3 \%)$ that the average temperature or total precipitation over the forecast period will fall within the upper, middle, or lower third of the conditions that occurred over 1961-1990.

For probability anomalies up to $30 \%$, the outlook shifts the probability of average temperatures and total precipitation only within the upper and lower third of the 19611990 historic distribution; the probability of average temperatures or total precipitation falling within the middle third of the 1961-1990 historic record remains at 33.3\%. For example, for a region contained within a 5-10\% "above" contour, the outlook says that there is still a $33.3 \%$ probability of average temperatures or total precipitation falling within the middle third of the 1961-1990 historic record. However, the probability of experiencing warmer average temperatures or greater total precipitation, falling within the upper third of the 1961-1990 historic record, is then shifted to between 38.3-43.3\% $(33.3+5=38.3 ; 33.5+10=43.5)$. The probability of experiencing cooler average temperatures or lesser total precipitation, falling within the lower third of the 1961-1990 historic record, is shifted to $23.2-28.3 \%(33.3-5=28.3 ; 33.3-10=23.3)$.

For probability anomalies larger than $30 \%$, the likelihood of occurrence of conditions represented by the central third of historic distribution is decreased as well, leaving a $3.3 \%$ probability in the least-likely category. For example, for a region contained within a 30-40\% "below" contour, the outlook says that there is a $63.3-73.3 \%$ probability $(33.3+30=63.3 ; 33.3+40=73.3)$ of experiencing cooler average temperatures or lesser total precipitation, falling within the lower third of the 1961-1990 historic record. It also says that there is still a $3.3 \%$ probability of experiencing warmer average temperatures or greater total precipitation, falling within the upper third of the 1961-1990 historic record. Finally, because the probabilities across all three categories must sum to $100 \%$, the outlook says that there is a $23.3-33.3 \%$ probability $(100-73.3-$ $3.3=23.3 ; 100-63.3-3.3=33.3)$ of experiencing average temperatures or total precipitation falling within the middle third of the 1961-1990 historic record.

The preceding example interpretations emphasize, through repetition, several key aspects of the outlooks. First, the outlooks relate only to the 1961-1990 historic record and do not express a likelihood of experiencing average temperatures or total 
precipitation outside that period. For locations where extreme conditions have occurred at other times in the past, the full historic record should be considered in decision making, but the CPC outlooks provide no means to do so directly. However, it may be useful to compare the frequency distribution of the full historic record with that of 19611990, and then with the shifted distribution of the CPC outlooks.

Second, the outlooks concern only average temperatures and total precipitation over the entire forecast period. They do not forecast conditions for any particular day within the forecast period. The outlooks say nothing about the likelihood of experiencing daily or weekly temperature extremes, or even about monthly extremes within a 3-month forecast period. Average temperatures within the middle third of the 1961-1990 historic record may occur as a combination of extreme cold and extreme warm conditions, especially over longer forecast periods, e.g., the 3-month outlooks. Additionally, the outlooks say nothing about whether precipitation, even above average precipitation, will occur as many small events or several severe events.

The procedures used to create the CPC outlooks affects their interpretation as well. Climatological probabilities (i.e., probability anomaly of zero) are specified for regions where forecast techniques have marginal accuracy and, for specific techniques, where that technique does not have sufficient record for determining accuracy. Thus, when an outlook specifies some anomalous probability for a region, there is an implicit statement that the tools used to create that outlook have some record of skill for that region for that forecast period. In contrast, a climatological probability may mean that several forecast tools suggest typical conditions over the forecast period, that no forecast tools work well for that region for that season, that some tools have not been tested over a sufficient period to establish skill at that location, or some combination of these reasons. The outlook maps don't specify which reasons apply, reinforcing the importance of consulting the outlook text discussion.

Further confusion about the proper interpretation of a climatological probability forecast results from inconsistency within the outlook legend. The legend shows 2 options for making forecast with enhanced probability for conditions to fall within the middle third of the 1961-1990 historic record. However, the associated interpretation is flawed, because the total probability across all 3 categories does not sum to 1, violating probability rules. By providing the 2 legend categories for enhanced probability of nearnormal conditions, the implication is that climatological probability forecasts are made only when and where forecast techniques lack skill. However, absence of actual use of those 2 legend categories and their associated interpretive errors suggests that forecasters use the climatological probability designation to forecast near-normal conditions.

\subsection{CPC Forecast Techniques}

Each CPC climate outlook is created by subjectively combining results from a variety of scientific techniques. Climate forecasters use their expert judgement to determine how the results should be combined, and sometimes to also subjectively adjust 
the final forecast products. Forecasts produced by individual techniques may be accorded more or less importance, depending on the forecaster's understanding of the recognized strengths and limitations of individual techniques, as well as their understanding of climate behavior. For example, the effects of past La Nina conditions along the U.S. West Coast are not considered directly applicable to the most recent event. There has been so much long-term oceanic warming in the region over the past few decades that current La Nina events are expected to have different coverage or influence than past events (CPC, 1998; Livezey, 1999).

As new scientific techniques are developed and tested, their results may be incorporated into the outlooks as well. Thus, one outlook may be created in a different manner than another, both within a suite of forecasts and from one month to the next. Additionally, the interpretation of the products may change, as occurred in July 1998, when the meaning of the probability statements associated with the outlook maps was modified to the present interpretation. The major distinction between the current CPC climate outlooks and outlooks prior to July 1998 is that climatologic probability forecasts must be made for regions where the individual forecast techniques have only marginal accuracy.

Documentation from the CPC about the individual forecast techniques is provided at several on-line locations (Section 4 at http://www.nnic.noaa.gov/products/predictions/multi season/13 seasonal outlooks/discu ssion.doc), and

http://www.nnic.noaa.gov/products/predictions/multi_season/13_seasonal_outlooks/discu ssion.doc), as well as in the scientific literature. However, forecast techniques change more frequently than the documentation, resulting in some inconsistent and unpredictably outdated descriptions. Further, while the techniques may be described in the scientific literature, such descriptions often require advanced training to properly interpret, and the techniques often differ in their actual operational implementation. The following descriptions of individual forecast techniques are provided only as an easily interpreted snapshot of current forecast methods.

Canonical Correlation Analysis (CCA) is a form of multiple linear regression used to predict the spatial patterns of anomalies of temperature and precipitation (Barnston, 1994). Anomalies are differences from longer-term average behavior; they are used because they are less sensitive to elevation and other local effects than actual values of temperature or precipitation. CCA uses the following variables as inputs for the predictions, expressed as spatial pattern anomalies over the previous four 3-month seasons: global sea surface temperatures, the height of the 700 millibar air pressure level over North America, and surface air temperatures and precipitation at 59 specific U.S. locations. This technique is useful because it considers the important, but slowly evolving, effects of ocean conditions on the atmosphere, such as the El Nino-Southern Oscillation (ENSO) and the North Atlantic Oscillation (NAO). This approach is strictly statistical, but incorporates conceptual understanding of actual physical processes through the choice of the input variables used in the regression. CCA shifted from experimental to operational status in 1996. The CPC provides on-line maps of performance of CCA for 
each of the seasonal outlook periods, as part of the climate outlook suite of products; an example is provided in Figure 20.

Screen Multiple Linear Regression (SMLR) is similar to CCA (Unger ,1996a,b). However, it provides forecasts only for single stations (at the 59 stations used in CCA), rather than the spatial anomaly patterns of CCA; those stations include Flagstaff, Phoenix, Tucson, and Winslow, Arizona. SMLR also considers only the single prior 3month season, rather than the previous 4 seasons. Finally, not all kinds of information are used for every forecast; the SMLR procedure determines which variables are used for which location and forecast period. Regression equations are based on data over 19551995 and have 1-5 predictor variables. For each month, 13 different equations are used to produce 13 3-month outlooks, with lead times ranging from 1-13 months. While SMLR is strictly statistical, it incorporates the additional conceptual understanding that not all variables are influential for all locations and seasons; the climate in locations with significant geographic features (e.g., mountains, large lakes, coastlines) may have unique relationships with only a few controlling ocean or atmospheric conditions. To evaluate the SMLR forecasts, Unger (1996b) used a bidirectional retroactive real time (BRRT) validation technique to develop temporal correlation coefficients between the climate forecasts and observations at the 59 stations. Results are presented only for the OctoberDecember forecast period with 1-month lead time (see Figs. 2 and 4 at http://www.nnic.noaa.gov/products/predictions/experimental/bulletin/Sep96/art57.html, also included herein as Figures 23 and 24). For this specific forecast period and lead time, temperature forecasts have the highest skill in Arizona, Nevada, and Utah; precipitation forecasts are not as good, but also have their highest skill in the lower Colorado River basin, excluding the Gila River basin.

The Optimal Climate Normals (OCN) forecast method (Huang et al., 1996) is a relatively simple statistical technique that incorporates the conceptual understanding that shifts in climate regimes can occur over several years, decades, or more; within a climate regime, conditions are more similar than across the full historic record. It moved from experimental to operational status in 1996. OCN forecasts are computed by subtracting the official 30-year climatologic averages (presently 1961-1990) from the averages over just the past 10 years for temperature, and 15 years for precipitation (a 10-year period was formerly used for precipitation as well). This approach reflects the persistence of conditions from year-to-year within a regime, but also improves forecasts if there is a long-term trend covering several decades. The OCN approach is not so useful if the climate has been in transition from one regime to another within the past 10 or 15 years. Note also that averaging periods other than 10 or 15 years may be more optimal for climate regimes that are significantly different in length, especially when one regime is relatively short and very different from another. Optimal averaging periods may actually vary regionally as well, although this is not done in current operational practice. Lamb and Changnon (1981) found a 5-year normal to work best overall in predicting seasonal precipitation and temperatures in Illinois, although when the predictions were in error, they were larger than predictions based on 10- or 15-year periods. Easterling et al. (1983) found seasonal heating degree day forecasts were best in Illinois when based on the most recent 10-12 years. The CPC provides on-line maps of performance of OCN for 
each of the seasonal outlook periods as part of the climate outlook suite of products; an example is provided in Figure 21.

The Soil Moisture Tool (SMT) considers soil moisture conditions and prior month temperature anomalies to reflect intraseasonal effects that soil moisture can have on regional surface climatology. SMT is generally used only over a few months during the summer when soil moisture feedbacks affecting atmospheric conditions are strongest.

Contructed Analogs are used for special cases where conditions have a strong signal in the historic record and have occurred several times previously within the historic record, e.g., El Nino. The usefulness of contructed analogs depends on the strength of similarities between present conditions and those during the analog period. Analogs are not considered appropriate for forecasting La Nina effects along the west coast, since there has been so much long-term oceanic warming in the region over the past few decades that new La Nina events are expected to have different effects and areal coverage of influence (CPC, 1998; Livezey, 1999).

The Coupled Model Prediction (CMP) technique (Ji et al., 1994a,b; Barnston, 1998b) has also been referred to as the Coupled Model Forecast (CMF) technique. It uses global climate models (GCMs) to consider the myriad complex physical processes that affect climate, including the mutual influence that the oceans and atmosphere have on each other. GCMs are computer models with many complex mathematical equations that are used to estimate changes over time in ocean and atmospheric conditions. Different GCMs are used, since some models contain more detail about slowly-evolving ocean-atmosphere interactions (e.g., the transfer of heat among different ocean depths and the atmosphere), while other models contain more detail about more rapidly changing atmospheric conditions (e.g., deep cumulus convection). Additionally, a single GCM may be used in slightly different ways, typically by use of a variety of starting conditions.

Operational procedures change often and some implementations are still considered experimental. Generally, results from several different coupled oceanatmosphere models (e.g., Ji et al., 1995) are used to forecast sea surface temperatures (SST) that are then used as starting conditions for several runs of the NCEP Medium Range Forecast (MRF) Model. Typically, another set of MRF Model runs uses starting conditions of recently observed SSTs, e.g., from one-half month ago. The total number of model runs varies, but each extends to only 6 months, meaning that they affect only the shorter lead-time 3-month outlooks in the suite of CPC forecast products. The final CMF is made up of a lagged average of forecasts starting from initial conditions from several months prior (e.g., March-May for July-September outlooks produced in June). The period used for initial conditions can vary, as exemplified in the July-September 1998 outlook produced in June 1998, where the discussion text mentions coupled model runs being different when using March-May initial conditions compared to use of only May initial conditions. 


\subsection{CPC Forecast Quality}

Forecast quality varies by region, by season, and by the dominant modes of climate variability. The CPC notes that, depending on the specific circumstances, a prediction for a 3 -month period 8 months into the future may actually be more reliable than an outlook for the next 3 months. When several forecast techniques produce similar results, their consistency suggests higher confidence in the combined forecast. Alternatively, when individual forecast techniques produce different results, often none of the forecasts are used. In that case, forecast probabilities are based only on climatology, i.e., historical climate statistics.

Greater confidence in the outlooks is possible for regions where climates are stabilized by nearby oceans, resulting in persistent climate trends and variations that are more easily distinguished from small-scale weather influences. Outlooks have low confidence in other regions where short-term climate variations are more common, especially in the mountainous western U.S.; in this region, the short-term complex interactions of air masses with widely varying terrain can overwhelm any clear signal of persistent climate variations. For the Southwest, climate conditions dominated by oceanic conditions (e.g., winter precipitation affected by ENSO) would be expected to be more reliably forecast compared to climate conditions dominated by local-scale phenomena (e.g., summer monsoon precipitation).

Generally, the CPC outlooks for average temperature are more accurate than the total precipitation outlooks. Average temperatures show less variation over larger regions than precipitation in the historic records, allowing longer-term climate variations to be more readily recognized, understood, and predicted. Precipitation records show much larger variation over even small regions, masking larger-scale and persistent climate influences that would enable better prediction. Briefly, for the conterminous U.S. in general, the January-March and July-September outlooks have the highest reliability or "skill". Likewise, the April-June and November-January outlooks have the lowest skill, because they are periods of transition between seasons, when weather is more highly variable. This is likely not true for the April-June period in the Southwest, since this period has relatively constant weather, with notable lack of precipitation.

At a workshop on regional climate variability and change, Leetma (1998) reviewed CPC climate outlook performance over the winter of 1997-1998. The December-February 1998 precipitation outlook issued in July 1997 was notable for its high accuracy. Apparently, outlooks generally have higher accuracy during extremely warm El Nino conditions, because there are recent analogs in the historic record, including a decadal signal in precipitation records that are similar to El Nino precipitation patterns. Additionally, the SST signal is strong and persistent, and numerical models seem to seem to work well under El Nino conditions. Livezey et al. $(1996,1997)$ conclude that forecasts for the winter seasons during both warm and cold ENSO phases (El Nino and La Nina, respectively) have moderate skill over the U.S., but no skill during non-ENSO winters. 
Detailed climate outlook evaluations, whether for individual techniques or the official operational products, are not typically focused on the Southwest. Rather, evaluations typically include the Southwest within a national analysis, using a few observation stations in the region. In the context of weather forecasts, the NWS Hydrometeorologic Prediction Center (HPC) encourages studies of model forecast performance at local scales (HPC, 1997); such analyses are appropriate in the context of climate outlooks as well. Evaluation results then need to be shared with forecasters and users.

SRP has tried using the CPC climate outlooks for use in long-range prediction of peak power loads during the summer (SRP, 1998b). However, they have found the CPC climate outlooks to be "useless". They claim there is a lack of any summer climate signal in the outlooks. Also, they claim that the temperature outlook probability anomalies are biased by the specific period (1961-1990) used in determining climatological normals; with Phoenix, AZ, experiencing steadily rising air temperatures due to urban heat island effects, use of only the most recent years to determine "normal" may be more appropriate.

\subsection{Other Climate Forecasts and Sources}

With the rapid growth of the WWW and easy linkage of websites, it is becoming increasingly common for governmental agencies to link to the CPC climate outlooks. Generally, these agencies are trying to provide "one stop shopping" for their constituents. However, with so many different avenues and formats for the same climate forecasts, there is real potential for confusion among users about which agency is actually providing the forecasts. Further, web links may access only portions of a forecast, while ignoring essential ancillary products, e.g., text discussions, or definitions of forecast categories; there may be lags in updating the links to access the most recent CPC outlooks, as well.

\section{NWS Weather Forecast Offices}

The NWS WFOs generally focus on short-term forecasts (i.e., weather events). However, the Tucson and Phoenix WFOs also convert the CPC climate outlooks into specialized products for specific locations. These products are generated on a nonsubscription basis for individual clients that have developed close relationships with the WFOs. Lists of those products and client relationships are not readily available, neither are performance statistics for those special forecast products.

\section{Western Regional Climate Center}

The Western Regional Climate Center (WRCC) is an important source of information related to climate forecasts for the Southwest. The mission of the WRCC is to disseminate high quality climate data and related information pertaining to the western U.S.; foster better use of climate information in decision-making; conduct applied 
research related to climate issues; and improve the coordination of applied climate activities at state, regional, and national levels. Making forecasts, however, is not within the WRCC mission. The WRCC has investigated climate trends and fluctuations in the West, the relationship of ENSO to western climate, and impacts of climate variability on various activities in the West. They also maintain historical climate databases for the West (http://www.wrcc.dri.edu/wrccmssn.html). The WRCC provides an alternative to direct access to CPC climate outlooks (http://www.wrcc.dri.edu/longrang.html). However, there are differences between WRCC and CPC products that may confuse users of the outlooks. Specifically, the WRCC link accesses only the CPC outlook maps, not the text discussion or skill maps. There can be significant lags in the access as well; as of 5 August 1998, the August outlook was not yet posted at the WRCC site, although it had been issued by the CPC in mid-July. The WRCC can provide hard-copy CPC outlooks to users, and serve as technical experts to assist users in understanding the outlooks and the skill and limitations behind various techniques used in making the outlooks. The WRCC also provides subscription-based services to about 200 clients for converting the CPC climate outlooks into specialized products for specific locations. For example, they can extend the precipitation anomaly outlooks into forecasts for the number of rainy days that can be expected at a specific location. The techniques used for creating those special products, however, are not generally available for use by others; neither have the performance of those special product forecasts been evaluated.

The WRCC is one of several regional climate centers developed under a national program to provide regional climate services. The structure of this program can be confusing, but was generally precipitated by termination of the national State Climatology Program in 1973 and passage of the National Climate Program Act (15 U.S.C. 2901, PL 95-367) in 1978. The goal is a 3-tiered climate services network consisting of national, regional, and local partners. The national partner is NOAA's National Climatic Data Center (NCDC) in Washington, DC.

The regional partners are the 6 regional climate centers, established in the 1980s; each belongs to the Consortium for Regional Climate Services, a non-profit organization that lobbies Congress for financial support for the program. Generally, the responsibilities of the regional climate centers focus on delivery of climate information, monitoring of regional climate anomalies, preparation of specialized historical climate data sets, and applied research on climate issues; the climate centers do not have a forecasting mission. The WRCC has the largest areal coverage of the regional climate centers, serving the 11 western continental states, Alaska, Hawaii, and the Pacific trusts and territories. Colorado and Wyoming, states within the Colorado River Basin, are also served by the High Plains Regional Climate Center (http://hpccsun.unl.edu/); Texas is served by the Southern Regional Climate Center (http://www.srcc.lsu.edu/index2.html).

The local partners have typically consisted of state offices or universities, established under state/national agreements or state legislation, to receive and use grants made available through the National Climate Program Act and other federal programs. Within the Colorado River Basin and the Southwest, the state partners are generally affiliated with universities. For example, the Arizona state partner is the Office of the 
Arizona State Climatologist; it is not a state agency, but was created by a memorandum of agreement between the NWS Western Region Headquarters, the NOAA National Climatic Data Center, and Arizona State University (through the Arizona Board of Regents). In contrast, the New Mexico state partner is the state climatologist, legally part of the New Mexico Department of Agriculture, although a 1997 state-level agreement between that department and New Mexico State University assigns operational responsibility to the university's Agricultural Experiment Station.

\section{Salt River Project}

The Salt River Project (SRP) uses a proprietary long-range precipitation model as a component of their water supply forecast procedures for the Salt and Verde river basins (SRP, 1998b). The precipitation model was developed for SRP by Entropy Limited and is unavailable for use by others. The Entropy precipitation model evaluates spatial patterns and temporal trends in SSTs, air temperatures, and precipitation at various locations throughout the Pacific Basin using 4 different pattern recognition schemes. The model produces a forecast of the probability of accumulated 3-month seasonal Salt River watershed precipitation being above or below the historic median. Confidence levels are determined by evaluating the similarity of results from the different pattern recognition schemes. Although they have no formal verification program, SRP claims that their Entropy precipitation forecast procedures have correctly predicted whether seasonal precipitation would be above or below the historic median during about $70 \%$ of the years for which they've used the model (SRP, 1998b).

In conjunction with Entropy, SRP has also tried to develop good long-range outlooks of summer conditions (e.g., average temperature, a discomfort index based on temperatures and humidity), but has been unsuccessful to date (SRP, 1998b).

\section{International Research Institute for Climate Prediction}

The International Research Institute for Climate Prediction (IRI) was created through cooperative agreement among the NOAA Office of Global Programs (OGP), Columbia University's Lamont-Doherty Earth Observatory, and the University of California - San Diego Scripps Institution of Oceanography (see http://iri.ldeo.columbia.edu/). Four divisions within IRI focus, respectively, on research and development of global climate models and data assimilation systems directed at seasonal to interannual climate forecasts; production of experimental forecasts at global and regional scales; extension of forecasts and associated evaluations to support policyand decision making related to climate variability; and linking data collection, model development research, and applications communities. IRI intends to become a global organization, with multi-national membership and governance.

IRI climate forecasts (http://iri.ldeo.columbia.edu/climate/forecasts/) are not directly available for operational use, implying recognition of the potential for confusion

and misapplication associated with experimental forecast products. Products are available only with significant time lags, generally several months; access to current forecasts 
requires obtaining a password from IRI. IRI contributes to confusion, however, by variously calling their forecasts "experimental", "research", and "official" products. The forecasts are made by the IRI Experimental Climate Forecast Division. An associated disclaimer states IRI forecasts are meant for research purposes only, and that, while IRI collaborates with official forecasting offices throughout the world, official forecasts are available only through various national offices (e.g., NWS NCEP CPC within the U.S.). However, IRI creates confusion by stating "The IRI Experimental Climate Forecast Division provides an official climate forecast" and linking to the forecasts with the heading "Official IRI Climate Forecasts" (http://iri.ldeo.columbia.edu/climate/forecasts/). IRI has no authorization to make official forecasts for the U.S.; that ability rests solely with the NWS. An example climate forecast product is illustrated in Figure 25, while subsequent observations for the same period are given in Figure 26. IRI also provides Supplemental Consensus Forecasts for different regions throughout the world, as conditions warrant (http://iri.ldeo.columbia.edu/climate/forecasts/sup/). These forecasts are developed in conjunction with climate scientists from the appropriate national entities in the countries covered by the forecast. These forecasts typically lack Southwest U.S. coverage, although Mesoamerica forecasts extend to the U.S.-Mexico border.

The IRI climate forecasts can be compared to the CPC climate outlooks in several ways. First, the IRI forecasts are expressed not as probability anomalies, but as probabilities that conditions will fall within the upper, middle, and lower third of the historic record. However, the forecast map legend describes the categories only as above-normal, near-normal, and below-normal. Further, the historic period used to create the tercile categories is not clearly indicated in either the forecast maps or text discussions. Some maps of tercile boundaries show the historic period as 1950-1995. This means that IRI and CPC climate forecasts are not directly comparable, because CPC outlooks are referenced to the 1961-1990 historic record.

Second, the IRI climatological forecast ("C" on the forecast maps) is described as indicating that forecasters had no basis for a shift in the probability distribution. However, as with the CPC climate outlooks, it is not clear whether the climatological forecast results from lack of skill of the techniques or their lack of agreement. The IRI forecasts can express an increased probability that conditions will fall in the middle third of the historic record (a near normal forecast); for example, in the forecast of Figure 25, the region north of the Great Lakes has forecast favoring near normal conditions. However, like the CPC climate outlooks, the maps lack any indication in the confidence associated with any parts of the forecasts; forecast discussions consider confidence only qualitatively.

The format of IRI climate forecasts differs in several ways from the NWS CPC climate outlooks. First, the probability anomalies are indicated directly on the maps, without requiring reference to a separate legend that can get separated from the forecast; however, the map legend lacks description of the areas designated with "C" and "D". Second, the forecasts lack the spatial resolution of the CPC outlooks, which often have contours surrounding regions with the most extreme probability anomaly forecasts. Third, the IRI forecasts show regions for which forecasts are considered irrelevant ("D" 
on the forecast maps), because the region is dry during the forecast period, typically receiving less than $5 \mathrm{~cm}$ of precipitation or less than $15 \%$ of the annual total precipitation. Fourth, the IRI forecasts are not limited to the U.S., extending both north and south into Canada and Mexico, respectively.

Like the CPC, IRI combines results from several different models to create their many forecast products, including coupled GCMs, simplified dynamic models, and statistical models. Ensembles and statistical composites are also used. Seasonal climate outlooks are generated in 3 steps (Graham, 1998). First, SST predictions are made based on observations and coupled ocean-atmosphere models. Second, the SST predictions are used as input to GCMs, including NCEP, ECHAM, and others. Each model is run several times using slightly different initial conditions. Third, the multiple model runs are combined into ensemble forecasts and then compared with historic climatology to produce a "net assessment probabilistic forecast". Evaluations of IRI forecasts have not focused on the U.S. Southwest, although IRI has expressed interest in working with CLIMAS in this area (L. Goddard, IRI, personal communication to T. Pagano, HWR-UA, 1998).

\section{Experimental Climate Prediction Center}

The Experimental Climate Prediction Center (ECPC) is a NOAA OGP Applied Research Center (ARC), located at the Scripps Institution of Oceanography, University of California at San Diego (see http://ecpc.ucsd.edu/ecpc.html). There can easily be confusion between IRI and ECPC forecasts due to overlap of institutions and personnel. However, ECPC is a partially federally funded university affiliate that contributes products and tools to the IRI; it is not part of IRI. ECPC goals include development of global to regional climate prediction tools, and evaluation of existing forecast methodologies (Roads et al., 1999). They presently display experimental products on the WWW, including monthly and seasonal global and regional climate predictions, and weekly to seasonal U.S. forecasts of precipitation, soil moisture, an index of fire weather. While ECPC make clear that their products are not operational, what they term experimental forecasts are more accurately considered research forecasts, because there is still significant development work underway (e.g., downscaling global forecasts to regional forecasts, changing land surface hydrologic formulations).

The ECPC is involved in development, evaluation, and extension of a wide variety of climate models, including NCEP's global spectral model (GSM), regional spectral model (RSM), and mesoscale spectral model (MSM); the Oberhuber global isopycnic ocean model; the hybrid climate model (HCM) that combines the Hamburg ocean model with atmosphere statistics for the tropical Pacific Ocean; and hydrologic and hydraulic routing models from the NWS River Forecast System (NWSRFS). Roads et al. (1998) and Roads and Chen (1998) provide details about specific model operations and forecast production and evaluation. To date, ECPC water resource-related forecasts of climate and other variables (e.g., snowpack) have been focused on the coastal U.S. West, namely California and the Sierra Nevada Mountains. 


\section{NASA Goddard Institute for Space Studies}

While NASA Goddard Institute for Space Studies (GISS) GCMs were developed to model climate behavior on decadal time scales, GISS is now using their SI97 GCM to periodically generate seasonal surface air temperature and precipitation outlooks (Borenstein et al., 1998; http://grads.iges.org/ellfb/Jun98/hansen.html). While GISS calls the forecasts experimental, they are more accurately considered research forecasts, since the forecasts are being used to direct improvements in the model. The SI97 GCM is an update of the SI95 GCM; the models are described by Wilder et al. (1997) and Hansen et al. (1997), respectively.

\section{Commercial Vendors}

With the growth of financial markets in weather and climate derivatives and appreciation by the insurance industry of risks associated with climate variability, there has also been development of private companies formed to provide climate forecast services. While not as numerous as commercial vendors of weather forecasts, these companies are probably represent only the beginning of a burgeoning industry. Some companies with a traditional focus on weather forecasts have expanded their services to include climate forecasts. Both AccuWeather and Fox Weather, presented in the chapter on weather forecasts, sell 30- and 90-day temperature and precipitation outlooks. AFC (http://www.advancedforecasting.com) offers forecasts with lead times extending to 18 months for a range of industries. Environmental Dynamics Research Inc. (http://www.ccc-weather.com) targets participants in the degree-day weather derivatives market. 


\section{CHAPTER 4. HYDROLOGIC FORECASTS}

\subsection{Introduction}

The state of hydrologic forecasting for the Southwest U.S. can be confusing due to the variety of hydrologic forecasts made by the NWS, diversity of product delivery, coordination of NWS forecasts with those made by other agencies, use of unique procedures for specific basins, and variable consideration of the historic record in presenting forecasts. In addition, confusion may also result from the apparent multitude of NWS units involved in support or generation of products and an NWS communications emphasis on future hydrologic forecast technologies rather than current practices.

Official NWS hydrologic forecast products may be issued by the national Hydrologic Information Center, various regional River Forecast Centers, and the many local Weather Forecast Offices. In addition, throughout the West, some official hydrologic forecasts are issued simultaneously by both the NWS River Forecast Centers and the Natural Resources Conservation Service, but in a different format and with slightly different information content. However, many other NWS units, as well as nonNWS entities, pass along these products. Also, the NWS is undergoing a major modernization initiative, producing changes in institutional structure, distribution of responsibilities, programmatic activities, software installations, and documentation; many changes are associated with changes in program names and acronyms. Further, in an effort to garner support for the changes, over the past several years much of the NWS programmatic documentation related to hydrologic forecasting has focused on plans for the future, swamping out communication about present practices.

Forecasts cover a variety of spatiotemporal scales, lead times, and hydrologic conditions. Flood warnings may be made only minutes in advance, while peak flow and stage forecasts are made with lead times of several days. Flood potential outlooks and water supply outlooks are made months in advance, providing predictions of extreme single-day streamflow behavior and total seasonal runoff volumes, respectively. Peak flow and stage forecasts and flood potential outlooks incorporate simple projections of water management decisions into the predicted stream conditions, while water supply outlooks represent flows supposedly without any human influences. In some forecasts, floods correspond to the traditional definition of flows or stages that overtop the streambanks, but other forecasts define floods as flows or stages at which damages begin to occur and their values can change from year to year. Quantitative precipitation forecasts (QPFs) are considered hydrologic forecasts by the NWS and herein, because they are generated for input into hydrologic models and producing forecasts of watershed runoff and river conditions.

The state of hydrologic forecasting shows clear contrasts with that of weather and climate forecasting. The state of weather and climate forecasting, presented previously, can be characterized by the rapid incorporation of a wide variety of research findings and 
products; experimental forecasts are routinely issued and operational forecasts can be adjusted based on recent climate diagnoses and newly-improved conceptual understanding of ocean and atmospheric dynamics and linkages. Different forecast techniques can take precedence in different regions, during different seasons, and for unusual conditions. Additionally, meteorologic forecasting has a strong history of forecast quality assessment.

In contrast, the state of hydrologic forecasting is characterized by much slower evolution, with constraints imposed by complex legacy data management systems, longstanding standard operating procedures, and an institutional preference for uniformity in operations. This exists even in the context of an NWS modernization program, which has produced more changes in graphical displays and user interfaces for hydrology than in core operational forecast methodologies. Further, quality assessments of operational products are uncommon; even coordinated comparisons of hydrologic model performance have been infrequent and typically contentious.

\subsection{Major Hydrologic Forecasting Institutions}

NOAA's National Weather Service (NWS) has official responsibility for hydrologic forecasts, on time-scales ranging from minutes to months. Within the NWS, a large number of different units are responsible for generation and distribution of forecast products, development of forecast tools, and technical support of forecasts via data collection and management. In addition, many other agencies assist the NWS in making hydrologic forecasts, by providing data, making alternative forecasts for NWS consideration, and conducting research. Agencies particularly important in forecasting operations for the Colorado River Basin and the Southwest U.S. include the Natural Resources Conservation Service (NRCS), Bureau of Reclamation (BuRec), U.S. Geological Survey (USGS), Salt River Project (SRP), and local water districts within the region. The California Department of Water Resources plays a key role in development of hydrologic forecasts for that state, while the U.S. Army Corps of Engineers (USACE) is an important partner throughout most of the nation.

\section{NWS River Forecast Centers}

Many hydrologic forecasts are created by the NWS River Forecast Centers (RFCs), with 4 different RFCs having responsibility for various watersheds covering portions of the Southwest U.S. The Colorado Basin River Forecast Center is responsible for creating products for both the upper and lower Colorado River basins (http://www.cbrfc.gov/). The West Gulf River Forecast Center includes the Rio Grande and Pecos River basins in New Mexico and Mexico (http://www.srh.noaa.gov/wgrfc/). The Arkansas-Red Basin River Forecast Center covers northeast New Mexico (http://info.abrfc.noaa.gov/), and the California-Nevada River Forecast Center covers southern California (http://nimbo.wrh.noaa.gov/cnrfc/). While staffing levels vary among the RFCs in response to regional hydroclimatic 
conditions and user needs, typical RFC staffing organization and responsibilities are presented at http://www.srh.noaa.gov/wgrfc/staff/positions.html.

Each of these RFCs has their own network of cooperating agencies, upon which they rely for acquisition of specific data, coordination of any water supply outlooks that may be made by these other agencies, and projections of other relevant water supply elements (e.g., irrigation water diversions, reservoir operations). This report focuses on the operations of the Colorado Basin River Forecast Center (CBRFC), since the entire Colorado Basin falls under its jurisdiction; other RFCs are mentioned only in contrast, where appropriate.

\section{NWS Weather Forecast Offices}

As explained earlier in the chapter on weather forecasts, NWS Weather Forecast Offices (WFOs) are responsible for providing forecasts and warnings for their areas of responsibility, including hydrologic forecasts. While many of the products are created within a WFO, others are created elsewhere and then simply transmitted by the WFOs, e.g., water supply outlooks from RFCs. Other hydrologic products are generated by the WFOs, using RFC guidance and support products. The 11 WFOs covering portions of the Southwest were listed previously in Table 1.

\section{NWS Hydrometeorologic Prediction Center}

The NWS Hydrologic Prediction Center (HPC, http://www.hpc.ncep.noaa.gov/), a unit within the National Centers for Environmental Prediction (NCEP), exists to support the operations of the NWS Weather Forecast Offices and River Forecast Centers. The HPC focuses on quantitative precipitation forecasts (QPFs), heavy snow forecasts, and medium-range weather forecasts. They serve as advisors to the WFOs and RFCs, answering questions about QPFs, modeling techniques, and differences among forecast model results. HPC forecast products are described by HPC $(1998,1999)$. However, the utility of HPC forecast products for WFO hydrologic forecasts is often marginal at best, due to the coarse resolution of HPC techniques that do not adequately consider local scale orographic effects or convective processes.

\section{NWS Office of Hydrology}

While RFCs focus on specific regions and generation of operational products, the 5 centers within the Office of Hydrology $(\mathrm{OH})$ have a national focus and are more involved with hydrologic forecasting through support of other NWS units or through communication activities.

Hydrologic Research Laboratory. The Hydrologic Research Laboratory (HRL) designs, develops, and implements hydrologic forecast tools and techniques for use at NWS RFCs and WFOs. They sponsor and conduct research on hydrologic processes and application of new scientific and computer technologies for hydrologic forecasting. They also provide training and implementation support, within the NWS, related to hydrologic 
forecasting techniques. The HRL was extensively involved in technological development in support of the NWS modernization effort, including the Next-generation Radar (NEXRAD) and Advanced Weather Interactive Processing System (AWIPS) projects.

Ongoing HRL projects include:

- development of the Advanced Hydrologic Prediction System (AHPS), which will incorporate weather and climate forecasts into probabilistic hydrologic forecasts with lead times of days to months;

- modernization of the Flash Flood Guidance System (FFGS), which will standardize procedures across all RFCs and WFOs and enable finer resolution flash flood products;

- development of the Integrated Hydrologic Forecast System (IHFS), which is envisioned as a large, complex system for performing all functions needed to support hydrologic forecast operations, through the incorporation of evolving scientific and technologic advances into data processing and analysis; product preparation and formatting; and model development, calibration, and operational verification;

- development of the NOAA Hydrologic Data System (HDS), which will provide integrated management of hydrology-related data of mixed time and quality, from provisional real-time to quality-controlled historical data;

- development of the WFO Hydrologic Forecast System (WHFS), which provides selected tools customized for use by individual WFOs in generating local hydrologic forecast products;

- modernization of the large, complex NWS River Forecast System (NWSRFS) through development of graphical user interfaces (GUIs), improved graphics output, interactive model calibration capabilities, site specific hydrologic models for WFO use, and use of probabilistic quantitative precipitation forecasts (QPFs) to generate probabilistic river stage forecasts; and

- development of additional procedures for modeling river mechanics, including flow routing schemes and dambreak analysis.

National Operation Hydrologic Remote Sensing Center. The National Operational Hydrologic Remote Sensing Center (NOHRSC; http://www.nohrsc.nws.gov/) is the NWS center of expertise in satellite and airborne remote sensing and geographic information systems (GIS) used to support the NWS operational hydrology program. The most widely used NOHRSC products are gridded estimates of the areal extent of snow cover and snow water equivalent, based on the integration of satellite, airborne, and groundbased observations. They also provide ancillary spatial data sets and GIS tools designed specifically for hydrologic applications. Although the NOHRSC conducts airborne snow surveys, flights have not been made operationally in the U.S. West for several years due to budget constraints (T. Carroll, NOHRSC, personal communication, 1998).

Hydrologic Information Center. The Hydrologic Information Center (HIC) serves as a national information services center for communication of NWS operational hydrology products. HIC prepares national summaries of hydrologic conditions, emphasizing extreme events, e.g., floods and low flows. In late winter and early spring, the HIC issues national flood outlooks based on operational products provided by the RFCs, WFOs, and 
other centers. During significant flood events it assembles information to brief upperlevel management within NOAA and other agencies. It also obtains, analyzes, and disseminates information on historic hydrologic events, statistics on losses resulting from flooding, and other select operational information (e.g., streamflow forecasts and observations).

Hydrologic Technology Transfer Center. The Hydrologic Technology Transfer Center (HTTC) primarily serves to assist other nations in adaptation and implementation of NWS operational hydrology technologies. However, they are also the official location for NWS operational hydrologic software and documentation.

Hydrometeorological Design Studies Center. The Hydrometeorological Design Studies Center (HDSC) is a primarily an applied research unit focusing on probable maximum precipitation (PMP) and precipitation frequency (PF) studies used in construction and development planning. The HDSC also collects and stores historical records of heavy precipitation events, conducts analyses of extreme precipitation events in and around the United States, and serves as a clearinghouse for all hydrometeorological reports and frequency studies. Publication of updated precipitation frequencies for the Southwest U.S. is expected soon (HDSC, 1998) and will provide a climatology of extreme precipitation for durations of 5 minutes through 10 days and for return intervals of 2-100 years.

\section{Natural Resources Conservation Service}

The Natural Resources Conservation Service (NRCS), an agency within the U.S. Department of Agriculture (USDA), has a long tradition of producing longer-term hydrologic forecasts. As the former Soil Conservation Service (SCS), they instituted the snow survey program in the U.S. West in 1935, and have since used those field estimates of snow depth and water equivalent as the basis for their forecasts, for use by local conservation districts. They also provide their snow data in support of forecasting efforts by other agencies (e.g., the NWS RFCs, the Salt River Project). Presently, the NRCS operates about 800 snow courses and 570 automated Snowpack Telemetry (SNOTEL) stations throughout the West. Their databases include monthly data for 1700 snow courses, 600 stream gages, 300 reservoirs, and 1200 precipitation stations, as well as daily data for 550 SNOTEL stations, and 2000 meteorologic stations (http://www.nwwc.nrcs.usda.gov/factpub/sect_5.html).

Through its National Water and Climate Center (NWCC), the NRCS provides a range of hydrologic forecasts, including seasonal streamflow volume forecasts, lake and reservoir stage forecasts, peak flow forecasts, and runoff recession and low flow forecasts. While NRCS forecasts are generally issued on a monthly basis, mid-month and weekly forecasts are made for specific clients under special arrangements. The range of products issued by the NRCS reflect a combination of long-standing decisions made early in the agency's history, national initiatives, feedback from specific users, and specific client requests (e.g., from irrigation districts). Seasonal streamflow volume forecasts, also known as water supply outlooks, are made using in-house techniques, but 
the values ultimately issued are coordinated with the NWS, and for the Salt/Verde Basins, with the Salt River Project.

NRCS forecast products are available via printed publications and electronically (http://www.wcc.nrcs.usda.gov/water/w_qnty.html). The NRCS Centralized Forecast System (CFS) is the primary focal point for distributing information to local conservation districts and NRCS field offices; computerized access is via 40 telephone lines, commercial systems, and the Federal Telecommunications System. Other elements in CFS include near real-time estimates of precipitation, snow depth, snow water equivalent, and reservoir conditions. Additionally, other CFS programs provide support for irrigation planning, from the district to farm level, by combining crop consumptive use data and NRCS state irrigation guides with the streamflow forecasts, and using regression analysis to relate streamflow forecasts to farm district irrigation supplies.

\section{Salt River Project}

The Salt River Project (SRP) manages 6 hydroelectric dams, 250 groundwater wells, a 131-mile system of primary canals, and more than 1100 miles of lateral canals, to serve water to agricultural and municipal water users in metropolitan Phoenix, Arizona (SRP, 1998a). Additionally, the SRP system is interconnected with the Salt and Verde Rivers, 8 municipal water treatment plants, privately owned irrigation ditches, the Central Arizona Project (CAP), and the Granite Reef Underground Storage Project (GRUSP). SRP also operates or participates in 6 thermal, 1 nuclear, and several smaller thermal and hydropower generation plants, with sales of over $25 \times 10^{6}$ megawatt-hours of electricity in 1997. With this infrastructure, SRP has become involved with sophisticated water exchange and sales arrangements, as well as power production.

The high economic value of their water and power production activities and infrastructure has enabled SRP to develop sophisticated weather, climate, and hydrologic monitoring and forecasting capabilities. The SRP Water Resource Operations group, responsible for daily reservoir operations, includes 3 meteorologists, 2 hydrologists, 1 civil engineer, and 2 graduate students. The SRP Power Operations group makes use of forecasts provided by the hydrometeorologic team within the Water Resource Operations group. SRP considers their climate and hydrologic forecasting capabilities to be an important asset and are expected to expand their forecasting activities throughout the West as electric utility deregulation advances (SRP, 1998b). Water reports for the SRP system are issued daily over the WWW. These reports track current storage conditions, river inflows, releases, lake evaporation, and precipitation (http://www.srpnet.com/, then link to "water operations" and "daily reports"). SRP forecasts are generally available for internal use only, with forecast needs determined by the Water Resource Operations and Power Operations groups. However, SRP does cooperate with the NWS CBRFC and NRCS NWCC in developing coordinated water supply outlooks for the Salt and Verde basins.

In their water supply and power production operations, SRP generates a variety of short- and long-range weather, climate, and hydrologic forecasts. Although they 
generally make use of forecasts generated by others (e.g., NWS) and adapt the products to their watersheds, 2 forecast techniques are proprietary to SRP. The various weather and climate forecasts were described previously, in their respective chapters. However, this chapter describes SRP forecasts related to hydrology, including water supply outlooks and quantitative precipitation forecasts.

\section{U.S. Geological Survey}

U.S. Geological Survey (USGS) involvement in operational hydrologic forecasting is generally limited to making streamflow observations and generating stagedischarge relationships as described by Mason and Weiger (1995). During extended periods of flooding, near real-time updates of stage-discharge relationships may be required. The USGS also sponsors and conducts research projects, often in conjunction with other agencies and institutions, related to hydrologic forecasting. For example, the USGS is working with the NWS to install a flood alert system for Cheyenne, Wyoming, and develop rainfall-flood flow relationships (Mason, 1994). In cooperation with the Bureau of Reclamation, the USGS has developed a Watershed and River System Management Program (WARSMP) and implemented it for the San Juan River basin, which is tributary to the Colorado River (Vaccaro, 1996). WARSMP consists of hydrologic process models within the Modular Modeling System (MMS), resource management models within the Power and Reservoir Systems Models (PRSYM), forecast models, and graphical user interfaces (GUIs). Additionally, as described in the previous chapters on weather and climate forecasts, the USGS is involved in several research projects to assess the value of those forecasts in improving hydrologic forecasts, but the areas of focus are in California, Colorado, and the Northwest rather than the Southwest (Schaefer, 1997).

\section{Bureau of Reclamation}

The Bureau of Reclamation (BuRec), an agency within the Department of Interior, has responsibility for managing flows from most of the reservoirs along the Colorado River and its tributaries. Long-term water supply outlooks are required by the operational management rules used to operate those reservoirs. For example, management of Lakes Mead and Powell require monthly outlooks with lead times of up to 2 years; the outlooks used must be the $10 \%, 50 \%$, or $90 \%$ quantile outlooks, depending on current and anticipated reservoir levels and releases. BuRec primarily relies on water supply outlooks issued especially for them by the NWS CBRFC; those outlooks are a combination of deterministic forecasts produced by regression analysis and simple longterm statistics. However, BuRec would like to develop special purpose products for their internal use. BuRec does support generation of NWS hydrologic forecasts, however, in a manner similar to that of the USGS, i.e., by providing data and participating in studies on the value of climate and hydrologic forecasts for their water management operations (Schafer, 1997). 


\subsection{Short Range Forecasts}

The temporal coverage of short-range forecasts varies from hourly to daily, while lead times vary from minutes to several days. Within the NWS, short range hydrologic forecast procedures are generally consistent among all RFCs. Efforts within NWS to modernize hydrologic operations are aimed at further standardizing forecast procedures, but can result in out-dated documentation and inconsistencies among different sources. It can be difficult to sort out from hydrology modernization plans what procedures are actually operational at various locations (Fread, 1995; Page, 1996; Shelton and May, 1996; Braatz et al., 1997). Some RFCs provide more thorough descriptions of their operational products and procedures than others. The West Gulf River Forecast Center provides an especially clear, non-technical overview of the general process used within the NWS for making short range forecasts of river conditions (http://www.srh.noaa.gov/wgrfc/making forecast.html) and is generally applicable for all RFCs.

Short range forecasts issued by the NWS RFCs or WFOs typically are not evaluated for their efficacy. However, the ESP Analysis and Display Program (ESPADP), to be implemented as part of the NWS hydrology modernization, is expected to provide capabilities to evaluate forecast quality and automatically adjust forecasts for model errors (Braatz et al., 1997).

\section{Flood Watches and Warnings}

NWS Weather Forecast Offices (WFOs) are responsible for issuing flood and flash flood watches and warnings for their service areas. Flash flood watches and warnings are used for events that are projected to occur within 6 hours, while flood watches and warnings refer to events projected to occur more than 6 hours after product issuance. Flash flood watches are generally issued for multi-county areas, while flash flood warnings are targeted to portions of counties (Tucson WFO, undated). Flood watches and warnings focus on specific river or stream reaches and are often associated with a specific flood forecast point. Depending on time of issuance relative to onset and termination of flooding, flood forecast products may be known as Flood Warnings, Flood Statements, or River Statements.

Various descriptions of flood watch and warning forecast procedures are given by HRL (1998), Sweeney (1998), and Larson (1996). However, actual practice may be somewhat different than the documentation. Key inputs required by WFOs include observed precipitation, forecast precipitation, and flash flood guidance. These inputs and issuance of flood watches and warnings rely on intense coordination among the NWS WFO, NWS RFC, and local emergency management agencies; coordination is so close between WFOs and local agencies that personnel have access to home phone numbers and use them often (G. Sampson, NWS Tucson WFO, personal communication, 1999).

Mean areal precipitation (MAP) estimates are made from rain gauge measurements, monitored in near real-time at 6-hour intervals. Depending on the gauge network configuration, single gauges may estimate precipitation over several hundred 
square miles. MAP estimates are greatly enhanced through rapid data acquisition and communication provided by Automatic Local Evaluation in Real Time (ALERT) systems. Both the Pima and Maricopa County Flood Control Districts operate ALERT systems (see http://156.42.96.70/ALERT/alert.htm and http://www.dot.co.pima.az.us/flood/overv/summary.htm).

While forecast precipitation is listed by the NWS as one of the key inputs for development of flood watches and warnings, the availability and use of quantitative precipitation forecasts (QPFs) varies. Much of the QPF technology was developed and tested for areas within the Arkansas-Red Basin RFC. That RFC receives QPFs twice each day from 12 WFOs. Each suite of QPFs is combined into a composite QPF for the next 24 hours at 6-hour increments, for input into hydrologic models; results are then forwarded to the WFOs for distribution. Documentation describes operations within other RFCs as having flood watches and warnings issued by WFOs typically based only on observed mean areal precipitation and RFC flood guidance. However, actual practice in the Southwest follows more along Arkansas-Red Basin procedures, with the CBRFC using QPFs generated by the WFOs (G. Sampson, NWS Tucson WFO, personal communication, 1999).

Flash flood guidance consists of several products, each of which is based on continuous soil moisture and snow cover accounting by the RFCs. Areal flash flood guidance describes the average depth of rain over an area during a specified period (e.g., $1,3,6$ hours) that will initiate flooding on small streams in the area; it can be issued for a zone, county, urban area, or some pre-defined grid, with each product having a different name. Flash flood guidance can also refer to a specific location immediately downstream of the specified area. Headwater flash flood guidance describes the average rain over an area during a specified period that will cause a specific stream to rise to a specific vertically referenced flood stage. Threshold runoff is the depth of runoff over a specific area resulting from precipitation of a specific duration that will cause a stream to slightly exceed flood stage or bankful, depending on the stream. Although flash flood guidance products are primarily intended only for internal use by the WFOs, they may be subsequently distributed by the WFOs to other users, including Local Flood Warning System (LFWS) cooperators (e.g., the Pima and Maricopa County Flood Control Districts). While RFCs provide flash flood guidance to the WFOs, the WFOs don't necessarily use that input for determining whether to issue a watch or warning. In practice, the CBRFC issues guidance because they are procedurally required to do so, but WFOs typically ignore it, relying instead on real-time monitoring of watershed conditions through coordination with local Flood Control Districts (G. Sampson, NWS Tucson WFO, personal communication, 1999). Exceptions occur during the winter months, when the WFOs will rely on CBRFC guidance during some winter storms.

The NWS is working to use Doppler radar data from the Next-generation Radar (NEXRAD) program to improve monitoring of the spatial and temporal variability of precipitation and thus also improve hydrologic modeling and forecasting. NEXRAD can provide hourly rainfall estimates at a resolution of $16 \mathrm{~km}^{2}$ (i.e., over a $4 \mathrm{~km} \mathrm{x} 4 \mathrm{~km}$ grid). However, the first priority in NEXRAD use is for predicting and tracking severe weather. 
Unfortunately, the mode of operation of the radar system is different for that purpose than for precipitation estimation (K. Redmond, workshop, 8 July 1998). Thus, for some storms, the radar swaps between modes of operation, producing precipitation estimates with varying quality, with no documentation of when the radar system was operated under the two priorities. There is real concern that precipitation estimates cannot be considered accurate under such circumstances, especially during extreme events, when the need for accurate precipitation estimates is most critical for hydrologic forecasting.

Additionally, NWS plans are for all local WFOs to generate their short-range flood-related forecasts using a system developed especially for them by the NWS Office of Hydrology, the WFO Hydrologic Forecast System (WHFS;

http://hsp.nws.noaa.gov/oh/hod_whfs/whfs_intro_wpd.html). The system consists of selected applications for data management, data display, and product management (e.g., suggesting issuance of watches or warnings, product formatting). Within the WHFS, the Area Wide Hydrologic Prediction System (AWHPS) combines radar-based gridded precipitation estimates from for the latest 1, 3, and 6 hour periods with RFC flash flood guidance, to precisely locate small areas of potential flooding. Eventually, as part of the Site Specific Hydrologic Prediction System (SSHPS), simplified versions of operational hydrologic models will be installed at each WFO, but they will still require RFC support for calibration and updating of basin moisture storage conditions (e.g., soil moisture, snow water equivalent). The AWHPS provides qualitative forecasts of flood potential over general areas, while the SSHPS will provide quantitative forecasts of flood flows and stages for specific stream locations. WHFS is the hydrologic component of the larger Advanced Weather Interactive Processing System (AWIPS) being developed and implemented within the NWS. As such, the WHFS is experiencing continual evolution and modification, based in part on input from WFO forecasters. As of March 1998, only the Salt Lake City WFO has the WHFS available within the Colorado River basin and the Southwest (Roe et al., 1998).

The NOAA National Environmental Satellite Data and Information Service (NESDIS) has created an experimental Flash Flood website (http://orbitnet.nesdis.noaa.gov/arad/ht/ff/index.html) consisting of a series of passive microwave satellite-based moisture estimation products to assist in forecasting flash flood potential. Two different rain rate estimates, based on different data processing algorithms, are provided along with estimates of atmospheric precipitable water and soil wetness. A tutorial (http://orbit-net.nesdis.noaa.gov/arad/ht/ff/tutorial.html) explains how such products might be used. Appropriate interpretation of the products and transformation into a reliable forecast clearly requires some technical training and meteorological expertise. However, the tutorial and products are available to anyone with Internet access, and the tutorial provides an example of how the owner of a canoe livery might access the NESDIS products, diagnose the meteorological conditions, and then generate a forecast. The tutorial may be a reflection of NESDIS inexperience with forecasting and user interactions; good flash flood forecasts require complex subjective decisionmaking, based on extensive data collection and analysis, as well as meteorologic expertise, that is more appropriately handled by the NWS WFOs rather than individual laypersons, e.g., canoe livery owners described in the tutorial. 


\section{Quantitative Precipitation Forecasts}

Quantitative precipitation forecasts (QPFs) have been issued by the NWS since 1960. The HPC has responsibility for generating national QPFs. The HPC currently issues 24-hour QPFs, 6-hour QPFs, 24-hour forecasts of excessive rainfall potential, and heavy snow forecasts. Schedules detailing times of forecast generation and distribution are provided at http://www.hpc.ncep.noaa.gov/qpf/qpf2.html The 6-hour

QPFs provide isohyetal contours of 6-hour rainfall totals of $0.25,0.50$, and 1.00 inches, along with expected maximum 6-hour precipitation totals. The forecasts are generated several times each day for 5 consecutive 6-hour periods, thus giving lead times out to 2430 hours. An example is provided in Figure 27. The 24-hour QPFs have varying raindepth resolution, with forecast isohyetal contours specified for 24-hour rainfall totals of $0.25,0.50,1.00$, and $>1.00$ inches. The forecasts are generated as preliminary and final products, with lead-times up to 2 days. An example is provided in Figure 28. Forecasts of excessive rainfall potential are defined according to 4 categories of occurrence over the 24-hour forecast interval: (1) rainfall may exceed flood guidance values; (2) accumulated precipitation may lead to runoff problems over large areas; (3) isolated, isolated intense thunderstorms may occur, used primarily over the U.S. West; and (4) rainfall exceeding 5 inches may occur over the remainder of the outlook period. The forecasts are issued 3 times each day, with each forecast updating the previous one and covering the same 24-hour period. They are based on the flash flood guidance issued by the various NWS River Forecast Centers. An example is provided in Figure 29. Outlooks for heavy snow are made for 30-hour forecast intervals, broken into 2 periods: 6-18 hours, and 18-30 hours into the future. The snow forecasts show snow depths expected over each 12-hour period, displayed using 4-inch isohyetal contours.

All QPFs issued by the HPC result from a forecaster combining a variety of input data with the results of several NWS meteorologic models, including the Eta, NGM, AVN, meso-Eta, and RUC models. These models and others are described in detail in the chapter on weather forecasts. A detailed review of current QPF methodologies, both operational and research, is given by Winchell (1996) and is not repeated here. Winchell notes that there is a need for more effective use of QPFs in subsequent hydrologic forecasting, but that acceptance of QPFs for operational hydrologic forecasting has been slow. The lack of computational power is not the limiting factor as in prior decades. Rather, Winchell speculates that difficulties in hydrologic use of QPFs may result from a mismatch between the areal coverage represented by QPFs and flood forecasts.

Regardless, the HPC has a variety of additional precipitation forecast products planned or in development, including 5-day QPFs, probabilistic QPFs, and total snow forecasts.

Details of verification of HPC precipitation forecasts are given by Olson et al. (1995). Verification differs between the 6-hour and 24-hour QPFs, with the former evaluated only at station locations and the latter evaluated against areal precipitation estimates. In a research mode, some QPFs have been evaluated by comparing observed stream flows with flows produced by transformation of QPFs in a hydrologic model (Georgakakos, 1986a,b; French and Krajewski, 1994). 
NWS WFOs also generated QPFs for their local area of coverage, using many of the same numerical weather models. However, WFO forecasters are able to also run higher resolution numerical weather models (e.g., MM5) focused on their local areas, that more effectively consider orographic effects. Additionally, WFO forecasters have more expertise in the subjectively combining model results with local observations and detailed understanding of local weather patterns. Thus, WFOs rely more on their own QPFs than those generated by the HPC. Further, the RFCs, especially during flood threats, rely on WFO QPFs (G. Sampson, NWS Tucson WFO, personal communication, 1999). However, the general comments made regarding HPC QPF methodologies and limitations apply to WFO QPFs as well.

Because winter storms can result in high streamflow or significant snow pack accumulation, the Salt River Project (SRP) generates 6-hour QPFs and forecasts of elevations of snow pack accumulation as conditions warrant. Although QPFs are not generated for summer monsoon thunderstorms, they are prepared when remnants of tropical storms pass through Arizona in late summer, due to the high precipitation those systems can produce over large regions. The 6-hour QPFs extend forward from the present to 2-3 days ahead and are produced by subjective combination of results from NWS Eta, NGM, AVN, Navy NOGAPS, and ECMWF numerical weather models.

SRP also generates 24-hour QPFs, as accumulated precipitation totals over specific watersheds with lead times ranging from 1-3 days, by subjectively combining results from the numerical weather models and an in-house proprietary QPF model developed by the Arizona state climatologist (B. Balling, Arizona State University). A regression model, the ASU/Balling QPF model uses $700 \mathrm{mb}$ atmospheric pressure heights and atmospheric moisture values from NWS upper air rawinsonde observations at Tucson and Winslow or Flagstaff, AZ; Desert Rock and Ely, NV; and San Diego, CA, in addition to NWS forecasts of upper air conditions. Accuracy of the QPFs produced by the ASU/Balling model, and SRP's reliance on the forecasts in operations, is considered to vary with the credibility of the NWS forecasts, although no formal evaluation has been done (SRP, 1998b).

Finally, SRP also generates QPFs and snow cover elevation forecasts over the next 3-10 days, twice each week during November-April. As with the other QPFs, SRP meteorologists subjectively combine results from a variety of numerical weather models. The NWS MRF model is used at high and low resolutions, out to 240 and 360 hours, respectively. Both the Navy NOGAPS and ECMWF models are used out to 144 hours. SRP is also beginning to incorporate the 6-10 day outlooks issued 3 times each week by the NWS NCEP. Improvements in SRP QPFs over 3-10 day intervals has "greatly improved" with the use of NWS NCEP ensemble forecasts obtained over the WWW (SRP, 1998b). 


\section{Daily Flow and Stage Forecasts}

Daily stage or discharge forecasts are made routinely by the NWS RFCs for over 4000 locations in conterminous U.S. and then issued through local NWS WFOs without modification. Stage forecasts are typically issued with 1-3 day lead times at most forecast points, while stage crests are forecast out to about 1 week for a few selected points.

However, there can be some variation in the specific temporal coverage of forecasts. The River Gage Review product (http://www.cbrfc.noaa.gov/public/hmd/review1.stage.html) provides forecasts of the peak flow expected over the next 5 days; the same forecasts are also expressed as flows as well (http://www.cbrfc.noaa.gov/public/hmd/review1.flow.html). For areas with significant recreational activity, stage or flow forecasts may be issued as River Recreational Statements. Experimental products may even extend over 2 months, e.g., the Ensemble Streamflow Prediction (ESP) traces for select locations (http://www.cbrfc.gov/public/hmd/esp/cameo/esp/glwc2ts.gif). The official operational forecasts are issued as text products, but the experimental products may be graphical; an experimental ESP forecast is presented in Figure 30.

The primary hydrologic forecasting tool used by the RFCs is the NWS River Forecast System (NWSRFS), which was initially developed in 1971 (HRL, 1972). This complex software system, comprised of over 400,000 lines of code (Fread, 1997), attempts to tie together numerous legacy computer programs for data management and modeling with new programs for graphical user interfaces (GUIs) and improved graphical output. Full documentation of the NWSRFS is available (http://hsp.nws.noaa.gov/oh/hrl/, link to "User's manuals" and "NWSRFS Manual"), but may contain outdated information. The Operational Forecast System (OFS) within the NWSRFS is used to generate streamflow or stage forecasts with lead times of up to 30 days, based on near real-time inputs of precipitation, air temperature, snow water equivalent, and river and reservoir stage data, combined with pre-determined model parameters.

Output from the OFS is deterministic, i.e., a single application of the OFS produces a single hydrograph of streamflows over the forecast period for each selected location. The Extended Streamflow Prediction (ESP) system within the NWSRFS generates probabilistic forecasts by successive implementation of the OFS with various meteorologic sequences of precipitation, air temperature, and potential evaporation extracted from the historic record. Figure 30 illustrates the variety of river discharge hydrographs possible using common initial conditions with variable meteorologic inputs. ESP forecasts are comprised of statistics (e.g., quantiles) describing the ensemble of individual streamflow traces, or ensemble members; to better reflect the basis for ESP forecasts, they are also termed Ensemble Streamflow Prediction (ESP) forecasts within the NWS. New GUIs allow forecasters to change model parameters interactively until updated model outputs of current flows or basin moisture storage conditions are consistent with recent observations.

Forecasts are determined by use of continuous hydrologic models with spatially lumped parameters and precipitation inputs. The relatively simplistic Antecedent 
Precipitation Index (API) model is still used for some forecasts (e.g., the Susquehannah River Basin in the northeastern U.S.), including some basins within Arizona (Secs. II.3.3 and V.3.3.10 of HRL, 1998b). API techniques were first developed in the 1940s (Kohler, 1944) and allowed modeling only on an event basis; i.e., for single storm events. Current implementations are computerized, but conceptually are little changed from earlier operational formulations (Kohler and Linsley, 1951; Kohler et al., 1958; McCallister, 1963). Changes were made in the 1960s (Sittner et al., 1969) enabling index values to be tracked continuously rather than only on an event basis; the model has been subsequently simplified (Nemec and Sittner, 1982). The current implementation at the CBRFC uses daily API values, 6-hourly basin rainfall and melt, and daily percent areal snow cover to generate runoff at 6-hour intervals.

However, the RFCs rely primarily on the Sacramento Soil Moisture Accounting (SAC-SMA) model to generate forecasts for watersheds with hydrologic response times greater than 12 hours. Initially developed in the early 1970s, the SAC-SMA has been described in many venues (Burnash et al, 1973; Burnash, 1995) and is not repeated herein; current implementations are described in Secs. II.3.5, V.3.3.66, and V.3.3.70 of HRL (1998b). The Colorado Basin RFC predominately uses the SAC-SMA as the continuous hydrologic model within the NWSRFS; however, it has not been implemented for all watersheds within the Colorado Basin.

Snow accumulation and ablation are modeled using the SNOW-17 model, which was evolved from snow models developed in the 1960s (Anderson and Crawford, 1964; Anderson, 1968). The current implementation is only slightly changed from that described by Anderson (1973) and is not repeated herein (see also Secs. II.2.1 and V.3.3.68 of HRL, 1998b). A state-space version of SNOW-17, called the NWS-43 snow model, has also been developed (Day, 1990). NWS-43 incorporates Kalman filtering to update model simulations using observed areal estimates of snow water equivalent; current implementation details are described in Secs. II.2.2 and V.3.3.69 of HRL (1998b).

Forecasters can subjectively modify some aspects of the OFS to improve the generated forecasts, including adjusting input time series, unit hydrograph values, or baseflow values; selecting precipitation type (rain or snow); or using the SAC-SMA frozen ground option or others within SNOW-17 and NWS-43. Flows at downstream locations may incorporate forecasts made for upstream locations, shifted downstream using one of several routing operations.

\section{Ensemble Forecasts}

The NWS developed the Extended Streamflow Prediction (ESP) approach to address several issues associated with the use of meteorologic forecasts with conceptual hydrologic models for making water supply outlooks (Day, 1985). The approach has evolved somewhat and is now also known as Ensemble Streamflow Prediction (ESP) and can be used for both short- and long-range hydrologic forecasts. Within ESP, multiple meteorologic time series selected from the historic record are used as independent input sequences for the SAC-SMA model (or any conceptual hydrologic model), generating 
multiple basin runoff time series. Each model simulation begins with the same estimates of current basin conditions (e.g., soil moisture, snow water equivalent) for model initialization. Each time series used in considered an ensemble member. Because use of conceptual models produces hydrographs, forecasts can be made for a variety of hydrologic characteristics, e.g., peak flows, minimum flows, total volumes.

A deterministic forecast can be generated by averaging all or selected runoff ensemble members. Alternatively, a probabilistic forecast can be generated by using each meteorologic sequence to produce multiple hydrologic forecasts, and then performing frequency analysis to define a probability distribution (Croley and Hartmann, 1984). The original NWS ESP approach assumed that all historic sequences were equally likely to recur, and thus did not consider the skill of available climate outlooks. Suggested improvements to ESP include objectively assigning weights to historic sequences according to their similarity to meteorologic conditions of the current year (Day, 1985). However, current operational procedures require the forecaster to subjectively assign the weights, resulting in non-use of ESP procedures (Perica, 1998).

Croley and Hartmann (1987) developed an approach to eliminate unlikely scenarios from consideration based on the CPC climate outlooks. After reading the forecast probabilities from the CPC climate outlooks, meteorologic quantile nonexceedance probability tables for the same months are scanned to identify several years of the historic record that best match the climate outlooks over the months of the forecast period. The nonexceedance probabilities are estimated by the relative number of days that temperature or precipitation did not exceed the quantiles used in the CPC outlooks (were the $30 \%$ and $70 \%$ quantiles, now the lower and upper terciles). Typically, many years of the historic record have nonexceedance probabilities that match, within 36 percentage points, the CPC probability outlooks for a single category (e.g., 1-month precipitation, 3-month temperature). However, few years match the CPC outlooks for all categories. Compromises are often required (e.g., sacrificing a close match on the 3month precipitation probabilities but getting matches within 3 percentage points for the remaining categories) in selecting the typical 3-5 corresponding periods from the historic record that best reflect the $\mathrm{CPC}$ climate outlook. The historic daily values of areally averaged temperatures and precipitation, corresponding to the months of the forecast period, are then taken from the historic record and used as the forecast meteorologic sequences. Thus, the spatial and temporal interdependencies of the meteorologic processes are preserved. Admittedly, the extremes are limited to only those of record, but this is not considered a problem when area averages are used, corresponding to large areas that do not have as extreme conditions as small areas. Forecasts of ancillary input meteorology are taken directly from the same identified period of the historic records as used for temperature and precipitation. In the absence of conceptual modeling of these ancillary variables, the historic values provide a simple estimate of future conditions; as they are derived from the same identified historic period as the temperature and precipitation used, the spatial and temporal interdependencies between all meteorologic processes are still preserved. Uncertainties in the hydrologic forecasts are then reflected by the uncertainties of the climate outlooks. 
With the extension of CPC climate outlooks to include 13 3-month outlooks as well as the 1-month outlook for the next month, the approach of Croley and Hartmann (1987) became difficult to implement. Croley (1996) developed an automated approach that corresponds to restructuring the historic meteorologic record to match the CPC climate outlook probabilities. The restructuring duplicates periods from the historic record, corresponding to the respective CPC outlook periods, until the relative frequencies of average air temperature and precipitation match the probabilities of the climate outlooks. While the sequences in the restructured historic record are neither independent nor equally likely and thus do not constitute a random sample, they can be considered a random sample conditioned on the climate outlooks. Computational efficiency is achieved by simultaneous solution of equations to determine the weights to apply to individual sequences within the historic record, rather than having to duplicate the sequences. However, the relative importance of each outlook (e.g., 1-month temperature, 1-month precipitation, 1-month lead 3-month temperature, 8-month lead 3month precipitation) must be made explicit to handle incompatibilities that may occur between different climate outlooks. Simultaneous use of areally averaged temperatures and precipitation, and ancillary data, from the same period in the historic record, for runoff model input preserves the spatial and temporal interdependencies among meteorologic processes.

Other approaches for meteorologic selection have been or are being considered by the NWS as well. One approach involves identifying relationships between streamflow and large-scale atmospheric patterns (e.g., ENSO) and then transforming those associations into weights (Georgakakos and Guetter, 1995). Another approach uses singular value decomposition to relate meteorologic forecasts to historic meteorologic patterns and then weight the historic sequences appropriately (Bretherton et al, 1992; Ingram et al, 1995). Still other approaches attempt to simultaneously consider a variety of short- and long-range meteorologic forecasts. Perica (1998) adjusts each historic meteorologic sequence to match the distributional characteristics of 1- to 5-day weather forecasts, 6- to 10-day weather forecasts, monthly climate outlooks, and the 13 3-month climate outlooks. The approach assumes that temperature and precipitation have, respectively, normal and gamma distributions. Adjustment factors are determined by comparing the probability anomaly statement of the appropriate meteorologic forecast with a fitted distribution based on historic meteorology. The adjustment is then applied directly to each historic meteorologic sequence. In order to test this approach, automated procedures for making ESP hindcasts have been developed by the NWS Office of Hydrology $(\mathrm{OH})$. The procedures enable generation of ESP forecasts, in a simulated operational setting, over an extended period of the past. Generation and evaluation of these hindcasts is synonymous with reanalysis efforts typically performed in climate modeling evaluation.

\section{Local WFO Hydrologic Forecasts}

Local WFOs may also generate other short-term flow and stage forecasts using a system, the WFO Hydrologic Forecast System (WHFS). The system was developed especially for the WFOs under efforts related to the NWS modernization program, by the 
NWS OH. The Site-Specific Hydrologic Prediction System (SSHPS) within WHFS generates stage and flow forecasts for headwater river locations; use at the WFOs will still require RFC support, however. The SSHPS is an interactive subset of the river modeling software used by the RFCs (e.g., NWSRFS), set up for specific WFO Hydrologic Service Area (HSAs) applications. The SSHPS includes tools for graphical display and modification of stream flow and stage hydrographs and precipitation hyetographs. However, the essential core of the system consists of hydrologic modeling tools, including rainfall-runoff models for determining the amount of areal precipitation that enters the stream as runoff, unit hydrographs for converting input runoff into stream flows, and stage-discharge rating curves for converting stream discharge to stage elevations. Some installations also include snowmelt models, different model formulations, and procedures for adjusting model behavior or time series. Typically, the appropriate RFC provides the calibrated modeling tools; they also routinely update estimates of basin moisture storage conditions (e.g., soil moisture, snow water equivalent), often daily. WFOs then provide mean areal precipitation (MAP) inputs for selected periods, typically 1-3 hours. However, official flow and stage forecasts are still generated by the RFCs, with WFOs simply issuing them without modification.

\subsection{Long-Range Forecasts}

While hydrometeorologic dynamics are complex, non-linear, and highly variable in both space and time, longer-term water supply forecasts are practical in the U.S. West, including the Southwest, because most usable water supplies in the region originate as mountain snowfall. Accumulation of snow over the winter season provides an intrinsic system memory that affects water supplies throughout the subsequent spring and summer. In the Southwest, the relationship between winter snowpack and resulting runoff is particularly strong because late spring and early summer have little additional precipitation. Further, rains associated with the summer monsoon typically produce only transient local effects, with little impact on useable water supplies in larger basins. This occurs because summer monsoon rains have high spatial and temporal variability, and evaporation and evapotranspiration are large relative to the rainfall.

\section{Flood Potential Outlooks}

Flood potential outlooks are issued by NWS WFOs as simple text discussions, although they are based on quantitative guidance from the RFCs. A common threshold for identifying flood flows is exceedance of the capacity of the stream channel; i.e., overtopping the streambanks. However, the NWS defines flood flows based on the initiation of damages; overbank flows may occur, but not result in damages. Thus, the NWS flood flow thresholds can change from year to year due to changes in channel characteristics, but also over longer periods due to changes in damage vulnerability.

\section{Snowmelt Peak Flow Forecasts}

The NWS CBRFC issues snowmelt peak flow forecasts each month during March-June and March-April for the Upper and Lower Colorado basins, respectively. 
Forecasts are available as published documents (e.g., CBRFC, 1992a) or electronically (http://www.cbrfc.gov/public/peak/). Snowmelt peak flow forecasts predict the maximum mean daily flow, expected to occur at a specific river location sometime during the identified snowmelt period, resulting from melt of the past winter's accumulated snow pack. For most locations in the West snowmelt peak flows occur during April-July, except in Arizona where the normal snowmelt period is March-May. Snowmelt peak flows are not instantaneous flows, but averaged over an entire day. However, when snowmelt is unaffected by unusual short-term events (e.g., rainfall, unusually warm air masses), hydrographs of the mean daily and instantaneous flows may be highly correlated.

Snowmelt peak flows differ from water supply outlooks (described subsequently) because the peak flows describe actual flows, incorporating the effects of regulations and diversions as appropriate. Because human impacts are difficult to forecast, especially during extreme conditions, peak flow forecast locations in the Colorado River Basin are generally restricted to headwater locations, where human impacts are minimal. However, peak flow forecasts are also made for some locations where regulation effects are highly correlated with natural flows and relatively unchanging from year to year. Snowmelt peak flow forecast locations are shown at http://www.cbrfc.gov/public/peak/1998/fcstpts.html and in Figures 31 and 32, for site locations and recreational river reaches, respectively.

Snowmelt peak flow forecasts are provided in tabular format as a set of 5 different probabilities of exceedance $(90,75,50,25$, and $10 \%$ exceedance quantiles). Those flows are placed in historical context via comparison with historic peak flows (largest mean daily flow in the entire period of record), average peak flows (mean of peak flows from period of record through 1990), flood flows, and the normal time that peak flows occur (range over period of record through 1990). The NWS flood flow definition is unusual; flood flows are not those that overtop the streambank, but rather the flows at which damages begin to occur. Due to changing channel characteristics and damage vulnerability, flood flow thresholds may vary each year at the same location. When flows have not yet peaked, but already exceed any of the forecast quantiles, values are simply not listed for those quantiles (e.g., http://www.cbrfc.gov/public/peak/1998/ucmay98.html). When flows have peaked, the forecasts may still provide a $10 \%$ exceedance probability forecast showing high flows that could occur with current basin conditions and possible future rainfall (e.g., http://www.cbrfc.gov/public/peak/1998/lcapr98.html).

Snowmelt peak flow forecasts are generated using either statistical regression or physically-based conceptual models (i.e., the SAC-SMA model), the latter applied in Extended Streamflow Prediction (ESP) mode. No identification is made concerning which methodology was used for any specific forecast, although that would affect the appropriate interpretation attributable to the forecast quantiles; regression quantiles result from error analysis while ESP quantiles result from ranking an ensemble of modeled forecasts (see discussion under water supply outlooks). Conceptual modeling requires forecasts of reservoir operations up to 5 months ahead, so it is generally restricted to 
headwater locations subject to only minimal regulation. Forecasts on the Green River below Flaming Gorge and the San Juan River below Navajo Reservoir incorporate Bureau of Reclamation regulation plans. Calibration of the regression or conceptual models uses historic maximum mean daily flows over March-May, even though peak flows may actually occur outside that period and the forecast period may be different (e.g., April-July for Upper Colorado locations). Further, those maximum daily flows are not selected to exclude unusual events that can produce higher peak flows than from routine snowmelt, e.g., rain-on-snow events, chinook conditions.

Snowmelt peak flow forecasts have large uncertainty because they attempt to predict a short-period event with long and indeterminate lead times. The CBRFC warns that the forecasts are much more uncertain than the water supply outlooks, but also says that users can have a "high degree of confidence" in the forecasts when the quantile ranges are narrow. No evaluations of performance of snowmelt peak flow forecasts have been made, however. Archives of past peak flow forecasts are available on-line, beginning in 1996 (http://www.cbrfc.noaa.gov/public/for/peak/).

\section{Water Supply Outlooks}

The official U.S. government water supply outlooks for the western U.S. are issued jointly by the NOAA NWS River Basin Forecast Centers and the Department of Agriculture (USDA) Natural Resources Conservation Service (NRCS) National Water and Climate Center (NWCC). Each agency uses their own in-house techniques to make provisional outlooks, which are then coordinated into a single final official product. Outlooks made for the Salt and Verde River basins also incorporate, via coordination, forecasts made by the Salt River Project (SRP) using their internal proprietary techniques. Coordination occurs through meetings of representatives of each of the agencies, with each agency bringing results from their suite of internal forecasting techniques. Other agencies may contribute ancillary data and participate in the coordination meetings as well, including BuRec, USGS, and local water districts. During the coordination meetings, the strengths and limitations of individual forecasts are subjectively assessed, forecaster expertise is used in making tradeoffs between forecasts, and a final set of forecast values is selected. If all individual forecasts are consistent, then the agencies have high confidence in the coordinated water supply outlooks, although that confidence is not explicitly expressed in the outlooks.

The NWS is a relative newcomer to seasonal water supply forecast arena, with the NRCS (as the Soil Conservation Service) issuing water supply outlooks since the 1930s (Shafer and Huddleston, 1984). The NWS issues the coordinated water supply outlooks, January - May, in a format different that that of the NRCS (described subsequently). For locations within the Colorado River basin, the CBRFC issues outlooks beginning in January, with both monthly and mid-monthly updates. Separate hard-copy Water Supply Outlook Reports are issued for the upper Colorado and lower Colorado basins (e.g., CBRFC, 1992a,b); parts of the Colorado basin are also included in hard-copy reports for Utah (e.g., CBRFC, 1992c). Outlooks are provided for entire watersheds (Table 10) and for specific river locations (Figure 33 for the lower Colorado basin). While water supply 
outlooks are issued in various graphical formats, they are typically simplistic and contain less information than the associated outlooks in tabular format.

Table 10. Watersheds in the U.S. Southwest for which water supply outlooks are made. ${ }^{1}$

Lower Colorado Basin

Salt River/Verde River/Tonto Creek

Gila River

Little Colorado

Upper Colorado Mainstem

Colorado River

Gunnison River

Dolores River

Green River

Upper Green River

Yampa/White Rivers

Lower Green River

San Juan River

Virgin River

${ }^{1}$ From CBRFC, 1992a,b,c.

The period covered by each water supply forecast varies spatially and temporally. For watersheds in the upper Colorado basin, the forecast period typically covers 1 April 31 July, although some basins have forecast periods covering 1 March - 31 July or 1 April - 1 September. Outlooks issued 1 May or later are different than those issued earlier, in that part of the forecast period covers the past (i.e., April). Watersheds in the lower Colorado basin have an earlier and shorter spring runoff season. Their forecast periods typically cover earlier periods and get shorter as the forecast season progresses. The forecast period shifts from 1 January - 31 May for outlooks issued in January, to 1 April - 31 May for outlooks issued in April. Forecast periods extend through June or July for some basins, however. Water supply outlooks are generally separated into monthly periods within the total forecast period. Alternatively, they may show individual volume forecasts for some months early in the season and then as a several-month total for the later months. For example, forecasts of flows into Lake Powell, issued 5 January 1998, show seasonal total volumes (January-July), monthly volumes (January, February, March), and a 3-month volume (April-July) (http://elk.cbrfc.gov/public/for/afos/esp/1998/SLCESPSLR.0105).

Water supply outlooks are given as "naturalized" runoff volumes, i.e., flows without any water management influence. Thus, practical use of the outlooks for anything more sophisticated than getting a general sense of potential conditions, requires users to adjust the projected runoff volumes for anticipated diversions, reservoir regulations, and other hydrologic manipulations over the forecast period. These adjustments can be complex (CBRFC, undated) and not every management impact is documented. The limited adjustments made can still be significant. April-July forecasts for the Colorado River near Cisco, UT (see Figure 34), require 34 adjustments for diversions or reservoir storage that cumulatively reduce naturalized flows by about $30 \%$. 
Adjustments of naturalized flows may produce values less than zero, especially for extreme downstream locations along some tributaries. Additionally, the values used for the adjustments are only simple projections based on typical management decisions rather than the actual values. During times of extreme conditions, there may be large deviations from typical management decisions, making adjustments to the projected naturalized flows even less certain. The complexity of adjustments for naturalization, the certainty of their incompleteness, and the potential for gross errors, especially during extreme drought, is clear when the high level of human interference with Colorado River flows is realized. In the lower Colorado River alone, there are over 200 water contractors, with almost 100 subcontractors, diversions at 63 locations, and 5000-10,000 groundwater wells that pump Colorado River water (BuRec, 1998b); certainly not all those impacts are considered in the published adjustments to naturalized flows.

Adjustments used for recent years (1996-1998) are available at http://www.cbrfc.noaa.gov/public/for/guide/.

Water supply outlooks are given as exceedance probabilities, but the names given to those probabilities may be misleading to users that don't have access to skilled interpretation. In the outlook reports, the "most probable forecast" is described as the "the best estimate of what the actual runoff volume will be this season", based on the current hydrometeorologic conditions up to the date of forecast production (CBRFC, undated). For most of the forecast locations, flows are assumed to have a normal distribution, so that both the mean and median flow volumes are identical, and the mean value does indeed represent the expected value, or most probable value, of the flow volume distribution.

However, for locations in the lower Colorado River basin below Lake Powell, flow volumes distributions are too highly skewed to reasonably approximate flows with a normal distribution. Low flows have a high frequency of occurrence, while high flows may be extremely high, but occur only infrequently. Thus, forecasts are given as median values; over many forecasts, the median forecast will produce the least total forecast error, but the probability of that specific flow volume actually occurring is no greater than any other specific flow volume. Rather, the proper interpretation of the median water supply outlook is that there is a $50 \%$ probability that water supplies will actually be above that specific flow volume and an equivalent $50 \%$ probability that water supplies will actually be below that specific flow volume. Stakeholders that use the "most probable" interpretation of the median forecast may be attributing an incorrectly high probability to that value and are likely to be disappointed in the forecast.

In the NWS RFC water supply outlooks, the $10 \%$ and $90 \%$ exceedance quantiles are termed the reasonable maximum and reasonable minimum forecasts. However, the reasonableness of the forecast depends on the occurrence of typical climate conditions; when NWS CPC monthly and seasonal climate outlooks show anticipated climate anomalies, the water supply outlooks become less reasonable, since they consider only typical hydrometeorologic inputs. Further, terming those quantiles "reasonable" may suggest to stakeholders that they are reasonable values for use in decision making, when 
the most appropriate values are highly dependent on the risk tolerance and loss functions that are unique to each stakeholder.

Other potential confusion about the water supply outlooks derives from documentation about how the forecasts are made (CBRFC, undated). The CBRFC says that forecasting of natural flows "can be done well". The documentation also says that "the relationship between observable hydrologic parameters (e.g., precipitation, snowpack, terrain, etc.) and natural runoff is predictable and well-defined". While presented in the context of why forecasts are made for naturalized flows rather than flows that incorporate management practices, at face value the comments overstate forecast capabilities. This sets the stage for inevitable user disillusionment when their experience with the forecasts inevitably show significant error.

The NRCS issues the coordinated water supply outlooks for each of the mountainous western states on the first of each month, January through June. Outlooks are available as printed publications or electronically (http://www.wcc.nrcs.usda.gov/water/quantity/westwide.html). The statistical regression techniques they use to generate the forecasts are similar to those used by the NWS RFCs, because they were initially developed within the NRCS (when the agency was still known as the USDA Soil Conservation Service). Typically, only the choice of specific variables used in the regression and the regression coefficient values are different. Details of the statistical regression technique are presented later in this chapter.

The NRCS NWCC water supply outlooks are provided in a different format that the NWS RFC outlooks. Both products, however, are based on the inter-agency coordinated forecasts. The median forecast is still termed the "most probable" forecast. However, the terms "reasonable maximum" and "reasonable minimum" are not used, and the outlooks also contain forecasts of the $30 \%$ and $70 \%$ exceedance quantiles. Additionally, on-line documentation provides guidance for use of different exceedance quantile forecasts to accommodate varying levels of stakeholder risk tolerance (http://www.wcc.nrcs.usda.gov/factpub/intrpret.html). For some forecast locations, the values listed under the $10 \%$ and $90 \%$ exceedance quantiles are actually the $5 \%$ and $95 \%$ exceedance quantiles, respectively, creating the potential for misunderstanding of the forecasts, and confusion with the NWS RFC outlooks; those locations are generally outside the Southwest, however.

Exceedance quantiles in the coordinated outlooks, whether issued by the NRCS or CBRFC, have a very specific interpretation, based on error analysis of the regression model. Given statistical assumptions of linearity and normality, the distribution of regression errors can be directly translated to exceedance quantiles for flow volumes. Thus, a water supply forecast is actually a forecast of a normal distribution, with the mean given by the regression equation and the standard deviation given by the standard error of the regression. Locations with skewed flows require transformation (e.g., log or square root transforms) to meet normality assumptions. When flow forecasts from the regression equations are changed during coordination, however, the interpretation of the exceedance quantiles becomes problematic (Garen, undated, b). The forecasts, as issued, shift the entire error distribution by having the coordinated forecast represent the mean of 
the error distribution. It would be more desirable to describe the coordinated forecast as having some exceedance probability with a separately defined confidence interval. Currently, if the water supply outlooks generated by the individual agencies are consistent, the agencies have high confidence in the coordinated outlooks. However, statements about that kind of confidence are not provided with the coordinated forecasts issued by any of the agencies.

Variants of the standard water supply outlooks also occur, creating additional potential for user confusion. Flood control forecasts, made for several reservoirs in the Upper Colorado basin, are simply water supply outlooks with fewer upstream adjustments (CBRFC, 1992b), although the details of those different adjustments are not provided. Water supply outlooks may also be issued for periods different than described above. For example, on 8 September 1998, the CBRFC issued water supply outlooks, for specific river locations in Arizona, covering 8-30 September (http://elk.cbrfc.gov/public/for/afos/esp/1998/SLCESPAZ.0909). Another outlook issued the same date provides forecasts of reservoir inflows for the coming months of September, October, and November (http://elk.cbrfc.gov/public/for/afos/esp/1998/SLCESPSLR.0909). The header code associated with those outlooks indicates that they were made using conceptual runoff models in an ESP mode, although no explanation accompanies the forecasts. Similar outlooks, issued aperiodically since 1996, are stored at http://elk.cbrfc.gov/public/for/afos/esp/.

The specific techniques used to create water supply outlooks and their variants are typically not identified with individual forecasts. They may be generated using statistical regression techniques or conceptual rainfall-runoff models applied in different ways. Proper interpretation of the outlook quantiles and the confidence associated with the outlooks varies, depending on the forecast technique used.

\section{Statistical Forecast Techniques}

Most operational water supply outlooks are generated using multiple linear regression techniques developed by the NRCS and transferred to the NWS RFCs. Implementations vary between the two agencies only in specific equation formulations. Unique regressions for each forecast period and location are developed using subsets of monthly or seasonal observations of precipitation, streamflow, and ground-based snow conditions, and routed streamflows. However, the equations are developed with one goal being consistency in the variables used from month to month. The regression equations produce seasonal volumes, dissaggregated into volumes for each month within the forecast period.

The choice of variables to be included in each regression equation are determined subjectively; suggested procedures and considerations are outlined in CBRFC internal seminar notes (CBRFC, 1992). Typically, antecedent soil moisture is represented by using prior autumn precipitation or runoff as regression variables. Winter season precipitation stored on the basin is usually represented by variables for snow water 
equivalent or winter precipitation; snow values may be from SNOTEL sites or manual snow course measurements. Precipitation during the spring snowmelt period is represented in the regression directly, using spring precipitation. Some regression equations may include forecasts from upstream locations, routed downstream. Southern Oscillation Index (SOI) values and even seasonal CPC outlooks can be incorporated in the regression equations, although only SOI is presently used and only for a few Arizona locations (e.g., along the Gila River). Figures 35 and 36 show that correlations between SOI and spring and summer runoff volumes in the U.S. West can be significant (NRCS, 1997).

Regression variables may be normalized using transformations or decorrelated using principal component analysis. Transformations are important when flows are highly skewed, such as occurs for several Arizona Rivers (e.g., the Gila River). Principal component analysis is important when several variables are highly cross-correlated (e.g., seasonal precipitation and snow water equivalent).

The "best estimate" forecast descriptions based on statistical forecast techniques derive from considering forecast error to be normally distributed, with the mean centered about the forecast. The various exceedance quantiles (e.g., 10\%, 90\%) simply result from using different fractions of the error distribution and do not represent estimates of $10 \%$ or 90\% exceedance flow volumes. As explained in detail by Garen (undated a,b), the water supply forecasts are most appropriately considered to be conditional probabilities, with the distribution mean given by the regression equation and the distribution standard deviation given by the standard error of the regression. Because the regression standard error compares forecast and actual water supplies, implicitly it incorporates all sources of forecast uncertainty, including regression model error and non-forecast weather variability during the forecast period.

Forecasts based on transformed flows (e.g., log or square root transformations) have normal distributions of error and forecasts only in the transformed space. When the transform is inverted back to water supply volumes, the error distribution becomes asymmetrical with larger variance above the median and smaller variance below the median. Additionally, the variance of the error distribution is larger for high flows and smaller for low flows.

\section{Conceptual Dynamic Modeling Forecast Techniques}

The CBRFC also concurrently generates experimental water supply outlooks using ESP with SAC-SMA and historic meteorology. However, forecasts are generally considered for internal evaluation only, although some can be accessed electronically (http://elk.cbrfc.gov/public/for/afos/esp/). Use of conceptual hydrologic models offers several advantages over the operational statistical techniques. First, the conceptual models enable consideration of conditions not represented in the historic record. Second, the conceptual models produce streamflow time series that can be subsequently analyzed to forecast peak flows, low flows, cumulative flow volumes, and other water supply characteristics. 
Forecasts of water supplies based on conceptual models require a meteorologic forecast. The selection of the forecast meteorology is important and difficult; the resulting water supply forecasts will be no better than the forecast of air temperatures and precipitation used in simulation. A standard method involves using mean or median air temperatures and precipitation, selected from the historic record, as the estimate of the most likely meteorology for the future. That method does not recognize the limited skill that exists for predicting the climate and ignores the interdependencies that exist between air temperature and precipitation. Since mean or median air temperatures do not usually occur at the same time as mean or median precipitation, their use together introduces biases into the forecast. An alternative method involves estimation of statistical models of the time series of air temperatures and precipitation. This approach, however, involves considerable uncertainty in the selection of the appropriate multivariate model that adequately relates the meteorologic processes at many points over the basin. The spatial and temporal interdependencies of all meteorologic variables would be difficult to capture with any confidence. Rather, a workable method is needed that preserves the spatial and temporal interdependencies of all meteorologic variables and that recognizes the limited skill of available climate outlooks.

\section{Other Forecast Techniques}

Salt River Project (SRP) long-range water supply forecast techniques are based around a long-range precipitation model developed by Entropy Limited; the model is proprietary to SRP and unavailable for use by others. The Entropy precipitation model evaluates spatial patterns and temporal trends in SSTs, air temperatures, and precipitation at various locations throughout the Pacific Basin using 4 different pattern recognition schemes. The model produces a forecast of the probability of accumulated 3-month seasonal Salt River watershed precipitation being above or below the historic median. Confidence levels are determined by evaluating the similarity of results from the different pattern recognition schemes. SRP uses a regression model and SCS curve numbers to convert the seasonal precipitation probability forecasts into quantitative water supply forecasts. These results are then compared to subjective evaluations based on staff understanding of watershed moisture storage conditions (e.g., snowpack), monitoring of Pacific SSTs and ENSO indices, and tracking of NWS CPC climate outlook maps and discussions. Water supply outlooks are usually generated beginning in October for December-March, with updates occurring monthly, or more often if conditions change abruptly. Water supply outlooks may also be produced beyond March, particularly during winters that experience continuing accumulations of snow pack, e.g., in warm El Nino winters.

\section{Water Supply Forecast Assessments}

Within the hydrologic community generally, forecast evaluations are rather limited. Participants at the Forecast Assessment Workshop recalled failed efforts in the late 1970s to compare operational performance of various hydrologic models and forecasts. Conflict arose over the basins to use in the comparisons, specific data sets to use, periods for comparison, and techniques for evaluation, among others. The overall sense of the situation was that the hydrologists and their institutions had too much at 
stake, professionally and financially, to risk their tools proving inferior to others in a head-to-head comparison.

NRCS and NWS RFC regression equations are evaluated as they are created, using standard error computed directly and as regression parameters vary with successive data elimination (termed jackknife error analysis by the CBRFC). SRP has no formal quantitative verification program for evaluating their water supply outlooks. The consensus view of participants in the Forecast Assessment Workshop was that forecasts issued in mid-March or April for the lower Colorado River watersheds are generally the most accurate, because these basins see little additional precipitation in late spring or early summer. The consensus view was also that the regression models provide more reliable water supply outlooks than the conceptual models used for ESP forecasts. Additionally, if the water supply outlooks generated by the individual agencies are consistent, the agencies have high confidence in the coordinated outlooks. However, statements about that kind of confidence are not provided with the coordinated forecasts issued by any of the agencies.

The most recent comprehensive evaluation of seasonal water supply outlooks is that of Shafer and Huddleston (1984). Earlier efforts focus on alternative statistical forecasting techniques, including Work and Beaumont (1958), Zuzel and Cox (1978), McCuen et al (1979), Lettenmaier and Garen (1979), and Hannaford et al (1980). Shafer and Huddleston (1984) assumed that all forecasts in the U.S. West and within each state were from the same population, in order to obtain sufficient sample sizes for standard statistical tests. Regional groupings of forecasts used 345 stations with at least 10 years of data, and another 206 stations with at least 30 years of data covering 1951-1980. New Mexico stations were combined with Colorado stations with a total of 45 stations used; Arizona was represented by 11 stations. Forecast error was expressed relative to average seasonal water supply volumes to avoid misleadingly high errors during low flow conditions. Table 11 shows selected results for the U.S. Southwest.

Of 302 March 1 forecasts (covering March-May) from 11 locations in Arizona, $56 \%$ were too high. In contrast, of 1296 April 1 forecasts (covering a mix of AprilSeptember and March-July) from 45 locations in New Mexico and Colorado, 58\% were too low. In general, however, for the entire U.S. West, Shafer and Huddleston (1984) found that the extreme forecast errors $(>50 \%)$ tended to be significant underestimates of high seasonal flows. This results because spring weather conditions that can significantly affect runoff are more likely to produce more flow (i.e., high precipitation) than lower flow (i.e., high evaporation or sublimation).

Because different regions have flows with varying degrees of variability, Shafer and Huddleston (1984) also computed a comparative forecast skill coefficient. The skill score is computed as the ratio of the sum of absolute differences between observed and average seasonal flows, and the sum of absolute differences between observed and forecast seasonal flows. A skill score of 1.0 indicates that the forecasts have no more skill than just using the average seasonal flow as a forecast. A skill score of 2.0 indicates that the regression forecasts have only half the error produced by simply using the 
average seasonal flow as a forecast. While March 1 forecasts (March-May) for Arizona had the largest average forecast error of all the states in the U.S. West, they had the second highest skill score (about 2.1).

Table 11. Selected water supply outlook performance statistics from Shafer and Huddleston (1984).

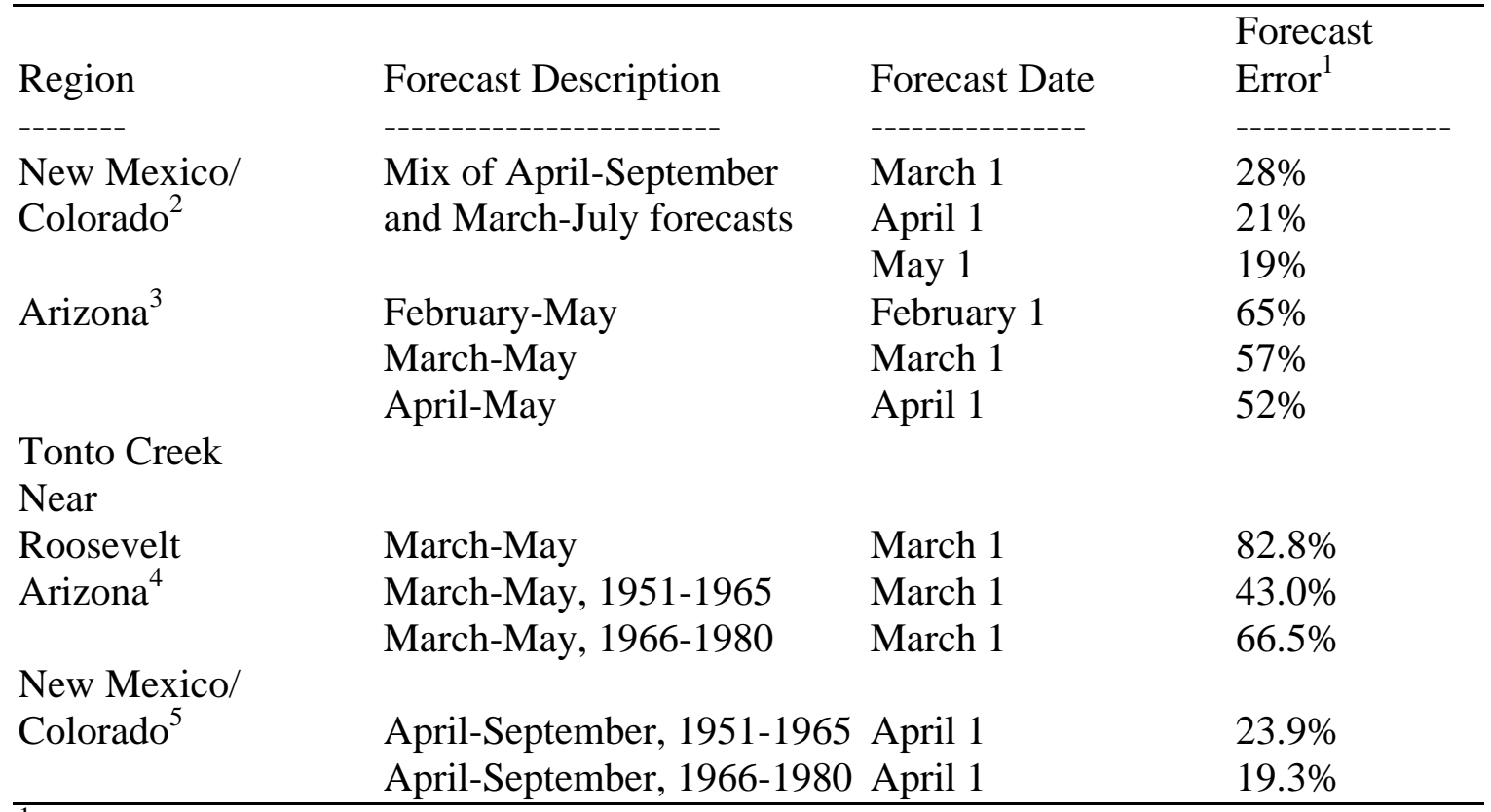

${ }^{1}$ Forecast error is average error relative to published average seasonal flow at the time of forecast.

${ }^{2}$ Stations $=45$.

${ }^{3}$ Stations $=11$.

${ }^{4}$ Stations $=6$.

${ }^{5}$ Stations $=31$.

A split sample analysis allowed Shafer and Huddleston (1984) to assess trends in forecast quality. They divided the record of water supply outlooks into 2 periods, 19511965 and 1966-1980. For states in the Southwest, changes in forecast error statistics (see Table 10) followed changes in variability of observed flows as measured by the coefficient of variation. While Arizona forecasts performed more poorly over 19661980, the coefficient of variation increased from 1.04 to 1.10 between the split sample periods. In contrast, the coefficient of variation for New Mexico/Colorado decreased from 0.50 to 0.44 between the split sample periods.

Comprehensive evaluations of the statistical water supply outlooks are limited by a lack of computerized data, details about the regression equations used, and records indicating when methodological changes were implemented. Potential assessments are also limited by the small sample size available, because few outlooks are issued each year and there is high correlation among the forecasts within a water supply season. Although hydrologic forecast techniques have changed repeatedly, with little record of their timing, 
it is still appropriate to assess the historical archive of forecasts. Actual forecasts are what users have responded to in their decision making (where they have used forecasts) or at least what they could have used in decision making. Such a historical approach is more realistic for an assessment of vulnerability and the role of forecasts than reanalysis studies. Reanalysis studies are better suited to evaluating skill of specific forecast techniques or the potential for improved decision making. A reanalysis study uses current methods to recreate a "historical" sequence of forecasts, representing the forecasts that would have resulted from the use of current technologies.

The NRCS recently developed a database of coordinated forecasts back to 1940, but it contains only the "most probable" forecast and the "actual" naturalized flows. CLIMAS researchers are expanding that database to include various quantile forecasts, through manual entry of historic coordinated water supply outlook reports. No records are available, within the NRCS or CBRFC, to indicate when statistical techniques or regression equation calibrations were changed, however. Since 1995, the CBRFC has been storing the water supply outlooks, issued from January-May, in a computerized database (http://www.cbrfc.gov/public/westwide/). The CBRFC has also been electronically storing results of their experimental ESP forecasts since 1995, but they are too few for adequate retrospective analysis. However, the NWS OH has procedures in place to recreate ESP forecasts in a simulated operational setting using historic hydrometerologic data (J. Shaake, 1998, personal communication). No RFC has yet used those procedures to evaluate their ESP forecasts. Finally, since July 1983 the NWS Surface Records Retention System (SRRS) has been automatically storing all NWS products, including water supply forecasts, in a master archive maintained by the NCDC. Retrieval of forecasts would incur significant costs (see http://ftp.ncdc.noaa.gov/pub/data/documentlibrary/pricelists/srrspric.doc). Further, there is a lack of experience in using the SRRS to access archived products, even within the NWS hydrologic groups, and the system is perceived as cumbersome.

Agency perceptions about the desired accuracy of water supply outlooks were explored during the Forecast Assessment Workshop. Workshop participants agreed in their perception that users themselves lack deep understanding of their own needs, making it difficult for the agencies to understand those needs. Perceptions of users needs include perfect deterministic forecasts, 5\% error for 1-year lead time forecasts, and $75 \%$ accuracy. Participants also noted the difficulty in training even sophisticated users in the proper interpretation of probabilistic forecasts. The NRCS periodically surveys registered recipients of their Basin Outlook Reports and other snow survey publications, ostensibly to improve constituent services. However, with only 4 general questions, it's questionable whether results can inform product improvements. The 4 questions and their possible responses are given in Table 12. The NRCS and CBRFC also receive unsolicited comments and provide opportunities for e-mail comments on their websites. The agencies also periodically hold joint meetings with invited participation of some of the larger user groups (e.g., Bureau of Reclamation, river commissions, irrigation districts). 
Table 12. NRCS snow survey and water supply forecasting government performance review act survey. ${ }^{1}$

1. Do you use information provided by the Natural Resources Conservation Service, Snow Survey and Water Supply Forecasting Program to make water use and management decisions? Yes, No

2. How satisfied are you with the timeliness of the printed and/or electronic information provided to you by the NRCS? Very satisfied, Satisfied, Dissatisfied, Very Dissatisfied

3. How satisfied are you with the usefulness of the water supply forecast information provided to you by the NRCS? Very satisfied, Satisfied, Dissatisfied, Very Dissatisfied

4. How satisfied are you with the ressponsiveness of NRCS snow survey and water supply personnel to your requested needs for information? Very satisfied, Satisfied, Dissatisfied, Very Dissatisfied

${ }^{1}$ From cover sheet of the Arizona Annual Data Summary, Water Year 1996, NRCS, Phoenix, Arizona.

\subsection{Other Forecasts}

In addition to the agencies listed above, many other entities provide hydrologic forecasts or access to forecasts. Typically, these forecasts simply reproduce or reformat official NWS hydrologic forecasts products and are not mentioned further herein. Rarely are the official forecasts reinterpreted or extended to new products. Like many commercial weather forecast providers, agencies typically seek to offer "one stop shopping" for a range of information, including hydrometeorologic data and forecasts, to targeted clientele. Research groups, e.g., universities and institutions, sometimes offer reinterpretations or extensions of NWS products, or have entirely new products. However, those forecasts are typically only experimental products, not operational. Several hydrologic forecasts are described herein, although none are operational products for the U.S. Southwest.

\section{NRCS Surface Water Supply Index}

For some regions within the U.S. West, although not in the Southwest, the NRCS extends the water supply outlooks into a surface water supply index, by combining the outlooks with pre-runoff reservoir storage (http://idsnow.id.nrcs.usda.gov/snow/bor/9802/idf2s07.htm). The index provides a comprehensive measure of water availability for situations where reservoirs provide significant storage of spring and summer runoff; thus, similar forecasts may have value in the Southwest. Index values are scaled between plus and minus 4.1, with 0 representing the historic median value. Threshold index values have been established for most basins in Idaho and are used there to forecast the potential for agricultural water shortages. Listing of recent years with index values similar to those being forecast enables users to perform analog analysis based on resource management decisions made in those years. 


\section{NWS CPC Integrated Soil Moisture Anomaly Forecasts}

The NWS Climate Prediction Center (CPC) periodically issues integrated soil moisture anomaly forecasts as part of the NWS NCEP threats assessment (http://nic.fb4.noaa.gov/products/predictions/threats/basic/daily/index.html). The soil moisture anomaly forecasts are not included in every threats assessment, but only as considered appropriate. For example, in response to the strengthening El Nino conditions of 1997, soil moisture anomaly forecasts were made in December 1997, extending through August 1998. Forecasts of anomalously wet soil conditions can suggest seasonlong potential for flooding, while forecasts of anomalously dry soil conditions can suggest potential for drought of significance to agriculture.

Forecasts are made using the CPC soil model (Huang et al., 1996), which is a simple bucket model using monthly observed precipitation estimates, Thornwhaite evapotranspiration, and parameterized surface runoff and groundwater losses. Identical model parameters are used for all 344 U.S. climate divisions, based on calibration using observed runoff in several river basins in Oklahoma. After updating model storages to the present, forecasts are made using selected historic input sequences analogous to extant ENSO conditions. The December 1997 forecast used 10 past cases when December-February was a warm El Nino event. Anomalies are computed consistent with the CPC climate outlooks, i.e., as normalized differences from 1961-1990 climatology, although the climatology is based on model estimates rather than measurements. Even with such a simple model formulation and the transfer of Oklahoma parameters nationwide, the CPC considered their soil moisture anomaly forecast issued December 1997 to have "reasonably high skill" through July 1998 (http://nic.fb4.noaa.gov/products/predictions/threats/faqa.html). In that same discussion, they associated the forecast with a "good guarantee for skill", although the meaning of the phrase is not entirely clear.

\section{Bureau of Reclamation Forecasts}

The U.S. Bureau of Reclamation (BuRec), within the Department of Interior, has significant responsibilities related to management of water resources throughout the West. Historically, they have built and operated large reservoir projects, primarily for irrigated agriculture. With shifting agency priorities, BuRec has become increasingly involved in decision support for improved management of water deliveries from their reservoirs. Their Agricultural Water Resources Decision Support (AWARDS) system reflects this shift in agency emphasis. AWARDS is an subscription service for computer access to weather data and forecasts of special interest to reservoir system operators, staff of water and irrigation districts, and agricultural irrigators and other water users (http://www.usbr.gov/rsmg/nexrad/awards.html). The AWARDS system collects NEXRAD radar rainfall estimates, weather station data, and forecasts from NWS sources and reformats or extends them into additional products. While AWARDS primarily presents recent weather data, several forecasts are available, including next-day quantitative precipitation forecasts (QPFs) as daily totals, and next-day daily crop water use forecasts. Through the BuRec Rivers and Meteorology Group (http://www.usbr.gov/rsmg/nexrad), free access is provided to a range of other NWS 
products, including daily QPFs for the next 2 days, and monthly and seasonal climate outlooks; links are also made to commercial vendors.

Except for short-term specialized products (e.g., crop water use forecasts) available through the AWARDS system, however, the BuRec appears to expect their clientele to either extend, on their own, weather and climate forecasts into hydrologic forecasts, or to access those forecasts elsewhere. While links are provided to NCEP daily and weekly QPFs and CPC climate outlooks, no links are provided to RFC flood guidance or water supply outlooks.

The BuRec uses NWS forecasts and makes their own related hydrologic forecasts in conjunction with their reservoir system annual operating plans, e.g., for the Colorado River (BuRec, 1998). BuRec uses monthly water supply outlooks provided by the NWS CBRFC for the next 2 water years (i.e., for water year 1998, beginning October 1998 and going through September 2000). Although these water supply outlooks are not official products to be used outside this specific BuRec application, they are generated using the same general statistical techniques used in creation of the provisional (i.e., prior to coordination) NWS outlooks (S. Shumate, NWS CBRFC, personal communication, 1998). Outlooks are provided for several different quantiles, with BuRec selecting 3 to use as hydrologic scenarios. When the "most probable" forecast is near normal, the 3 outlooks used are the 10,50, and 90 percent exceedance quantiles, used as the "probable maximum", "most probable", and "probable minimum" forecasts, respectively. BuRec then uses these 3 scenarios to determine which reservoir operation criteria will take precedence throughout the upcoming water year; the criteria differ depending on reservoir storage and river flow conditions.

Although actual reservoir operations can be modified during the year as RFC water supply outlooks are adjusted to reflect the evolution of snowpack, basin storage, and flow conditions, the scenarios developed under the annual operating plan do affect water management decisions. The operating plan suggests to water users whether they should expect to receive their full water allotment or even surplus flows. Additionally, early commitments in reservoir operations may be made. For example, reservoir drawdowns were increased in the winter of 1998 in an attempt to prepare for potential high spring runoff due to El Nino. For 1999, reservoir operation plans are focused on accommodating the high storages and flows expected to occur under the "most probable" and "probable maximum" scenarios. Going into water year 1999, consideration was being given to making flood releases from Hoover Dam throughout the fall and winter months, prior to actual snowpack accumulation, to avoid the anticipated possibility of extra releases that would coincide with the typically high runoff season of January-July.

Through various research units, the BuRec also develops improved river basin modeling techniques and tools that have potential for improved hydrologic forecasts in the Southwest. For example, BuRec recently completed development of the Lower Colorado River Accounting System, enabling improved modeling of the plethora of water uses and irrigation return flows in the Lower Colorado basin (BuRec, 1997). 


\section{Central Arizona Project Forecasts}

The Central Arizona Project (CAP) is an extensive system for delivering Colorado River water to customers in central and southern Arizona, including the Phoenix and Tucson metropolitan areas. CAP is also a key component in the Arizona Water Bank (AWB). The AWB is designed to bring Arizona's unused entitlement of Colorado River water into central and southern Arizona and store it in underground aquifers. If future droughts cause Colorado River flows to be insufficient to meet allotments, water stored in the AWB can be used to replace those shortfalls.

As part of their operations, CAP produces an annual system demand forecast each December, for the upcoming year. This forecast is made for each month throughout the upcoming year, and is divided into the following components: total customer deliveries, water back deliveries, total canal losses, Waddell Dam pumping (outflows), Waddell Dam releases, and Colorado River diversions. The 1998 forecast, issued 18 December 1997, is available at http://www.cap-az.com/customers/schedu.htm. CAP also produces forecasts of conditions and operations at the New Waddell Dam/Lake Pleasant on a monthly basis for the upcoming year; Lake Pleasant water is derived from both the Colorado River via CAP and the Agua Fria River. It also appears that CAP makes a 3year forecast for operations planning (http://www.capaz.com/Lake Pleasant/operatingforecast.htm).

CAP annual forecasts are used to determine water billing and deliveries. Although water use significantly increases during the summer months, CAP bills customers using a levelized payment schedule, based on the monthly average of the total annual water use projected by each customer. Deliveries of CAP water are also scheduled according to the annual forecast, although customers must provide weekly updates to their monthly water demand projections.

CAP forecast methodologies are not fully explained in extant documentation (http://www.cap-az.com/Lake_Pleasant/forecast2.htm). Rainfall and inflow are "based on normal years", although the period of record and precipitation gage locations are not described. CAP does require, each fall, that individual customers provide projections of their water demand for each month in the coming year.

\section{International Boundary and Water Commission Forecasts}

In the same manner that the CAP projects monthly water requirements for the upcoming calendar year, the Mexican section of the International Boundary and Water Commission (IBWC) forecasts monthly water delivery requirements of the water users in Mexico. These forecasts are presented to the U.S. section of the IBWC before the start of the upcoming calendar year. Because the BuRec Colorado River annual operating plan is issued well in advance, the Mexico water use forecasts can potentially reflect anticipated hydroclimatic conditions, e.g., the occurrence of surplus flows to Mexico resulting from flood releases during the fall and winter in anticipation of high snowmelt runoff volumes. For example, Mexico delivery requests for winter of 1998 were low compared to normal, in anticipation of flood releases from Hoover Dam during that period; thus, those surplus 
flows would not count toward Mexico's Colorado River allotment, thereby increasing guaranteed water deliveries later in the year (Pope, 1998).

\section{California Department of Water Resources Forecasts}

The California Department of Water Resources (CDWR) plays a significant role in operational runoff forecasting in California regions served by the NWS CaliforniaNevada River Forecast Center (CNRFC). The CDWR operational forecasts use ensemble streamflow prediction (ESP) techniques, assuming that each historic precipitation sequence has equal probability of occurrence (Roos, 1998). Experimental forecasts use CPC climate outlooks to constrain or shift the probability of the historic precipitation sequences. Forecasts expressed as exceedance quantiles can vary significantly between the operational and experimental approaches depending on the nature of the climate outlooks.

Impacts of the use of operational or experimental ESP forecasts on water management depend on specific operating rules as well as differences in forecast volumes. The California Central Valley Project generally bases early season water delivery allocations on $90 \%$ exceedance probability water supply forecasts. The California State Water Project has relatively little storage capacity relative to annual flow volumes or water usage, and the value of the water used is high. Thus, water management strategies have evolved to avoid reductions in planned water deliveries after the delivery season has started. Changes in water delivery are made only if the $90 \%$ exceedance probability forecast made for December is subsequently exceeded by the 99\% exceedance probability made for any later month, i.e., only if later forecasts show higher flow volumes with higher probability of occurrence. During the El Ninoinfluenced winter of 1997-1998, water management allocations would not have changed using the experimental rather than operational forecasts. However, other conditions would likely show different management strategies using different forecast approaches. As forecasters and water managers develop more experience with the experimental ESP forecasts, expectations are that water management strategies will change.

\section{Forecasts from Universities, Institutes/Centers/Consortiums}

Meteorologic forecasts are made by a variety of non-governmental organizations, both public (universities and government/university consortiums) and private. However, with the exception of the Salt River Project, hydrologic forecasts do not appear to be made operationally by groups other than units of the NWS and NRCS for the Colorado River Basin and the southwest U.S. Many research groups commit substantial resources toward innovative hydrologic modeling of basins within the region, but none of the models are used operationally in a forecast mode. For example, studies have been conducted on the possible teleconnections between the El Nino - Southern Osciallation (ENSO) phenomena and hydroclimatology in the southwest U.S. (Redmond and Koch, 1991; Kahya and Dracup, 1993). However, those studies are not, themselves, forecasts, nor have existing operational forecast techniques been extended to include the results of those studies. 
A recently initiated project, with investigators from the University of Arizona, Portland State University, and the University of California, plans to develop new methodologies to make monthly forecasts of precipitation, snow water equivalent, and streamflow, for at least a year in advance (Valdez et al., 1998). Two new forecasting approaches will be developed and compared based on their predictive skill; they are expected to improve forecasts compared to existing methodologies due to the extent to which they will incorporate ENSO conditions. Further, a decision support system that can use the new forecasts will be developed and tested for use in management of Arizona reservoir systems, among others in the West.

\subsection{The Future of Hydrologic Forecasting}

The future of hydrologic forecasting is certain to include the use of more sophisticated approaches and a greater diversity of data. However, there are 2 distinctly different paths that may be taken in creating improved forecasts.

The first represents a continuation of empirical modeling (e.g., regression techniques), but making use of new system modeling concepts. In particular, neural networks show promise for incorporating the non-linear dynamics of watershed processes and improving streamflow estimates. Neural networks can incorporate a wide range of data, including satellite remote sensing of earth and atmospheric conditions, as well as traditional gage-based estimates of temperature, precipitation, and flows. However, neural networks still possess the same limitations as all empirical models in a forecast setting. When conditions occur outside those for which the neural network was trained, results may be highly erroneous. Further, no direct means exist for incorporating new physical conditions or relationships within the neural network, without first experiencing those changes and then retraining the system model. Thus, these models are not suitable for exploring effects of land management practices, shifts in climatic regimes, or other types of system change.

The second vision of the future of hydrologic forecasting is similar to the evolution of weather and climate forecasts over the last decade, with hydrologic forecasts making use of increasingly complex conceptual models applied in a distributed fashion at multiple spatial and temporal scales. Massive research programs, with extensive collaboration among federal, state, and other agencies, and research and educational institutions, have been developed over the past decade to develop sophisticated distributed modeling capabilities. Commonalities among the variety of distributed models that have been developed include use of geographic information systems (GIS), digital elevation models, advanced spatial estimation algorithms, land characterization data, and remote sensing of atmospheric and land surface conditions.

These distributed conceptual models offer better understanding of the physical processes controlling hydrologic response under various conditions. By incorporating physical processes, the models are expected to provide more robust and reliable estimates 
of watershed behavior for conditions outside those for which the model has been calibrated. Thus, the models have potential application for use in studies on the impacts of system change, including global warming or changing land use. Further, these models have potential for addressing multiple resource management issues, through incorporation of additional physical processes, e.g., soil erosion, water quality.

While these models will incorporate explicit formulations of the physics controlling hydrologic processes, limitations of these models for streamflow forecasting must be realized. These distributed models are unlikely to be calibrated simply to provide the best estimate (and thus assumed best forecast) of streamflow, but to also provide good estimates of conditions related to soil erosion, water quality, and effects of land management practices. Depending on the relative importance attributed to streamflow, multiple objective calibration techniques may accept larger errors in streamflow estimates to improve estimates of other variables.

Each of these two avenues for progress in hydrology have produced only incremental improvements, and few of those have moved beyond research projects to operations. Because their associated research is exciting, with the promise of significant improvements in hydrologic modeling and forecasting capabilities over the next several decades, often little attention is paid to making marginal improvements in existing approaches. However, with longer time series of more sophisticated climate and hydrologic indices, there is real potential for relatively rapid marginal improvements in current operational statistical forecast techniques for water supply outlooks. Of particular importance and promise is the use of analog and conditional probability approaches for considering specific climatic regimes, e.g., ENSO, the Pacific Decadal Oscillation.

Institutional paradigms within the NWS appear to pose barriers to rapidly incorporating hydrologic research and improved conceptual models into forecast operations. The NWS has made an institutional commitment to only 2 models, the API and SAC-SMA. Although the NWSRFS includes one other model, termed the Chinese Model in their documentation, it is used rarely, if at all. There appears to be little effort to even experimentally incorporate other models for even a few basins. While some institutional and technical barriers to use of other models may be rational or even legitimate, this paradigm appears difficult to support over the long term, given the significant efforts underway to improve conceptual runoff modeling. For example, the $14^{\text {th }}$ Conference on Hydrometeorology (AMS, 1999) was replete with descriptions of new conceptual models with potential to improve a range of short- and long-range hydrologic forecasts (e.g., Miller et al, 1999). With few exceptions (notably Jones et al, 1999), improvements in NWS forecast capability were focused on issues other than the conceptual models. NWS hydrologic forecast improvements are primarily focused on improved data access and graphical displays (e.g., Braatz et al, 1999), different approaches for implementing ESP (e.g., Fread et al, 1999; Perica et al, 1999; Schaake et al, 1999), and improved statistical analysis of model outputs (e.g., Gunderson and Krzysztofowicz, 1999). 
Because of the complexity of the NWSRFS, any new hydrologic models that will be managed by the NWS must be compatible with that system. Additionally, while NWS efforts to reduce the "anarchic" situation of having many different data management systems (Bonin, 1996) are laudable, they will take years to complete. However, alternatives exist that could speed operational implementation of advanced hydrologic modeling tools. The coordination of seasonal water supply outlooks developed by multiple agencies provides a precedent for incorporating hydrologic forecasts developed by others, even non-governmental groups. For example, the USGS operates a comprehensive system of physical process models that includes all data and product processing (the WASRMP). It has been applied to the San Juan River basin, which is tributary to the Colorado River (Vaccaro, 1996). That system could be implemented operationally and coordinated with NWS products. 


\section{CHAPTER 5. CONCLUSIONS AND RECOMMENDATIONS}

\subsection{Conclusions}

\section{Hydrologic versus Weather and Climate Forecasting}

The state of hydrologic forecasting shows clear contrasts with that of weather and climate forecasting and appears to stem in part from different institutional philosophies within the NWS units responsible for the different forecasts.

The state of meteorologic forecasting can be characterized by the rapid incorporation of a wide variety of research findings and products; experimental forecasts are routinely issued and operational forecasts can be adjusted based on recent climate diagnoses and newly-improved conceptual understanding of ocean and atmospheric dynamics and linkages. Different forecast techniques can take precedence in different regions, during different seasons, and for unusual conditions. New forecast techniques move relatively quickly from research to experimental to operational status. Different units within NOAA have responsibility for different types of forecasts and even for the different models. Forecasts generated by groups outside NOAA are also routinely incorporated into official meteorologic forecast products. Additionally, meteorologic forecasting has a strong history of forecast quality assessment.

In contrast, the state of hydrologic forecasting is characterized by much slower evolution, with constraints imposed by complex legacy data management systems, longstanding standard operating procedures, and an institutional preference for uniformity in operations. The NWS has made a strong commitment to only 2 conceptual hydrologic models (API and SAC-SMA); any new models must accommodate the infrastructure surrounding those 2 core models. Further, quality assessments of operational products are uncommon; even coordinated comparisons of hydrologic model performance have been infrequent and typically contentious.

However, the philosophy reflected in the production of official water supply outlooks offers some opportunity for extending hydrologic modeling capabilities beyond the API and SAC-SMA models. Official water supply outlooks issued by the NWS are generated through coordination with other groups, including private organizations (e.g., the Salt River Project). This precedence provides potential for incorporating new forecast methodologies more rapidly, by having other organizations produce experimental or operational forecast products that can then be coordinated with NWS hydrologic forecasts.

\section{The Future of Forecasting}

Rapidly increasing computer power and the evolution of remote sensing of oceanic, atmospheric, and land (surface and below) conditions have produced significant shifts in the philosophy and practice of weather, climate, and hydrologic forecasting, 
although less so for the latter. The climate modeling community experienced an earlier shift than the hydrologic community to a spatially variable approach to dynamic conceptual modeling, usually via use of grids. Conceptual hydrologic models are still largely lumped models, where large regions are considered to behave as a single unit, without spatial variation in behavior. However, the availability of geographic information systems, digital elevation models of terrain characteristics, and satellite remote sensing have fostered substantial research effort to develop distributed hydrologic models, where spatial variations in watershed characteristics are explicitly considered. Development of distributed hydrologic models is an active area of research, with models far from being used operationally.

Additionally, there is much research focused on the interaction among oceanic, atmospheric, and land systems, although only limited coupling is presently incorporated into operational forecasts. In particular, sea surface temperatures (SSTs) over the Pacific Ocean are used in several large-scale climate models to affect climate forecasts over continental areas. The El Nino-Southern Oscillation (ENSO) phenomenon is incorporated into some statistical models for water supply in the Southwest. However, other large-scale phenomena (e.g., the Pacific North America [PNA] and Southwest Trough circulation patterns), while recognized as having important consequences for Southwest hydroclimatology (Cayan and Peterson, 1989; Redmond and Kock, 1991; Cayan, 1996; Woodhouse, 1997), have not yet been incorporated into operational models or forecasts. Further, many other teleconnections (e.g., the Pacific Decadal Oscillation [PDO]) are the focus of active research programs, with much work to be done before they can be incorporated into operational forecasts.

Because different climate and hydrologic processes occur at different spatial and temporal scales, coupling between climate and hydrologic models may need to occur at multiple scales as well. The use of nested models is becoming more typical in atmospheric models, but many alternative implementations remain to be explored (e.g., use of one-way or two-way feedbacks between nested models, nesting with more than two tiers of models). Use of nesting in strictly hydrologic models would generally be limited to one-way nesting, because with the exception of relatively limited backwater effects, flows are affected only in the downstream direction. For short-term hydrologic forecasts, one-way nesting is accomplished by routing forecast flows downstream. Longterm hydrologic forecasts are not nested; anticipated flow conditions are computed only for separate watersheds, with no relationship between upstream and downstream forecasts, with the exceptions that flow at an upstream gage is sometimes an input variable in statistical regression techniques.

Nesting of models of different spatial coverage and resolution is wrought with complexity relating to the appropriate linkage of processes and other issues. In contrast, temporal nesting is conceptually straightforward, yet has been comparatively neglected. The climate occurring over several months is comprised of a succession of short-term conditions. While operational forecasts are made for time scales ranging from minutes to several months, there are no explicit connections between such forecasts. Further, while there is general recognition that the accumulation of short-term forecasts should be 
consistent with the longer-term forecasts, evaluations of models or forecasts generally do not consider multiple time intervals.

A reasonable vision of forecasting over the extended future is for increasing complexity and interconnectivity of all phases of modeling. A forecast system of the future might be expected to include incorporation of a greater variety of data; coupling between oceanic, atmospheric, and hydrologic processes; nesting across multiple spatial and temporal scales; and updating of forecasts by assimilation of recent observational data based on forecast error characteristics. Further, the future of forecasting is likely to include a larger number of forecast techniques, both statistical and dynamical, empirical and conceptual. The best means for integrating and communicating those diverse forecasts will likely become an increasingly important question for both forecasters and forecast users.

Large research programs, with joint participation of many research groups, are focused on developing the next generation of forecast tools. However, based on the present rate of transition of research into operational tools for hydrologic modeling, it is likely to be many years before these research programs result in new operational forecast tools; the present generation of hydrologic forecast tools is likely to be in place for years to come. Theoretically, there are significant opportunities for relatively rapid improvement of operational hydrologic forecasts based on recent improvements in the skill of climate forecasts. However, because current operational techniques are not included in hydrologic research programs, which are generally devoted to the next generation of forecast tools, those opportunities have not been realized. Additionally, there is a notable lack of research attention being paid to the on-going evaluation of present operational hydrologic forecasting techniques. This results in an absence of any quantitative basis for forecast credibility.

\subsection{Recommendations}

Review of the climate, weather, and hydrologic forecasts available for the Southwest, along with consideration of the efforts of agencies and institutions, suggests a range of needs that CLIMAS is uniquely suited to address. The following recommendations for future CLIMAS activities have been assigned varying levels of priority, based primarily on consensus views of participants at the Forecast Assessment Workshop. Priority 1 recommendations are those that can relatively quickly provide results directly applicable to stakeholders in the Southwest; typically, the tasks use data and forecast products that already exist in usable form. Priority 2 recommendations require more extensive work, generally to recreate forecast products using special procedures. Priority 3 recommendations are important for improved hydrologic forecasting, but either they do not directly affect current operational forecast procedures, are expected to require years of effort, or are the focus of other research programs outside of CLIMAS. 


\section{Recommendations: Forecast Evaluations}

Priority 1. Evaluate CPC 1-and 3-month temperature and precipitation outlooks. Assessment of the complete series of CPC outlooks, focusing on just the Southwest, enables demonstration of incremental improvements in the outlooks over time, providing a quantitative basis for forecast credibility within the region, and identification of seasons during which the outlooks have been consistently strong or weak. Evaluations should consider both regional fields and point locations. This will identify locations where forecasts are especially reliable, although it is more likely to identify locations where forecasts are especially inappropriate, suggesting the presence of unique land-atmosphere interactions, e.g., orographic effects, and identifying needs for improved modeling. Because techniques for producing the climate outlooks are constantly evolving, there is an insufficient record of outlooks for evaluating the current mix of techniques. Such an evaluation requires a reanalysis approach, whereby current techniques are used in a simulated operational setting covering a suitably extensive historic period. Reanalysis is practical only for individual techniques, however, since the process for combining forecasts is subjective and requires substantial forecaster expertise. However, the objective requirement that climatologic probabilities be issued where techniques have only marginal skill could be incorporated in a more comprehensive reanalysis. Further, while climate forecast techniques have changed, it is still appropriate to assess the historical archive of forecasts, because resource management decisions have been made using those forecasts, providing a more realistic assessment of vulnerability to climate variability and forecast uncertainty.

Priority 1. Evaluate water supply outlooks: coordinated seasonal volumes. There is a notable lack of research attention being paid to the on-going evaluation of present operational hydrologic forecasting techniques. This results in an absence of any quantitative basis for forecast credibility. Although forecast techniques have changed over the decades, it is appropriate to assess the historical archive of forecasts. Many water management decisions have been made using those forecasts, providing a more realistic assessment of vulnerability to climate variability and forecast uncertainty. After creation of the historic forecast database, various measures of forecast quality will be evaluated, since different users require different forecast performance qualities.

Priority 2. Reanalysis of water supply outlooks: seasonal volumes and hydrographs from ESP forecast procedures. Past problems with specific weather, climate, and hydrologic outlooks can engender a tendency towards skepticism, even though physical understanding and forecast techniques have improved. One approach to improving credibility associated with current forecasts is to conduct reanalysis or hindcast evaluation studies. Both reanalysis and hindcasting refer to the use of current operational techniques with historic data to create forecasts in a simulated operational setting. That series of forecasts is then used to evaluate the predictive skill of current operational procedures.

Presently, the NWS CBRFC generates experimental probabilistic water supply outlooks using Ensemble Streamflow Prediction (ESP) procedures. However, the number of forecasts is insufficient for evaluation. Reanalysis evaluation of the ESP 
forecasts was identified as a critical need by participants in the Forecast Assessment Workshop and water managers elsewhere (Roos, 1998). The NWS Office of Hydrology has created procedures for reanalysis studies using the experimental ESP procedures (Perica, 1998), although no forecast assessments have yet been done (Schaake, 1998). Reanalysis evaluation of ESP forecasts will also enable comparison of different methodologies for selection of appropriate meteorology to drive the conceptual runoff models.

Priority 2. Reanalysis of water supply outlooks: seasonal volumes and hydrographs from statistical forecast procedures. Except for the standard error analysis conducted during determination of the regression coefficients used in the statisical approach for water supply forecasting, little evaluation of model performance has been conducted. Historic records of official water supply outlooks have been made using a mix of evolving techniques. More appropriate evaluation of the strengths and limitations of the current water supply outlook techniques requires use of those techniques in reanalysis or hindcast studies. Both reanalysis and hindcasting refer to the use of current operational techniques with historic data to create forecasts in a simulated operational setting. That series of forecasts is then used to evaluate the predictive skill of current operational procedures. Such an approach will allow consideration of a broader variety of forecast performance measures of quality than simple standard error analysis. In particular, evaluation of marginal and conditional probabilities should be informative for directing future areas of focus for improving statistical-based water supply forecasts.

\section{Recommendations: Improve Modeling}

Priority 1. Incorporate climate outlooks into statistical water supply outlook techniques. Although this recommendation was rated at the highest priority in the Forecast Assessment Workshop, it was noted that such activities are often ranked low in advanced modeling research programs. However, based on the present rate of transition of research into operational tools for hydrologic modeling, it is likely to be many years before these research programs result in new operational forecast tools; the present generation of hydrologic forecast tools is likely to be in place for years to come. There are significant opportunities for relatively rapid improvement of operational hydrologic forecasts based on recent improvements in the skill of climate forecasts. However, because current operational techniques are not included in hydrologic research programs, which are generally devoted to the next generation of forecast tools, those opportunities have not been realized.

\section{Priority 3. Evaluate gridded precipitation and snow estimates for use in forthcoming} distributed forecast procedures. Proper initialization of hydrologic models requires good estimates of moisture storage available for runoff. Depending on the forecast time scale and lead time, good estimates are required of the spatial distribution of precipitation, snowpack conditions, or both. For water supply outlooks, high quality estimates of snow water equivalent are required throughout a watershed. Snow data over 1990-present, archived by the NOAA NOHRSC, will be converted to a consistent format. Hypertemporal spatial analyses will be used in conjunction with water balance analyses 
to evaluate the potential use of those gridded snow products in anticipated distributed hydrologic forecast procedures, as well as in extending existing operational statistical models.

Priority 3. Improve conceptual distributed hydrologic modeling capabilities. This activity is a high priority of other research programs (e.g., NASA's EOS program). However, in the context of the CLIMAS mission, other activities have higher precedence. Thus, while acknowledged here as an important area for future activity, CLIMAS involvement should be ancillary to other efforts.

\section{Recommendations: Improve Forecast Products and Communication}

Priority 1. Evaluate use of climate and hydrologic forecasts products during the 1998-99 La Nina episode. Recent work completed in conjunction with the CLIMAS project used in-depth interviews of key personnel in water management agencies in Arizona to develop a thorough understanding about the relationship between 1997-98 El Nino information and forecasts and decision making related to anticipated water surpluses. Subsequent transition to strong La Nina conditions provides a unique opportunity to extend that understanding to drought conditions, given that the La Nina signal in the Southwest is even stronger and more certain than for El Nino or when compared to other regions. However, drought is a slowly cumulative condition that does not receive the same media coverage as potential flooding; additionally, impending drought and water deficits have no easy action options.

Priority 1. Develop location-specific climate outlook products. Presently, CPC climate outlooks are shown as regionally varying maps of probability anomalies. Proper interpretation requires coordination with historic data, although that's not provided in the CPC outlooks. A useful product would show the 1961-1990 distribution, a shifted distribution based on the CPC outlooks, and the full period-of-record distribution. The distributions could be developed for specific locations (e.g., Benson, AZ) or relatively localized regions (e.g., Tohono O'odham reservation lands). Additionally, the shifted distributions should reflect the uncertainty associated with the climate outlooks, based on past forecast performance. New products and formats should be developed through an ongoing iterative process with stakeholders, to ensure their needs are directly addressed.

Priority 1. Develop improved hydrologic forecast products. Individual NWS RFCs present water supply outlooks in different formats, some of which are more informative than those presently issued by the CBRFC. Improvements are possible in graphical presentation of water supply outlook volumes, past forecast performance, and comparison to flow distributions based on varying historic periods. New products and formats should be developed through an ongoing iterative process with stakeholders, to ensure their needs are directly addressed. 


\section{REFERENCES}

ADWR, 1994. Arizona Water Resources Assessment, Vol. 1: Inventory and Analysis. Arizona Department of Water Resources, Phoenix, AZ.

Air Weather Service, 1996. The Navy Operational Global Atmospheric Prediction System, Version 3.4 (NOGAPS 3.4). Check It Out 96-04.

Anderson, E.A. and N.H. Crawford, 1964. The synthesis of continuous snowmelt runoff hydrographs on a digital computer. Technical Report No. 36, Department of Civil Engineering, Stanford University, Stanford, CA.

Anderson, E.A., 1968. Development and testing of snow pack energy balance equations. Water Resources Research 4(1):19-37.

Anderson, E.A., 1973. National Weather Service River Forecast System snow accumulation and ablation model. NOAA Technical Memorandum NWS HYDRO-17, NWS Office of Hydrology Hydrologic Research Laboratory, Silver Springs, MD.

Anthes, R.A. and T.T. Warner, 1978. Development of hydrodynamic models suitable for air pollution and other mesometeorological studies. Monthly Weather Review 106:10451078.

American Water Resources Association, 1995. Special Issue: Coping with Severe Sustained Drought in the Southwestern United States. Water Resources Bulletin 31(5): 779-944.

Barnston, A.G., 1994. Linear statistical short-term climate predictive skill in the Northern Hemisphere. Journal of Climate 5:1514-1564.

Barnston, A.G., M. Ji, A. Kumar, and A. Leetma, 1998a. Forecasts of tropical Pacific SST using a comprehensive coupled ocean-atmosphere dynamical model. Experimental Long-lead Forecast Bulletin, http://grads.iges.org/ellfb/Jun98/bar1.html.

Barnston, A.G., A. Kumar, W. Wang, M. Ji, and A. Leetma, 1998b. Forecasts of North American surface climate using a GCM with SST boundary conditions that are forecasted by a coupled ocean-atmosphere dynamic model. Experimental Long-lead Forecast Bulletin, http://grads.iges.org/ellfb/Jun98/bar2.html.

Benequista, N. and J.S. James, 1998. Climate impact assessment of the Southwest: pilot stakeholder assessment report. Institute for the Study of Planet Earth, University of Arizona, Tucson, AZ. 
Benjamin, S.G., J.M. Brown, K.J. Brundage, B.E. Schwartz, T.G. Smirnova, T.L. Smith, and L.L. Morone, 1998. RUC2: the rapid update cycle version 2. Technical Procedures Bulletin, NOAA ERL Forecast Systems Laboratory, Boulder, Co, URL:

http://maps.fsl.noaa.gov/ruc2.tpb.html.

Bonin, G.M., 1996. The NOAA Hydrologic Data System. Presented at the $12^{\text {th }}$ International Conference on Interactive Information and Processing System for Meteorology, Oceanography, and Hydrology, American Meteorological Society, Atlanta, GA, 28 January-2 February.

Borenstein, S., J. Hansen, J. Knox, R. Miller, R. Ruedy, S. Wallace, and J. Wilder, 1998. Summer forecast by the GISS SI97 model based on fixed SST anomalies. Experimental Long-lead Forecast Bulletin, http://grads.iges.org/ellfb/Jun98/hansen.html.

Braatz, D.T., J.B. Halquist, R.J. Warvin, J. Ingram, J.J.Feld, and M.S. Longnecker, 1997. NWS hydrologic products and services: moving from the traditional to the technically advanced. Presented at the $13^{\text {th }}$ International Conference on Interactive Information and Processing Systems for Meteorology, Oceanography, and Hydrology, American Meteorological Society, Long Beach, CA, February 1997.

Braatz, D.T., S.D. Buan, M.M. DeWeese, W.H. Koellner, J.T. Stiman, J.T. Burant, and J.J. Ingram, 1999. Enhanced hydrologic products and services utilizing advanced models and procedures. $14^{\text {th }}$ Conference on Hydrology, American Meteorological Society, Boston, MA, pp.67-72.

Branick, M., 1996. A comprehensive glossary of weather terms for storm spotters. NOAA Technical Memorandum NWS SR-145, second edition. URL: http://www.nssl.noaa.gov/ nws/branick2.html.

Bretherton, C.S., C. Smith, and J.M. Wallace, 1992. An intercomparison of methods for finding coupled patterns in climate data. Journal of Climate 5:541-560.

Bureau of Reclamation, 1996. Description and assessment of operations, maintenance, and sensitive species of the Lower Colorado River. Lower Colorado Region, U.S. Bureau of Reclamation, Boulder City, NV.

Bureau of Reclamation, 1997. Lower Colorado River Accounting System. Lower Colorado Regional Office, Boulder City, NV. URL: http://www.lc.usbr.gov/ g4000/lcras_rpt.html.

Bureau of Reclamation, 1998a. Draft Annual Operating Plan for Colorado River Reservoirs, 1999. URL: http://www.uc.usbr.gov/wrg/crsp/crsp_aop.html.

Bureau of Reclamation, 1998b. 1998 Lower Colorado Region Overview. URL: http://www.lc.usbr.gov/ovrvw98.html. 
Burnash, R.J.C., Ferral, R.L., and McGuire, R.A., 1973. A generalized streamflow simulation system - conceptual modeling for digital computers. U.S. Department of Commerce National Weather Service and California Department of Water Resources.

Burnash, R.J.C., 1995. The NWS river forecast system - catchment modeling. Computer Models of Hydrology, V.P. Singh (Ed.), 311-366.

Cayan, D.R., 1996. Interannual climate variability and snowpack in the western United States. Journal of Climate 9:928-948.

Cayan, D.R. and D.H. Peterson, 1989. The influence of North Pacific atmospheric circulation and streamflow in the West. Aspects of Climate Variability in the Pacific and the Western Americas, Geophysical Monographs 55, D.H. Peterson (Ed.), American Geophysical Union, Washington, DC, pp. 375-397.

CBRFC, 1992. Operational water supply forecasting. Internal Seminar Notes, Colorado Basin River Forecast Center, Salt Lake City, UT.

CBRFC, 1992a. Water supply outlook for the Lower Colorado, March 1, 1992. Colorado Basin River Forecast Center, Salt Lake City, UT.

CBRFC, 1992b. Water supply outlook for the Upper Colorado, March 1, 1992. Colorado Basin River Forecast Center, Salt Lake City, UT.

CBRFC, 1992c. Water supply outlook for Utah, March 1, 1992. Colorado Basin River Forecast Center, Salt Lake City, UT.

CBRFC, undated. Guide to water supply forecasting. Colorado Basin River Forecast Center, Salt Lake City, UT. URL: http://www.cbrfc.gov/public/guide.

Changnon, S.A., S.T. Sonka, and S. Hofing, 1988. Assessing climate information use in agribusiness. Part I: actual and potential use and impediments to use. Journal of Climate 1:757-765.

Changnon, S.A., 1990. The dilemma of climatic and hydrologic forecasting for the Great Lakes. Proceedings of the Great Lakes Water Level Forecasting and Statistics Symposium, H. Hartmann and M. Donahue (Eds.), Great Lakes Commission, Ann Arbor, MI, pp. 13-26.

CLIMAS, 1998. Survey of NWS-Tucson convective outlook web pages. Institute for the Study of Planet Earth, University of Arizona, Tucson, AZ, URL: http://www.ispe.arizona.edu/swclimate/COS table main.htm.

Cotton, W.R., G. Thompson, and P.W. Mielke, Jr., 1994. Real-time mesoscale prediction on workstations. Bulletin of the American Meteorological Society 75:349-362. 
Cotton, W.R., G. Thompson, G.D. Alexander, R. Hertenstein, R.L. Walko, R.L. McAnelly, and M. Nicholls, 1995. Cloud venting. Earth Science Review 39:169-206.

CPC, 1995. Climate Analysis Center Outlook Products Frequently Asked Questions. Climate Prediction Center, NCEP, NWS, Camp Springs, MD, 10 February 1995. URL: http://www.nnic.noaa.gov/products/predictions/README.

CPC, 1998. Prognostic discussion for long-lead outlooks. Climate Prediction Center, NCEP, NWS, Camp Springs, MD, 16 July 1998.

Croley, T.E., II, 1996. Using NOAA's new climate outlooks in operational hydrology. Journal of Hydrological Engineering 1(3):93-102.

Croley, T.E., II and H.C. Hartmann, 1984. Lake Superior basin runoff modeling. NOAA Technical Memorandum ERL GLERL-50, National Technical Information Service, Springfield, VA.

Croley, T.E., II and H.C. Hartmann, 1987. Near real-time forecasting of large lake supplies. Journal of Water Resources Planning and Management 113(6):810-823.

Day, G.N., 1985. Extended streamflow forecasting using NWSRFS. Journal of Water Resources Planning and Management 111(2):157-170.

Day, G.N., 1990. A methodology for updating a conceptual snow model with snow measurements. NOAA Technical Report NWS-43, NWS Office of Hydrology Hydrologic Research Laboratory, Silver Springs, MD.

Day, G.N., L. Brazil, C.S. McCarthy, and D.P. Laurine, 1992. Verification of the National Weather Service Extended Streamflow Prediction Procedure. Presented at the $28^{\text {th }}$ Conference and Symposium on Managing Water Resoures During Global Change, Reno, NV, November 1992.

Dudhia, J., D. Gill, Y.R. Guo, D. Hansen, K. Manning, and W. Wang, 1999. PSU/NCAR Mesoscale Modeling System Tutorial Class Notes and Users' Guide. University Corporation for Atmospheric Research, NCAR, Boulder, CO.

Easterling, W.E., J.R. Angel, and S. Kirsch, 1988. On the appropriate use of climatic information in Illinois natural gas utility weather normalizations. Contract Report, Illinois State Water Survey, Champaign, IL.

ECPC, 1997. Scripps Experimental Climate Prediction Center models. Scripps Experimental Climate Prediction Center. Scripps Institution of Oceanography, University of California, San Diego, CA, 15 October, URL: http://meteoroa.ucsd.edu/ecpc/ecpc.html. 
EMC, 1998. EMC: Mesoscale modeling branch FAQ. URL: http://nnic.fb4.noaa.gov:8000/research/FAQ-eta.html.

Fread, D.L., 1995. A pathway toward improving hydrologic predictions. Proceedings of the Iowa Hydraulics Colloquim, Iowa City, IA, 22-24 May 1995.

Fread, D.L., 1997. Advanced hydrologic prediction services using weather and climate forecasts. Informal Seminar Series, Department of Hydrology and Water Resources, University of Arizona, Tucson, AZ, 31 January 1997.

Fread, D.L., D.T. Braatz, and J.C. Schaake, 1999. Recent experience with ensemble streamflow prediction in the DeMoines River basin. $14^{\text {th }}$ Conference on Hydrology, American Meteorological Society, Boston, MA, pp.4-7.

French, M.N. and W.F. Krajewski, 1994. A model for real-time quantitative rainfall forecasting using remote sensing, part 1: formulation. Water Resources Research 30(4):1075-1083.

Garen, D.C., undated, a. Regression fundamentals and principal component analysis. Notes prepared for the NWS Colorado Basin River Forecast Center. West National Technical Center, USDA Soil Conservation Service, Portland, OR.

Garen, D.C., undated, b. Forecast adjustment. Notes prepared for the NWS Colorado Basin River Forecast Center. West National Technical Center, USDA Soil Conservation Service, Portland, OR.

Garen, D.C., 1992. Improved techniques in regression-based streamflow volume forecasting. ASCE Journal of Water Resources Planning and Management 118(6):654670.

Georgakakos, K.P., 1986a. A generalized stochastic hydrometeorological model for flood and flash-flood forecasting, 1. formulation. Water Resources Research 22(13):2083-2095.

Georgakakos, K.P., 1986a. A generalized stochastic hydrometeorological model for flood and flash-flood forecasting, 1. case studies. Water Resources Research 22(13):2096-2106.

Georgakakos, K.P., and A.K. Guetter, 1995. Association of U.S. regional streamflow and the EL Nino/Southern Oscillation. Preprints, $11^{\text {th }}$ Conference on Hydrology, American Meteorological Society, Boston, MA, pp. 181-185.

Graham, N., 1998. Comments at California Workshop on Regional Climate Variability and Change, Office of Global Programs, NOAA, Santa Barbara, CA, 10 March 1998. 
Gregg, F. and D.H. Getches, 1991. Severe, sustained drought in the Southwestern United States: Phase I completion report to the Man and the Biosphere Program - U.S. State Department, Department of Renewable Natural Resources, University of Arizona, Tucson, AZ. NTIS Doc. No. PB92-115013.

Gunderson, L.F. and R. Krzysztofowicz, 1999. Interface for displaying probabilistic river forecasts to decision makers. $14^{\text {th }}$ Conference on Hydrology, American Meteorological Society, Boston, MA, pp.39-42.

Hannaford, J.F., R.L. Hall, and A.J. Brown, 1980. Forecast error and operational application of water supply forecasts. Proceedings, ASCE Hydraulics Specialty Conference, Portland, OR.

Hansen, J. and 42 others, 1997. Forcings and chaos in interannual to decadal climate change. Journal of Geophysical Research 102:25,679-25,720.

Hogan, T.F. and L.R. Brody, 1993. Sensitivity studies of the Navy's Global Forecast Model parameterizations and evaluation of improvements to NOGAPS. Monthly Weather Review 121:2373-2395.

Huang, J., H.M. van den Dool, and K.G. Georgakakos, 1996. Analysis of modelcalculated soil moisture over the U.S. (1931-1993) and applications to long range temperature forecasts. Journal of Climate 9:1350-1362.

Huang, J., H.M. van den Dool, and A.G. Barnston, 1996. Long-lead seasonal temperature predictions using optimal climate normals. Journal of Climate 9:809-817.

HRL, 1972. National Weather Service River Forecast System River Forecast Procedures. NOAA Technical Memorandum NWS HYDRO-14, Office of Hydrology, NWS, Silver Springs, MD.

HRL, 1998a. Flash Flood Guidance System Document. Office of Hydrology, NWS, Silver Springs, MD. URL: http://www.nws.noaa.gov/oh/hrl2/ffg/index.html.

HRL, 1998b. National Weather Service River Forecast System (NWSRFS) User's Manual. Office of Hydrology, NWS, Silver Springs, MD. URL:

http://hsp.nws.noaa.gov/oh/hrl/nwsrfs/users_manual/htm/xrfsdochtm.htm.

Hydrometeorological Design Studies Center, 1998. Precipitation frequency for the United States Southwest. NOAA Atlas 14.1, HDSC, National Weather Service Office of Hydrology, Silver Springs, MD (to be published in 1998).

HPC, 1997. Model biases. HPC, Camp Springs, MD, 5 November 1997. URL: http://www.ncep.noaa.gov/HPC/mdlbias.shtml. 
HPC, 1998. QPF Products/Verification. HPC, Camp Springs, MD, 13 August 1998.

URL: http://www.hpc.ncep.noaa.gov/research/products/index.htm.

HPC, 1999. Products Familiarization Page. HPC, Camp Springs, MD, 20 April 1999.

URL: http://www.hpc.ncep.noaa.gov/html/famtxt.html.

Ingram, J.J., M.D. Hudlow, and D.L. Fread, 1995. Hydrometeorological coupling for extended streamflow predictions. Preprints, $11^{\text {th }}$ Conference on Hydrology, American Meteorological Society, Boston, MA, pp. 186-191.

Janzic, Z., 1994. The step-mountain Eta coordinate model: further developments of the convection, viscous sublayer, and turbulence closure schemes. Monthly Weather Review 927-945.

Ji, M., A. Kumar, and A. Leetmaa, 1994b. An experimental coupled forecast system at the National Meteorological Center: some early results. Tellus 46A:398-418.

Ji, M., A. Kumar, and A. Leetmaa, 1994a. A multi-season climate forecast system at the National Meteorological Center. Bulletin of the American Meteorological Society 75:569-577.

Ji, M., A. Leetma, and J. Derber, 1995. An ocean analysis system for seasonal to interannual climate studies. Monthly Weather Review 123:460-481.

Jones, A.T., M.D. Eilts, J.T. Johnson, B.E. Vieux, and L. Song, 1999. Real-time implementation of a distributed hydrologic models for testing at the Sterling, Virginia NWS forecast office. $14^{\text {th }}$ Conference on Hydrology, American Meteorological Society, Boston, MA, pp.63-65.

Junker, W., 19XX. The performance of the NCEP operational models from an HPC perspective. HPC, Camp Springs, MD, 12 August 1998. URL:

http://www.hpc.ncep.noaa.gov/HPC/research/model/index.html

Kahya, E. and Dracup, J.A., 1993. U.S. streamflow patterns in relation to the El Nino/Southern Oscillation. Water Resources Research 29(8):2491-2503.

Kohler, M.A., 1944. The use of crest stage relationships in forecasting the rise and fall of the flood hydrograph. U.S. Weather Bureau (internal mimeograph).

Kohler, M.A. and Linsley, R.K., 1951. Predicting the runoff from storm rainfall. Research Paper No. 34, U.S. Weather Bureau.

Lamb, P.J. and S.A. Changnon, 1981. On the best temperature and precipitation normals - the Illinois situation. Journal of Applied Meteorology 20(12):1383-1390. 
Larson, L.W., 1996. National Weather Service advanced capabilities in flash flood forecasting. Presented at IAHS Conference on Destructive Water: Water-caused natural Disasters - Their Abatement and Control, International Association of Hydrological Sciences, Anaheim, CA, 24-28 June 1996.

Leetma, A., 1998. Forecasts of the 1997-98 El Nino: what was forecasted and what happened. California Workshop on Regional Climate Variability and Change, Office of Global Programs, NOAA, Santa Barbara, CA, 10 March 1998.

Lettenamier, D.P. and D.C. Garen, 1979. Evaluation of streamflow forecasting methods. Proceedings, 1979 Western Snow Conference, pp. 48-54.

Lettenamier, D.P. and E.F. Wood, 1993. Hydrologic forecasting. In: Handbook of Hydrology, D.R. Maidment (Ed.), McGraw-Hill, Inc., New York, NY, pp. 26.1-30.

Leverson, V., 1997. Potential regional impacts of global warming on precipitation in the western United States. Global Climate Change Response Program, U.S. Bureau of Reclamation, Denver, CO.

Linsley, R.K., M.A. Kohler, and J.L.H. Paulus, 1958. Hydrology for Engineers. McGraw-Hill, New York, NY.

Livezey, R.E., 1999. Putting together winter forecasts for U.S. temperatures and precipitation - La Nina and long-term trends. Climate Prediction Center, NCEP, NWS, Camp Springs, MD.

Livezey, R.E., M. Masutani, and M. Ji, 1996. SST-forced seasonal simulation and prediction skill for versions of the NCEP/MRF model. Bulletin of the American Meteorological Society 77:507-517.

Livezey, R.E., M. Masutani, A. Leetma, H. Rui, M. Ji, and A. Kumar, 1997. Teleconnective response of the Pacific-North American region atmosphere to large central equatorial Pacific SST anomalies. Journal of Climate 10:1787-1820.

Maidment, D.R. (Ed.), 1993. Handbook of Hydrology. McGraw-Hill, Inc., New York, NY.

Mason, J.P., 1994. Flood investigation for Cheyenne, Wyoming (Urban Hydrology). USGS Project WY100- Urban Hydrology, USGS District Office, Cheyenne, WY.

Mason, R.R., Jr., and B.A. Weiger, 1995. Stream gaging and flood forecasting: a partnership of the U.S. Geological Survey and the National Weather Service. Fact Sheet FS-209-95, USGS. URL: http://water.usgs.gov/public/wid/FS_209-95/masonweiger.html. 
McCallister, J.P., 1963. Role of digital computers in hydrologic forecasting and analyses. Publication No. 63, U.S. Geological Survey.

McCuen, R.H., W.J. Rawls, and B.L. Whaley, 1979. Comparative evaluation of statistical methods for water supply forecasting. Water Resources Bulletin 15(4):933947.

Miller, N.L., J. Kim, J. Farrara, K. Mo, and D. Cayan, 1999. Short-term and seasonal streamflow predictions for a California coastal basin during the 1997-1998 winter. $14^{\text {th }}$ Conference on Hydrology, American Meteorological Society, Boston, MA, pp.255-256.

Mittelstadt, J., 1997. Current and upcoming changes to the Eta models. Western Regional Technical Attachment No. 97-06, 18 February 1997, URL: http://nimbo.wrh.noaa.gov/wrhq/97TAa/TA9706/ta97-06.html.

Mote, P., 1998. Presentation at the Southwest Climate Assessment Project meeting. University of Arizona, Tucson, AZ, 27 October 1998.

NOAA, 1991. 18 January 1991. Federal Register 56(13):1984. URL: http://www.nws.noaa.gov/im/fedreg.htm.

NOAA, 1998. Packet \#5, California Pilot Project on the Use of Climate Information. NOAA, 27 April 1998. Office of Global Programs, National Oceanic and Atmospheric Administration, Washington, D.C.

NRCS, 1997. Southern oscillation index statistical correlation with spring runoff in the western U.S. National Water and Climate Center, NRCS, Portland, OR, 15 October, URL: http://idsnow.id.nrcs.usda.gov/snow/water/soiwsf2.htm.

Nemec, J. and W.T. Sittner, 1982. Application of the continuous API catchment model in the Indus River forecasting system in Pakistan. Applied Modeling in Catchment Hydrology, Water Resources Publications, pp. 313-322.

NWS, 1999. NWS glossary. San Francisco Bay WFO, San Francisco, CA, last update March, accessed via URL: http://www.weathersite.com/BanWxterms1.html.

O'Grady, K. and L. Shabman, 1990. Communicating the probability of Great Lakes water levels and storms. Proceedings of the Great Lakes Water Level Forecasting and Statistics Symposium, H. Hartmann and M. Donahue (Eds.), Great Lakes Commission, Ann Arbor, MI, pp. 197-204.

Olson, D.A., N.W. Junker, and B. Korty, 1995. Evaluation of 33 years of quantitative precipitation forecasting at the NMC. Weather and Forecasting 10:498-511. 
Pagano, T.C., 1999. The role and usability of climate forecasts for flood control and water supply agencies in Arizona: a case study of the 1997-98 El Nino. M.S. Thesis, Department of Hydrology and Water Resources, University of Arizona, Tucson, AZ.

Pagano, T.C., H.C. Hartmann, S. Sorooshian, and R. Bales, 1999. Advances in seasonal forecasting for water management in Arizona: a case study of the 1997-98 El Nino. Technical Report HWR 99-040, Department of Hydrology and Water Resources, University of Arizona, Tucson, AZ.

Page, D., 1996. The implementation of an interactive river forecast system for the National Weather Service. Presented at the $12^{\text {th }} 13^{\text {th }}$ International Conference on Interactive Information and Processing Systems for Meteorology, Oceanography, and Hydrology, American Meteorological Society, Atlanta, GA, 28 January-2 February 1996.

Perica, S., 1998. Integration of meteorological forecasts/climate outlooks into an ensemble streamflow prediction system. Proceedings, $14^{\text {th }}$ Conference on Probability and Statistics in the Atmospheric Sciences, American Meteorological Society, Boston, MA, pp.130-133.

Perica, S., J.C. Schaake, and D.J. Seo, 1999. National Weather Service River Forecast System (NWSRFS) operational procedures for using short and long range precipitation forecasts as input to ensemble streamflow prediction (ESP). $14^{\text {th }}$ Conference on Hydrology, American Meteorological Society, Boston, MA, pp.1-3.

Pielke, R.A., 1985. The use of mesoscale numerical models to assess wind distribution and boundary-layer structure in complex terrain. Boundary Layer Meteorology 31:217231.

Pielke, R.A., W.R. Cotton, R.L. Walko, C.J. Tremback, W.A. Lyons, L.D. Grasso, M.E. Nicholls, M.D. Moran, D.A. Wesley, T.J. Lee, and J.H. Copeland, 1992. A comprehensive meteorological modeling system - RAMS. Meteorology and Atmospheric Physics 49:69-91.

Pope, D., 1998. Summary of Yuma water rights and issues and value of irrigated agriculture to the Yuma area. Presentation to University of Arizona Watershed Management Fields Studies Seminar - WSM696a, 20 March 1998, Yuma County Water Users Association, Yuma, AZ.

Pulwarty, R.S. and K.T. Redmond, 1997. Climate and salmon restoration in the Columbia River basin: the role and usability of forecasts. Bulletin of the American Meteorological Society 78(3):381-397.

Redmond, K. and Koch, R., 1991. Surface climate and streamflow variability in the western United States and their relationship to large-scale circulation indices. Water Resources Research 27(9):2381-2399. 
Roads, J., T. Barnett, D. Cayan, S. Chen, K. Georgakakos, A. Miller, N. Schneider, R. Somerville, and W. White, 1999. Scripps Experimental Climate Prediction Center. Scripps Institution of Oceanography, University of California, San Diego, CA, URL: http://meteora.ucsd.edu/ecpc/general/general_bg.html.

Roads, J. and S.C. Chen, 1998. Evaluation of the Experimental Climate Prediction Center's global to regional and daily to seasonal prediction system. $23^{\text {rd }}$ Annual Climate Diagnostics Meeting, Miami, FL, 20-26 October.

Roads, J., S.C. Chen, and J. Ritchie, 1998a. ECPC's weekly to seasonal U.S. forecasts of FWI, soil moisture, and precipitation. Experimental Climate Prediction Center, Scripps Institution of Oceanography, University of California, San Diego, CA, URL: http://grads.iges.org/ellfb/Sep98/roads.html.

Roe, J., M. Glaudemans, C. Gobs, P. Taylor, and J. Zimmerman, 1998. Implementation of modernized hydrologic operations and services in the National Weather Service: overview and status. Presented at the $78^{\text {th }}$ Annual Meeting, American Meteorological Society, Phoenix, AZ, January 1998.

Rogers, E., D.G. Deaven, G.J. Dimego, 1995. The regional-analysis system for the operational early Eta-model - original 80-km configuration and recent changes. Weather and Forecasting 10(4):810-825.

Roos, M., 1998. Comments at California Workshop on Regional Climate Variability and Change, Office of Global Programs, NOAA, Santa Barbara, CA, 10 March 1998.

Rosmond, T.E., 1992. The design and testing of the Navy Operational Global Atmospheric Prediction System. Weather and Forecasting 7:262-272.

Schaake, J.C., D.J. Seo, and S. Perica, 1999. Parameter estimation for short-range ensemble precipitation generation. $14^{\text {th }}$ Conference on Hydrology, American Meteorological Society, Boston, MA, pp.23-24.

Schaefer, M., 1997. Statement of Deputy Assistant Secretary for Water and Science, U.S. Department of the Interior before the Subcommittee on Water and Power, Committee on Resources, U.S. House of Representatives, 30 October 1997, Washington, DC.

Shafer, B.A. and J.M. Huddleston, 1984. Analysis of seasonal volume streamflow forecast errors in the western United States. Proceedings, A Critical Assessment of Forecasting in Water Quality Goals in Western Water Resources Management, American Water Resources Association, Bethesda, MD, pp. 117-126.

Shelton, D.R., and E.L. May, 1996. Modernized hydrologic forecast operations at National Weather Service weather forecast offices. Presented at the $12^{\text {th }} 13^{\text {th }}$ International Conference on Interactive Information and Processing Systems for 
Meteorology, Oceanography, and Hydrology, American Meteorological Society, Atlanta, GA, 28 January-2 February 1996.

Sheppard, P.R., A.C. Comrie, G.D. Packin, K. Angersbach, and M.K. Hughes, 1999. The Climate of the Southwest. Report to the Climate Assessment Project for the Southwest, Institute for the Study of Planet Earth, University of Arizona, Tucson, AZ.

Silberberg, S., G. Sebenste, B. Commare, N. Marsih, and M. Russo, 1997. Northern Illinois University real-time model verification. Department of Geography, Northern Illinois University, DeKalb, IL.

Silberberg, S., 1998. NCEP/ECMWF/NOGAPS model performance: severe storm forecasting implications. Department of Geography, Northern Illinois University, DeKalb, IL.

Sittner, W.T., C.E. Schauss, and J.C. Monro, 1969. Continuous hydrograph synthesis with an API-type hydrologic model. Water Resources Research 5(5):1007-1022.

SRP, 1998a. URL: http://www.srpnet.com/

SRP, 1998b. Weather and Climate Forecasting at SRP: Summary for the Forecast Assessment Workshop. Forecast Assessment Workshop, Southwest Climate Assessment Project, Institute for the Study of Planet Earth, University of Arizona, Tucson, AZ, 8 July 1998.

Staudenmaier, M.J., 1996a. A description of the meso Eta model. Western Regional Technical Attachment No. 96-06, 27 February 1997, National Weather Service Forecast Office, Salt Lake City, UT.

Staudenmaier, M.J., 1996b. The convective parameterization scheme in the meso Eta model. Western Regional Technical Attachment No. 96-23, 17 September 1996, National Weather Service Forecast Office, Salt Lake City, UT.

Staudenmaier, M.J., 1996c. The explicit cloud prediction scheme in the meso Eta model. Western Regional Technical Attachment No. 96-29, 19 November 1996, National Weather Service Forecast Office, Salt Lake City, UT.

Staudenmaier, M.J., 1996d. The initialization procedure in the meso Eta model. Western Regional Technical Attachment No National Weather Service Forecast Office. 96-30, 26 November 1996, National Weather Service Forecast Office, Salt Lake City, UT.

Staudenmaier, M.J., 1997a. The benefits of higher resolution in representing topography. Western Regional Technical Attachment No. 97-01, 7 January 1997, National Weather Service Forecast Office, Salt Lake City, UT. 
Staudenmaier, M.J., 1997b. Why is high resolution important in the West? An early look at the Eta-10 model output. Western Regional Technical Attachment No. 97-03, 21 January 1997, National Weather Service Forecast Office, Salt Lake City, UT.

Staudenmaier, M.J., 1997c. The soil model in the Eta. Western Regional Technical Attachment No. 97-07, 25 February 1997, National Weather Service Forecast Office, Salt Lake City, UT.

Staudenmaier, M.J., 1997d. The Navy Operational Global Atmospheric Prediction Systems (NOGAPS). Western Regional Technical Attachment No. 97-09, 25 March 1997, National Weather Service Forecast Office, Salt Lake City, UT.

Sweeney, T.L., 1998. Modernized flash flood guidance. Hydrologic Research Laboratory, Office of Hydrology, NWS, Silver Springs, MD. URL: http://hsp.nws.noaa.ogv/oh/hrl/ffg/ffgplan.htm.

Tarboton, D.G., 1995. Hydrologic scearios for severe sustained drought in the Southwestern United States. Water Resources Bulletin 31(5):803-814.

Tucson WFO, undated. The role of hydrology at NWS Tucson. NWS Weather Forecast Office, Tucson, AZ, URL: http://www.wrh.noaa.gov/Tucson/hydro/hydrorole.html.

Unger, D.A., 1996a. Long lead climate prediction using screening multiple linear regression. Proceedings of the $20^{\text {th }}$ Annual Climate Diagnostics Workshop, Climate Prediction Center, National Centers for Environmental Prediction, NOAA, Silver Springs, MD, pp. 425-428.

Unger, D.A., 1996b. Forecasts of surface temperature and precipitation anomalies over the U.S. using screening multiple linear regression. Experimental Long Lead Bulletin 1(4):

http://www.nnic.noaa.gov/products/predictions/experimental/bulletin/Sep96/art57.html, Climate Prediction Center, National Centers for Environmental Prediction, NOAA.

USDA, 1998. Introducing the GEM Climate Simulation Model. Fact Sheet, National Water and Climate Center, Natural Resources Conservation Service, Portland, OR.

Vaccaro, J.J., 1996. Watershed and river system management program (Yakima initiative). USGS Project WA407 - Yakima Initiative, USGS District Office, Tacoma, WA.

Valdes, J., K. Lansey, R. Koch, and H. Loaiciga, 1998. Decision support system for river system management under hydroclimatic uncertainty. State Water Resources Research Institutes 1998 Competitive Grants Award, U.S. Geological Survey. URL: http://water.usgs.gov/wrri/98grants/98grants.html. 
WeatherSites, 1998. What forecast terms mean. URL:

http://www.weathersite.com/BanWxterms1.html.

Wells, E. and M. Markus, 1996. A verification system for probabilistic hydrographs. Presented at the 1996 International Conference on Natural Disaster Reduction, American Society of Civil Engineers, Washington, DC, December 1996.

Western Regional Climate Center, 1998. Long-lead Climate Outlook Frequently Asked Questions. Desert Research Institute, University and Community College Systems of Nevada, Reno, NV. URL: http://www.wrcc.dri.edu/longrang/question.html.

Whitaker, J.S. and A.F. Loughe, 1997. The relationship between ensemble spread and ensemble mean skill. Monthly Weather Review 126(12):3292-3302.

Wilder, J., K. Beckford, S. Borenstein, L. Druyan, A. Estrella, J. Hansen, J. Knox, R. Miller, and R. Ruedy, 1997. Winter forecast by the GISS SI97 model based on fixed SST anomalies. Experimental Long-Lead Forecast Bulletin 6:2-8.

Winchell, M., 1996. Exploring the need for more effective use of QPFs in short term hydrologic forecasting. Unpublished report, Department of Hydrology and Water Resources, University of Arizona, Tucson, AZ, 24 pp. [Available from H. Gupta, Harshbarger Room 122, University of Arizona, Tucson, AZ 85721]

Woodard, G. and C.M. Horn, 1988. Effects of weather and climate on municipal water demand in Arizona. Report prepared for the Arizona Department of Water Resources and Tucson Water, Division of Economic and Business Research, University of Arizona, Tucson, AZ.

Woodhouse, C.A., 1997. Winter climate and atmospheric circulation patterns in the Sonoran Desert region. International Journal of Climatology 17:859-873.

Woods, A., 1997. ECMWF operational deterministic forecasting system, December 1996 - a summary. Accessed via HPC frames, updated 7 January 1997. Contact: Austin.Woods@ecmwf.int.

Woolhiser, D.A., C.L. Hanson, and C.W. Richardson, 1988. Microcomputer Program for Daily Weather Simulation. Technical Report ARS-75, USDA Agricultural Research Service, Tucson, AZ.

Work, R.A. and R.T. Beaumont, 1958. Basic data characteristics in relation to runoff forecast accuracy. Proceedings, 1958 Western Snow Conference, pp.45-53.

Zuzel, J.F., and L.M. Cox, 1978. A review of operational water supply forecasting techniques in areas of seasonal snowcover. Proceedings, 1978 Western Snow Conference, pp. 69-77. 
Figure 1. 12-hour short-range weather forecast graphical product issued by the NWS Hydrometeorological Prediction Center (HPC).

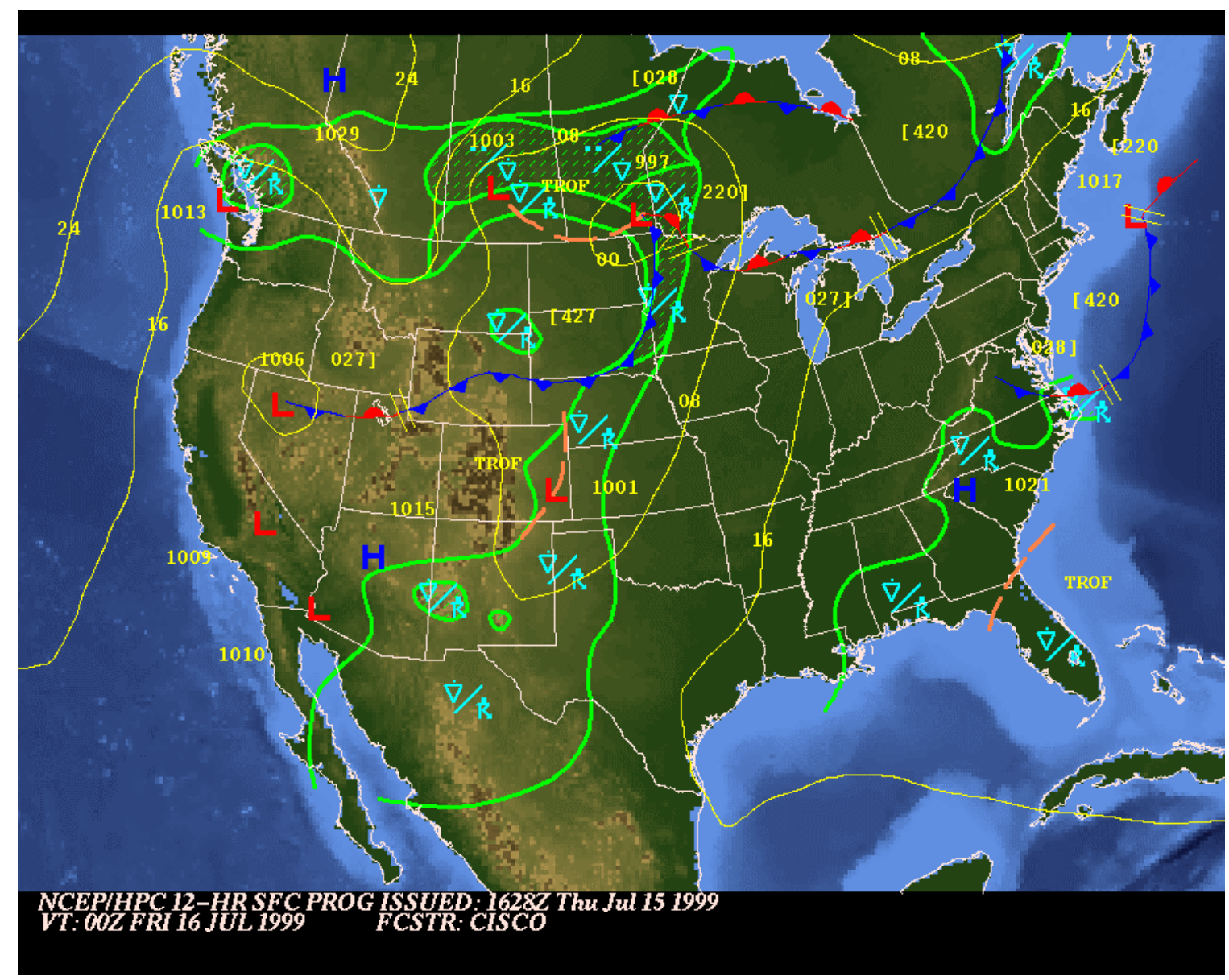


Figure 2. 48-hour short-range weather forecast graphical product issued by the NWS HPC.

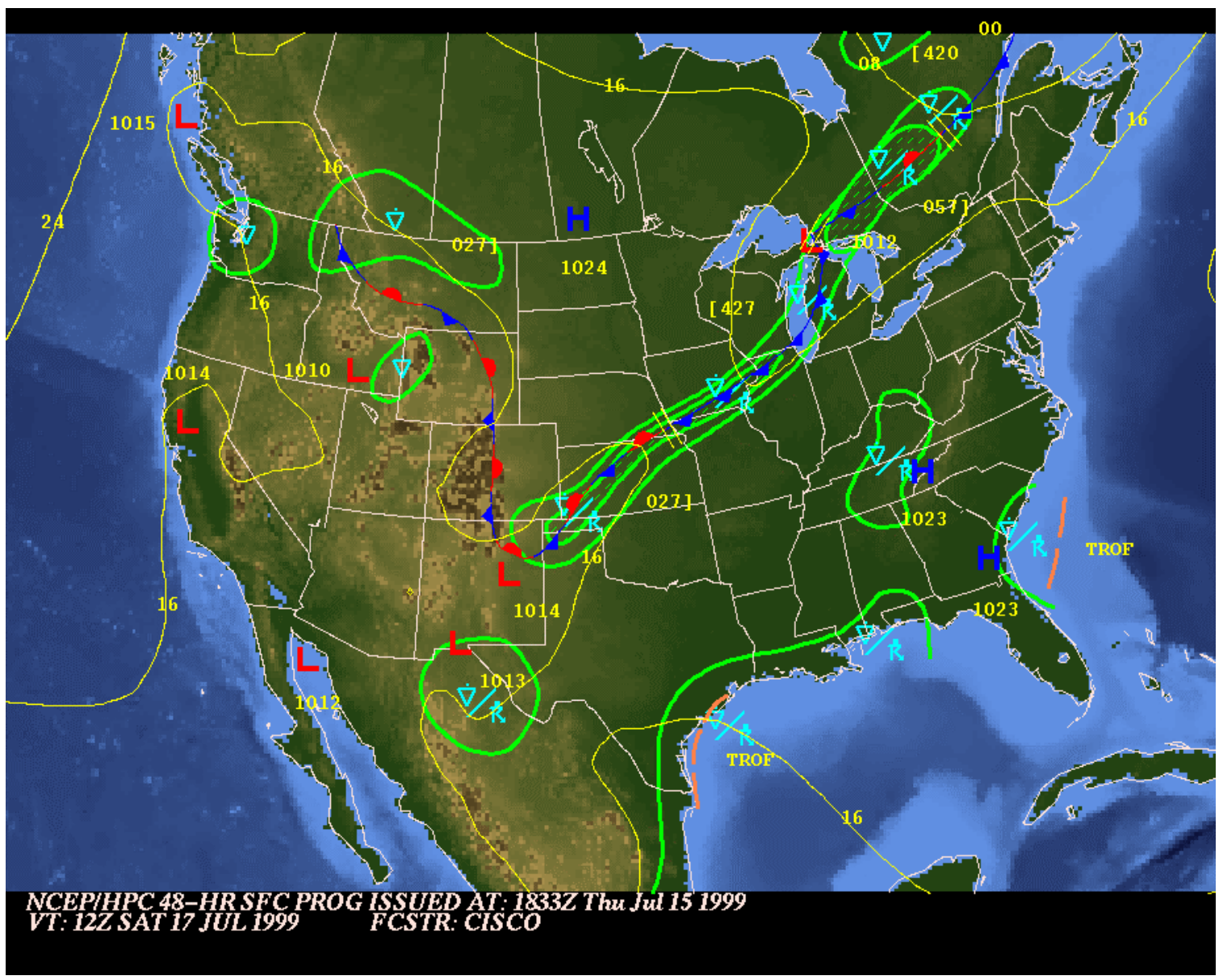


Figure 3. 3-day lead-time forecast of daily maximum air temperature issued by the NWS HPC.

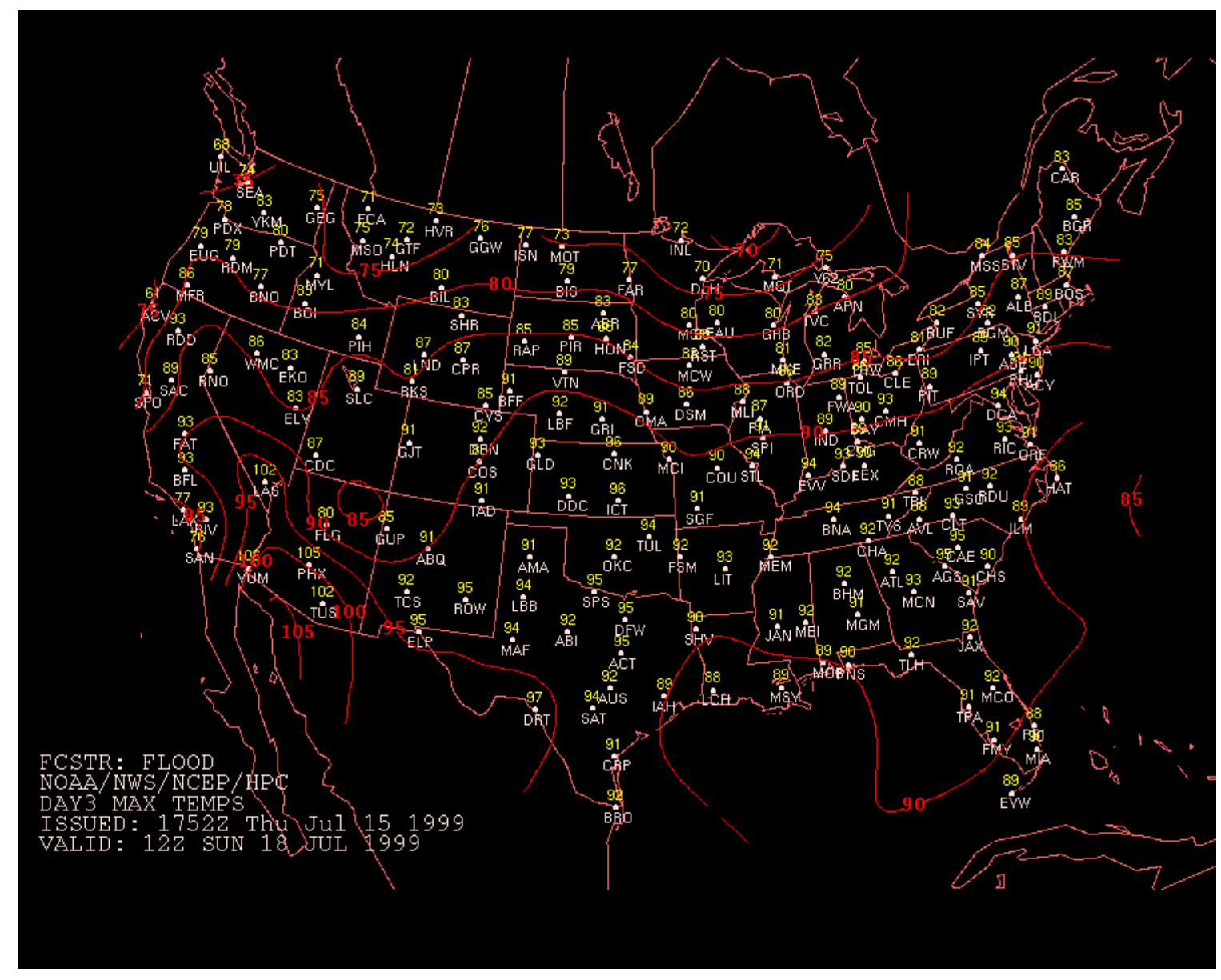


Figure 4. 5-day lead-time forecast of precipitation probability issued by the NWS HPC.

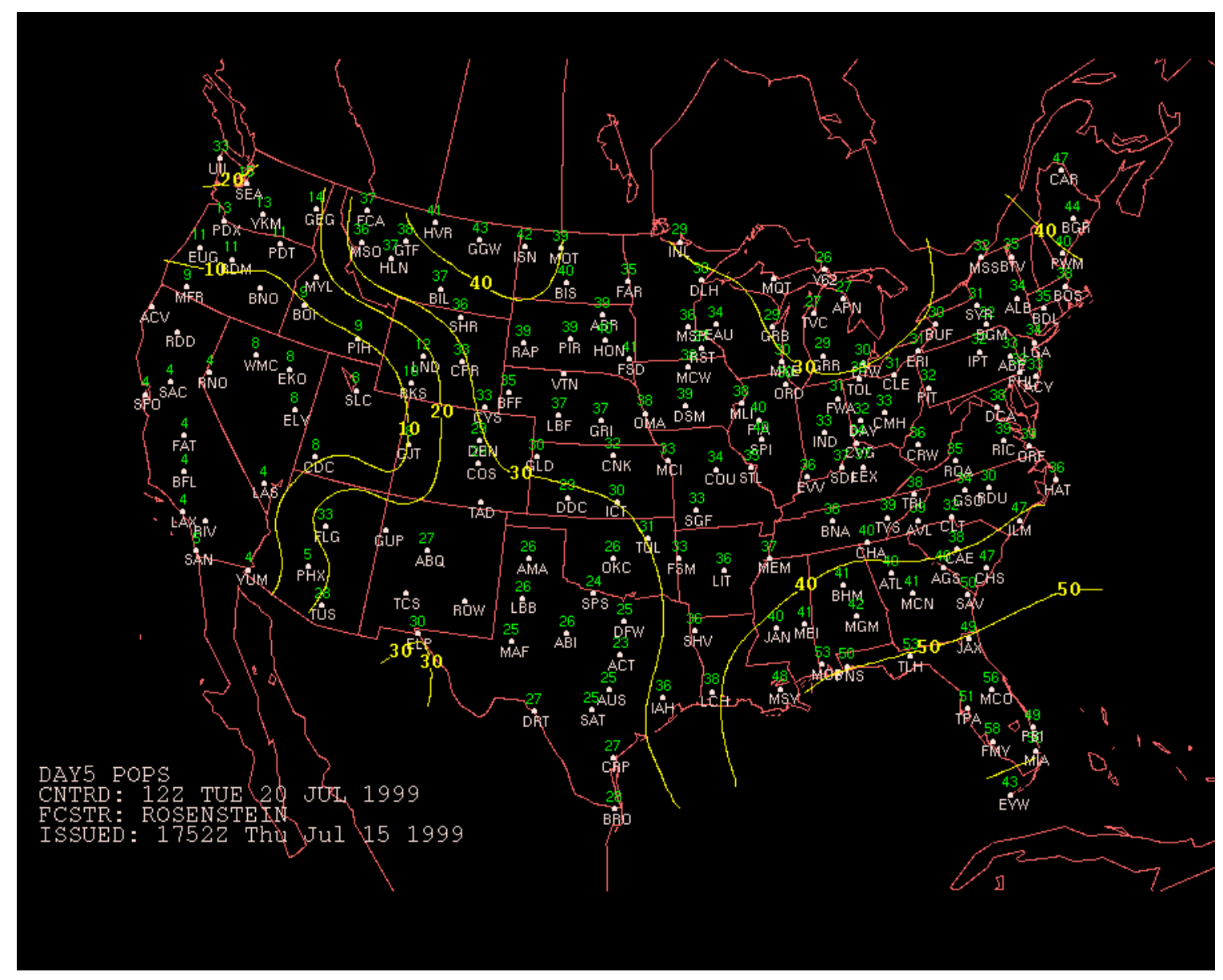


Figure 5. 5-day total precipitation forecast issued by the NWS HPC.

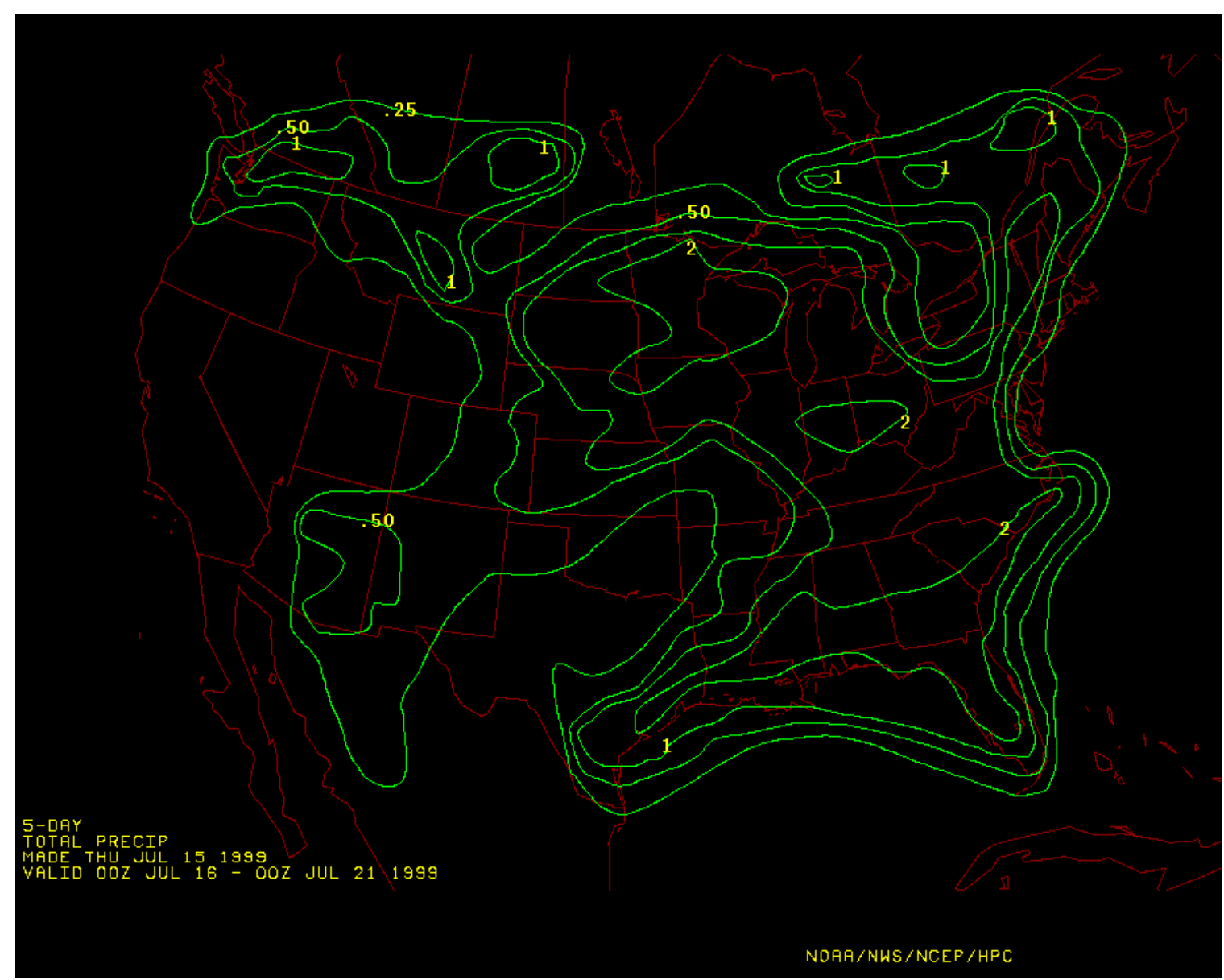


Figure 6. 7-day lead-time precipitation probability forecast issued by the NWS HPC.

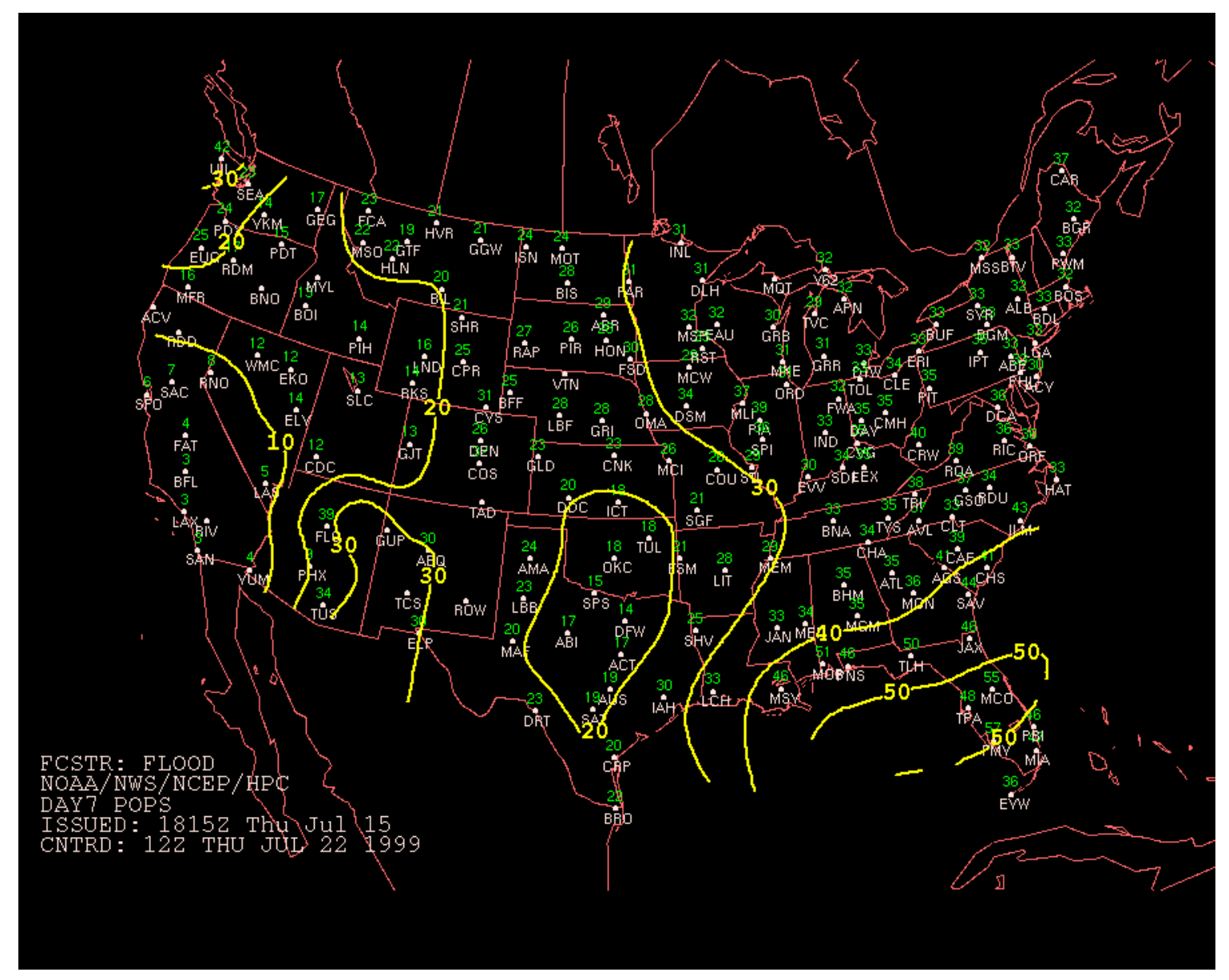


Figure 7. Ensembles of forecasts of atmospheric pressure height contours, from the NWS NCEP Medium Range Forecast (MRF) model. Top image is for day 3 of the forecast period, middle image is for day 7, and bottom image shows the day 3-7 mean contour location.
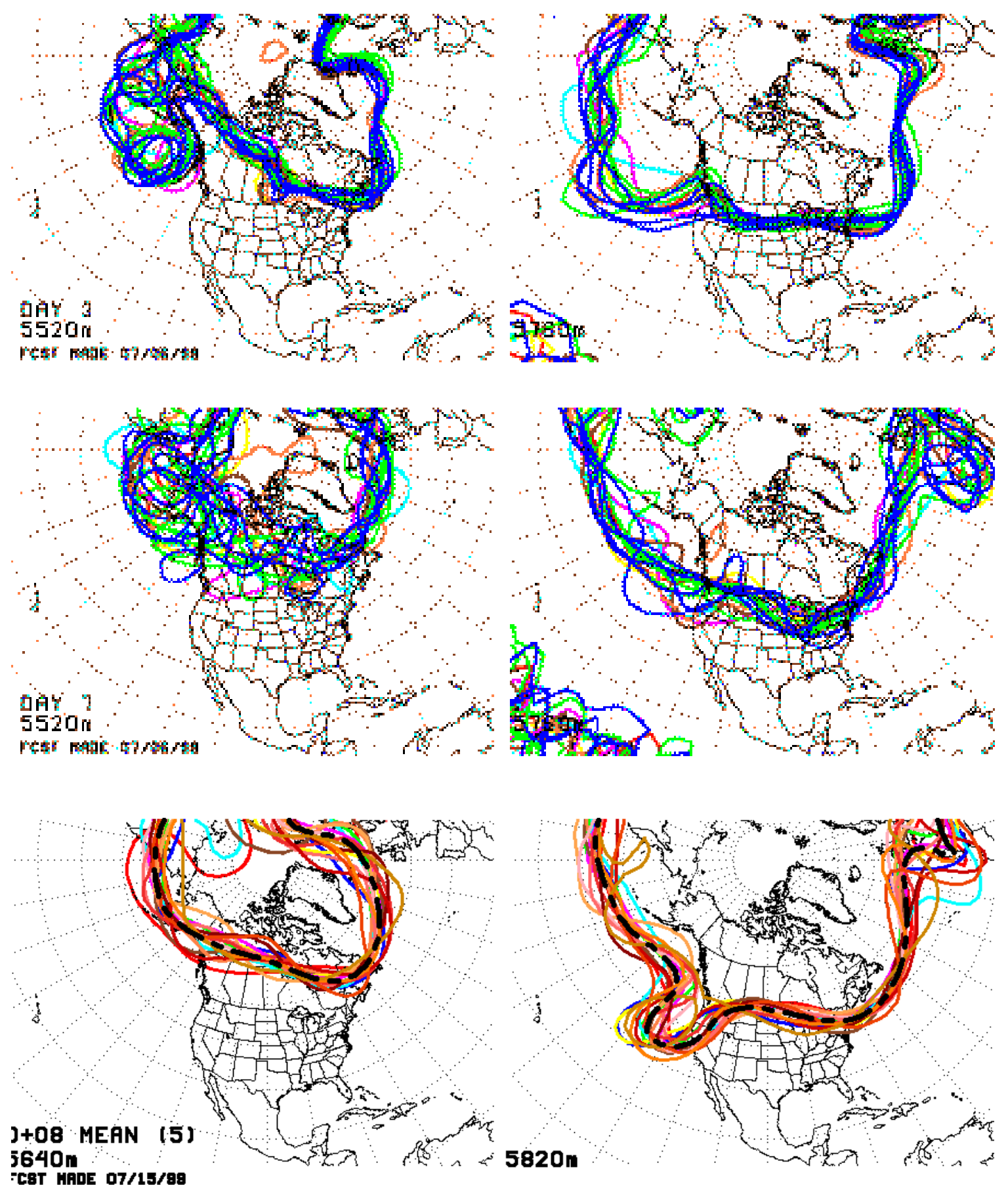
Figure 8. Experimental threats assessment issued by the NWS National Centers for Environmental Prediction (NCEP).

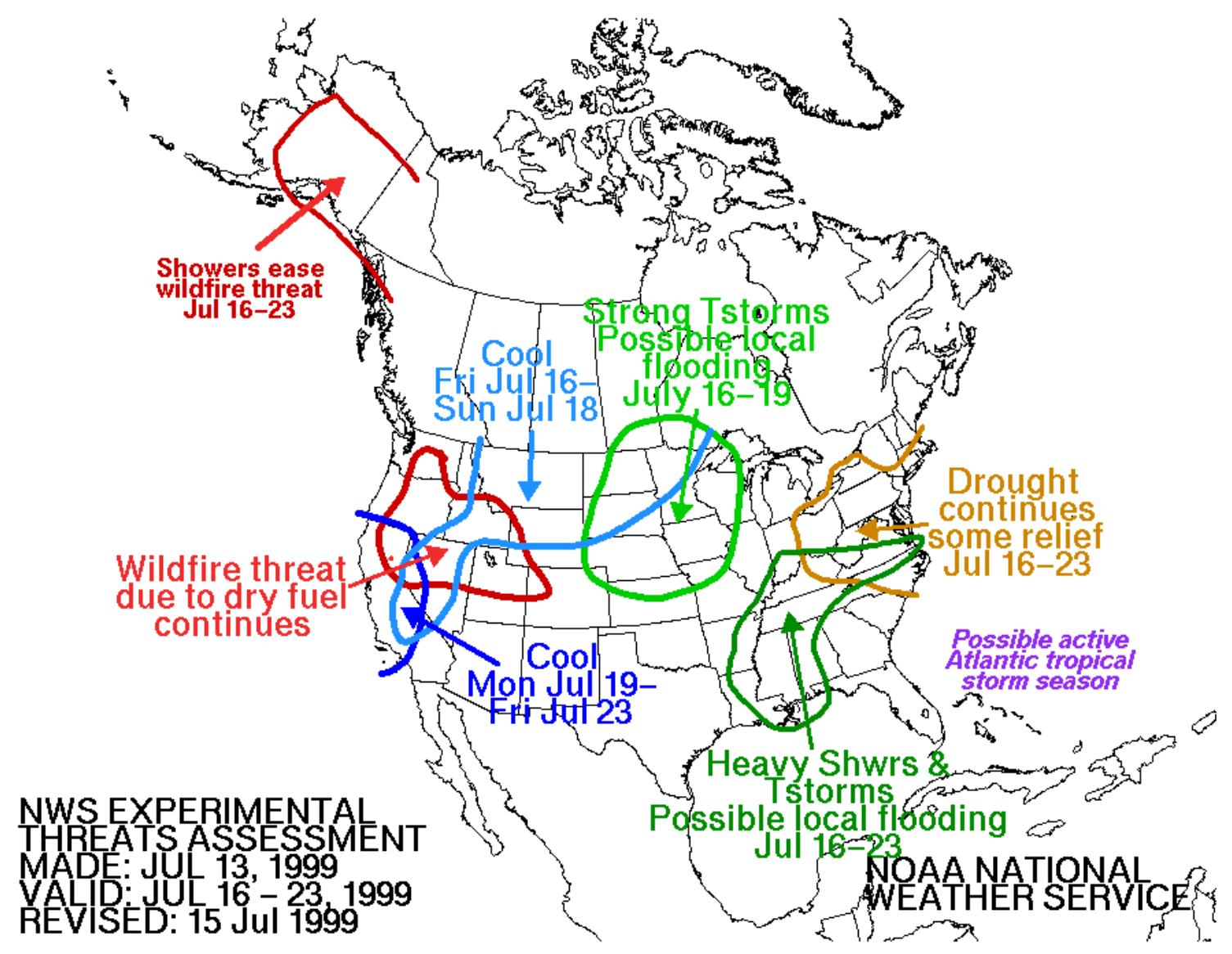


Figure 9. Southeast Arizona convective outlook graphical forecast of expected areal coverage of thunderstorms. Issued by the NWS Tucson Weather Forecast Office (WFO).

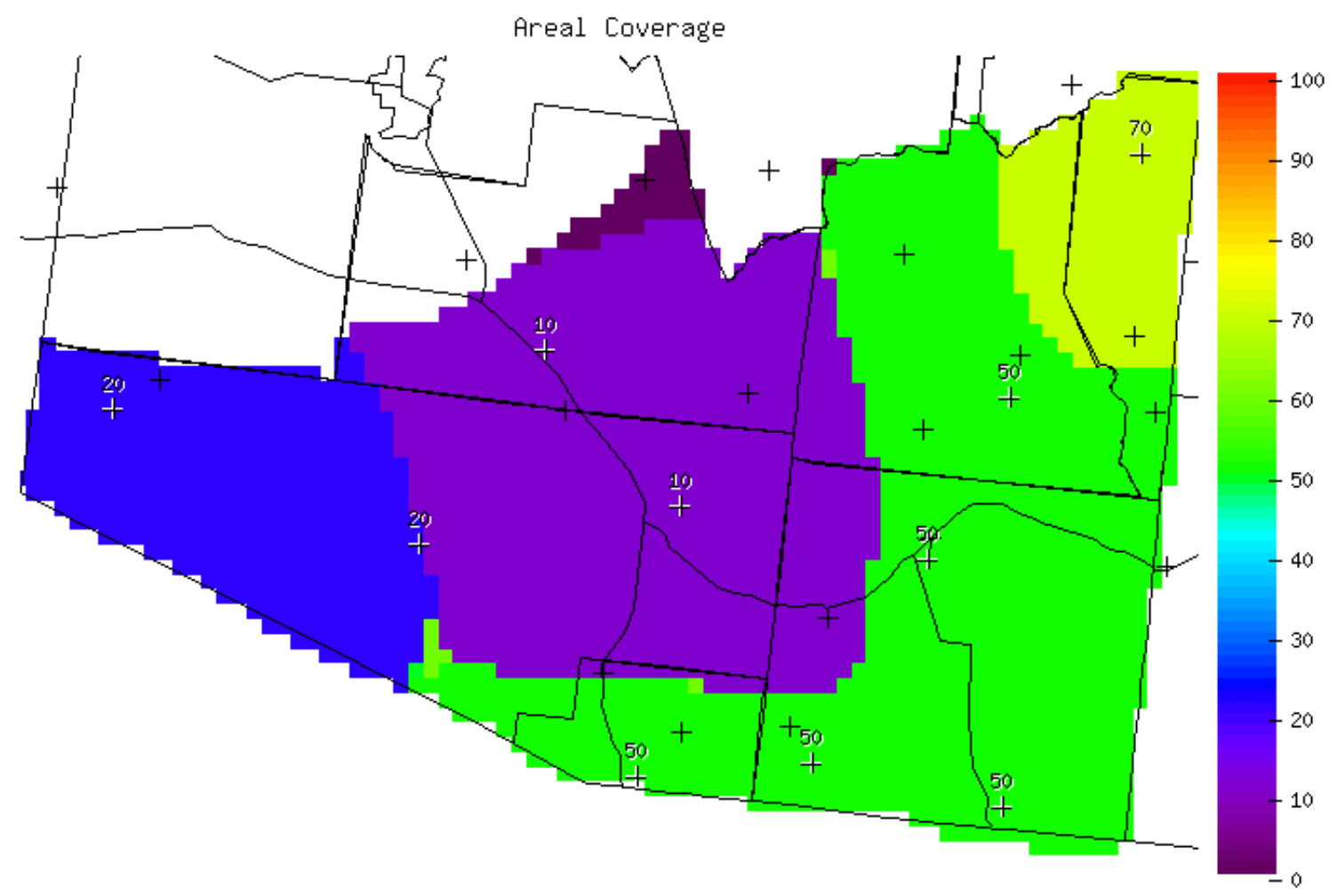

From: Jul 14202 To: Jul 15082 
Figure 10. Southeast Arizona convective outlook graphical forecast showing the conditional probability of receiving at least 1 inch of precipitation from a thunderstorm. Issued by the NWS Tucson WFO.

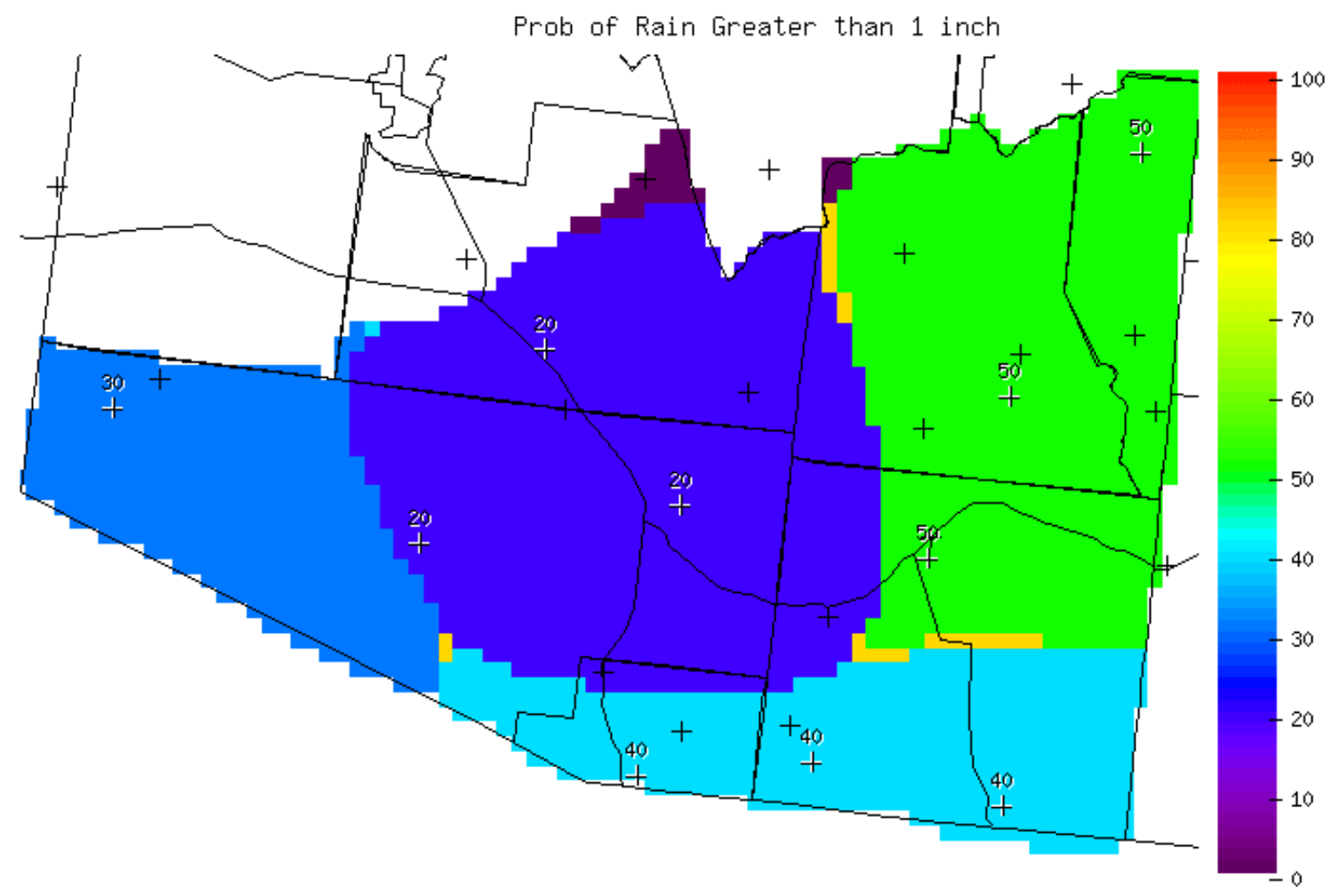

From: Jul 14202 To: Jul 15082 
Figure 11. Example 1- and 3-month climate outlooks for temperature and precipitation, issued by the NWS Climate Prediction Center (CPC).
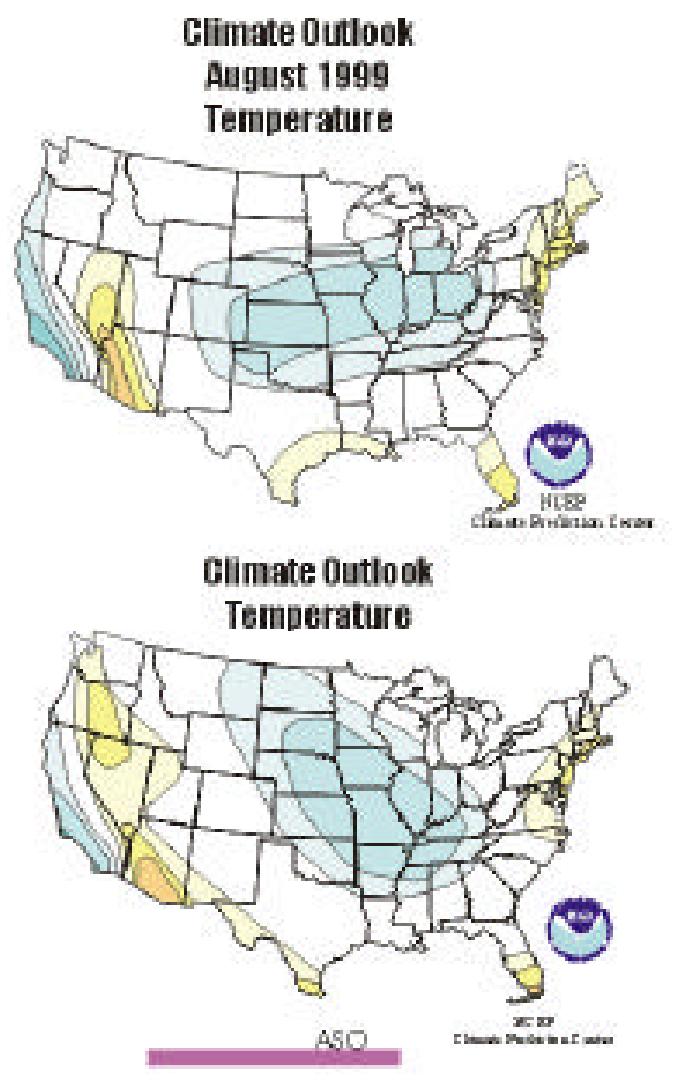

Climate 0utlook

August 1999

Precipitation

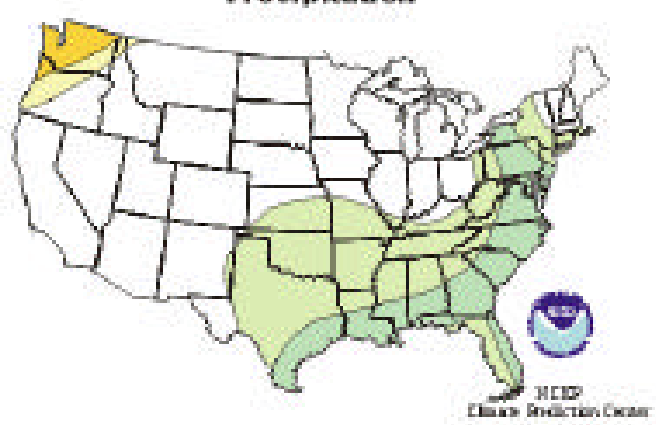

Climate 0utlook

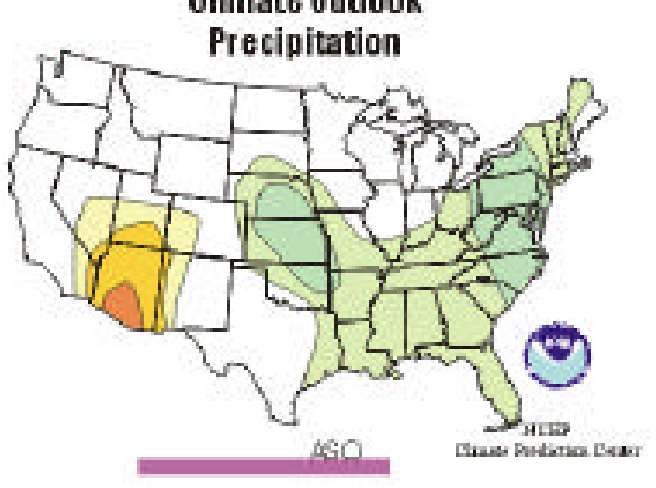

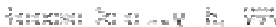


Figure 12. Example series of 12 seasonal temperature outlooks, issued by the NWS CPC.
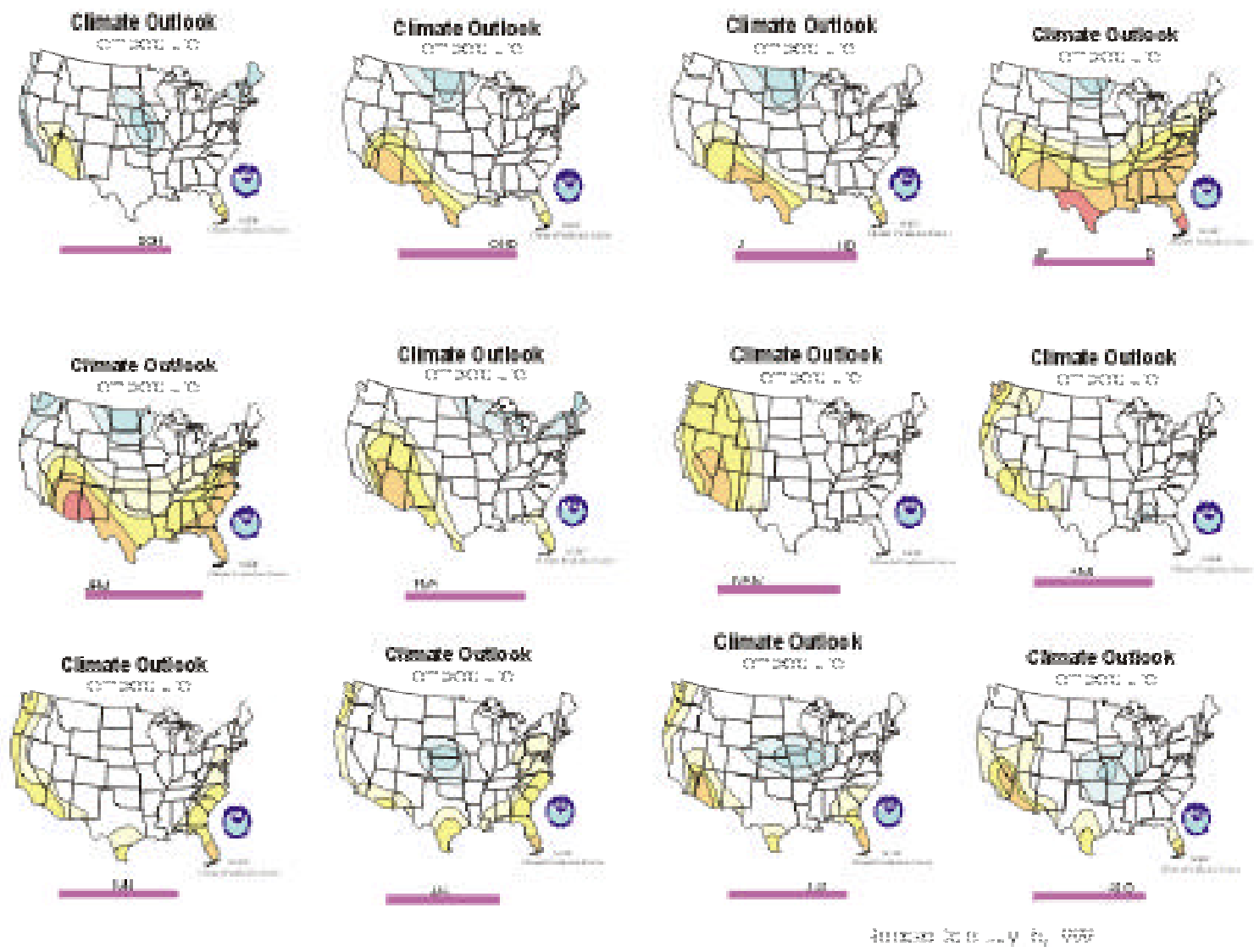
Figure 13. Example series of 12 seasonal precipitation outlooks, issued by the NWS CPC.
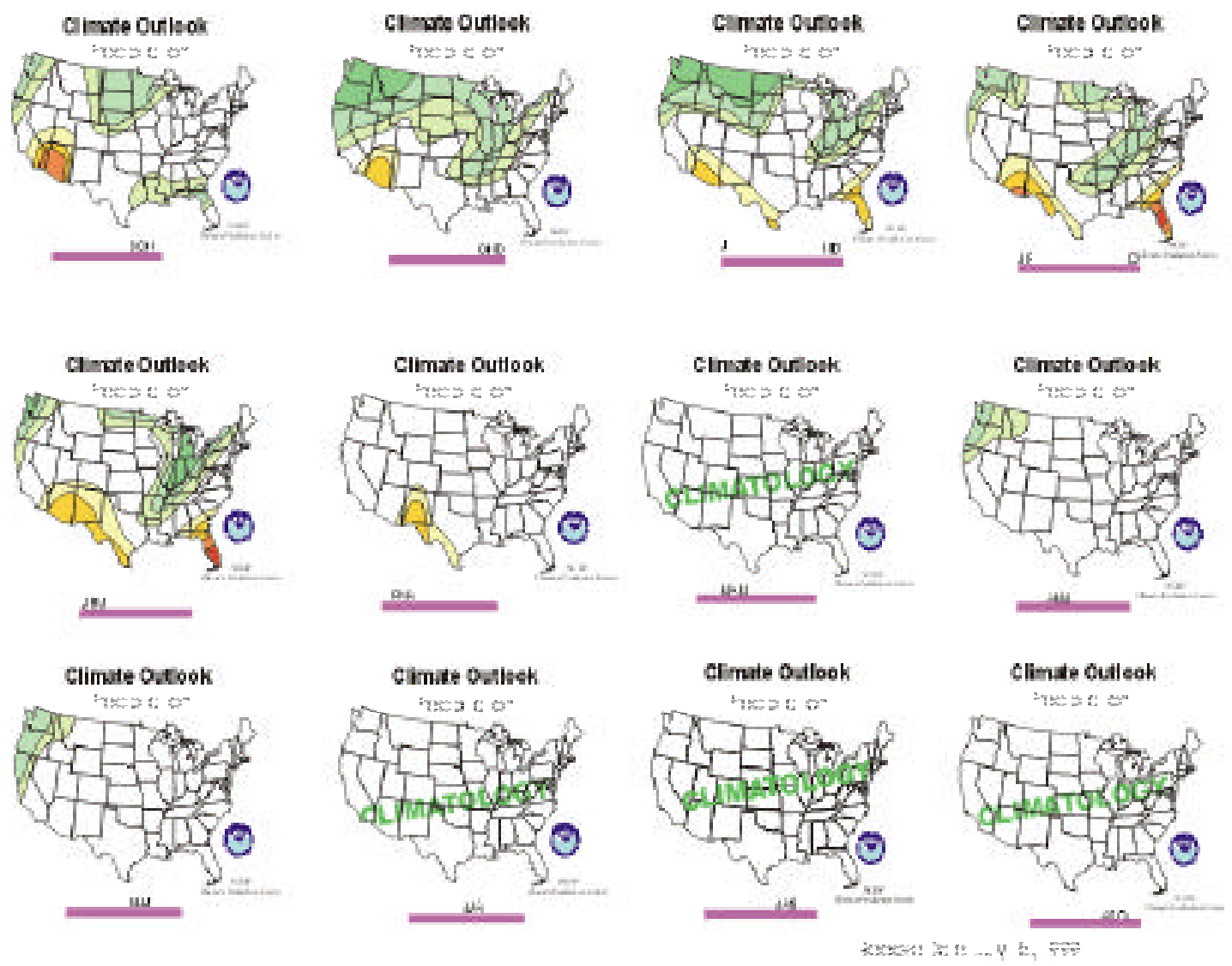
Figure 14. Legend to be used with the NWS CPC climate outlooks.

\section{Climate Outlook}

Thekey below is used to interpret each of the color versions of the Climate $O$ utlook products. In areas where confidence in $r$ redictive skill has been established, the probabilities of the above normal, near norm al or below normal categories ate incre ace d accordingly abovethe climatology level of $1 / 3$ for each categoy. These probabilities a contour ed at interval susingc olors as depi dedin the key below.

In those ar eas where the skill of aur pre ænt predction tools is not sufficient, the defaultis clim a ol cgy (white color). The $\mathrm{r} r$ babilities of ex periencirg e $\boldsymbol{\alpha}$ h of the thee categoties (above mormal, near nom al or bel ow normal) re main equalylikely (1/3)in the white areas onattached maps

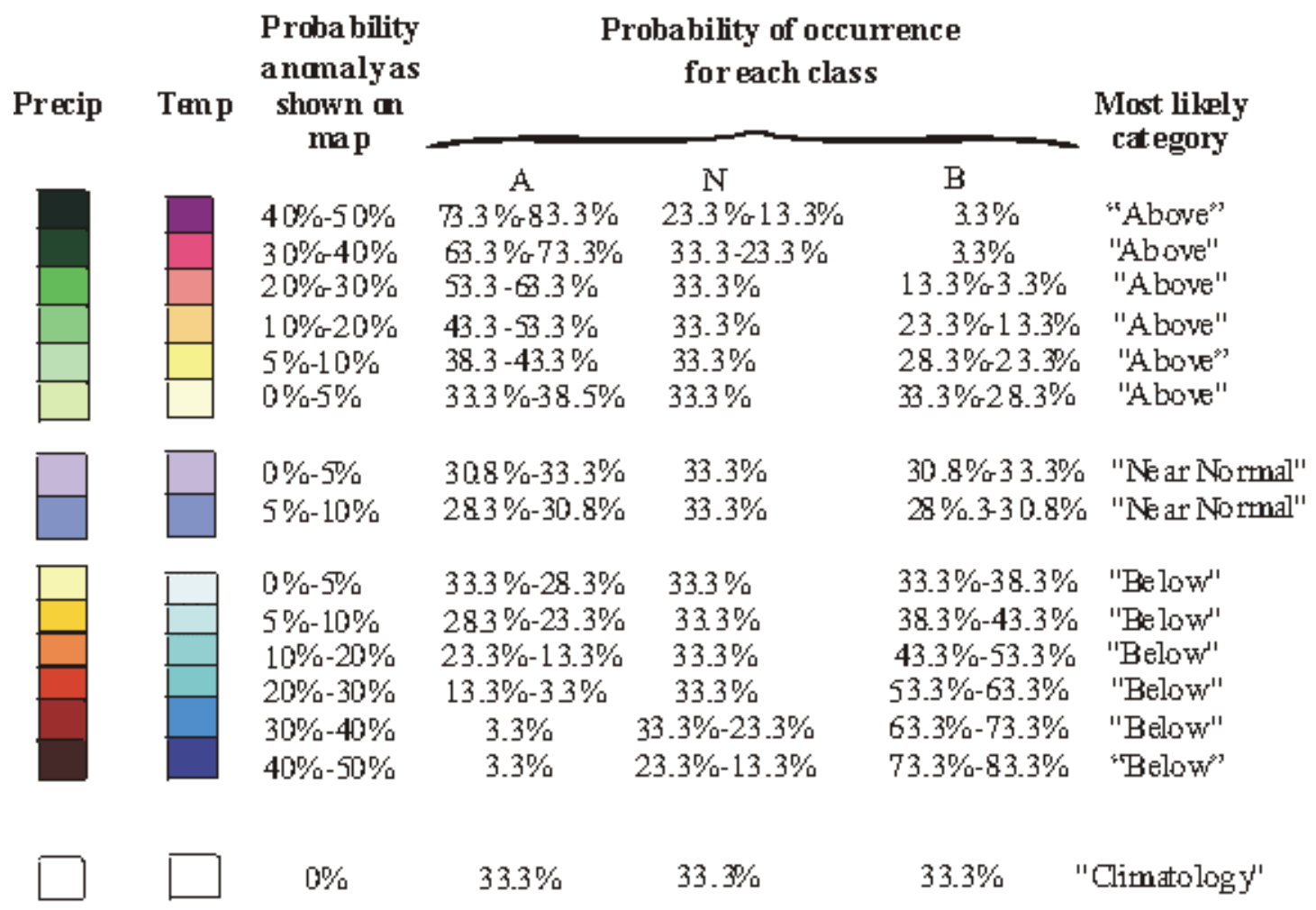
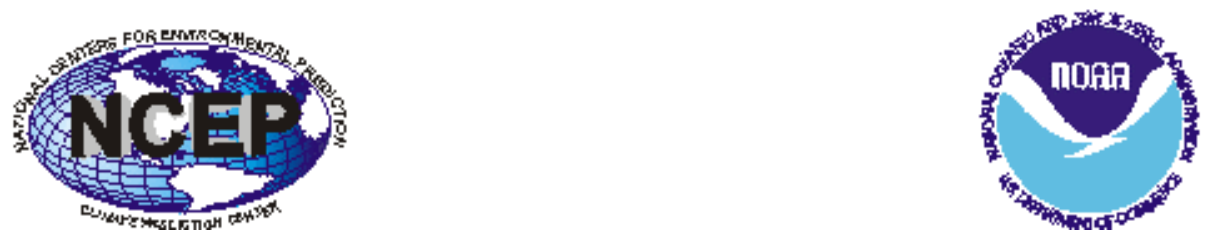
Figure 15. Example text discussion for monthly and seasonal climate outlook series, issued by the NWS CPC.

\author{
PROGNOSTIC DISCUSSION FOR LONG-LEAD OUTLOOKS \\ CLIMATE PREDICTION CENTER NCEP \\ NATIONAL WEATHER SERVICE WASHINGTON DC \\ 3 PM EDT THURSDAY JULY 151999 \\ PROGNOSTIC DISCUSSION OF SST FORECASTS \\ CURRENT CONDITIONS IN THE EAST-CENTRAL EQUATORIAL PACIFIC (120-170W \\ LONGITUDE AND 5S TO 5N - ALSO CALLED NINO 3.4) INDICATE THAT AT LEAST A \\ MODERATELY STRONG COLD ENSO EVENT IS CONTINUING. SSTS IN THE NINO 3.4 \\ AREA CONTINUE AT SLIGHTLY LESS THAN 2 STANDARD DEVIATIONS - 1 CELSIUS \\ DEGREE - BELOW NORMAL. WITH THE APPROACH OF NH SUMMER THE STANDARD \\ DEVIATION OF NINO 3.4 SST NORMALLY DECLINES TO HALF ITS WINTER VALUE. \\ THE TRADES ARE ABOVE AVERAGE - ESPECIALLY NEAR THE DATELINE - THERE \\ CONTINUES TO BE COLD SUB-SURFACE WATER BETWEEN 155E AND 90W AND \\ ATMOSPHERIC CIRCULATION AND CONVECTION PATTERNS IN THE TROPICAL PACIFIC \\ CONTINUE TO REFLECT LA NINA CONDITIONS.
}

THE NCEP COUPLED MODEL AND THE CCA PREDICT THAT THE SST ANOMALY IN THE NINO 3.4 REGION WILL MAINTAIN OR STRENGTHEN FROM ITS CURRENT VALUE OF 1 CELSIUS DEGREES. THE CONSTRUCTED ANALOG TOOL PREDICTS EVEN STRONGER NEGATIVE SST ANOMALIES THERE. ALL TOOLS PREDICT THAT THE ANOMALY WILL REACH ITS GREATEST MAGNITUDE IN LATE FALL OR EARLY WINTER - WITH A RAPID DECREASE IN MAGNITUDE THEREAFTER AND INCREASE IN UNCERTAINTY FOLLOWING MAM SO THAT - BY LATE SPRING 2000 - THE STATE OF ENSO WILL BE QUITE UNCERTAIN. BY SUMMER 2000 THE CCA MODEL INDICATES - WITH GREAT UNCERTAINTY - THAT AN EL NINO MIGHT BEGIN. THE CONSOLI- DATED FORECAST FOLLOWS THE CONSTRUCTED ANALOGUE FOR ALL LEADS THROUGH MAM 2000 - AFTER WHICH IT TRACKS CLOSER TO CCA. THE OFFICIAL FORECAST IS FOR CONTINUED LA NINA CONDITIONS WITH NINO 3.4 SST ANOMALIES NEAR -2 CELSIUS DEGREES THROUGH JFM 2000 AFTER WHICH THERE IS A RAPID DECLINE CULMINATING IN LATE SPRING 2000. CONSEQUENTLY - AFTER MAM 2000 ONLY CCA AND OCN WERE USED AS FORECAST TOOLS.

PROGNOSTIC DISCUSSION OF OUTLOOKS - ASO 1999 TO ASO 2000

AMONG THE TOOLS THAT WERE USED WERE CCA AND OCN FOR ALL LEADS. ANOTHER ESTIMATE FOR TREND - A LINEAR FIT SINCE 1966 - AND MULTIPLE LINEAR REGRESSION (MLR) WERE CONSIDERED FOR ALL LEADS AS WELL. WE GAVE CONSIDERABLE WEIGHT TO THE CAS SOIL MOISTURE TOOL FOR THE FIRST LEAD. THE HISTORICAL DISTRIBUTIONS OF U.S. T AND P ASSOCIATED WITH MODERATE TO STRONG LA NINA CONDITIONS WERE USED FROM ASO ONWARD THROUGH ABOUT FMA 2000. THE KNOWN IMPACT OF TROPICAL HEATING ANOMALIES ON THE MIDLATITUDES IS FAR LESS STRONG IN NH SUMMER THAN IN WINTER SO LA NINA COMPOSITES WERE WEIGHTED MOST HEAVILY DURING THE LATE FALL AND WINTER SEASONS .

EL NINO AND LA NINA COMPOSITES HAVE BEEN MOST RELIABLE AS PREDICTORS DURING THESE SEASONS. INDIRECT ENSO EFFECTS SUCH AS ABNORMALLY COLD SURFACE WATERS ALONG THE ENTIRE WEST COAST OF NORTH AMERICA AND ENSO INFLUENCE ON ATLANTIC BASIN TROPICAL STORM ACTIVITY - AS WELL AS CONTINENTAL U.S. SOIL MOISTURE ANOMALIES - APPEAR IN THE OTHER TOOLS SUCH AS CAS - CCA - CMP AND MLR. THE CMP FORECAST WAS RELIED UPON ONLY 


\section{Figure 15, cont'd. Example text discussion for monthly and seasonal climate outlook series, issued by the NWS CPC.}

THROUGH NEXT WINTER BECAUSE ITS SST ANOMALY IS PREDICTED TO WEAKEN TO SMALL VALUES BY THE FOLLOWING SPRING.

THE ASO FORECAST CALLS FOR ABOVE NORMAL TEMPERATURE IN MUCH OF THE WESTERN INTERMOUNTAIN REGION - SOUTHERN FLORIDA AND THE SOUTHERN NEW ENGLAND AND MIDDLE ATLANTIC COASTAL PLAINS. AGREEMENT AMONG THE SMT CMP AND TREND LEAD TO A FORECAST FOR A LARGE AREA OF BELOW NORMAL TEMPERATURE FOR MUCH OF THE GREAT PLAINS - MISSISSIPPI VALLEY AND THE LOWER OHIO VALLEY. PARTS OF CALIFORNIA ARE FORECAST TO BE COLD DUE TO SUB-NORMAL SSTS NEAR THE COAST. MODEST PROBABILITIES FOR ABNORMALLY WET CONDITIONS ARE PREDICTED FOR THE CENTRAL GREAT PLAINS AND LOWER HALF OF THE MISSISSIPPI VALLEY EASTWARD TO THE ATLANTIC COAST EXTENDING NORTHWARD OVER THE LOWER GREAT LAKES REGION AND ALL BUT COASTAL NEW ENGLAND. THIS IS CONSISTENT WITH THE ACTIVE ATLANTIC TROPICAL STORM SEASON EXPECTED DURING LA NINA - HENCE - MUCH OF THE EASTERN U.S. HAS A SLIGHTLY ENHANCED STATISTICAL CHANCE FOR WET CONDITIONS. BOTH THE COUPLED MODEL AND THE SOIL MOISTURE (CAS) TOOLS WERE IN GOOD AGREEMENT IN MOST AREAS AND WERE WEIGHTED HEAVILY FOR THE ASO FORECASTS OF BOTH TEMPERATURE AND PRECIPITATION. GUIDANCE FROM THE LA NINA COMPOSITES - WITH SUPPORT FROM THE COUPLED MODEL - WAS USED TO PREDICT RELATIVE DRYNESS IN THE SOUTHWEST.

FOR SON THROUGH FMA WE USED CCA - OCN - TRENDS AND COMPOSITES. THE WEIGHT OF THE LA NINA COMPOSITES WAS GREATLY REDUCED FOR FMA AND MAM ESPECIALLY FOR PRECIPITATION - AND WAS NOT USED THEREAFTER. THE COUPLED MODEL PREDICTS COLD TEMPERATURES OVER MUCH OF WESTERN CANADA JUST NORTH OF THE U.S. BORDER STATES PRIOR TO AND CONTINUING THROUGH THESE SEASONS. HENCE THE PREDICTION OF MODEST PROBABILITIES FOR BELOW NORMAL TEMPERAURES OVER THE NORTHERN PLAINS FROM OND THROUGH JFM EXTENDING EASTWARD THROUGH THE NORTHEAST IN FMA. THE CMP FORECAST WAS LARGELY CORRECT IN ITS INDICATIONS OF A GENERALLY MILD WINTER LAST YEAR OVER MUCH OF THE U.S. THE DIFFERENCE BETWEEN THIS YEAR AND LAST YEAR MAY BE THAT LAST YEAR THE ATMOSPHERE HAD STILL NOT DISSIPATED ALL THE RESIDUAL HEAT FROM THE PRIOR EL NINO. THIS YEARS COUPLED MODEL FORECASTS ARE IN QUITE GOOD AGREEMENT WITH THE RAW LA NINA COMPOSITES UNCORRECTED FOR THE TREND SIGNAL - AND THESE TOOLS WERE USED FOR THE FORECASTS ALONG THE NORTHERN BORDER DURING THOSE COLD SEASONS WHEN A WARMING TREND HAS BEEN MOST PRONOUNCED. FURTHER SOUTH - CCA - OCN AND BOTH TYPES OF LA NINA COMPOSITES GAVE STRONG SIGNALS FOR A LARGE AREA OF ABNORMAL WARMTH FOR DJF AND JFM - BUT THE RELIABLE WARM SIGNALS WERE CONFINED TO ONLY THE SOUTHWEST AND FLORIDA DURING THE REMAINING COLD SEASONS.

BELOW NORMAL TEMPERATURES ARE PREDICTED TO CONTINUE ALONG THE WEST COAST THROUGH SON IN RESPONSE TO EXPECTED BELOW NORMAL SSTS THROUGH THAT SEASON. HOWEVER - THE ATMOSPHERIC CIRCULATION PREDICTED BY THE COUPLED MODEL IMPLIES THAT TROUGHS WOULD NOT BE AS LIKELY TO DEEPEN NEAR THE WEST COAST OVER CALIFORNIA AS THEY DID MUCH OF LAST WINTER AND SPRING - BUT WOULD BE FAVORED FURTHER INLAND AND MORE TO THE NORTH. THUS WITH COLDER AIR INDICATED MORE IN THE INTERIOR AND TO THE NORTH THE CHANCES FOR POSSIBLE EPISODES OF WARMING DOWNSLOPE WINDS ALONG THE WEST COAST ARE INCREASED FROM OND THROUGH SUCCEEDING SEASONS - 
Figure 15, cont'd. Example text discussion for monthly and seasonal climate outlook series, issued by the NWS CPC.

RESULTING IN FORECASTS OF CLIMATOLIGICAL PROBABILITIES ALONG THE COAST UNTIL SPRING. AFTER THAT - WITH WANING INFLUENCE FROM LA NINA - THE STRONG TREND SIGNAL FOR WESTERN WARMTH INDICATED BY BOTH OCN AND CCA IS EXPECTED TO REASSERT ITSELF.

THE LA NINA SIGNAL IS EXPECTED TO PRODUCE DRYNESS IN THE SOUTHWEST THROUGHOUT AND IN THE SOUTHEAST BEGINNING WITH NDJ WHEN POSSIBLE INFLUENCES OF LA NINA-ENHANCED TROPICAL ACTIVITY SHOULD BE PAST. LA NINA COMPOSITE INDICATIONS FOR DRYNESS OVER THE SOUTHERN AND CENTRAL GREAT PLAINS DURING MUCH OF THE LATE WINTER AND SPRING WERE DISCOUNTED AS THAT AREA HAS A STRONG LONG-TERM TREND FOR MOSTLY WET CONDITIONS REGARDLESS OF THE PHASE OF ENSO. THEREFORE ABOVE MEDIAN PRECIPITATION WAS FORECAST WHERE OCN AND LA NINA COMPOSITES AGREED - AND CL WAS FORECAST WHERE THEY DISAGREED OR WERE WEAK. WET CONDITIONS FORECAST FOR THE PACIFIC NORTHWEST AND ALONG THE NORTHERN BORDER DURING THE COLD SEASONS COME MAINLY FROM LA NINA COMPOSITES. RELATIVELY HEAVY LATESEASON PRECIPITATION PREDICTED OVER THE PACIFIC NORTHWEST FOR AMJ AND MJJ - AFTER LA NINA INFLUENCES HAVE WEAKENED - IS DUE TO STRONG AGREEMENT OF BOTH CCA AND OCN. THESE WERE THEONLY TOOLS USED BEYOND FMA 2000. THE ALASKAN FORECASTS REFLECT PRIMARILY THE COUPLED MODEL TOOL DURING THE SHORTER LEADS AND ARE BASED ON ONLY THE CCA TOOL AT LONGER LEADS. THE LATTER GAVE AN UNSUALLY STRONG SIGNAL FOR WARMTH FROM NEXT SPRING THROUGH SUMMER - AND WAS BELIEVED RELIABLE DUE TO RECENT OBSERVED TRENDS.

FOR A DESCRIPTION OF THE STANDARD FORECAST TOOLS - THEIR SKILL -AND THE FORECAST FORMAT PLEASE SEE OUR WEB PAGE AT:HTTP : / /WWW. CPC.NCEP.NOAA.GOV/PRODUCTS / PREDICTIONS / MULTI-SEASON/13_SEASONAL_OUTLOOKS / TOOLS

NOTE - THESE CLIMATE OUTLOOKS ARE INTENDED FOR USE PRIOR TO THE START OF THEIR VALID PERIODS. WITHIN ANY GIVEN VALID PERIOD OBSERVATIONS AND SHORT AND MEDIUM RANGE FORECASTS SHOULD BE CONSULTED. ALSO - THIS SET OF OUTLOOKS WILL BE SUPERSEDED BY THE ISSUANCE OF THE NEW SET NEXT MONTH ON THURSDAY AUG 191999. 
Figure 16. Contour map of $\mathbf{3 3 . 3 \%}$ non-exceedance quantile precipitation for August-October, issued by the NWS CPC.

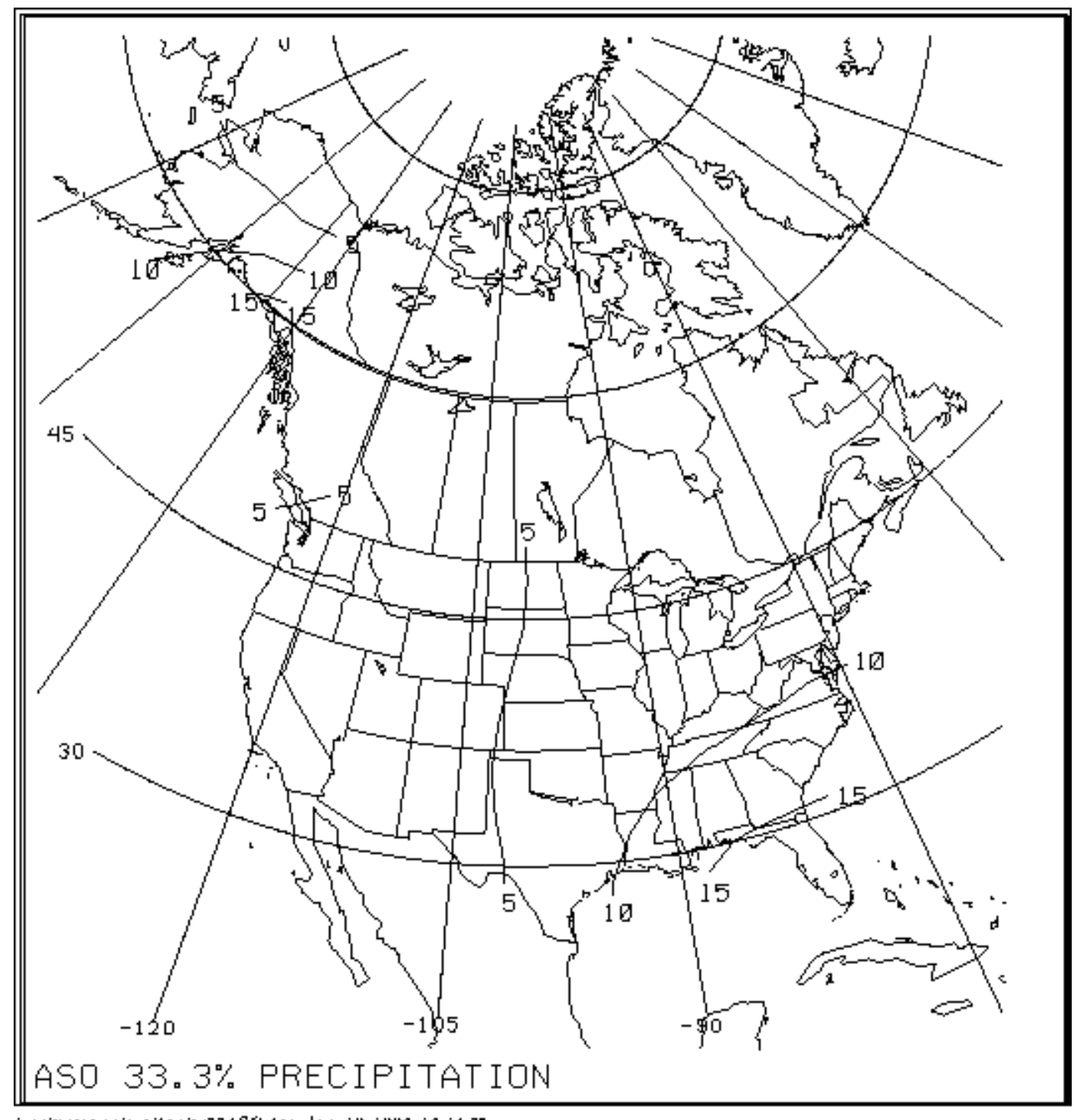

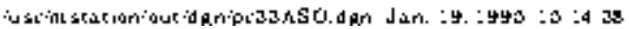


Figure 17. Contour map of $66.7 \%$ non-exceedance quantile precipitation for August-October, issued by the NWS CPC.

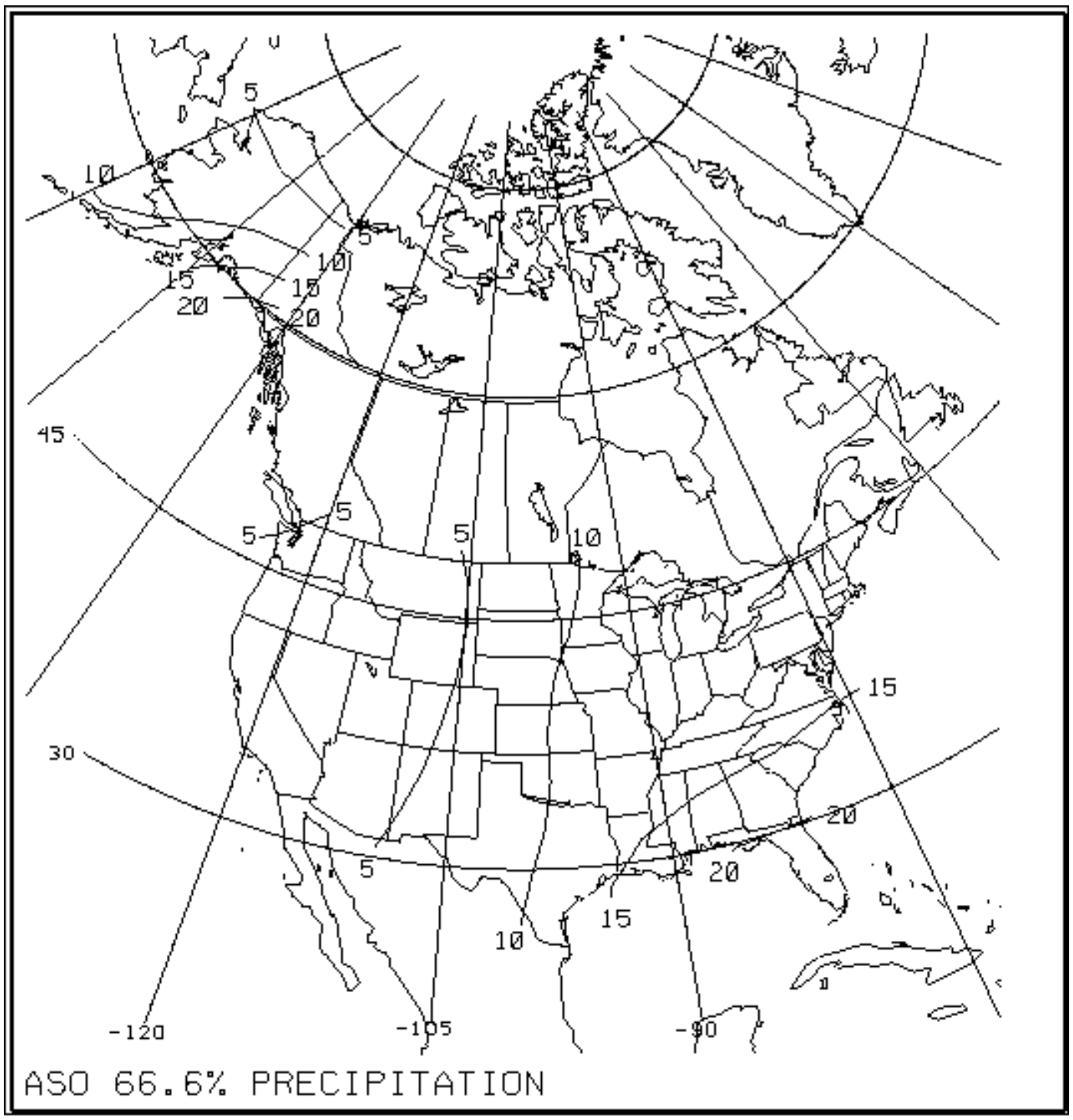

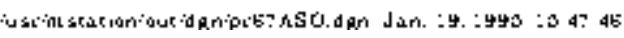


Figure 18. Contour map of mean temperatures for August-October, issued by the NWS CPC. Dashed line shows one standard deviation class limits.

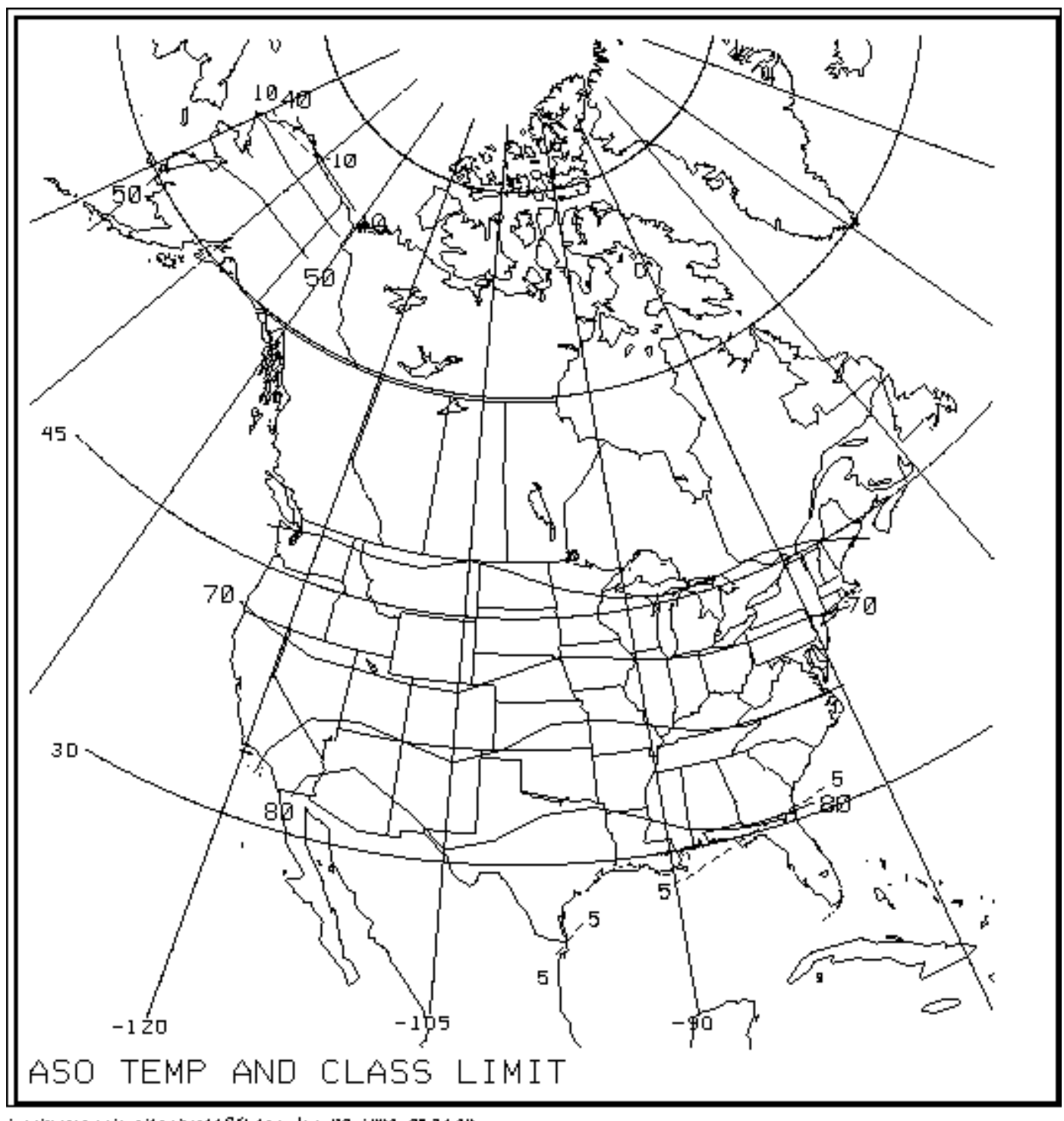

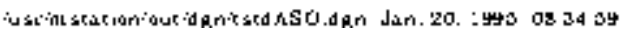


Figure 19. Contour map of mean temperatures for January-March, issued by the NWS CPC. Dashed line shows one standard deviation class limits.

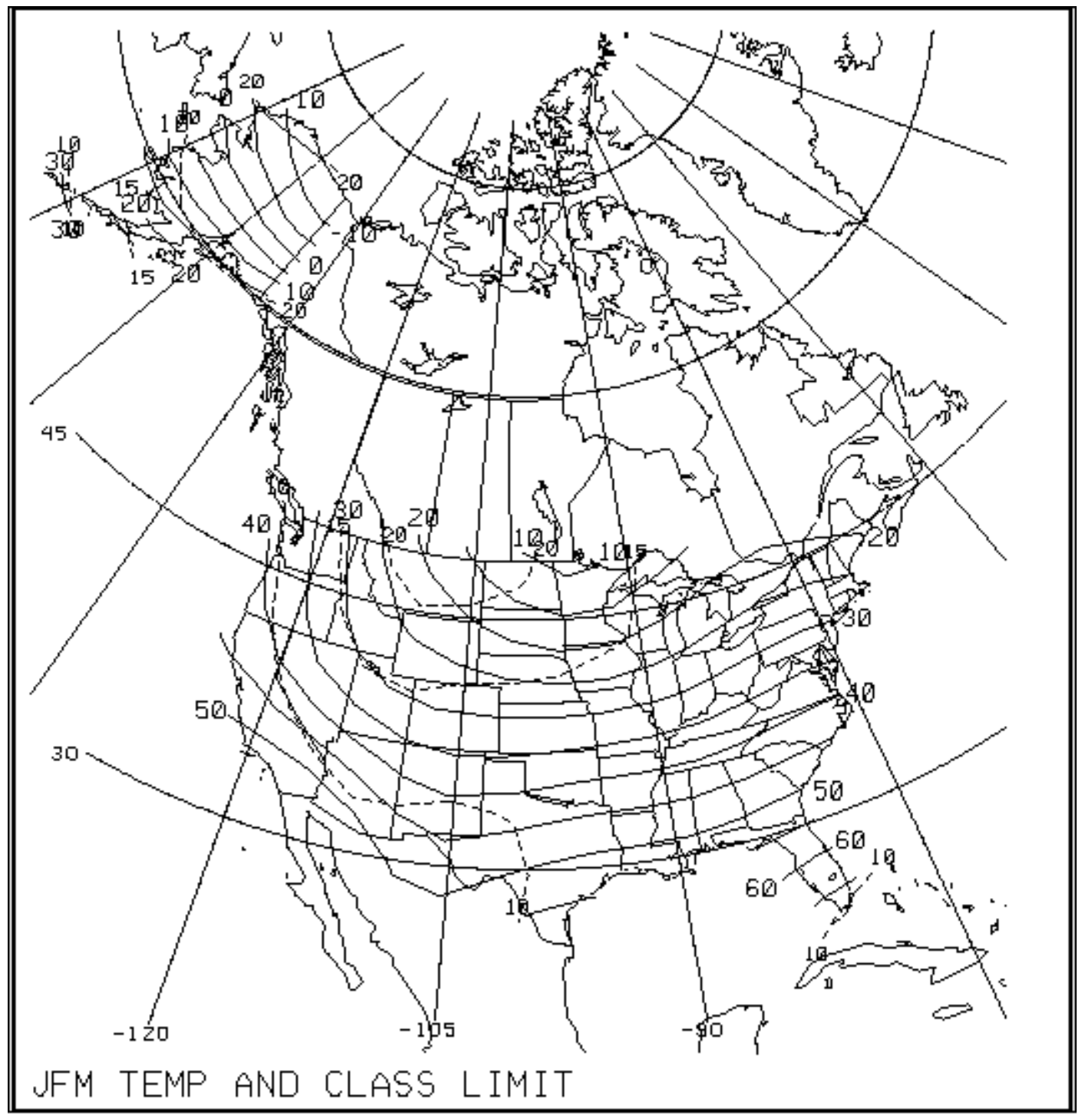

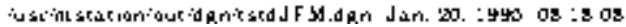


Figure 20. Map of predictive skill for temperature and precipitation using canonical correlation analysis with 0.5 -month lead-time, from the NWS CPC.
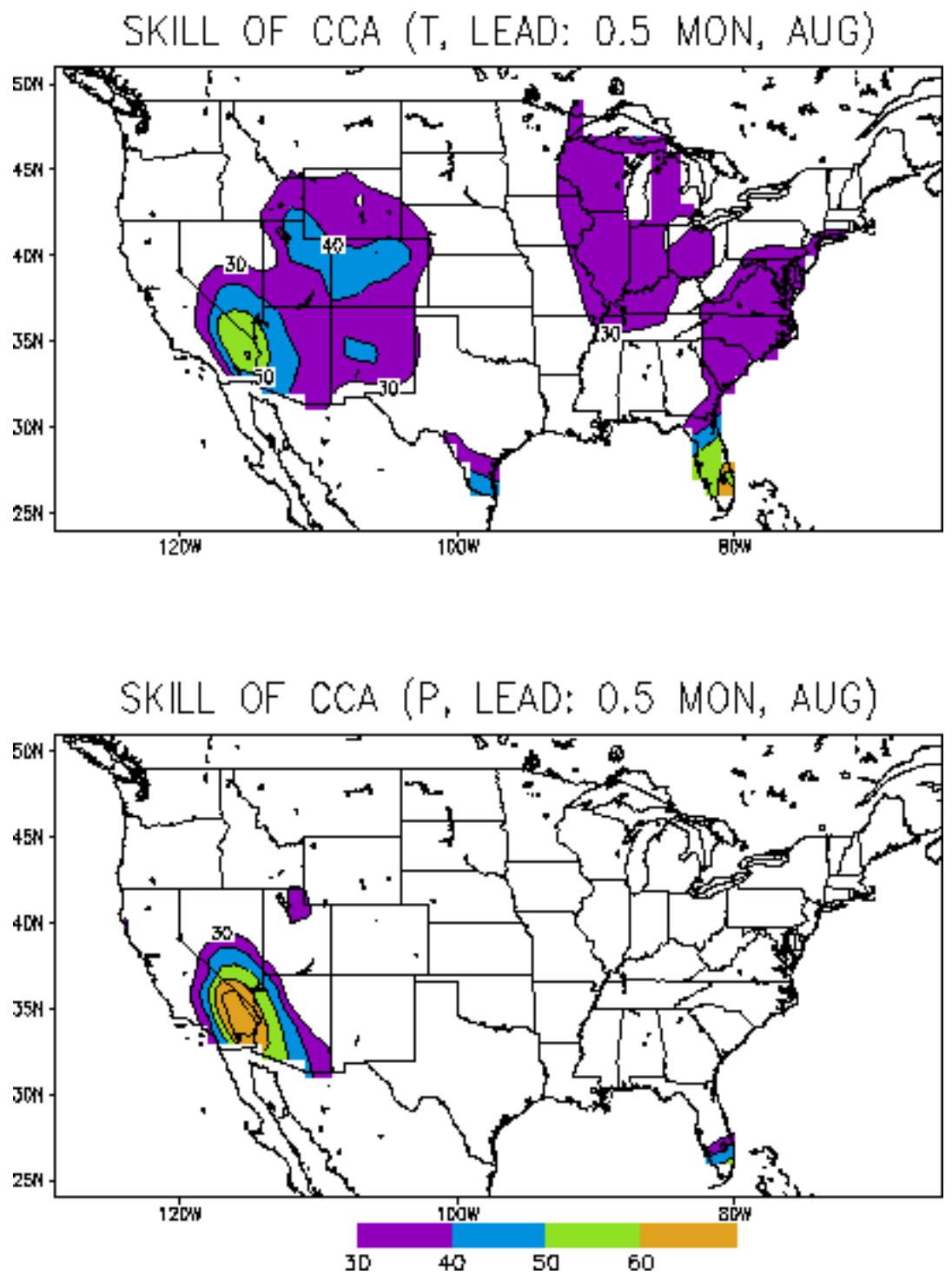
Figure 21. Map of predictive skill for temperature and precipitation using optimal climate normals with 0.5- to 8.5-month lead-times, from the NWS CPC.
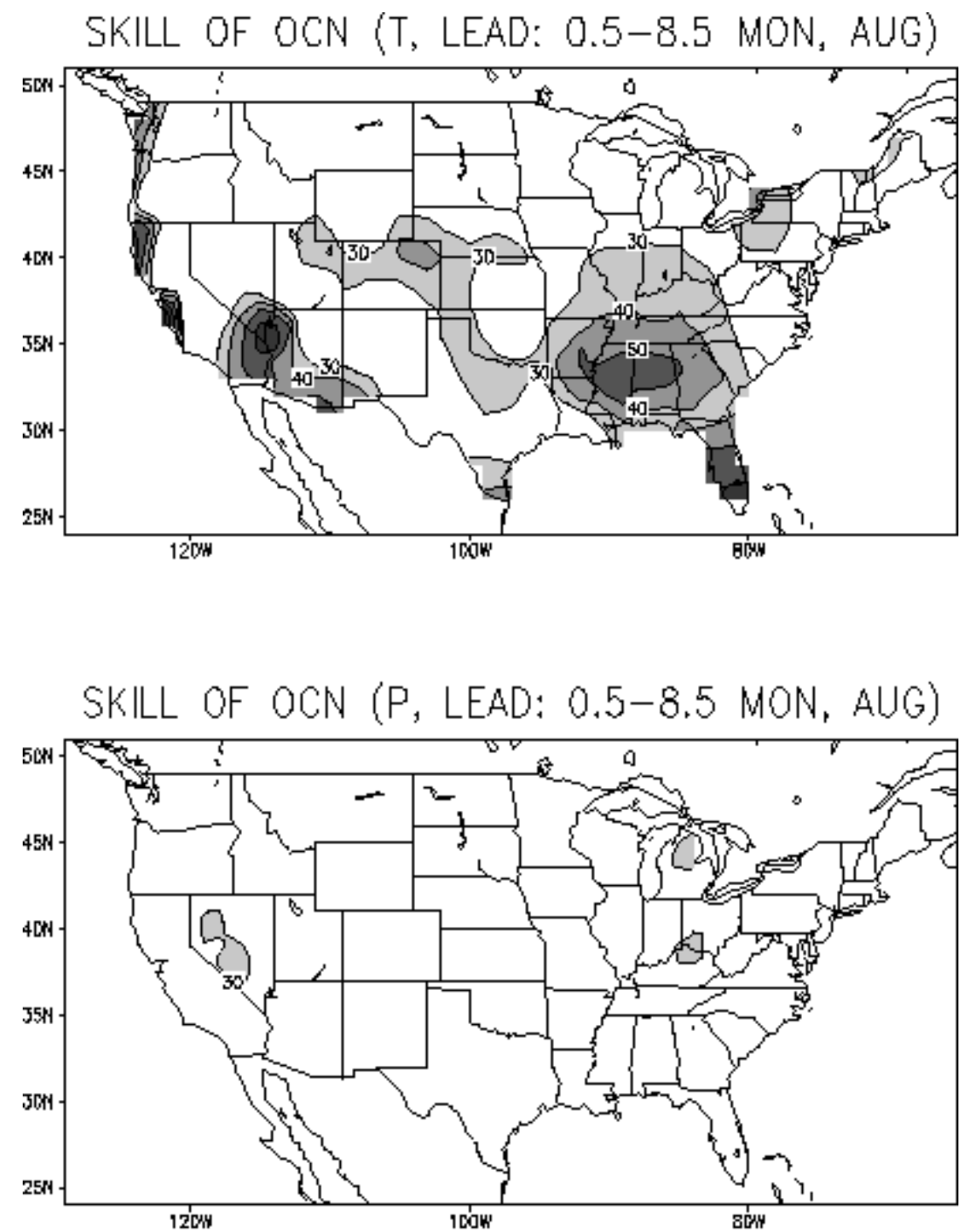

The dots is through JuN, 1999

$K=10$ for $T, K=15$ for $P$ 
Figure 22. Example alternate form of monthly climate outlook, issued by the NWS CPC.

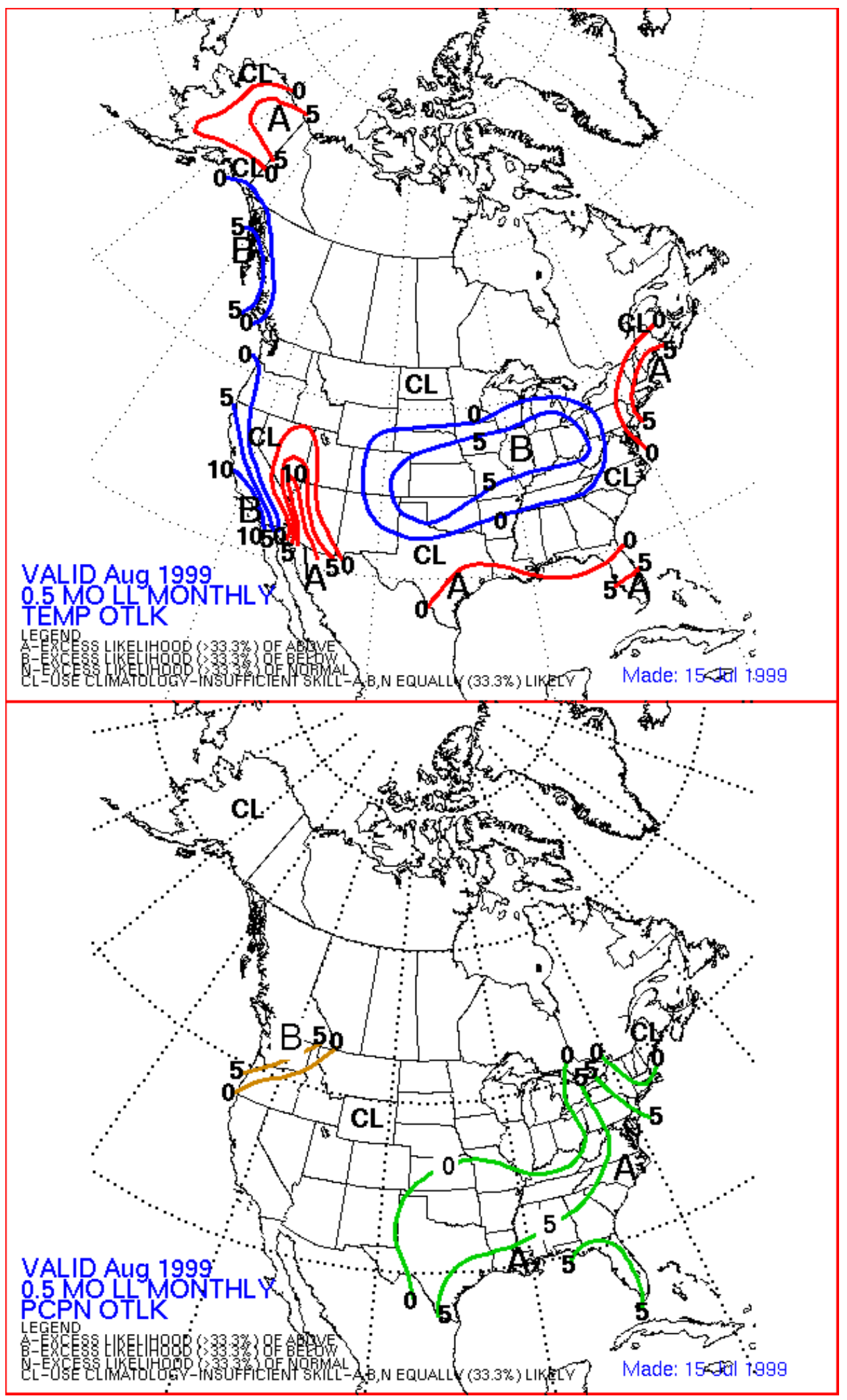


Figure 23. Map of predictive skill for October-December temperatures based on screen multiple linear regression (SMLR) with 1-month lead-times, from Unger (1996b). Values are correlation between forecasts and observations over 1955-1995.

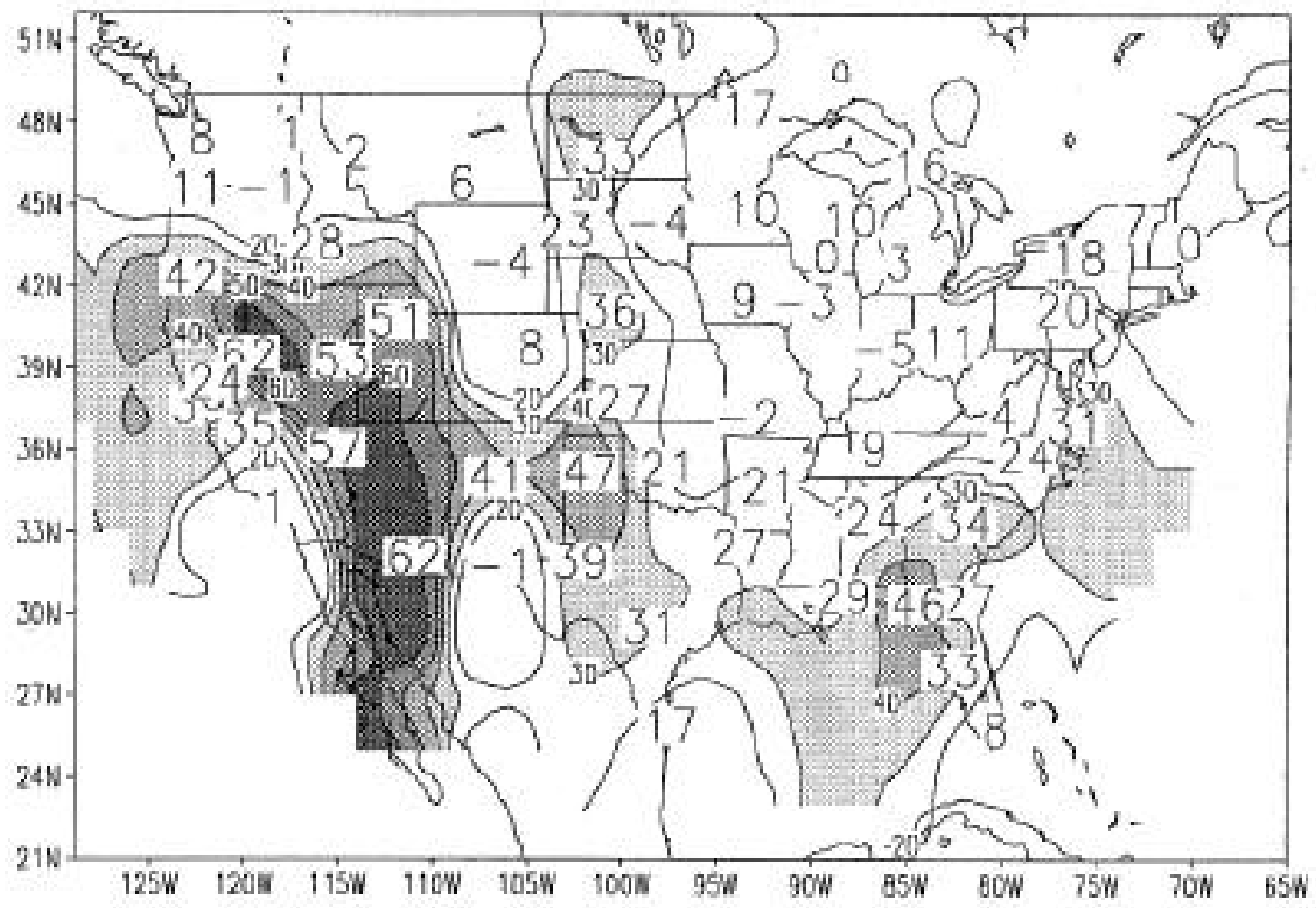


Figure 24. Map of predictive skill for October-December precipitation based on screen multiple linear regression (SMLR) with 1-month lead-times, from Unger (1996b). Values are correlation between forecasts and observations over 1955-1995.

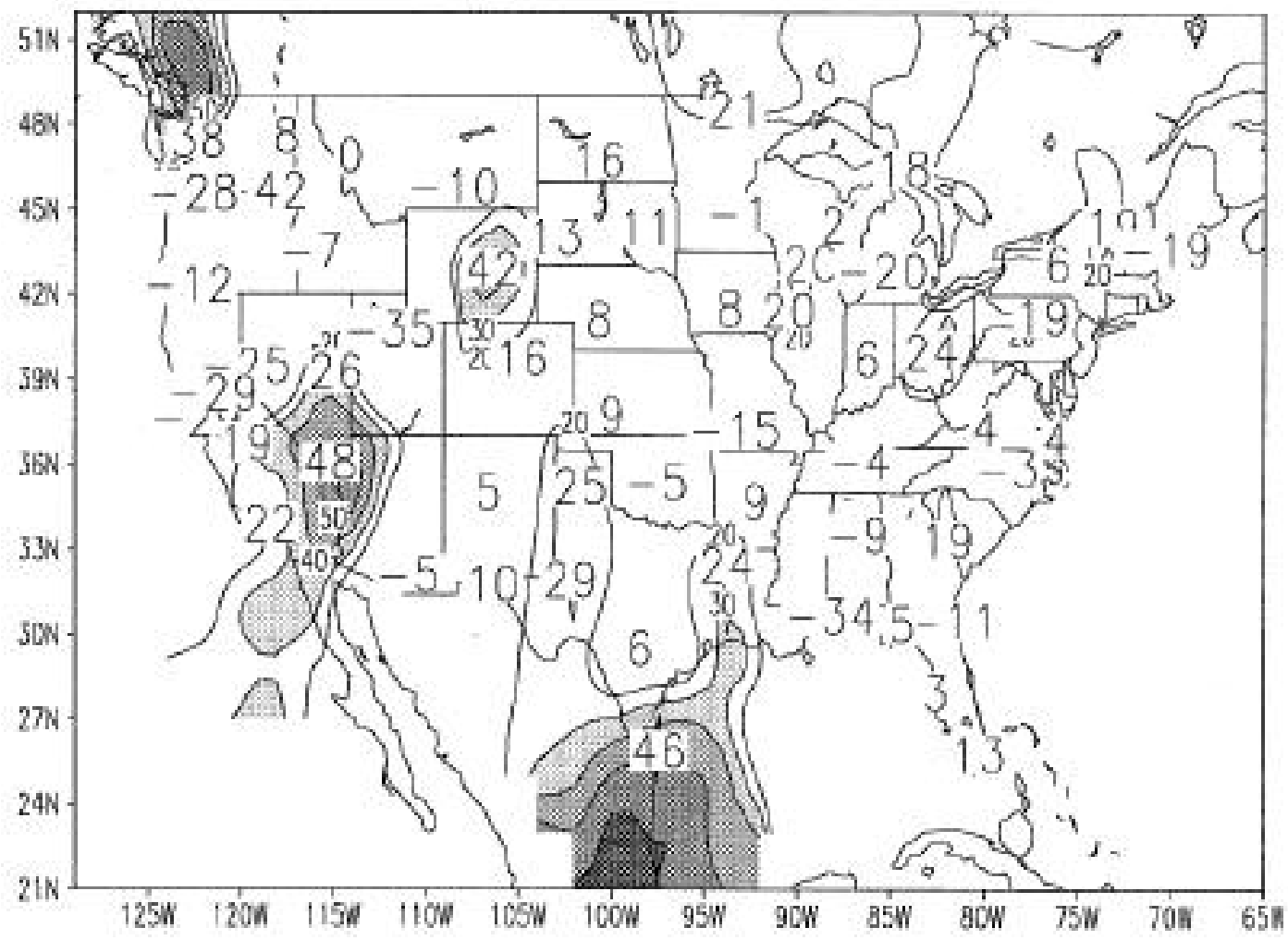


Figure 25. Example experimental seasonal precipitation forecast issued by the International Research Institute for Climate Prediction (IRI).

\section{IRI \\ EXPERIMENTA L CLIMATE FORECAST DIVISION}

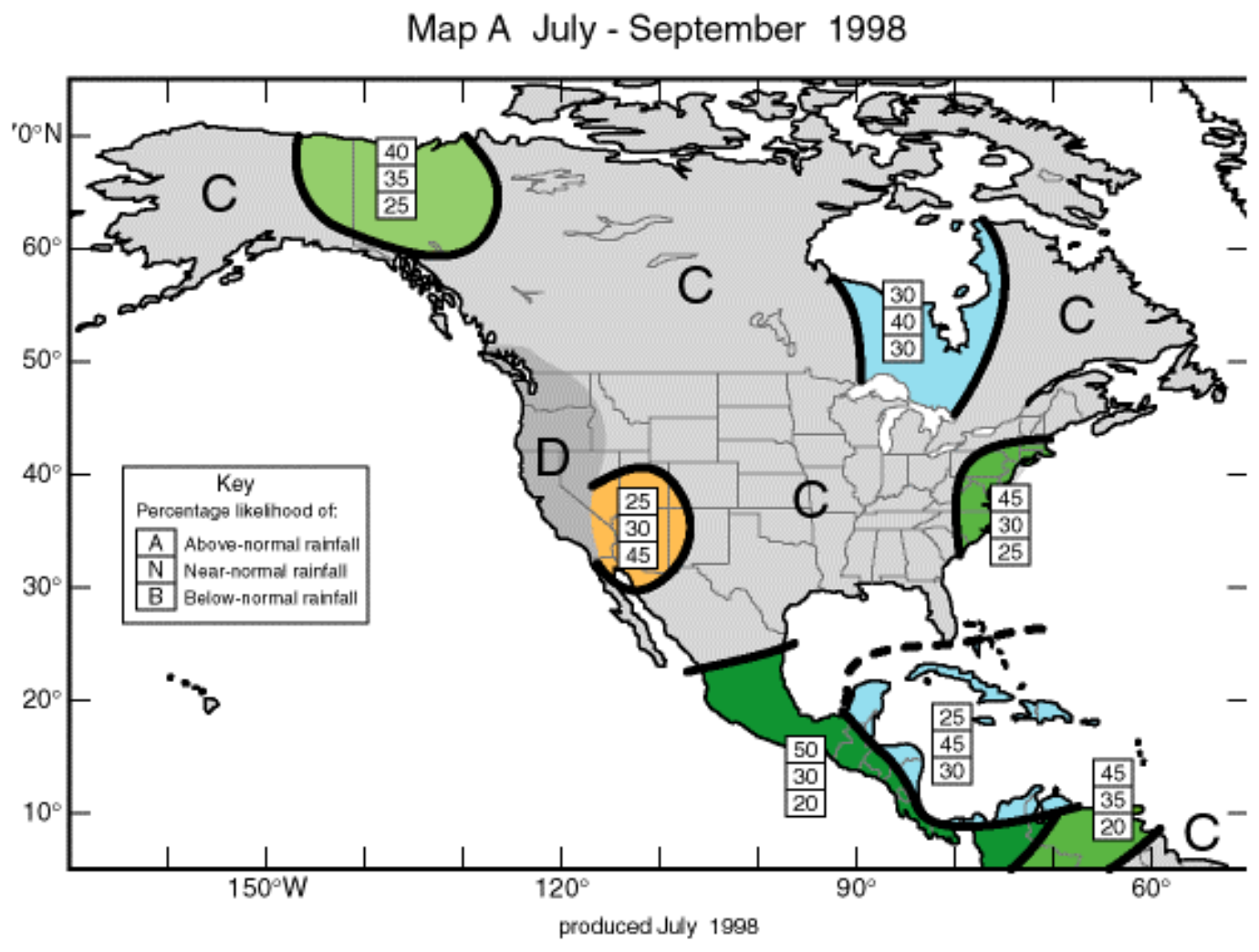

IRI is a cooperative agreenent between NOAA Ofice of Global Programis, Lammat-Doherty Earth Observatery of Colembia University and Scripps Institation of Oeeanography/University of Califoraia, San Dicze. 
Figure 26. Observations corresponding to the seasonal precipitation forecast of Figure 25, issued by the IRI.
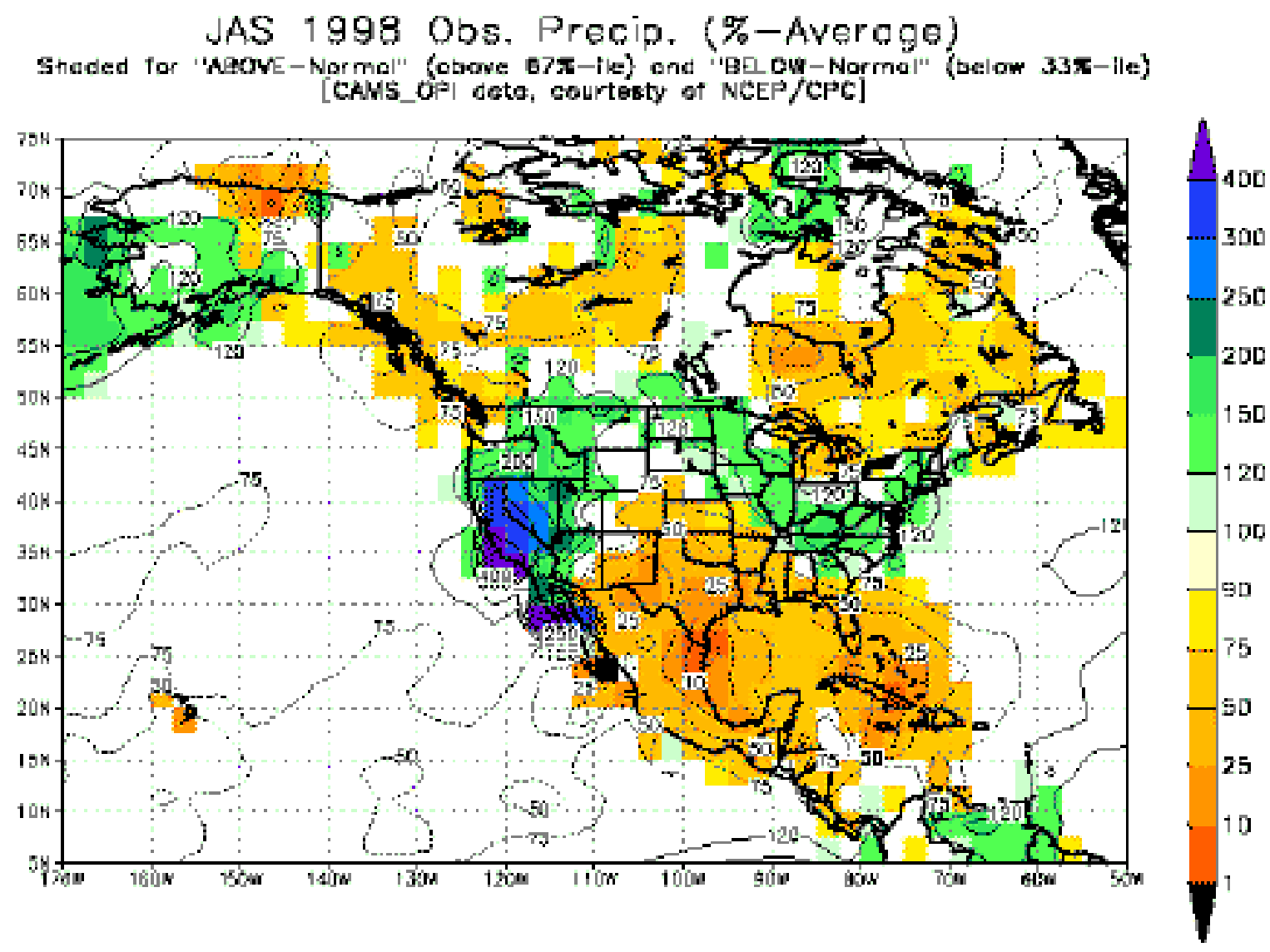

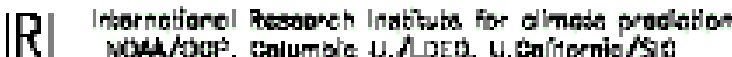

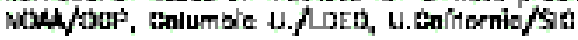


Figure 27. Example quantitative precipitation forecast (QPF) for 6-hour precipitation totals with a 6-hour leadtime. Issued by the NWS Hydrometeorological Prediction Center (HPC).

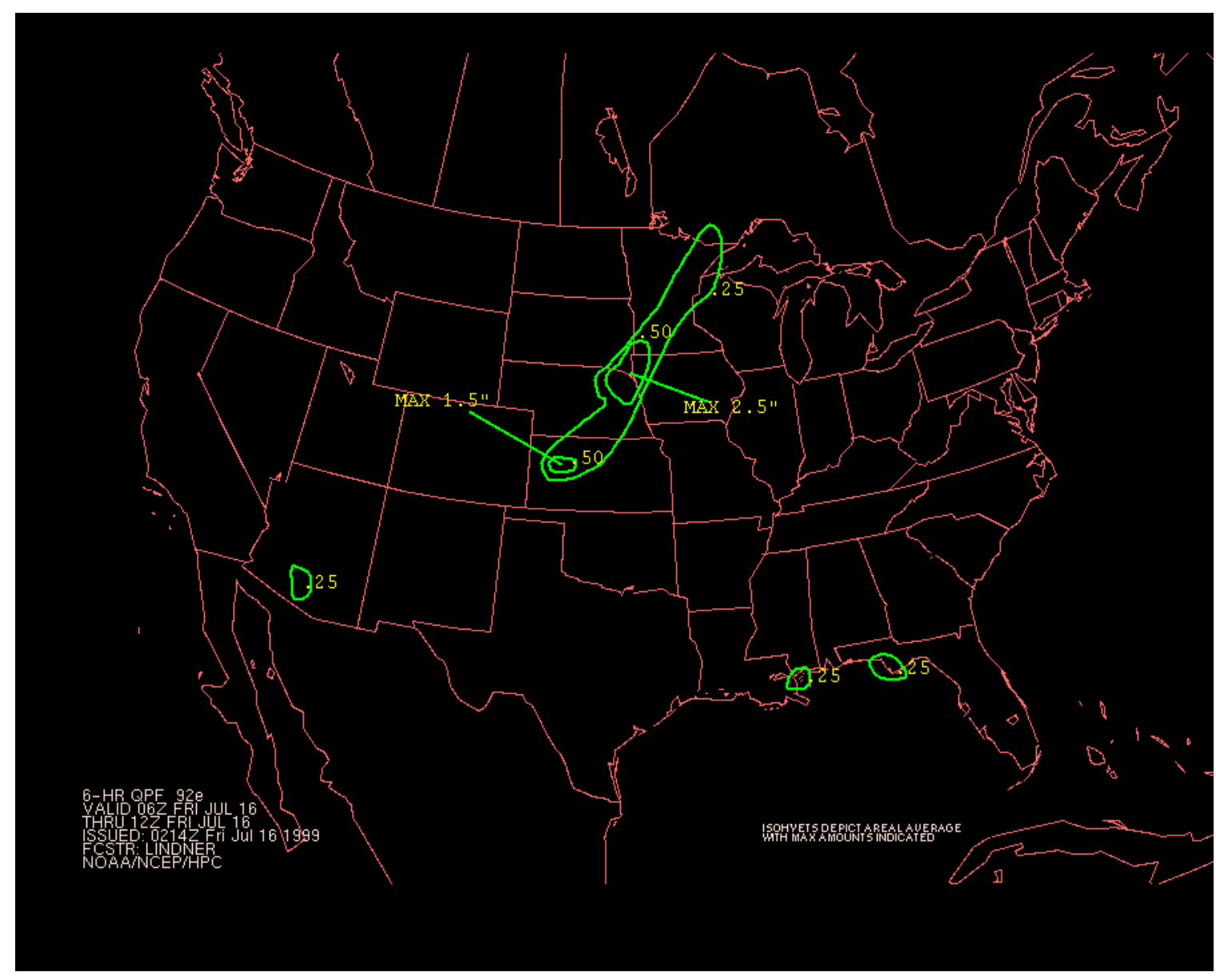


Figure 28. Example day 1 quantitative precipitation forecast (QPF) for 24-hour precipitation totals, issued by the NWS HPC.

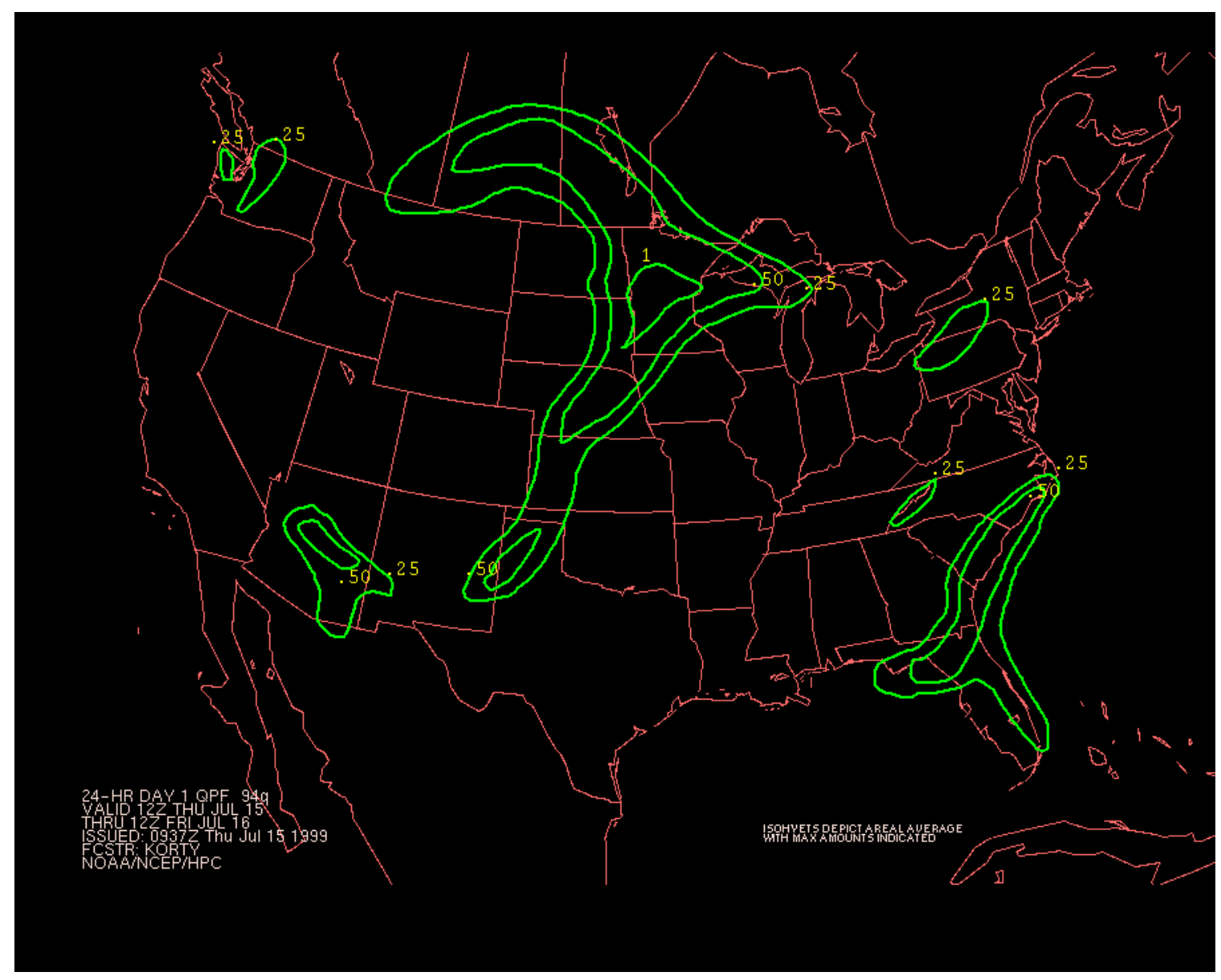


Figure 29. Example forecast of potential for precipitation to exceed flash flood guidance of NWS River Forecast Centers (RFCs), issued by the NWS HPC. APCHG = may approach potential from synpotic systems. ISOLD = spatially isolated potential.

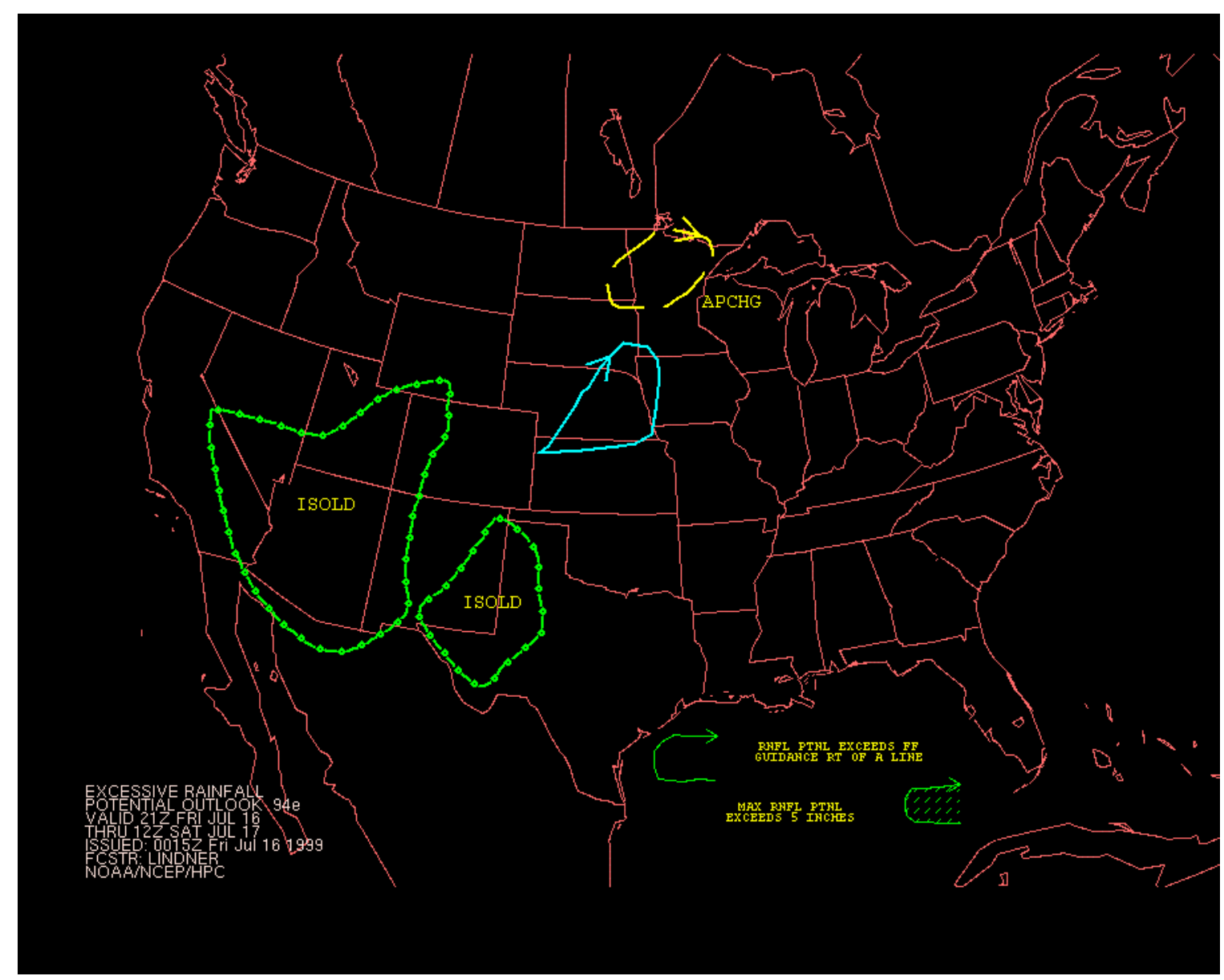


Figure 30. Example experimental Ensemble Streamflow Prediction (ESP) forecast of maximum mean daily dischage of Roaring Fork River, Colorado. Issued by the NWS Colorado Basin River Forecast Center (CBRFC).

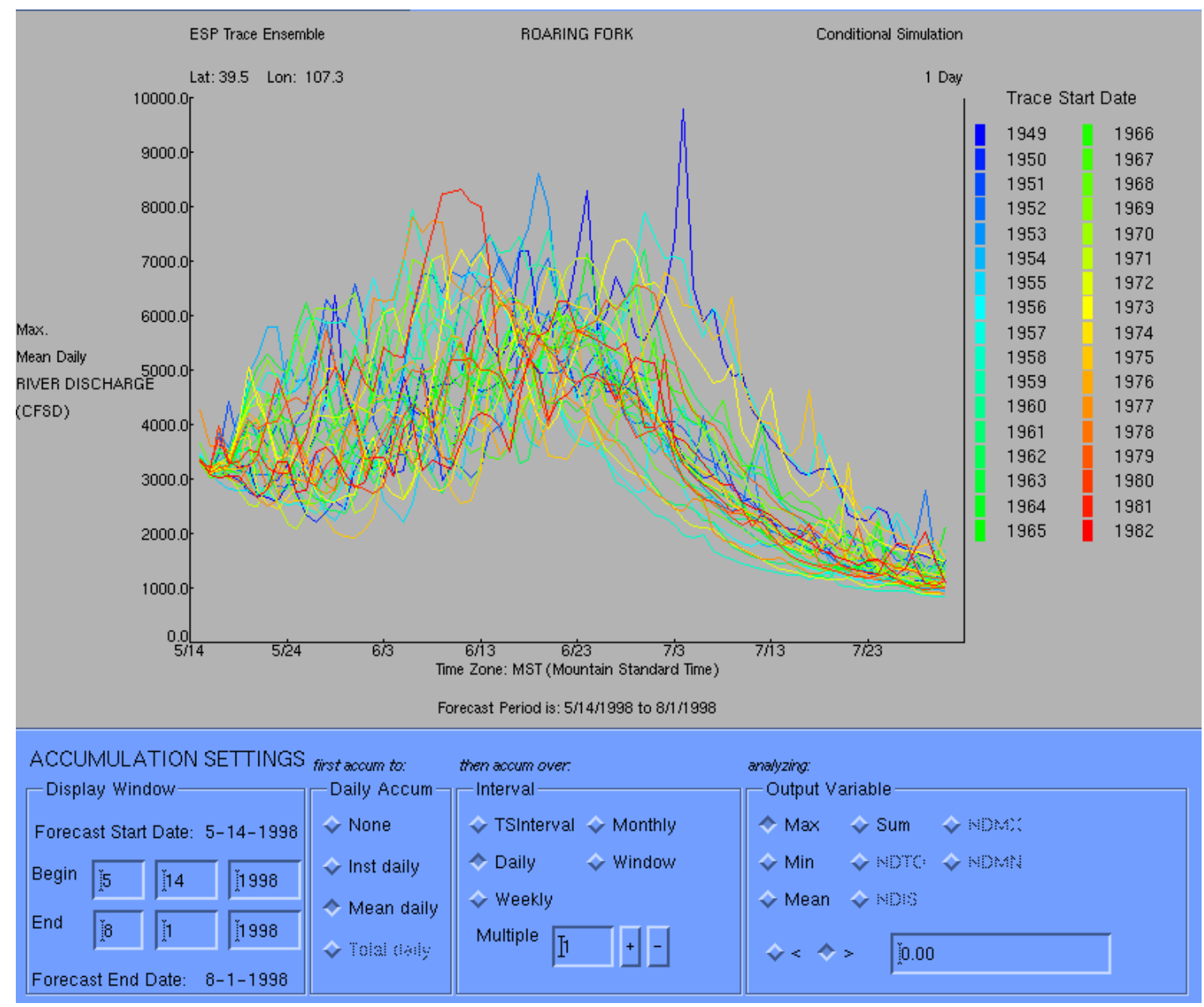


Figure 31. Location schematic for snowmelt peak flow forecasts issued by the NWS CBRFC.

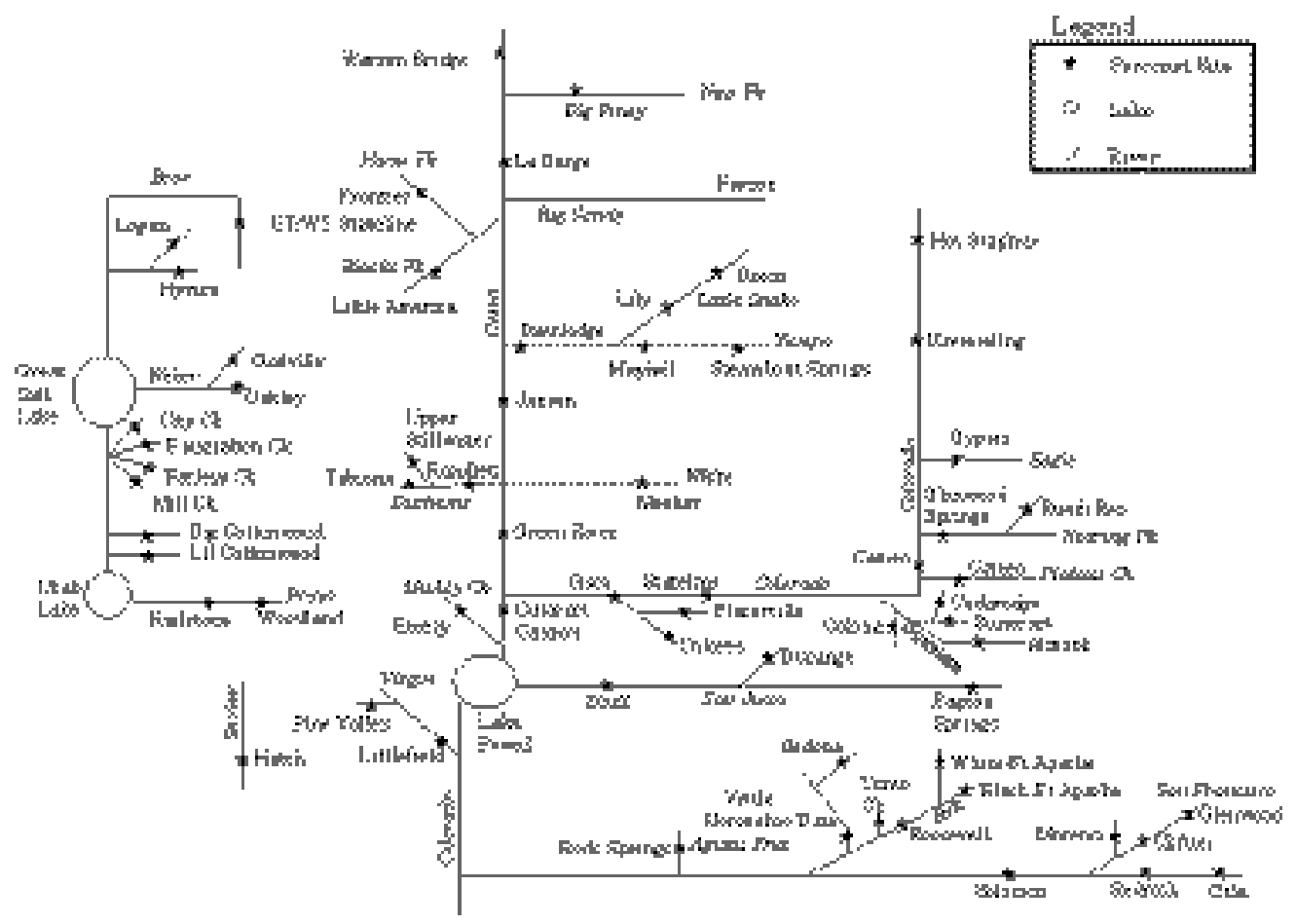

Peal Flow Forecast Stte Sekematie 
Figure 32. Location schematic for specific river reach snowmelt peak flow forecasts issued by the NWS CBRFC.

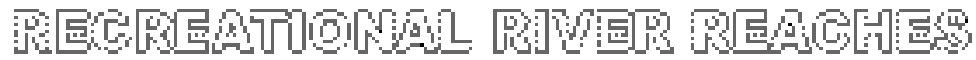

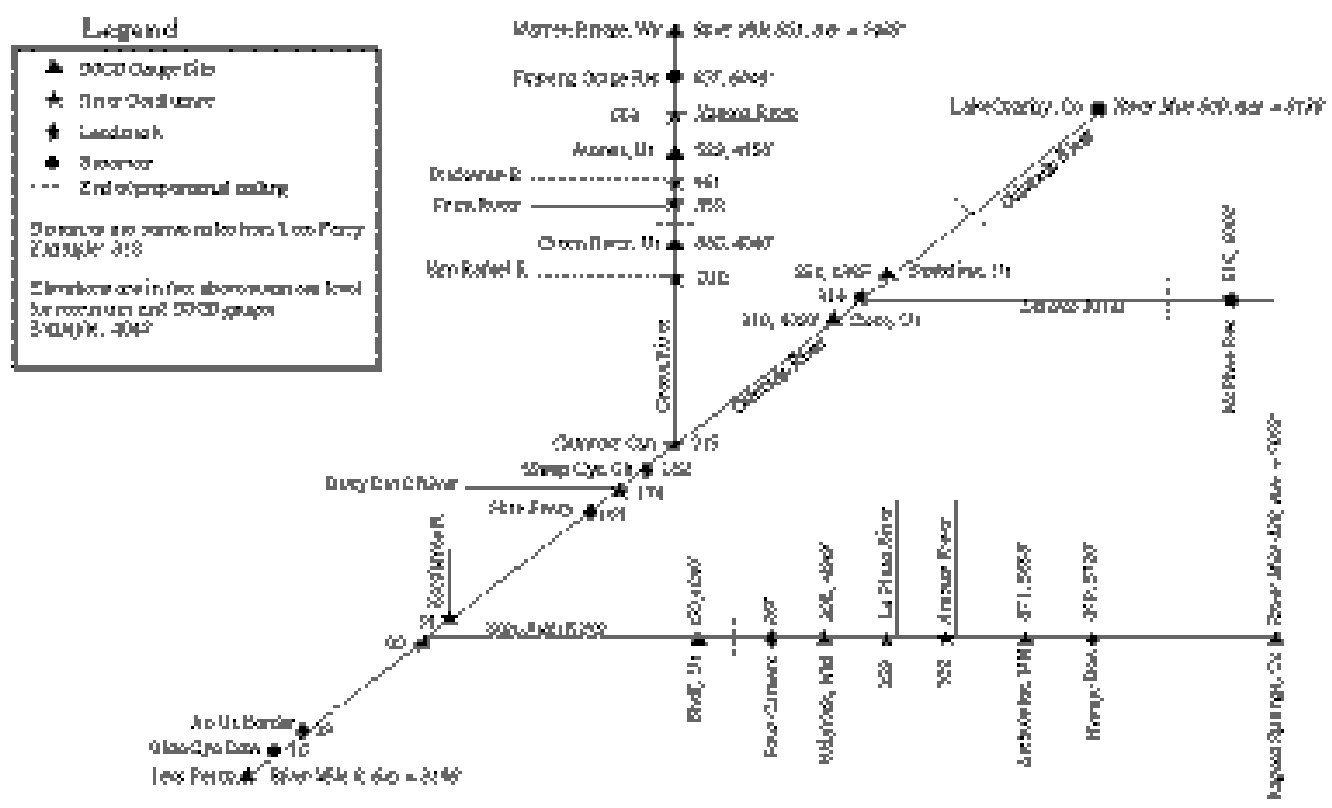


Figure 33. Location schematic for Lower Colorado Basin water supply outlooks issued by the NWS CBRFC.

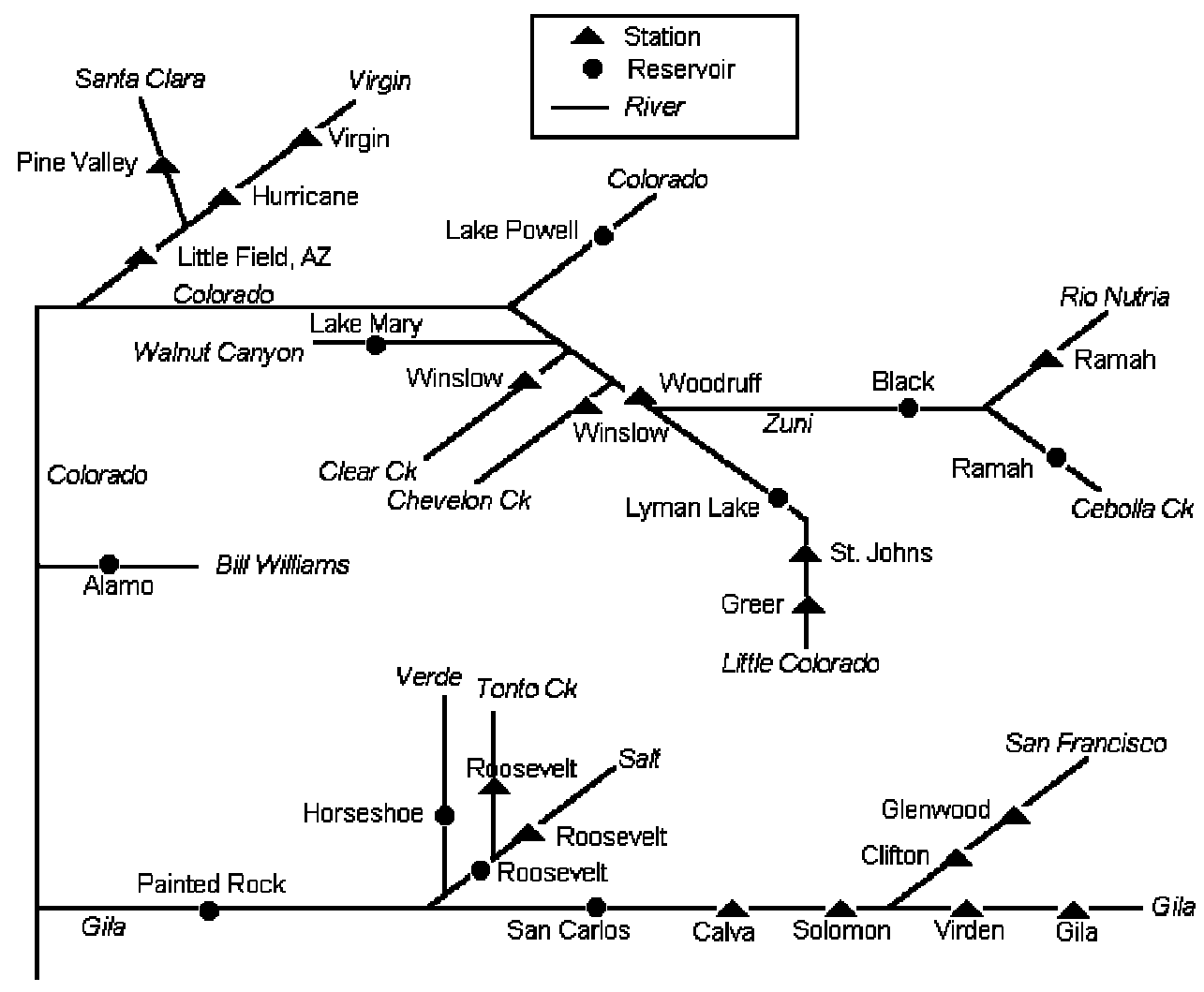


Figure 34. Schematic of adjustments affecting use of naturalized water supply outlooks, from the NWS CBRFC.

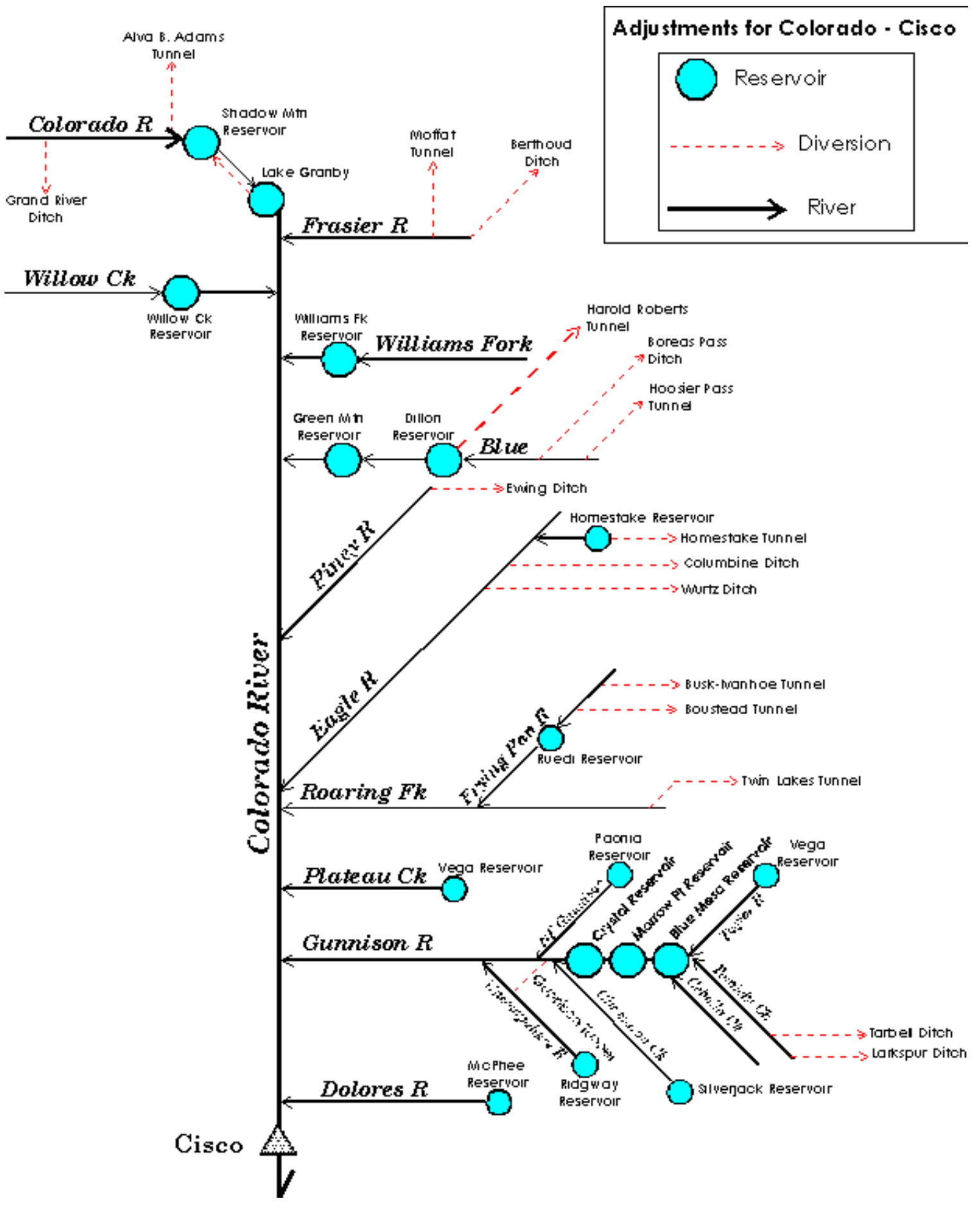


Figure 35. Correlation between seasonal water supplies and Southern Oscillation Index, from the Natural Resources Conservation Service (NRCS).

\begin{tabular}{|c|c|c|c|}
\hline STATE/BASIN & RUNOFF PERIOD & SOI PERIOD & CORRELATION \\
\hline \multicolumn{4}{|l|}{ ARIZONA } \\
\hline Gila & Jan-May & Oct-Dec & -0.49 \\
\hline Salt & Jan-May & Oct-Dec & -0.49 \\
\hline \multicolumn{4}{|l|}{ COLORADO } \\
\hline Purgatoire & Apr-Sep & Oct-Dec & -0.58 \\
\hline Dolores & Apr-Jul & Oct-Dec & -0.41 \\
\hline Animas & Apr-Jul & Oct-Dec & -0.36 \\
\hline \multicolumn{4}{|l|}{ IDAHO } \\
\hline St. Joe at Calder & Apr-Jul & Sep-Dec & 0.56 \\
\hline NF Clearwater (Dworshak Res & Apr-Jul & Jul-Dec & 0.67 \\
\hline Salmon at Salmon & Apr-Jul & Aug-Sep & 0.40 \\
\hline \multicolumn{4}{|l|}{ MONTANA } \\
\hline Fisher nr. Libby & Apr-Jul & Apr-Sep & 0.67 \\
\hline Lower Willow Inflow & Apr-Jul & Apr-Sep & 0.61 \\
\hline Blackfo ot nr Bonner & Apr-Jul & Apr-Sep & 0.58 \\
\hline Bitterroot at Darby & Apr-Jul & Aug-Sep & 0.58 \\
\hline Clarks Fork nr. Belfry & Apr-Jul & Aug-Sep & 0.52 \\
\hline Hungry Horse Inflow & Apr-Jul & Apr-Sep & 0.50 \\
\hline Swan River nr. Bigfork & Apr-Jul & Aug-Sep & 0.50 \\
\hline Yellowstone at Corwin Spgs. & Apr-Jul & Aug-Sep & 0.49 \\
\hline Big Hole River nr. Melrose & Apr-Jul & Aug-Sep & 0.48 \\
\hline Boulder nr. Big Timber & Apr-Jul & Aug-Sep & 0.47 \\
\hline Yaak River nr. Troy & Apr-Jul & Apr-Sep & 0.42 \\
\hline Marias nr. Shelby & Apr-Jul & Jul & 0.40 \\
\hline St. Mary nr. Babb & Apr-Jul & Apr-Sep & 0.38 \\
\hline Madison nr. Grayling & Apr-Jul & Aug-Sep & 0.37 \\
\hline Missouri at Toston & Apr-Jul & Apr-Sep & 0.36 \\
\hline Clark Fork abv. Missoula & Apr-Jul & Apr-Sep & 0.35 \\
\hline \multicolumn{4}{|l|}{ NEW MEXICO } \\
\hline Pecos & Mar-Jul & Oct-Jan & -0.52 \\
\hline Zuni & Jan-May & Oct-Dec & -0.46 \\
\hline Rio Hondo & Mar-Jul & Oct-Dec & -0.45 \\
\hline Rio Chama & Mar-Jul & Oct-Nov & -0.41 \\
\hline Lower Rio Grande & Mar-Jul & Oct-Dec & -0.38 \\
\hline Canadian & Mar-Jun & Nov-Jan & -0.37 \\
\hline \multicolumn{4}{|l|}{ OREGON } \\
\hline Rogue River@ Grants Pass & Apr-Jul & Sep & 0.46 \\
\hline North Umpqua@ Winchester & Apr-Jul & Sep & 0.43 \\
\hline NF John Day at Monument & Apr-Jul & May-Sep & 0.36 \\
\hline Little Deschutes near LaPine & Apr-Jul & Sep-Dec & 0.36 \\
\hline Blue Lake Inflow & Apr-Jul & Oct-Dec & 0.57 \\
\hline \multicolumn{4}{|l|}{ UTAH } \\
\hline Sevier River@ Hatch & Apr-Jul & Oct-Jan & -0.60 \\
\hline Virgin & Apr-Jul & Oct-Dec & -0.56 \\
\hline Minersville Reservoir Inflow & Apr-Jul & Oct-Jan & -0.56 \\
\hline Recapture Creek & Mar-Jul & Sep-Nov & -0.55 \\
\hline Beaver River near Beaver & Apr-Jul & Oct-Dec & -0.48 \\
\hline Vernon Creek near Vernon & Apr-Jul & Oct-Nov & -0.46 \\
\hline Duchesne & Apr-Jul & Nov-Dec & -0.45 \\
\hline Muddy Creek & Apr-Jul & Oct-Nov & -0.39 \\
\hline Cottonwood Creek & Apr-Jul & Oct-Dec & -0.37 \\
\hline \multicolumn{4}{|l|}{ WASHINGTON } \\
\hline Yakima at Cle Elum & Apr-Jul & Sep-Dec & 0.53 \\
\hline Skagit at Newhalem & Apr-Jul & Jun-Oct & 0.49 \\
\hline Chelan at Chelan & Apr-Jul & Jun-Oct & 0.47 \\
\hline \multicolumn{4}{|l|}{ WYOMING } \\
\hline Wind River nr Dubois & Apr-Jul & Aug-Sep & 0.53 \\
\hline Snake above Palisades & Apr-Jul & Jun-Sep & 0.48 \\
\hline Buffalo Bill Resv Inflow & Apr-Jul & Aug-Sep & 0.44 \\
\hline Boysen Reservoir Inflow & Apr-Jul & Aug-Sep & 0.36 \\
\hline
\end{tabular}


Figure 36. Map of correlation between seasonal water supply volumes and Southern Oscillation Index, from the NRCS.

\section{Legend}

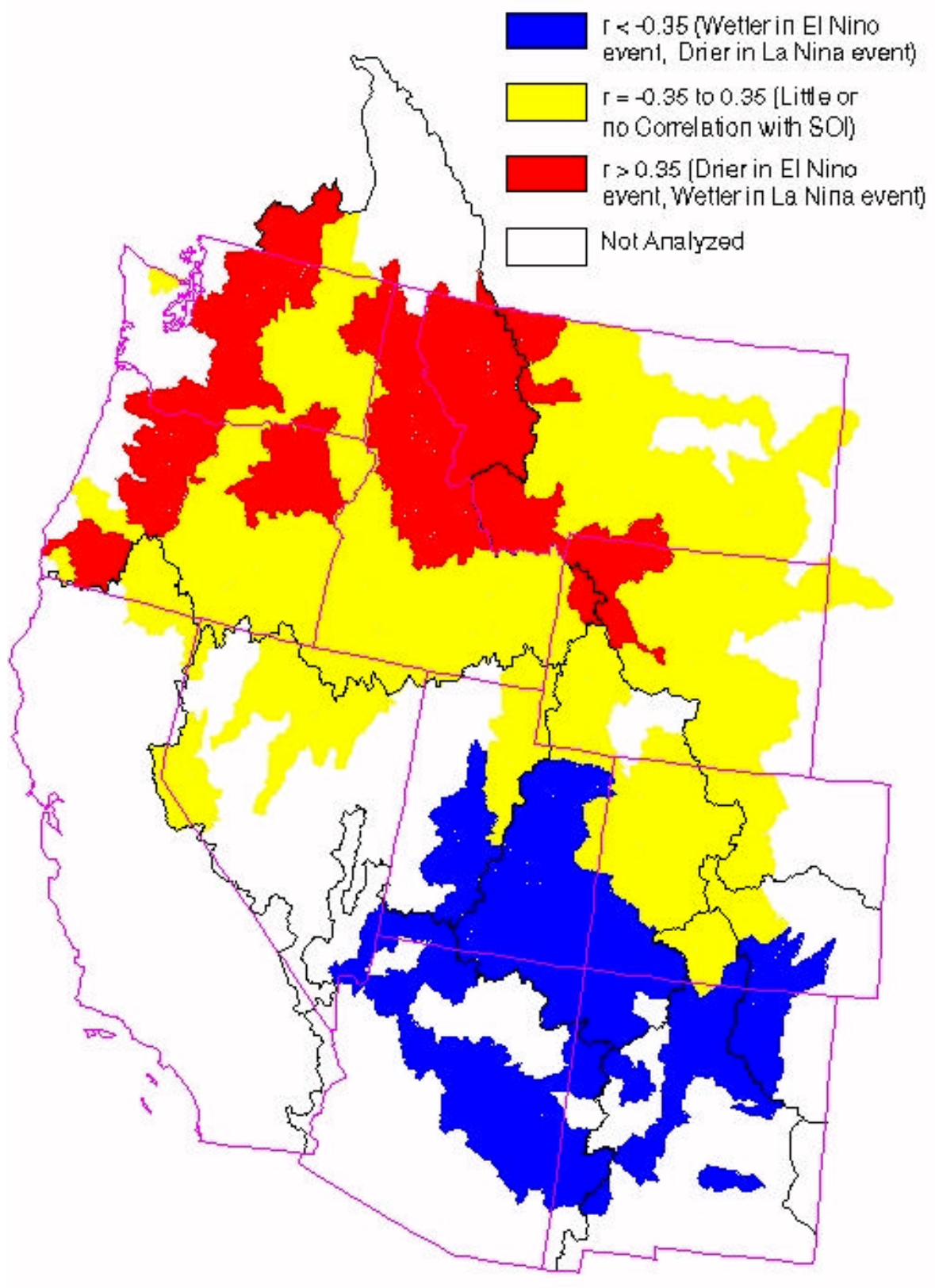

